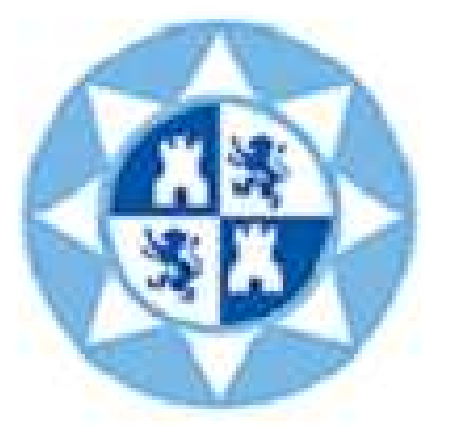

Universidad Politécnica de Cartagena

\title{
Respuesta de tomate a condicionantes abióticos y mitigación de su efecto mediante estrategias agronómicas
}

Virginia Hernández Pérez

2017

\author{
Programa de Doctorado
}

Técnicas Avanzadas en Investigación y Desarrollo Agrario y Alimentario 



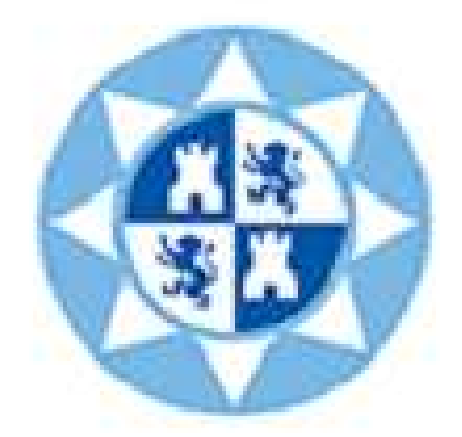

Universidad Politécnica de Cartagena

\title{
Respuesta de tomate a condicionantes abióticos y mitigación de su efecto mediante estrategias agronómicas
}

\author{
Directoras: \\ María del Pilar Flores Fernández-Villamil \\ María del Pilar Hellín García
}

Virginia Hernández Pérez 2017 



\section{AGRADECIMIENTOS}

Este momento requiere mi más sincero agradecimiento a la Doctora $\mathrm{M}^{\mathrm{a}}$ Pilar Flores Fernández-Villamil, por todo su tiempo, su profesionalidad y gracias a la cual, ha sido posible el desarrollo de esta tesis doctoral. Así como a la Doctora Mํㅡㄹ Pilar Hellín García por su dirección, apoyo y positivismo en el día a día.

Agradecer también a mis compañeros del equipo de Sostenibilidad y Calidad de Productos Hortofrutícolas del IMIDA, por tenerlos siempre cuando los he necesitado y por su enorme trabajo en cada uno de los ensayos de esta tesis, especialmente a María e Inma, por su gran trabajo en el laboratorio y a Juani por su inmejorable trabajo de determinación analítica. Por hacerme tan fácil y cómodo el día a día durante la jornada laboral, también gracias a Fenoll, Isabel, May, Inma y Herminia.

Además quiero agradecer a mis compañeros del IMIDA, que no forman parte de mi equipo, pero con los que puedo contar y echar unas risas cuando me los encuentro. Gracias por los momentos en casa Rita, en los que he podido recargar pilas y lucidez para la redacción de esta tesis.

A todos mis amigos, en especial a Loli, Manolo, Juan, Braulio, Jose, por estar siempre ahí y por los ratos buenos que me dan.

A mis padres y a mi hermano, por todo el apoyo que me brindan y por confiar en mi, y gracias a los cuales he podido llegar hasta aquí.

A toda mi familia, a mi madrina, tíos y primos, con los que he pasado muy buenos momentos. A mi familia política, por hacerme sentir una más en todo momento.

En especial quiero agradecer a Fran, mi bichito Alejandro, y al proyecto de bichito (Álvaro), por ser mi motivación y por los que cada día me levanto con ganas de comerme el mundo.

A mi estrella, mi abuela Dolores, que toda la vida me ha llenado de alegría y dulzura y a la que le doy las gracias por haberme hecho mejor persona. Al resto de mis abuelos, porque gracias a ellos me he sentido muy especial en muchos momentos de mi vida. 

A mis padres y hermano

A Fran, Alejandro y Álvaro 

RESUMEN/ABSTRACT 



\section{RESUMEN}

El tomate es una de las hortalizas más cultivadas y consumidas a nivel mundial, siendo un ingrediente básico en la cocina de todas las culturas. Además de su importancia socioeconómica, el tomate destaca por su alto contenido en compuestos bioactivos, con propiedades beneficiosas para la salud. En el sureste español, debido a su climatología, el rendimiento y la calidad de esta hortaliza se ven afectados por diferentes factores medioambientales, entre los que destaca la alta temperatura. Este problema se ve agravado por el hecho de que la mayor parte de la producción en la Región se desarrolla bajo invernadero, donde el aumento de temperatura es mucho más acusado. En numerosas ocasiones, el estrés térmico se presenta de forma simultánea con otros condicionantes abióticos, como la escasez de recursos hídricos y la salinidad de suelo y agua. El objetivo principal de esta tesis fue conocer la influencia de la alta temperatura sobre el rendimiento y la calidad de tomate, centrándose en acumulación de metabolitos relacionados con la calidad organoléptica y nutricional del fruto, y establecer diferentes estrategias agronómicas basadas en el manejo de la nutrición mineral, la utilización de mallas de sombreo y la aplicación de bioestimulantes para minimizar los efectos negativos del estrés térmico. Para ello se plantearon diferentes ensayos tanto en cámara de crecimiento (condiciones controladas) como bajo invernadero, con el fin de conocer la respuesta de la planta a nivel fisiológico, bioquímico y agronómico. Los ensayos bajo condiciones controladas permitieron identificar los principales compuestos bioactivos de tomate y conocer el impacto de la alta temperatura sobre su acumulación en fruto, dependiendo del tiempo de exposición al estrés. Se demostró la capacidad de las plantas de tomate para adaptarse a condiciones de estrés térmico, pudiendo incluso restaurar las concentraciones de los metabolitos interés después de largos períodos de exposición a alta temperatura. Por otro lado, se estudió la interacción del estrés térmico y la salinidad, tanto a nivel agronómico como bioquímico, concluyéndose que la pérdida de productividad como consecuencia de ambos estreses, puede ser en parte compensada, en términos de valor nutritivo, por el incremento de la concentración de ciertos compuestos bioactivos. La optimización del manejo de la nutrición nitrogenada 
permitió, por un lado, mejorar la calidad nutricional de los frutos y por otro, compensar el efecto negativo de la utilización de mallas de sombreo sobre el rendimiento. Por último, el uso de bioestimulantes se mostró como una alternativa capaz de mejorar el rendimiento de tomate bajo condiciones de alta temperatura, aumentando además, en determinados casos, el contenido de tomate en compuestos bioactivos con reconocidos efectos beneficiosos sobre la salud. 


\section{ABSTRACT}

The tomato is one the most widely cultivated and consumed vegetables worldwide, and a basic ingredient in the cuisine of most cultures. In addition to its socioeconomic importance, the tomato is well known for its high content of bioactive compounds with health-promoting properties. In south-eastern Spain, the yield and quality of this vegetable are affected by several environmental factors high temperature being the most prominent among them. This problem is compounded by the fact that tomato in this area is mainly cultivated in greenhouse conditions, which involves even higher temperatures. Frequently, severe temperature stress must contend with other abiotic factors, such as a shortfall in water resources and the salinity of the soil and waters. The main goal of this thesis was to undertsnd how high temperature affect the yield and quality of tomato. We focus on the accumulation of metabolites related to the organoleptic and nutritional quality of the fruit and establish different agronomic techniques based on mineral nutrition optimization, the use of shading and application of biostimulants to minimise the negative effects of the stress. To this end, studies were carried out under controlled (growth chamber) and greenhouse conditions to know the plant response at physiological, biochemical and agronomical levels. These studies under controlled conditions allowed the main bioactive compounds of tomato to be identified allong with the impact of high temperatureson their accumulation in fruit depending on the length of exposure to the stress conditions. The capacity of tomato plants to adapt to high temperature was demonstrated, along with their ability to restore the concentrations of major metabolites after long periods under such stress conditions. In addition, the interaction of high temperature and salinity was studied at both agronomic and biochemical levels. It is concluded that the loss of productivity as a result of both stresses can be partially compensated in terms of nutritional value by increases in the concentration of certain bioactive compounds. Optimizing nitrogen nutrition improved the nutritional quality of the fruits and compensated for the negative effect of shading on yield. Lastly, the use of biostimulants as an alternative to improve tomato yield under high temperature conditions was demonstrated, increasing in certain cases the levels of bioactive compounds with recognized beneficial effects on health. 

ÍNDICE 



\section{ÍNDICE}

CAPÍTULO 1. Introducción 1

1.1. Características del cultivo 1

1.1.1. Descripción botánica 1

1.1.2. Importancia económica 3

1.1.3. Requerimientos edafoclimáticos del cultivo 4

1.1.4. Ciclos de cultivo 5

1.1.5. Usos 6

$\begin{array}{ll}\text { 1.2. Valor nutricional y funcional de tomate } & 7\end{array}$

1.2.1. Carotenoides 8

1.2.2. Compuestos fenólicos 11

1.2.3. Vitaminas C y E $\quad 15$

1.3. Factores que afectan al desarrollo del cultivo y a la calidad del fruto 18

1.3.1. Factores agronómicos 18

1.3.1.1. Material genético 18

1.3.1.2. Nutrición mineral 19

1.3.1.3. Riego 20

1.3.1.4. Sistemas de producción 21

1.3.1.5. Técnicas de cultivo 23

1.3.1.5.1. Poda 23

1.3.1.5.2. Sombreo 23

1.3.2. Factores medioambientales 24

1.3.2.1. Factores abióticos 24

1.3.2.1.1. Luz 25

1.3.2.1.2. Temperatura 26

1.3.2.1.3. Salinidad 27

1.3.2.1.4. Humedad 28

1.3.2.2. Factores bióticos 29

1.3.2.3. Respuesta de la planta a factores abióticos

y bióticos 

1.4.1. Modo de acción de elicitores 34

1.4.2. Ácido salicílico 36

1.4.3. Metil jasmonato $\quad 37$

1.4.4 Quitosano 39

1.4.5. Brasinoesteroides y análogos $\quad 40$

CAPÍTULO 2. Objetivos 43

CAPÍTULO 3. Técnicas analíticas $\quad 45$

3.1. Parámetros de intercambio gaseoso 45

3.2. Parámetros físicos 46

3.2.1. Peso 46

3.2.2. Calibre ecuatorial y longitudinal 46

3.2.3. Color 46

3.3. Análisis de metabolitos en fruto $\quad 47$

3.3.1. Análisis de azúcares solubles y ácidos orgánicos 47

3.3.1.1. Extracción $\quad 47$

3.3.1.2. Determinación de azúcares $\quad 47$

3.3.1.3. Determinación de ácidos orgánicos 48

3.3.2. Análisis de compuestos fenólicos 48

3.3.2.1. Extracción 48

3.3.2.2. Determinación 49

3.3.3. Análisis de carotenoides y vitamina $\mathrm{E} \quad 50$

3.3.3.1. Extracción $\quad 50$

3.3.3.2. Determinación $\quad 50$

3.3.4. Análisis de vitamina $C \quad 51$

3.3.4.1. Extracción 51

3.3.4.2. Determinación 52

CAPÍTULO 4. Respuesta de la variedad enana de tomate Micro-Tom al estrés salino y nutricional 

4.1. Materiales y métodos 56

4.1.1. Sitio de estudio y material vegetal 56

4.1.2. Diseño experimental y manejo del cultivo 56

4.1.3. Análisis estadístico 56

4.2. Resultados y discusión 58

4.2.1. Perfil de compuestos fenólicos en la variedad Micro-Tom 58

4.2.2. Perfil de carotenoides en la variedad Micro-Tom 61

4.2.3. Respuesta varietal al estrés nutricional y salino 65

4.2.3.1. Rendimiento y composición de los frutos 65

4.2.3.2. Contenido del fruto en compuestos bioactivos 68

4.3. Conclusiones 73

CAPÍTULO 5. Variación del contenido de compuestos bioactivos en tomate como respuesta al aumento de la temperatura 75

5.1. Materiales y métodos 76

5.1.1. Material vegetal y manejo del cultivo 76

5.1.2. Diseño experimental 76

5.1.3. Análisis estadístico 78

5.2. Resultados y discusión 79

5.2.1. Rendimiento y parámetros físicos de los frutos 79

5.2.2. Contenido en compuestos bioactivos 81

5.3. Conclusiones 86

CAPÍTULO 6. Influencia de la nutrición nitrogenada y su interacción con el sombreo, en el rendimiento y la calidad de tomate 89

6.1. Materiales y métodos 91

6.1.1. Material vegetal y sitio de estudio 91

6.1.2. Diseño experimental 92

6.1.2.1. Interacción N x sombreo sobre la producción

y calidad 92

6.1.2.2. Reducción de la dosis de $\mathrm{N}$ en diferentes fases de desarrollo 93

6.1.3. Muestreo y parámetros analizados 94 

6.1.4. Análisis estadístico 95

6.2. Resultados y discusión 95

6.2.1. Interacción $\mathrm{N}$ x sombreo sobre la producción y calidad 95

6.2.1.1. Producción 95

$\begin{array}{ll}\text { 6.2.1.2. Calidad } & 97\end{array}$

6.2.2. Reducción de la dosis de $\mathrm{N}$ en diferentes fases

de desarrollo 106

6.2.2.1. Producción 106

6.2.2.2. Calidad 109

6.3. Conclusiones

114

CAPÍTULO 7. Influencia de la temperatura y la salinidad sobre el contenido $\begin{array}{ll}\text { de tomate en compuestos bioactivos } & 115\end{array}$

$\begin{array}{ll}\text { 7.1. Materiales y métodos } & 116\end{array}$

7.1.1. Material vegetal y manejo del cultivo 116

7.1.2. Diseño experimental 117

7.1.3. Análisis estadístico 117

$\begin{array}{ll}\text { 7.2. Resultados y discusión } & 117\end{array}$

7.2.1. Rendimiento 117

$\begin{array}{ll}\text { 7.2.2. Calidad } & 118\end{array}$

$\begin{array}{ll}\text { 7.3. Conclusiones } & 123\end{array}$

CAPÍTULO 8. Respuesta de la planta de tomate a la aplicación de bioestimulantes en condiciones de alta temperatura 125

8.1. Materiales y métodos 126

8.1.1. Material vegetal y sitio de estudio 126

8.1.2. Manejo del cultivo 127

8.1.3. Diseño experimental 128

8.1.4. Parámetros analizados 130

8.1.5. Análisis estadístico 131

8.2. Resultados y discusión 131

8.2.1. Respuesta fisiológica de la planta a los bioestimulantes 131

8.2.2. Respuesta agronómica de la planta a los bioestimulantes 136 

Índice

8.2.3. Calidad de tomate tratado con bioestimulantes 138

8.2.3.1. Producción 138

8.2.3.2. Color de los frutos 140

8.2.3.3. Azúcares solubles 143

8.2.3.4. Vitamina C 146

8.2.3.5. Carotenoides 148

8.2.3.6. Compuestos fenólicos 154

$\begin{array}{ll}\text { 8.3. Conclusiones } & 161\end{array}$

CAPÍTULO 9. Conclusiones 163

$\begin{array}{lr}\text { CAPÍTULO 10. Bibliografía } & 167\end{array}$ 



\section{Capítulo 1}

\section{INTRODUCCIÓN}

\subsection{Características del cultivo}

\subsubsection{Descripción botánica}

El tomate (Solanum lycopersicum L.) es una de las hortalizas más cultivadas en todo el mundo, lo que le concede una gran importancia a nivel socio-económico. Es una planta dicotiledónea perteneciente a la familia de las Solanáceas. La taxonomía generalmente aceptada es:

i. Clase: Dicotyledoneas.

ii. Orden: Solanales (Personatae).

iii. Familia: Solanaceae.

iv. Subfamilia: Solanoideae.

v. Género: Solanum.

vi. Especie: Lycopersicum.

Se trata de una planta perenne de porte arbustivo que se cultiva como anual. Puede tener dos tipos de crecimiento: crecimiento determinado e indeterminado. La planta indeterminada es la más común y en ella los tallos presentan segmentos uniformes con tres hojas (con yemas) y una inflorescencia, terminando siempre con un ápice vegetativo. La planta determinada tiene tallos con segmentos que presentan progresivamente menos hojas por inflorescencia y terminan en una inflorescencia, lo que resulta en un crecimiento limitado. El tallo típico tiene de 2 a $4 \mathrm{~cm}$ de diámetro en la base y está cubierto por pelos glandulares y no glandulares, que salen de la epidermis. El sistema radicular del tomate está constituido por una raíz principal, raíces secundarias y raíces 
adventicias. Las hojas son compuestas, imparipinnadas con 7 o 9 foliolos. Una hoja típica de las plantas cultivadas tiene unos $0,5 \mathrm{~m}$ de largo, algo menos de anchura con un gran foliolo terminal y hasta 8 laterales que, a su vez, pueden ser compuestos (Chamarro, 1995).

La inflorescencia está compuesta de 4 a 12 flores. Sus flores son radiales y con cinco estambres. Las flores, en número variable, se agrupan en inflorescencias de tipo racimoso (Figura 1.1). El ovario, súpero bicarpelar, contiene numerosos primordios seminales, produciendo bayas polispermas. Los carpelos se presentan en posición oblicua con respecto al plano mediano de la flor. El fruto es una baya de forma globular, ovoide o aplastada cuyo peso oscila, según variedades entre 5 y 500 gramos y puede ser biplurilocular o plurilocular. Está unido a la planta por un pedicelo con un engrosamiento articulado que contiene la capa de abscisión. Posee una semilla discoidal-lenticular comprimida y embrión enrollado, de diámetro más o menos uniforme (Chamarro, 1995). El fruto de tomate presenta una gran diversidad de tamaños, formas y colores (Figura 1.2).

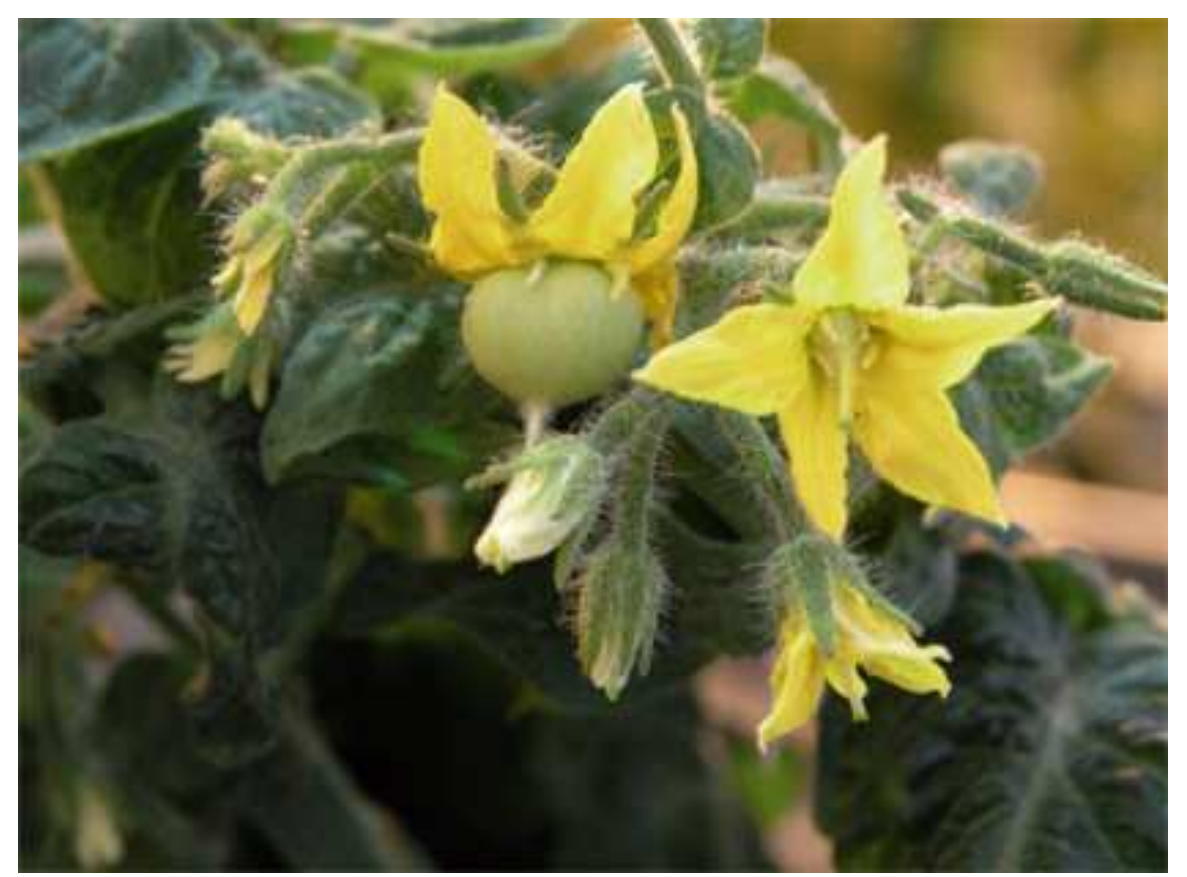

Figura 1.1. Inflorescencia de tomate tipo racimoso. 


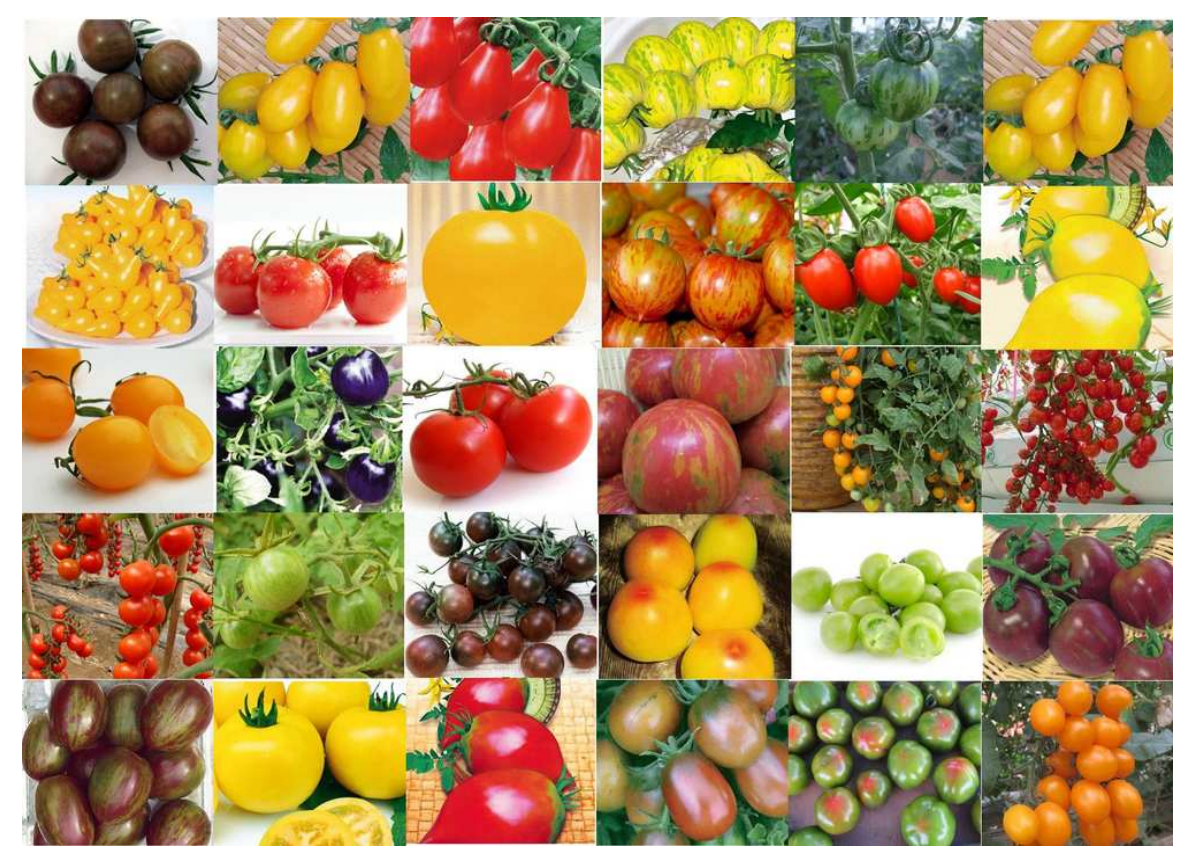

Figura 1.2. Diversidad de formas y variedades de tomate.

\subsubsection{Importancia económica}

Según datos de la Organización de las Naciones Unidas para la Agricultura y la Alimentación (FAO, 2013), la producción mundial de tomate para consumo en fresco se eleva a 163,9 Mt y es en las regiones tropicales y subtropicales donde se encuentran los mayores productores a nivel mundial. En 2013, la producción mundial de esta hortaliza se incrementó en un 1,6\% con respecto al año anterior, continuando con la línea ascendente que llevaba desde 1999. La demanda a nivel mundial de este fruto aumenta continuamente, siendo el segundo fruto más consumido después de la patata (Foolad, 2004). El incremento de la producción en los últimos años, se ha debido principalmente a un aumento del rendimiento y en menor proporción, al aumento de la superficie cultivada. Por países, China es el principal productor mundial con 50,1 Mt, lo que representa el 30,5\% de la producción total mundial (Figura 1.3), aumentado su producción en 2,4 Mt con respecto al año 2012. El segundo lugar lo ocupa India, con 18,3 Mt (11,2\%) y con un 2,3\% menos que en el 2012, figurando Estados Unidos en la tercera posición con 12,6 Mt (7,7\%), también disminuyendo su producción con respecto al año anterior en un 4,8\%. España se encuentra en la novena posición con 3,7 Mt, el 
2,3\% de la producción mundial de tomate destinada a consumo en fresco, bajando una posición con respecto al año anterior. La producción de este fruto en la Unión Europea en 2013 fue de 15,4 Mt. España fue el segundo país productor con un 23,9\%, por detrás de Italia con el 32,1\% del total. Además, España es el tercer país de la Unión Europea con mayor superficie dedicada a este cultivo (19\%), por detrás de Italia (37\%) y Rumania (19,2\%).

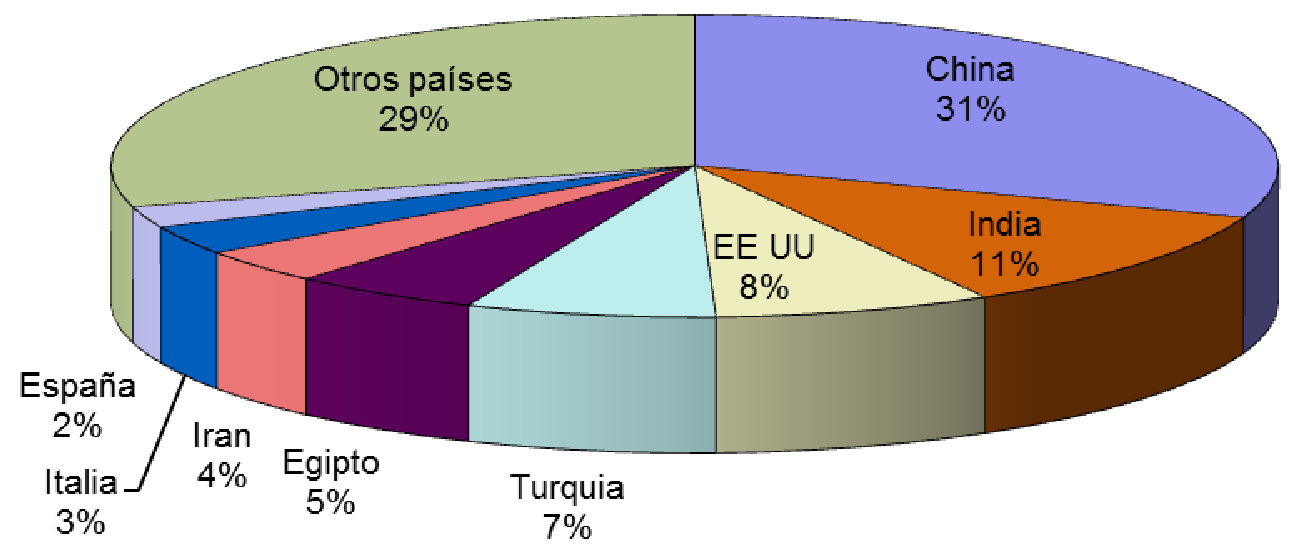

Figura 1.3. Representación de los principales países productores de tomate a nivel mundial (Mt).

\subsubsection{Requerimientos edafoclimáticos del cultivo}

La temperatura óptima para el desarrollo del cultivo de tomate oscila entre 15 y $18{ }^{\circ} \mathrm{C}$, durante la noche y de 20 a $28{ }^{\circ} \mathrm{C}$ durante el día. Temperaturas superiores a 30-35 ำ provocan fallos en la fructificación y en el desarrollo tanto de la planta como del sistema radicular. Temperaturas inferiores a $12-15{ }^{\circ} \mathrm{C}$ pueden originar problemas en el desarrollo de la planta y temperaturas superiores a $25^{\circ} \mathrm{C}$ e inferiores a $12^{\circ} \mathrm{C}$, provocan fecundaciones es defectuosas o nulas. Respecto al fruto, la maduración se encuentra muy influida por la temperatura en lo que se refiere tanto a la precocidad como a la coloración. Así, valores cercanos a los $10^{\circ} \mathrm{C}$ y superiores a los $30^{\circ} \mathrm{C}$ originan tonalidades amarillentas. En los 
momentos críticos durante el período vegetativo resulta crucial la interrelación entre las temperaturas diurna y nocturna y la luminosidad.

La humedad relativa óptima oscila entre $60 \%-80 \%$. Humedades relativas muy elevadas favorecen el desarrollo de enfermedades aéreas y el agrietamiento del fruto y dificultan la fecundación, debido a que el polen se compacta, provocando el aborto de flores. También una humedad relativa baja dificulta la fijación del polen al estigma de la flor.

En relación al suelo, la planta de tomate requiere de suelos sueltos de textura silíceo-arcillosa y ricos en materia orgánica pero también se desarrolla en suelos arcillosos enarenados.

\subsubsection{Ciclos de cultivo}

La duración y época de los ciclos de cultivo vienen en gran parte determinadas por el sistema de cultivo adoptado, al aire libre o protegido. En el sureste español, el cultivo tradicional de tomate al aire libre está en recesión, debido fundamentalmente a los graves problemas de virosis. Estas enfermedades son producidas por insectos vectores, como la mosca blanca Bemisia tabaci y el trips Frankliniella occidentalis, transmisores del virus de la cuchara (TYLCV) y del bronceado del tomate (TSWV), respectivamente, que aumentan su multiplicación coincidiendo con el ciclo de tomate al aire libre. Todo ello a ocasionado que gran parte de la superficie que se cultivaba en condiciones de aire libre, en ciclos de verano-otoño, se haya transformado a la modalidad de cultivo bajo malla o invernadero. Bajo dichos sistemas y dependiendo de las condiciones climáticas de la zona, fechas deseadas de producción, cultivares empleados y destino del fruto (fresco o industria), el tomate es cultivado en diferentes ciclos. Habitualmente se siembra en semillero y los transplantes se realizan con cepellón de turba 45-50 días después, si es planta no injertada, y entre 60 y 70 días, si se trata de planta injertada. En concreto, en la Región de Murcia se pueden distinguir tres ciclos: 
- Ciclo de otoño: El trasplante se realiza a finales de agosto y la recolección de los frutos tienen lugar principalmente durante el mes de febrero. Los cultivares más empleados en este tipo de ciclo de cultivo son los asurcados (cuello verde).

- Ciclo de primavera: El transplante se realiza hasta finales de enero y las recolecciones de los frutos se llevan a cabo principalmente durante el mes de junio. Los cultivares mas empleados en este ciclo de cultivo son los de tipo liso y asurcado, con predominio de los de larga vida.

- Ciclo largo: El trasplante se realiza a mediados de agosto o principios de septiembre y las recolecciones de los frutos se pueden alargar hasta primavera. Los cultivares más empleados en este ciclo de cultivo son muy vigorosos y de tipo liso y asurcado, principalmente de larga vida.

\subsubsection{Usos}

El tomate es uno de los principales componentes de la denominada "dieta mediterránea", muy importante en España e Italia, cuya base son productos procedentes en su mayoría de la agricultura local, y que se caracteriza por su elevado contenido en productos vegetales y grasas monoinsaturadas. El consumo de tomate per cápita en España se encuentra cercano a los $15 \mathrm{~kg}$ por persona y año (FEPEX, 2012). Se consume principalmente en ensaladas, aunque también se utiliza como ingrediente de muchas preparaciones culinarias, cocido o frito. Aproximadamente, el $40 \%$ de la producción total se destina a la transformación industrial (pelado, concentrado, deshidratado, dados, etc.). Así, existen en el mercado numerosos productos derivados de este fruto en forma de zumos, gazpacho, salsas, purés, pastas, conservas de tomate entero o partido, tomate en polvo, etc. Mientras que otras comunidades como Extremadura, producen tomate sobre todo para conserva, la producción de Murcia es principalmente para consumo en fresco. 
En la actualidad, existe una amplia gama de cultivares híbridos creados con el objetivo de mejorar la productividad, la calidad y la adaptación a distintas condiciones de cultivo, lo que ha permitido cubrir un amplio rango de necesidades. Los cultivares de tomate para consumo en fresco que se emplean actualmente, presentan grandes diferencias en tamaño, forma (achatado, redondeado, alargado, en forma de pera) y color (desde el amarillo hasta el rojo oscuro). Los principales cultivares de tomate que actualmente se comercializan en la Región de Murcia pertenecen a los tipos marmande, larga vida, beef, vemone, moneymaker, cocktail, cereza (cherry), liso y ramillete.

\subsection{Valor nutricional y funcional de tomate}

El tomate es una excelente fuente de nutrientes y compuestos bioactivos con propiedades funcionales y farmacológicas muy interesantes, lo que le ha permitido ser catalogado como alimento funcional (Canene-Adams y col., 2005). Además, el bajo aporte calórico de este fruto $(22 \mathrm{kcal} / 100 \mathrm{~g})$, junto con su alto contenido en agua $(<90 \%)$, minerales y vitaminas (Tabla 1.1), lo convierten en un alimento muy apreciado de acuerdo con las pautas de alimentación actuales. Es una fuente importante de fibra, minerales ( $K$ y $P$ ), folatos y vitaminas, entre las que destacan las vitaminas $C, E$, provitamina $A$ y las del grupo $B\left(B_{1}\right.$ y $\left.B_{3}\right)$. El contenido en sólidos solubles oscila entre $4,5-7 \%$, siendo la gran parte de ellos fructosa y glucosa, mientras que los ácidos orgánicos mayoritarios detectados en el zumo son el ácido cítrico y el málico. Además de estos nutrientes, contiene altas concentraciones de metabolitos secundarios, como carotenoides y compuestos fenólicos con probadas propiedades beneficiosas para la salud por su actividad antioxidante, presentando un efecto protector frente a los radicales libres causantes de múltiples procesos degenerativos (Story y col., 2010; Karipcin y col., 2016). En particular, su consumo ha sido correlacionado con la prevención de enfermedades crónicas, tales como enfermedades cardiovasculares y neurodegenerativas así con la de ciertos tipos de cáncer (Canene-Adams y col., 2005). Concretamente el consumo de tomate y de sus productos derivados, se ha asociado con un menor riesgo de desarrollar cáncer de tracto digestivo y de 
próstata. Por último, el fruto, contiene tomatina, compuesto con propiedades antibacterianas, antimicóticas y antiinflamatorias (Nicoleta y col., 2016).

Tabla 1.1. Composición nutricional de tomate (por $100 \mathrm{~g}$ de porción comestible).

\begin{tabular}{|c|c|c|c|c|}
\hline Energía (kcal) & Proteína (g) & Grasa (g) & $\begin{array}{l}\text { Hidratos de } \\
\text { carbono }(\mathrm{g})\end{array}$ & Fibra (g) \\
\hline 22 & 1 & 0,11 & 3,5 & 1,4 \\
\hline Agua (g) & Calcio (mg) & Potasio (mg) & Magnesio (mg) & Zinc (mg) \\
\hline 94 & 11 & 290 & 10 & 0,22 \\
\hline Yodo $(\mu \mathrm{g})$ & Hierro (mg) & Sodio (mg) & Fósforo (mg) & Selenio $(\mu \mathrm{g})$ \\
\hline 7 & 0,6 & 3 & 27 & Trazas \\
\hline Tiamina (mg) & $\begin{array}{l}\text { Riboflavina } \\
\text { (mg) }\end{array}$ & $\begin{array}{c}\text { Vitamina } B_{6} \\
(\mathrm{mg})\end{array}$ & $\begin{array}{c}\text { Vitamina } B_{3} \\
(\mathrm{mg})\end{array}$ & Vitamina C (mg) \\
\hline 0,06 & 0,04 & 0,11 & 0,8 & 26 \\
\hline Folatos $(\mu \mathrm{g})$ & $\begin{array}{c}\text { Vitamina A } \\
(\mu g)\end{array}$ & $\begin{array}{c}\text { Vitamina } B_{12} \\
(\mathrm{mg})\end{array}$ & $\begin{array}{l}\text { Vitamina D } \\
(\mu \mathrm{g})\end{array}$ & Vitamina $E(\mathrm{mg})$ \\
\hline 28 & 82,3 & 0 & 0 & 1,2 \\
\hline
\end{tabular}

\subsubsection{Carotenoides}

Los carotenoides son un grupo de pigmentos liposolubles de origen vegetal que el hombre no es capaz de sintetizar y necesita adquirirlos a través de la dieta, principalmente a través de la ingesta de frutas y hortalizas. La estructura básica es un tetraterpeno de 40 carbonos, simétrico y lineal formado a partir de ocho unidades isoprenoides de 5 carbonos, unidas de manera que el orden se invierte en el centro (Figura 1.4). Este esqueleto básico puede modificarse de varias maneras por ejemplo por hidrogenación, dehidrogenación, ciclación, isomerización, migración del doble enlace, acortamiento o extensión de la cadena, reordenamiento, introducción de funciones oxigenadas o por combinaciones de estos procesos, dando como resultado una gran diversidad de estructuras. En la naturaleza se han aislado y caracterizado más de 700 carotenoides, sin embargo 
solo unos 40-50 están presentes en la dieta humana (Di Pietro y col., 2016). Su color, que varía desde amarillo pálido, pasando por anaranjado, hasta rojo oscuro, se encuentra directamente relacionado con su estructura y el número de enlaces dobles que presenta.

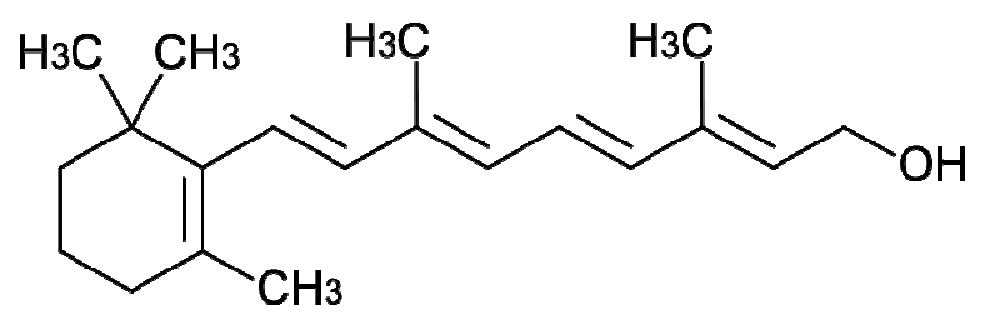

Figura 1.4. Estructura básica de terpenos.

Los carotenoides, atendiendo a su composición química se dividen en carotenoides hidrocarbonados o carotenos, incluyendo, entre otros, $\alpha$-caroteno, $\beta$ caroteno y licopeno y carotenoides oxigenados o xantofilas como luteína y zeaxantina. Los carotenoides ya sean carotenos o xantofilas, pueden ser acíclicos, monociclitos o bicicliclos. La ciclación ocurre en uno o ambos extremos de la molécula, formando uno o dos anillos $\beta$ de seis miembros ( $\beta$-ionona) 0 anillos $\varepsilon$ ( $\alpha$-ionona). Así el monocíclico, $\gamma$-caroteno tiene un anillo $\beta$ mientras que los bicíclicos, $\beta$-caroteno, $\beta$-criptoxantina, zeaxantina y astaxantina tienen dos de estos anillos. Los bicíclicos $\alpha$-caroteno y luteína tienen cada uno un anillo $\beta$ y un anillo $\varepsilon$ (Fraser y Bramley, 2004).

El rasgo estructural distintivo de los carotenoides es un sistema extenso de dobles enlaces conjugados, el cual consiste en alternar enlaces carbono-carbono simples y dobles. Esto se denomina cadena poliénica. Esta parte de la molécula conocida como cromóforo, es responsable de la capacidad de los carotenoides de absorber luz en la región visible y en consecuencia, de su gran capacidad de coloración. Son necesarios mínimo siete enlaces dobles conjugados para que un carotenoide produzca color, p.e. ל-caroteno es amarillo suave. El fitoflueno con cinco enlaces es incoloro. El color se acentúa a medida que se extiende el 
sistema conjugado, así el licopeno es rojo. La ciclación causa algún impedimento, por tanto el $\beta$-caroteno y el $\gamma$-caroteno son de color naranja y rojo-naranja respectivamente, aunque tienen el mismo número de enlaces dobles conjugados que el licopeno. La intensidad y matiz de los colores en los alimentos dependen de que carotenoides estén presentes, de sus concentraciones y estado físico (Rodríguez-Amaya, 1999; Rodríguez-Amaya y Kimura, 2004). El calor, la exposición a la luz, la exposición a ciertos disolventes o la presencia de superficies activas, promueven la isomerización de los carotenoides de las formas trans (configuración habitual y más estable) hacia la formación de isómeros cis. Esto es debido, a las repulsiones que inducen los grupos metilos laterales (Nguyen y Schwartz, 1998; Boileau y col., 1999).

El tomate es un fruto rico en carotenoides, especialmente en licopeno ( $80 \%-90 \%$ del contenido total) y en $\beta$-caroteno ( $7-10 \%$ del contenido total), principales pigmentos responsables de su color rojo característico (Figura 1.5).

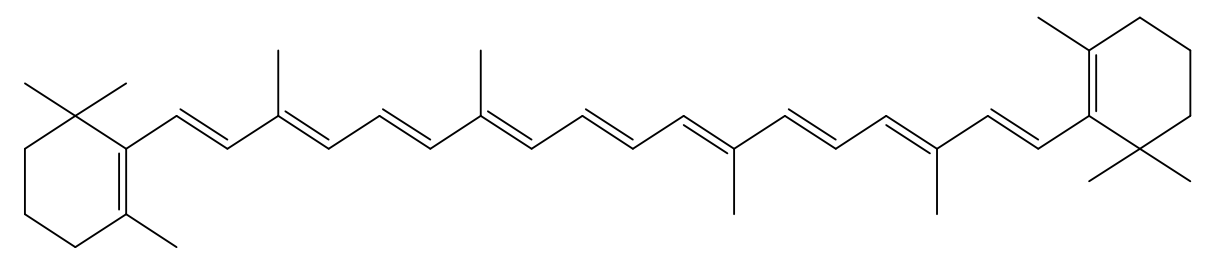

$\beta$-caroteno

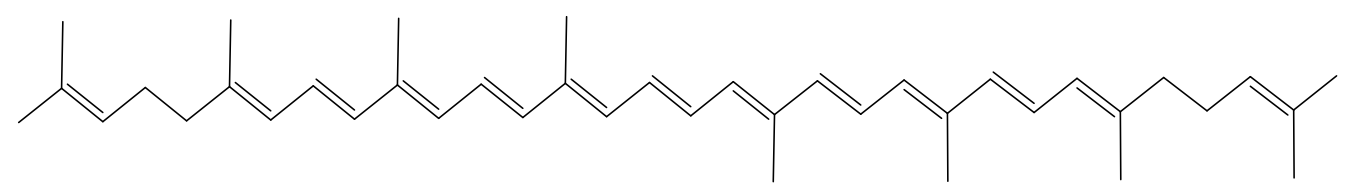

licopeno

Figura 1.5. Estructura química de los principales carotenoides en tomate, licopeno y $\beta$-caroteno.

El fruto de tomate representa la fuente más importante de licopeno en la dieta y su contenido en este fitoquímico es considerado como criterio de calidad 
funcional, ya que posee un gran poder antioxidante, por lo que es un referente en la prevención de enfermedades cardiovasculares, diferentes tipos de cáncer y en general, en el envejecimiento de nuestro organismo (Arias y col., 2000; Mein y col., 2008). A su vez, $\beta$-caroteno también es un potente antioxidante, aunque en menor medida que licopeno. Es soluble en grasa y destaca por ser precursor de la vitamina A (Kiokias y Gordon, 2004). Su consumo se relaciona con la disminución del riesgo de sufrir accidentes cerebrovasculares y cardiovasculares, así como fatiga crónica y enfermedades como el lupus (Hyson, 2002). Por otro lado también es destacable el papel que juega la vitamina $A$ en la protección de la visión. (Bartley y Scolnik, 1995). El tomate también contiene otros carotenoides, los cuales se encuentran en baja concentración como son $\gamma$-, $\delta$ - y $\varepsilon$-caroteno, neurosporeno, fitoeno y fitoflueno, estos dos últimos precursores de licopeno, menos estudiados pero con propiedades funcionales reconocidas (Ramaprasad y col., 2013).

\subsubsection{Compuestos fenólicos}

Los compuestos fenólicos constituyen un amplio grupo en el que se han podido identificar más de 8000 compuestos diferentes. En general, engloban todas aquellas sustancias que poseen uno o varios grupos fenol (anillo aromático) unidos a estructuras aromáticas o alifáticas (Croteau y col, 2000). Se localizan en todas las partes de las plantas y su concentración es variable a lo largo del ciclo vegetativo. Atendiendo a su estructura, los compuestos fenólicos se pueden dividir en dos categorías: flavonoides y no flavonoides (Figura 1.6) (Waterhouse, 2002). 


\section{COMPUESTOS FENÓLICOS}

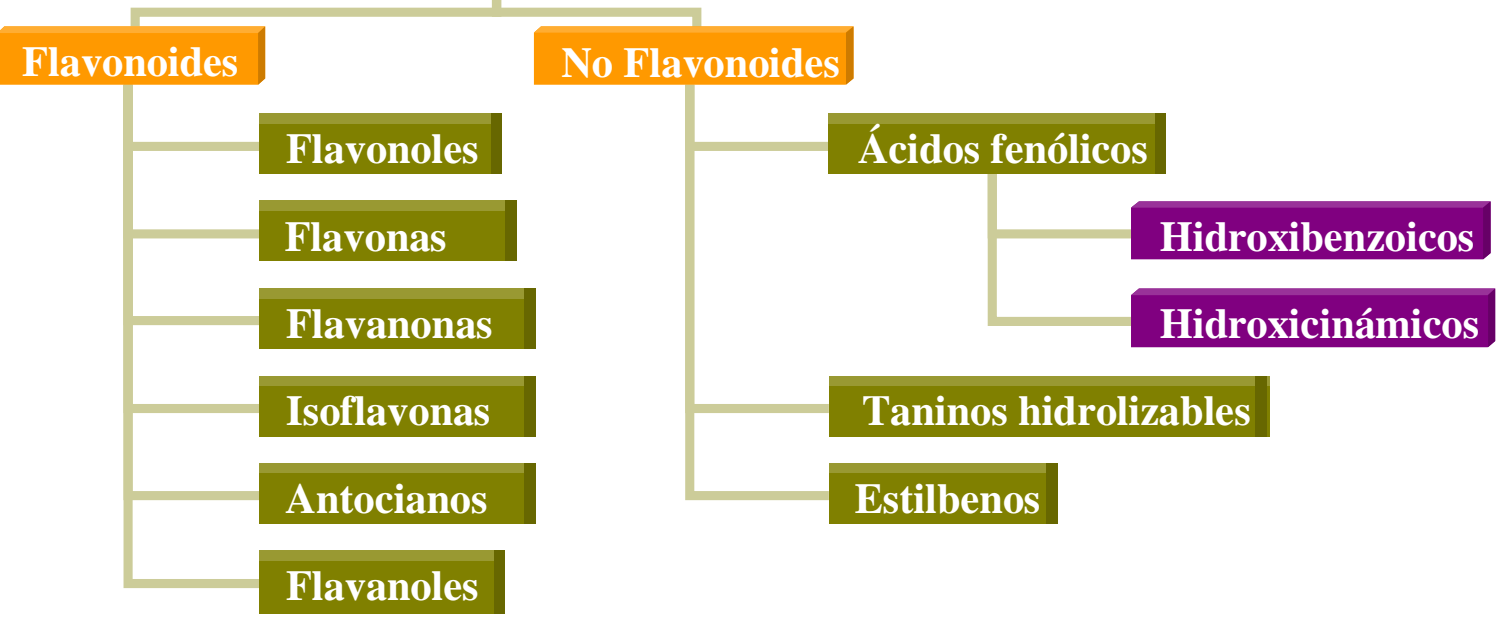

Figura 1.6. Clasificación de compuestos fenólicos.

\section{- Flavonoides}

La estructura común de los flavonoides consiste en dos anillos aromáticos $(\mathrm{A}+\mathrm{B})$ conectados mediante un anillo heterocíclico oxigenado (C). Este grupo, a su vez, se divide en varias clases, siendo las más importantes: flavonoles, flavonas, flavanonas, isoflavonas, antocianos y flavanoles. Las distintas clases tienen distinto nivel de oxidación y diferentes sustituyentes en el anillo heterociclo, mientras que los compuestos dentro de cada clase difieren en los sustituyentes de los anillos aromáticos. Los flavonoides se encuentran en las plantas en forma de aglicona o como glucósidos, siendo esta última su forma más habitual.

Los flavonoles son los flavonoides más abundantes en alimentos de origen vegetal. Se acumulan en los tejidos de las plantas normalmente en forma de conjugados glicosilados y están representados principalmente por quercetina, kaempferol y miricetina.

Las flavonas son estructuralmente similares a los flavonoles y difieren solo en la ausencia de hidroxilación en la posición 3 del anillo C. Están principalmente representadas en la dieta por apigenina y luteolina, encontrándose principalmente 
en apio (Apium raveolens), perejil (Petroselinum crispum) y alcachofa (Cynara scolymus) (Crozier y col., 2006).

Las flavanonas están representados principalmente por naringenina y hesperidina y se encuentran principalmente en cítricos (Manach y col., 2004) aunque también se han encontrado en tomate, kiwi y banana (Krause y Galensa, 1992; Kanazawa y Sakakibara, 2000; Dégenéve, 2004).

Las isoflavonas, a diferencia de la mayoría de los flavonoides, se caracterizan por presentar el anillo B en la posición C3 en lugar de en la posición C2. Las más comunes son genisteína, daidzeína, y gliciteína cuya distribución es muy limitada en el reino vegetal, encontrándose solo en grandes cantidades en leguminosas como la soja (Dixon y Steele, 1999). Las isoflavonas son conocidas por su actividad estrogénica y han recibido mucha atención debido a su posible papel en la prevención del cáncer de mama y la osteoporosis (Barnes, 2003).

Los antocianos son los principales responsables de los colores rojo, azul y violeta de las frutas. En la naturaleza se encuentran alrededor de diecisiete antocianos, pero solo seis de ellos (cianidina, delfinidina, petunidina, peonidina, pelargonidina y malvidina) son de importancia en la dieta.

Los flavanoles, también llamados catequinas, se encuentran como agliconas o esterificados con ácido gálico, siendo los más comunes (+) catequina y (-) epicatequina, los cuales se encuentran en grandes cantidades en albaricoque, uva, mora, melocotón y nectarina (Porter, 1988; Hong y col., 2004).

\section{- No flavonoides}

Dentro de los no flavonoides, se distinguen tres grupos, ácidos fenólicos (serie benzoica y cinámica), taninos hidrolizables y estilbenos. Los ácidos fenólicos, a su vez se clasifican en dos grupos, los derivados del acido hidroxibenzoico y del ácido hidroxicinámico. Estos últimos son los más comunes en plantas, y entre ellos los ácidos p-cumárico, cafeico, ferúlico y sináptico, generalmente estos compuestos, están presentes en diversas formas conjugadas, 
siendo más frecuentes como ésteres. Se encuentran principalmente en el café, manzana, zanahoria y tomate (Clifford, 1999; Paganga y col., 1999; Alasalvar y col., 2001; Clifford y col., 2003).

Los taninos hidrolizables tienen como núcleo central un alcohol polihídrico como la glucosa y grupos hidroxilo que se encuentran esterificados parcial o completamente, formando galotaninos y elagitaninos, respectivamente. Estos compuestos se encuentran principalmente en nuez, frambuesa, fresa y granada (Espín y Tomás-Barberán, 2006).

Los estilbenos se caracterizan por la presencia de un núcleo 1,2difeniletileno con grupos hidroxilo en los anillos aromáticos. Pueden encontrarse en forma de monómeros y oligómeros, siendo el más conocido el resveratrol (3,5,4'-trihidroxiestilbeno) presente en uva, vino tinto y cacahuetes (Burns y col., 2002; Han y col., 2007).

Los compuestos fenólicos constituyen una de las principales clases de metabolitos secundarios de las plantas donde desempeñan diversas funciones fisiológicas, tales como asimilación de nutrientes, síntesis proteica, actividad enzimática, fotosíntesis, formación de componentes estructurales, alelopatía y defensa frente a factores adversos ambientales. Los fenoles también están asociados al color, las características sensoriales (sabor, astringencia, etc.), las características nutritivas y las propiedades antioxidantes de los alimentos de origen vegetal. La actividad antioxidante de los compuestos fenólicos se debe principalmente a la actividad del grupo fenol (Robbins, 2003; Kähkönen y col, 2001). Estos compuestos presentan una gran capacidad para captar radicales tóxicos debido a la presencia de grupos hidroxilo unidos a los anillos aromáticos (Frontela y col., 2009). Numerosos trabajos describen un incremento de los niveles de compuestos fenólicos en tejidos de plantas sujetas a condiciones de estrés, tales como alta intensidad de luz, ataques de patógenos, lesiones y déficit de nutrientes (Ramkrishna y Aswathanarayana, 2011).

Los compuestos fenólicos presentan un gran interés nutricional y juegan un papel importante en la salud humana ya que ayudan a prevenir el envejecimiento, y enfermedades como arteriosclerosis, cáncer, Alzheimer y Parkinson, mediante 
la inhibición de la formación de radicales libres y la peroxidación de lípidos (Poiroux-Gonord y col., 2010). El fruto de tomate, posee entre 450-600 $\mathrm{\mu g} \mathrm{g}^{-1} \mathrm{PF}$ de compuestos fenólicos, de los cuales los ácidos fenólicos y los flavonoides son los grupos más representativos. De ellos, el conjugado más conocido es el ácido clorogénico, que se forma de la esterificación de los ácidos cafeico y quínico y constituye el derivado hidroxicinámico predominante en tomate (Clifford, 2000). Además, el tomate es rico en flavonoles, que se concentran principalmente en la piel, de los cuales las formas conjugadas de quercetina y kaempferol representan un $98 \%$ (Stewart y col., 2000).

En un estudio realizado por Martínez-Valverde y col (2002) sobre nueve variedades de tomate comerciales, los principales compuestos fenólicos

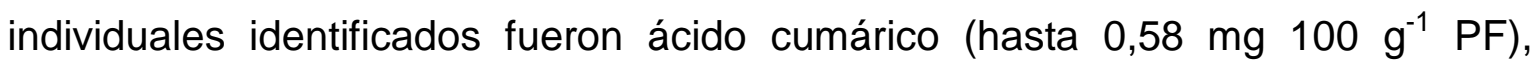
clorogénico (1,4-3,3 mg $\left.100 \mathrm{~g}^{-1} \mathrm{PF}\right)$ y cafeico $\left(0,14-1,30 \mathrm{mg} 100 \mathrm{~g}^{-1} \mathrm{PF}\right)$, así como quercetina $\left(0,72-4,36 \mathrm{mg} 100 \mathrm{~g}^{-1} \mathrm{PF}\right)$, kaempferol (0,23-0,57 mg $\left.100 \mathrm{~g}^{-1} \mathrm{PF}\right) \mathrm{y}$ naringenina (0,5-6,90 mg $\left.100 \mathrm{~g}^{-1} \mathrm{PF}\right)$. La concentración de estos compuestos depende de diferentes factores, entre ellos la variedad y la época del año en la que se recogen los frutos (Crozier y col., 1997). También el proceso de maduración afecta a estos compuestos de forma diferente; mientras unos compuestos fenólicos disminuyen conforme avanza la maduración, otros no sufren apenas cambios o incluso aumentan (Buta y Spaulding, 1997).

\subsubsection{Vitaminas $C$ y E}

La vitamina $\mathrm{C}$ es un compuesto hidrosoluble de seis átomos de carbono que se encuentra principalmente en alimentos de origen vegetal. El hombre carece de la enzima que cataliza la etapa terminal de la síntesis de ácido ascórbico, la L-gulonolactona oxidasa, por lo que debe adquirirlo a través de la alimentación. El ácido L-ascórbico (AA) es la principal forma activa de la vitamina C. EI AA se oxida de forma reversible para formar ácido L-dehidroascórbico (ADHA), que también presenta actividad biológica (Figura 1.7). Esta oxidación puede ser inducida por la exposición a altas temperaturas, $\mathrm{pH}$ alto, luz o presencia de oxígeno. Cada una de las formas derivadas del ácido ascórbico 
poseen diferentes propiedades antioxidantes y nutricionales (Davey y col., 2000; Deutsch, 2000).

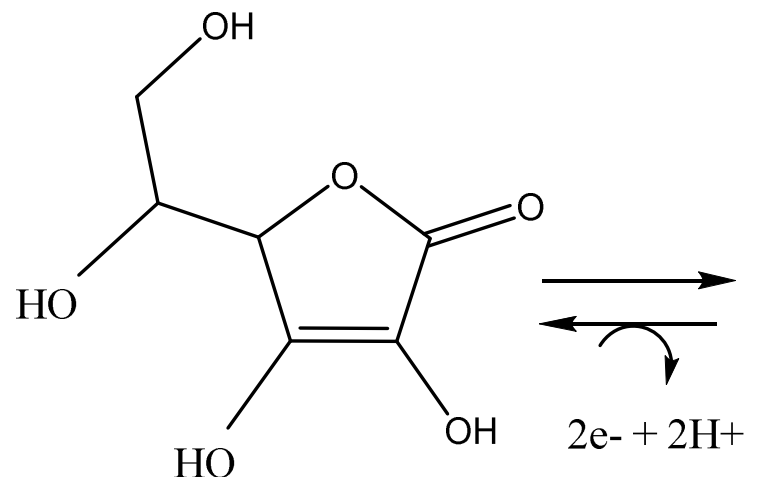

Ácido Ascórbico

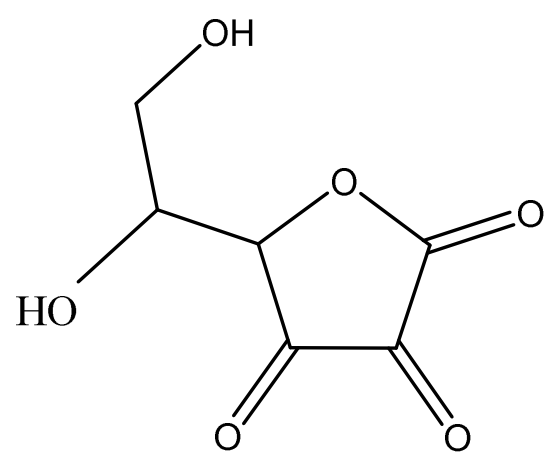

Ácido Dehidroascórbico

Figura 1.7. Estructura del ácido ascórbico y de su forma oxidada, el ácido dehidroascórbico.

Una de las funciones más claramente definida de la vitamina $C$ en el metabolismo de animales y plantas, es la de actuar como modulador de un gran número de reacciones enzimáticas que contienen hierro o cobre en el sitio activo y que requieren AA para su máxima actividad. Este es el caso de la ferrodioxigenasa, involucrada en la generación y el mantenimiento del colágeno en la piel, el cartílago y el tejido conectivo (Furusawa, 2001). En planta superiores, la vitamina $C$ está directamente involucrada en múltiples procesos fisiológicos fundamentales, entre otros muchos, la eliminación de especies activas de oxígeno, el control del crecimiento y del metabolismo de las células, la división celular, la expansión de la pared celular y la síntesis de otros metabolitos (Smirnoff y col., 2001). En humanos su consumo se ha relacionado con la reducción del daño oxidativo y la mejora en procesos inflamatorios (Aguirre y May, 2008). Los vegetales son la mayor fuente de vitamina $C$ de la dieta humana y los procesos que determinan el contenido de esta vitamina en dichos vegetales (síntesis y degradación del ácido ascórbico) condicionan de forma directa la 
calidad nutricional de los mismos. Concretamente en tomate, la concentración de ácido ascórbico oscila entre 3 y $30 \mathrm{mg} 100 \mathrm{~g}^{-1}$ de materia fresca.

La vitamina $E$, hace referencia a un grupo de moléculas solubles en grasa, donde se encuentran tocoferoles $(\alpha, \beta, \gamma$ y $\delta)$ y tocotrienoles $(\alpha, \beta, \gamma$ y $\delta)$. La clasificación de estas moléculas se basa en la naturaleza de la cadena lateral de los isoprenoides, que o bien está totalmente saturado o insaturado en tres posiciones (Figura 1.8). Además, los sustituyentes en el anillo cromanol están determinadas por las formas moleculares de la vitamina $E(\alpha, \beta, y$ y $\delta)$. Esta vitamina es un potente antioxidante y por lo tanto, su consumo se recomienda para prevenir diversas enfermedades degenerativas crónicas (Raiola y col., 2015). Los niveles de vitamina $E$ en tomate están comprendidos entre 2 y $6 \mathrm{mg} \mathrm{g}^{-1}$ peso fresco.<smiles>Cc1c(C)c2c(c(C)c1O)CC[C@](C)(CCC[C@H](C)CCC[C@H](C)CCCC(C)C)O2</smiles>

$\alpha$-tocoferol<smiles>Cc1cc(O)c(C)c2c1O[C@](C)(CCC[C@H](C)CCC[C@H](C)CCCC(C)C)CC2</smiles>

$\beta$-tocoferol

Figura 1.8. Estructura básica de tocoferoles. 


\subsection{Factores que afectan al desarrollo del cultivo y a la calidad del fruto}

El rendimiento de los cultivos hortícolas en general, y del tomate en particular, está condicionado por factores agronómicos y medioambientales. Concretamente, la composición nutritiva y antioxidante de los alimentos vegetales además de estar determinada por factores endógenos, puede ser modulada por estímulos externos, tales como las condiciones medioambientales y determinadas prácticas agronómicas. Así, factores como el régimen de riego (De Pascale y col., 2001), el estrés salino (Matsuzoe y col., 1998), la temperatura, la intensidad de la radiación (Slimestad y Verheul, 2005) y la fertilización (Warner y col., 2004), pueden afectar el desarrollo, composición química y calidad general de los frutos de tomate.

\subsubsection{Factores agronómicos}

\subsubsection{Material genético}

Los factores genéticos tienen gran influencia en el rendimiento, calidad sensorial, composición nutricional y vida postcosecha de frutas y hortalizas (Crisosto y Mitchell, 2007). Existen evidencias de la variabilidad en el contenido de compuestos bioactivos entre especies del mismo género y variedades de la misma especie; Kavitha y col. (2013) observaron variaciones en la concentración de vitamina $\mathrm{C}$, entre diferentes variedades de tomate, entre 107 y $208 \mathrm{mg} \mathrm{kg}^{-1}$. En este mismo estudio se describen variaciones en la concentración de carotenoides y de compuestos fenólicos totales, entre 90 y $221 \mathrm{mg} \mathrm{kg}^{-1}$ y entre 203 y $426 \mathrm{mg}$ $\mathrm{kg}^{-1}$, respectivamente. Esto muestra la importancia del genoma de la planta sobre la composición de los frutos, además de sobre otros parámetros como la capacidad de conservación y la resistencia a plagas y enfermedades. Ante esta variabilidad, la selección varietal es esencial, ya que la obtención de frutos de calidad dependerá de su potencial genético además de las condiciones ambientales y el manejo del cultivo. 


\subsubsection{Nutrición mineral}

El manejo de la nutrición mineral juega un papel esencial en el desarrollo de los cultivos y como consecuencia, sobre la calidad del fruto, dada su naturaleza de órgano sumidero. Tanto la dosis como el equilibrio entre los nutrientes, puede afectar al crecimiento y estado fisiológico del fruto, pudiendo originar alteraciones tanto por deficiencia como por exceso. Aunque se ha estudiado la incidencia de numerosos macro y microelementos sobre la calidad, los que han despertado un mayor interés han sido nitrógeno $(\mathrm{N})$ y calcio $(\mathrm{Ca})$, por participar de forma activa en numerosos procesos metabólicos. La asimilación de $\mathrm{N}$ está directamente relacionada con la síntesis de proteínas y carotenoides, pudiendo afectar a la coloración del fruto, tanto a nivel de la piel como de la pulpa (Pereira y col., 2011). En general, un excesivo aporte de $\mathrm{N}$ se ha relacionado con un mayor desarrollo vegetativo a costa de una menor calidad del fruto, en la mayoría de cultivos hortofrutícolas (Romojaro y col., 2006). Esto afecta no solo a parámetros nutricionales como vitamina $\mathrm{C}$ y aminoácidos esenciales, sino también a la textura, tamaño final de los frutos y retrasos en la maduración (Rueda, 2013).

Respecto a $\mathrm{Ca}$, es el elemento que con más frecuencia se ha relacionado con la calidad de los productos hortofrutícolas y en especial con la textura, debido a que participa en numerosos procesos del desarrollo y mantenimiento de la estructura de la pared celular, por su capacidad para establecer enlaces iónicos con los grupos carboxilados de las pectinas (Poovaiah y col., 1988). El déficit de Ca produce fisiopatías en el fruto como la podredumbre apical o blossom end rot (BER) en tomate (Figura 1.9) y pimiento. Estos efectos, pueden acentuarse si en el fruto, los niveles de potasio $(\mathrm{K})$ o $\mathrm{N}$ son elevados o los de fósforo $(\mathrm{P})$ bajos (Beverly y col., 1993). 


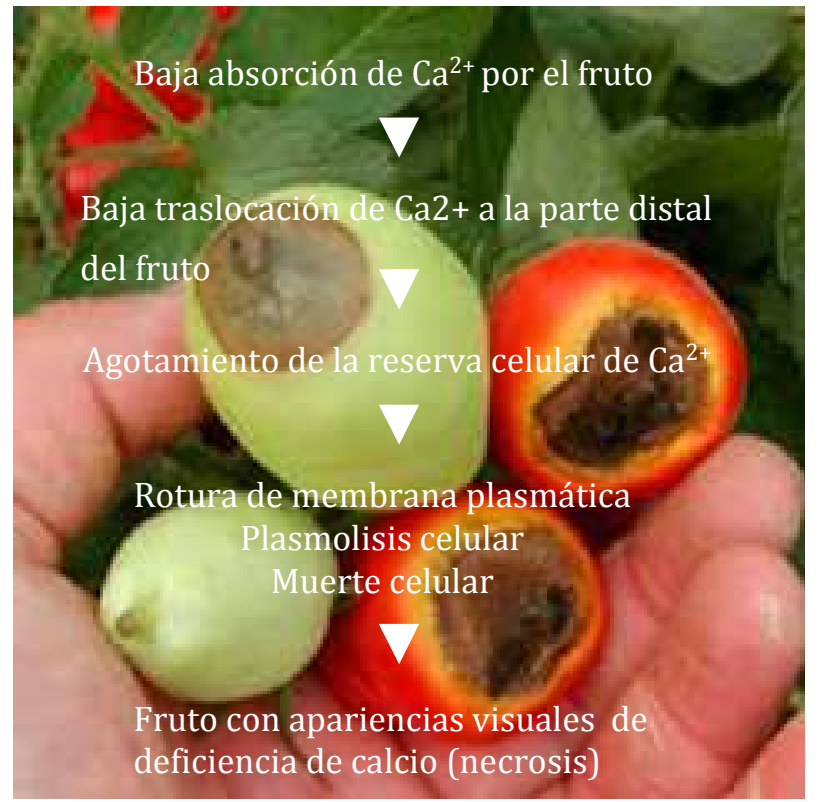

Figura 1.9. Mecanismo de aparición de podredumbre apical (BER) en fruto de tomate.

\subsubsection{Riego}

Otro de los factores que condicionan el rendimiento, la calidad del fruto y su conservación, es la cantidad y momento de aplicación del agua de riego. En tomate es importante mantener aportes hídricos óptimos en periodos fisiológicos críticos, como el cuajado del fruto y engorde del mismo. El aporte de agua a la planta condiciona la tasa de transpiración de la misma, ya que determina el gradiente de potencial hídrico entre el tejido vegetal y el aire. Una excesiva pérdida de agua por transpiración, produce un aumento del flujo de agua hacia las hojas, disminuyendo en consecuencia el flujo de agua y de nutrientes hacia el fruto, lo que afecta al rendimiento y a la calidad del mismo (Romojaro y col., 2006). El sistema de riego y momento del aporte hídrico, también afectan a la calidad y a la aparición de fisiopatías y podredumbres durante la postrecolección.

En función del manejo del riego se puede conseguir un equilibrio entre calidad y producción. Mientras que un estrés severo por sequía induce la reducción de ambos parámetros, cuando dicho estrés es moderado sólo es negativo para la producción, pudiendo incluso mejorar algunos atributos de 
calidad (Sánchez-Rodríguez y col, 2012). Matsuzoe y col. (1998) demostraron que un déficit de agua acelera el desarrollo de color en tomate tipo cherry. Por otro lado, un riego excesivo en fechas próximas a la recolección, aumenta el tamaño de los frutos y provoca una dilución de los componentes celulares, con el consiguiente rajado del fruto y pérdida de calidad sensorial (Romojaro y col., 2006).

\subsubsection{Sistemas de producción}

Se define "Sistema de Producción Agrícola" como un ecosistema que cambia, maneja y administra el hombre con el fin de producir bienes que le son útiles. Para modificar estos ecosistemas el hombre utiliza los factores de producción fuerza de trabajo, tierra y capital. Cada uno de estos factores de producción, tiene a su vez otros muchos factores, y su mayor o menor presencia, influye en las interrelaciones entre ellos y determina la diversidad de sistemas de producción existentes. Así, por ejemplo, el clima, los suelos, el modo de tenencia de la tierra, la tecnología disponible, el nivel de formación, las posibilidades de financiación, los mercados y niveles de precios, etc., influyen y condicionan la forma en la que se organiza la producción agrícola en cada sistema. No hay una definición única aceptada del concepto "Sistema de Producción Agrícola”, por lo que es frecuente encontrar clasificaciones diversas de los tipos y sistemas en función del objetivo que se persiga. Así, por ejemplo, la agricultura se puede clasificar en de secano o regadío, de monocultivo o policultivo, extensiva 0 intensiva, etc., y en cada una de estas tipologías se pueden definir uno o varios sistemas de producción, cada uno de ellos, implicando unos determinados cultivos, unos modos de producción, uso de insumos, etc.

Debido a los problemas medioambientales y de salud pública que la agricultura convencional puede provocar, han surgido otros modelos de producción más respetuosos con el medio ambiente y que garantizan una más agricultura sostenible, como son la producción integrada, el cultivo ecológico o el cultivo sin suelo. 
En la región de Murcia el sistema de producción mas empleados en el cultivo de tomate es la producción integrada bajo invernadero. En este tipo de agricultura se pretende aprovechar al máximo los recursos y los mecanismos de producción naturales, asegurando a largo plazo una agricultura sostenible, utilizando métodos biológicos, tecnológicos y químicos de control, y otras técnicas o estrategias que confieran protección al medio ambiente, productividad y calidad de los productos hortofrutícolas. Este sistema de producción, ya se utiliza en el $5 \%$ de los cultivos españoles.

Otro sistema de producción cada vez más demandado por los consumidores es la producción ecológica, que se define como un sistema general de gestión agrícola y producción de alimentos que combina las mejores prácticas ambientales, un elevado nivel de biodiversidad, la preservación de recursos naturales, la aplicación de normas exigentes sobre bienestar animal y una producción conforme a las preferencias de determinados consumidores por productos obtenidos a partir de sustancias y procesos naturales. La producción ecológica excluye normalmente el uso de productos químicos de síntesis como fertilizantes y plaguicidas. Su principal problema es la menor productividad, con reducciones de aproximadamente un $20 \%$ del rendimiento, respecto al alcanzado para una misma superficie en sistemas convencionales (Maeder y col., 2002). Diversos estudios han mostrado que frutas y hortalizas cultivadas bajo el sistema de agricultura ecológica, tienen mejores propiedades nutricionales que los cultivados de manera convencional (Vallverdú-Queralt y col., 2012; Luthria y col., 2010). Esto va asociado a la influencia que tienen algunas de las prácticas de este sistema de producción sobre la calidad, normalmente asociado a un menor aporte de fertilizantes y agua de riego, lo que da lugar a un suelo más equilibrado. Además, a menudo la planta está más expuesta a diferentes estreses bióticos, lo que a pesar de afectar negativamente al rendimiento, favorece en muchos casos su contenido en compuestos bioactivos. Concretamente, en un estudio realizado en tomate, se observó que el zumo de tomate ecológico, tenía un mayor contenido en compuestos fenólicos y capacidad antioxidante que el procedente de tomate cultivado tradicionalmente (Vallverdú-Queralt y col., 2012). En otro estudio, frutos de tomate de las variedades Felicia, Izabella y Paola, cultivadas bajo 
producción ecológica, alcanzaron mayor contenido en vitamina C y carotenoides que las mismas variedades cultivadas de manera tradicional (Caris-Veyrat y col., 2004). Otros estudios muestran un menor tamaño y peso de frutos ecológicos frente a frutos crecidos en sistema convencional, pero también una mejoría en su calidad, concretamente en la concentración de sólidos solubles y fotoquímicos, tales como compuestos fenólicos y vitamina C (Oliveira y col., 2013).

\subsubsection{Técnicas de cultivo}

\subsection{Poda}

La poda es una herramienta básica de adaptación de la planta al sistema de cultivo que se va a llevar a cabo. Es por ello que, para su aplicación, se debe de tener en cuenta la variedad, el portainjertos y factores de cultivo como fertirrigación, control fitosanitario, aplicación de reguladores del crecimiento y diseño y orientación de la plantación. La densidad de plantación, el sistema de poda y el entutorado deben optimizar la intercepción de radiación por parte del cultivo, especialmente en la época invernal cuando la radiación es más limitante ya que la reducción de radiación implica una reducción lineal de la cosecha (Cookshull, 1988). Además, con una poda adecuada se puede mejorar la calidad de los frutos, tanto el calibre como las cualidades organolépticas (Romojaroy col., 2006; Romojaro y col., 2007; Rueda, 2013). En concreto en tomate, el tipo de poda que se realiza en la zona del sureste español consiste en eliminar los brotes laterales, con el fin de guiar verticalmente y de forma individual a la planta mediante hilos o rafias, consiguiendo una mejor aireación e iluminación en la planta.

\subsection{Sombreo}

Uno de los principales problemas de los cultivos realizados bajo invernadero en el sureste español, especialmente durante el ciclo de primavera, es la elevada temperatura ambiental, ocasionada por altos niveles de radiación 
incidente. Esto provoca situaciones prolongadas de estrés, que a menudo impiden un desarrollo óptimo del cultivo (González-Real y Baille, 1998). La técnica más empleada tradicionalmente para reducir este aumento de temperatura, es el sombreo mediante blanqueo de la cubierta (Pérez-Parra y col., 2001). Sin embargo, esta técnica destinada a mejorar el rendimiento de las cosechas, presenta algunos inconvenientes como la falta de homogeneidad y la imposibilidad de graduar con precisión el nivel de sombreo. Una alternativa más tecnificada es el empleo de mallas o pantallas móviles, que permiten una gestión más eficiente del sombreo. Con ambas técnicas, además de reducir la temperatura ambiental, también se reduce la radiación, lo que puede repercutir tanto en el desarrollo de las plantas, como en la calidad y composición final de los frutos. Así, un sombreo excesivo puede provocar que las plantas se ahílen y aumente la incidencia de aborto floral (especialmente en tomate, pimiento y berenjena). La polinización y el tamaño final del fruto también se ven afectados por la baja luminosidad (Van de Voorent, 1986). Todo esto hace que, para la gestión de los sistemas de sombreo automatizados, se deba tener en cuenta aspectos tales como el desarrollo del cultivo en cuestión, la radiación y las temperaturas.

\subsubsection{Factores medioambientales}

\subsubsection{Factores abióticos}

El efecto de los factores ambientales sobre los cultivos ha cobrado gran relevancia en los últimos años, debido principalmente a los cambios ambientales asociados al llamado "cambio climático". Las fluctuaciones a corto y largo plazo de las pautas del clima, pueden tener una gran repercusión en la producción agrícola, reduciendo drásticamente el rendimiento de las cosechas. Estos cambios en el entorno productivo, requieren adecuar el manejo del cultivo a las nuevas exigencias fisiológicas de la planta. En condiciones de campo, la mayoría de los factores ambientales que influyen en el desarrollo del cultivo son difícilmente modulables y se ha comprobado que tienen una gran influencia tanto en el rendimiento como en la calidad y valor nutricional de numerosos productos. 
El manejo racional de los factores climáticos de forma conjunta es fundamental para el adecuado desarrollo del cultivo, ya que todos se encuentran estrechamente relacionados y la actuación sobre uno de estos incide sobre el resto (Rothman y Tonelli, 2010).

\subsection{Luz}

Aunque es difícil correlacionar la composición de los frutos con las condiciones medioambientales, existen evidencias de que la luz puede afectar al contenido de compuestos antioxidantes de los frutos, probablemente debido al papel fotoprotector de estos compuestos (Dumas y col., 2003; Gautier y col., 2008). La luz es un estímulo que activa un amplio rango de genes en las plantas, relacionados con la fotosíntesis y fotomorfogénesis. Algunos estudios, describen que la luz regula procesos tan importantes como la activación de genes que inducen la biosíntesis de carotenoides y que estos metabolitos son requeridos durante la fotosíntesis en plantas y algas (Woitsch y Romer, 2003; Briggs y col., 2007).

Tomate es un cultivo clasificado como planta de día neutro (PDN), es decir, florece independientemente de la longitud del día, aunque requiere buena iluminación (Calvert, 1973). La limitación lumínica reduce la fotosíntesis neta de la planta y, por lo tanto, implica una mayor competencia por los fotoasimilados, incidiendo de forma negativa sobre el desarrollo vegetativo y los procesos de floración y fecundación, afectando finalmente a la producción (Aung, 1976). En particular, en tomate, la luz juega un papel fundamental en la concentración de metabolitos de interés, como vitamina C (Rosales y col., 2006; Gautier y col., 2009), carotenoides (Becatti y col., 2009) y compuestos fenólicos (Luthria y col., 2006). En los momentos críticos durante el período vegetativo, resulta crucial la interrelación existente entre la temperatura diurna y nocturna y la luminosidad (Rothman y Tonelli, 2010). Valores de radiación total diaria en torno a 0,85 $\mathrm{MJ} \mathrm{m}^{-2}$ son los umbrales considerados mínimos para la floración y cuajado, siendo preferible mayor iluminación en menor período de tiempo que iluminaciones más débiles durante más tiempo (Kinet, 1977). 


\subsection{Temperatura}

El tomate es una planta termoperiódica, que crece mejor con temperatura variable que constante, siendo las diferencias térmicas óptimas noche/día de 6 a $7 \stackrel{\circ}{\circ}$ (Went, 1957). Durante la fase de crecimiento vegetativo, temperaturas alrededor de $25 \stackrel{\circ}{\circ}$ favorecen el crecimiento foliar, a expensas del ápice, mientras que a temperaturas más bajas $\left(15^{\circ} \mathrm{C}\right.$ ) ocurre lo contrario. Calvert (1973) sugirió como temperaturas óptimas de cultivo, 25-22/18-15 ${ }^{\circ} \mathrm{C}$ (día/noche). Debido a su cultivo se desarrolla principalmente en zonas áridas y semiáridas, el estrés por altas temperaturas se convierte en uno de los principales problemas que limita su correcto desarrollo. Además, es uno de los factores precosecha que más afectan a la calidad del fruto, pudiendo originar un amplio abanico de alteraciones. La magnitud del daño depende de la temperatura alcanzada, tiempo de exposición, estado de desarrollo del fruto, etc. El estrés causado por altas temperaturas provoca importantes cambios en la planta tanto a nivel fisiológico, bioquímico y molecular (Chaves-Barrantes y Gutiérrez-Soto, 2017). El estrés térmico suele ir asociado a déficit hídrico y cierre estomático (Wahid y col., 2007), lo que reduce la cantidad de $\mathrm{CO}_{2}$ disponible para la planta y disminuye la relación $\mathrm{CO}_{2} / \mathrm{O}_{2}$ en los cloroplastos (Foyer y Noctor, 2005). Estos cambios afectan en gran medida a la eficiencia de la fotosíntesis, siendo ésta un proceso muy sensible a la alta temperatura (Wise y col., 2004). Durante la floración, la temperatura óptima para un buen cuajado es de $22{ }^{\circ} \mathrm{C}$ (Rylski, 1979). Temperaturas por encima de 26/20 oC (día/noche) durante la fructificación provocan aborto floral y limitan el cuajado (Stevens y Rudich, 1978; El-Ahmadi y Stevens, 1979). Por otro lado, temperaturas inferiores a $10 \stackrel{\circ}{\circ}$ plantean problemas de fecundación que disminuyen la producción. Para paliar estos efectos negativos, se utilizan tratamientos mecánicos o químicos para mejorar la polinización y fructificación (Rylski, 1979; Callejón, 2003).

En el fruto, el efecto directo de la alta temperatura induce daño en membranas celulares, proteínas y ácidos nucleicos y de forma indirecta, inhibición de la síntesis de pigmentos y/o degradación de los ya existentes, produciéndose una amplia gama de síntomas de escaldado y quemaduras. En manzanas, fresas y peras se ha puesto de manifiesto una relación entre firmeza y temperatura, la 
cual se mantiene mejor a temperaturas bajas (Sams, 1999). En algunos casos se aprecian efectos globales que afectan a la maduración, inhibiéndola 0 acelerándola, como en plátano y calabaza respectivamente. Concretamente en tomate, cuando las condiciones de alta temperatura se prolongan durante un largo periodo, puede afectar a la fisiología y morfología de los frutos (Peet y col., 1997; Camejo y col., 2005). Algunos de estos efectos pueden verse amplificados cuando las altas temperaturas están asociadas a una radiación solar intensa, afectando no solo a las alteraciones de color (pardeamientos) sino también a las propiedades organolépticas, debido a cambios en el contenido en sólidos solubles y acidez valorable. Las altas temperaturas también pueden provocar la aparición de BER, fisiopatía muy común en cultivos de tomate y pimiento consistente en la podredumbre apical de los frutos que los invalida comercialmente. Esto es debido a que el aumento de temperatura provoca una disminución de la transpiración, limitando el transporte de Ca a los frutos (Adams y Ho, 1992). Dependiendo del cultivo, la temperatura puede tener mayor o menor influencia en la calidad nutricional, por ejemplo, aunque temperaturas inferiores a $20 \stackrel{\circ}{C}$ favorecen el aumento de la vitamina $C$ en diversos cultivos hortícolas, tomate la acumulación máxima tiene lugar entre 27 y $30 \stackrel{\circ}{C}$ (Shewfelt, 1990).

\subsection{Salinidad}

Debido a su clima semiárido, en la Región de Murcia la salinidad del suelo y aguas es uno de los principales factores que limita al crecimiento y producción de los cultivos agrícolas. Las principales sales que se encuentran en los suelos y que afectan negativamente a la producción vegetal son cloruros $\left(\mathrm{Cl}^{-}\right)$y sulfatos de sodio $\left(\mathrm{Na}_{2} \mathrm{SO}_{4}\right)$, calcio $\left(\mathrm{Ca}^{2+}\right)$, magnesio $\left(\mathrm{Mg}^{2+}\right)$ y potasio $\left(\mathrm{K}^{+}\right)$, siendo $\mathrm{Na}^{+}, \mathrm{Cl}^{-} . \mathrm{y}$ $\mathrm{SO}_{4}{ }^{2-}$ los iones más perjudiciales para las plantas (Munns y Tester, 2008). Las causas principales de la salinización del suelo suelen ser el uso excesivo de fertilizantes, utilización de aguas de mala calidad, suelos asfixiantes y la tala de vegetación arbórea que favorezca la lixiviación a aguas subterráneas. El tomate es un cultivo que puede ser utilizado en zonas donde la calidad del agua y del suelo sería muy limitante para otros cultivos, ya que es moderadamente sensible 
a la salinidad, con valores óptimos de conductividad de la disolución de riego entre 3 y 5 dSm ${ }^{-1}$ (Cuartero y Fernández Muñoz, 1999).

Uno de los principales efectos negativos de la salinidad para el desarrollo y rendimiento de las plantas es el "efecto osmótico", relacionado con la disminución del potencial osmótico del agua en el medio radicular. La consecuencia directa del mismo es la disminución de la disponibilidad de agua para las raíces por una disminución de la energía libre del agua en el suelo, debido a la presencia de sales solubles (Bernstein y Hayward, 1958). Para combatirlo, la planta tiene mecanismos como es la acumulación de iones y de solutos compatibles en los orgánulos. Algunos de los iones acumulados bajo estas condiciones son esenciales para el correcto crecimiento y desarrollo de un cultivo, como el potasio (K), aunque la mayoría de compuestos son solutos orgánicos, como azúcares simples (principalmente glucosa y fructosa), alcoholes derivados de azúcares y azúcares complejos (manitol), además de diferentes aminoácidos, como la prolina, y compuestos amonio cuaternarios, como la glicina betaína (Yokoi y col., 2002). La acumulación de dichos compuestos permite a las células el disminuir su potencial osmótico, hecho que facilita el movimiento del agua hacia el interior de las células de las raíces. Por otro lado, la salinidad provoca un "efecto específico" asociado a los desequilibrios iónicos producidos en las células normalmente por la absorción y acumulación masiva de iones, como $\mathrm{Cl}^{-}$y $\mathrm{Na}^{+}$, en concentraciones tóxicas para las plantas. Esta acumulación origina una cadena de efectos secundarios, como son problemas de toxicidad específica y de desequilibrio nutricional, vinculados a la menor absorción de iones esenciales para el crecimiento y desarrollo de las plantas (Yokoi y col., 2002). Así, elevadas concentraciones de $\mathrm{Na}$ en la solución externa, causan una disminución en las concentraciones de $\mathrm{K}$ y $\mathrm{Ca}$ en los tejidos de las plantas ( $\mathrm{Hu}$ y Schmidhalter, 1997).

\subsection{Humedad}

Bajo invernadero, la humedad ambiental juega un papel relevante en el desarrollo del cultivo. El aire se enriquece de vapor de agua por evaporación del 
suelo y por transpiración de las plantas, como mecanismo para refrigerarse, transportar nutrientes y regular su crecimiento. La transpiración depende del déficit de saturación entre los estomas y el aire. Cuando los déficits de saturación son demasiado altos o demasiado bajos influyen en la fisiología del cultivo y su desarrollo (Huertas, 2008).

Los valores de humedad para el cultivo de tomate oscilan entre 70 y $80 \%$ (Winspear y col., 1970), y siempre inferiores al 90\%, ya que valores superiores favorecen el desarrollo de enfermedades, especialmente la provocada por Botrytis (Harper y col., 1979; Hurd y Sheard, 1981). En condiciones de baja humedad relativa la tasa de transpiración aumenta, lo que puede provocar, especialmente en fase de fructificación cuando la actividad radicular es menor, estrés hídrico, cierre estomático y reducción de la fotosíntesis (Rawson y col., 1977). Por otro lado, valores excesivos de humedad reducen el cuajado del fruto en tomate (Van Koot y Van Ravestjin, 1963). Los efectos negativos de la alta humedad relativa pueden ser más drásticos si se combinan con baja iluminación, reduciéndose la viabilidad del polen (Burns y col., 1979). Además, bajo estas condiciones, se ve limitada la evapotranspiración del cultivo, reduciendose la absorción de agua y nutrientes y generándose un déficit de elementos como $\mathrm{Ca}$ lo que induce desórdenes fisiológicos (podredumbre apical) (Adams, 1980; Hurd y Sheard, 1981).

\subsubsection{Factores bióticos}

Los factores bióticos son todos aquellos organismos vivos que interaccionan con la planta, tanto de manera beneficiosa, como por el contrario distorsionando su homeostasis. Entre los organismos que interaccionan de forma beneficiosa, se encuentran especies de bacterias promotoras del crecimiento vegetal (PGRP), hongos micorrízicos, nematodos beneficiosos, ciertos protozoos, algas y microartrópodos (Johansson y col., 2004). Estos organismos pueden promover numerosos procesos fisiológicos de la planta (desarrollo radicular, regulación de la actividad metabólica de la raíz), mejorar determinadas 
propiedades físicas y químicas del suelo, así como actuar como rizoremediadores (González-Chávez, 2005).

Los principales factores bióticos que afectan el crecimiento de las plantas incluyen plagas y patógenos. Las principales plagas que afectan al cultivo de tomate en la zona del sureste español son: Diferentes especies de mosca blanca Bemisia tabaci y Trialeurdores vaporariorum, no solo por los daños que puedan hacer directamente sobre el cultivo, sino por ser vectores de virosis ToCV (virus de la clorosis del tomate) y TICV (virus infeccioso de la clorosis del tomate); Pulgones, que son insectos homópteros como la mosca blanca, y que también pueden ser vectores de virus como CMV (virus del mosaico del pepino y PVY (virus $\mathrm{Y}$ de la patata); Trips, Frankliniella occidentalis, insectos muy polífagos que además de causar daños directos sobre el cultivo, son vectores del virus del bronceado del tomate (TSWV); Tuta absoluta, lepidóptero que constituye una de las plagas que más problemas ha causado en las producciones de tomate en los últimos años causando galerías en frutos y hojas, y así, invalidando el producto. Debido a su difícil control se establecen medidas a nivel comarcal; Orugas o gusanos, que pueden pertenecer a distintas especies de lepidópteros como la oruga medidor, heliotis, rosquilla verde y negra; Por último, otro grupo de plagas que destaca en tomate son los ácaros, como araña roja (Tetranychus urticae) y el ácaro del bronceado o vasates (Aculops lycopersici).

En cuanto a los patógenos causantes de enfermedades, destacan por un lado las producidas por hongos como Oidio, Botrytis, Alternaria, Mildiu, etc., y por otro, las producidas por bacterias, menos frecuentes pero que presentan daños intensos en las plantaciones afectadas, entre ellas, Pseudomonas, Erwinia y Clavivacter. Otro grave problema es la infección por nematodos, principalmente diversas especies de Meloidogyne, en el caso de tomate. 


\subsubsection{Respuesta de la planta a factores abióticos y bióticos}

La respuesta de la planta a cualquier estímulo exógeno, es la consecuencia de una compleja red de interacciones entre distintas rutas de señalización (Figura 1.10). En el caso de infección por patógenos, la transmisión de la señal está mediada por hormonas como etileno, ácido abcísico (ABA) y ácido jasmónico (Dong, 1998; Feys y Parker, 2000). La señal generada por estas hormonas, es transportada en cascadas moleculares complejas hasta llegar al núcleo celular, donde participan tanto en la activación como en la represión de la transcripción de ciertos genes de respuesta al estrés (Azcon-Bieto y Talón, 2008). Algunas de estas moléculas, como el caso de ABA, también participan de forma activa en la señalización de muchas de las respuestas de la planta al estrés abiótico (Arbona y Gómez-Cadenas, 2008; Albacete y col, 2009). En general, la exposición de las plantas a condiciones desfavorables (abióticas y bióticas), desencadena un estrés oxidativo, es decir, una sobreproducción de especies reactivas de oxígeno (ROS) (Arbona y col, 2008) (Figura 1.11). Esta producción descontrolada de ROS puede causar daño celular, rotura de complejos ADN/ARN, oxidación de proteínas y peroxidación lipídica, entre otros procesos. De entre las ROS producidas en plantas, el ion superóxido $\left(\mathrm{O}^{-}\right)$y el peróxido de hidrógeno $\left(\mathrm{H}_{2} \mathrm{O}_{2}\right)$, son los más importantes debido a su alta toxicidad, su permeabilidad a través de la membrana y sus niveles de acumulación en la célula (Gil y Tuteja, 2010). Para protegerse de los daños del estrés oxidativo, la planta ha desarrollado una poderosa maquinaria de defensa antioxidante que incluye sistemas de defensa enzimáticos (superóxido dismutasa, catalasa, ascorbato peroxidasa, etc.) y no enzimáticos (ascorbato, glutatión, compuestos fenólicos, aminoácidos no proteicos y $\alpha$-tocoferol) (Szalai y col., 2009).

Un ejemplo de la complejidad de la respuesta de la planta ante un estrés, es el mecanismo descrito por Miranda-Ham y Castro-Concha (2009) y Vizinaiz (2004), en plantas de tomate infectadas con Phytophthora infestans. Dichos autores demostraron la existencia de interconexiones complejas entre la regulación secuencial y concertada de las actividades de las enzimas antioxidantes y el estado redox intracelular, que a su vez están mediando el encendido y apagado de la síntesis de otras moléculas como el ácido salicílico, el 
ácido jasmónico y el óxido nitroso, que amplifican y regulan otros mecanismos de defensa. Otros autores han descrito un amplio número de interacciones entre las diferentes rutas de señalización, como es el caso de los jasmonatos con otras rutas de señalización hormonal como la del etileno, ácido salicílico, auxinas o ácido abcísico (Turner y col., 2002; Rojo y col., 2003). Además, también puede haber interacciones antagonistas entre ellas, lo que complica aún más su estudio. Así, algunos trabajos muestran que el ácido salicílico inhibe la síntesis y activación de genes de respuesta al ácido jasmónico en casos de herida sistémica en tomate y patata (Doares y col., 1995; Harms y col., 1998; Niki y col., 1998; O'donnell y col., 1996).

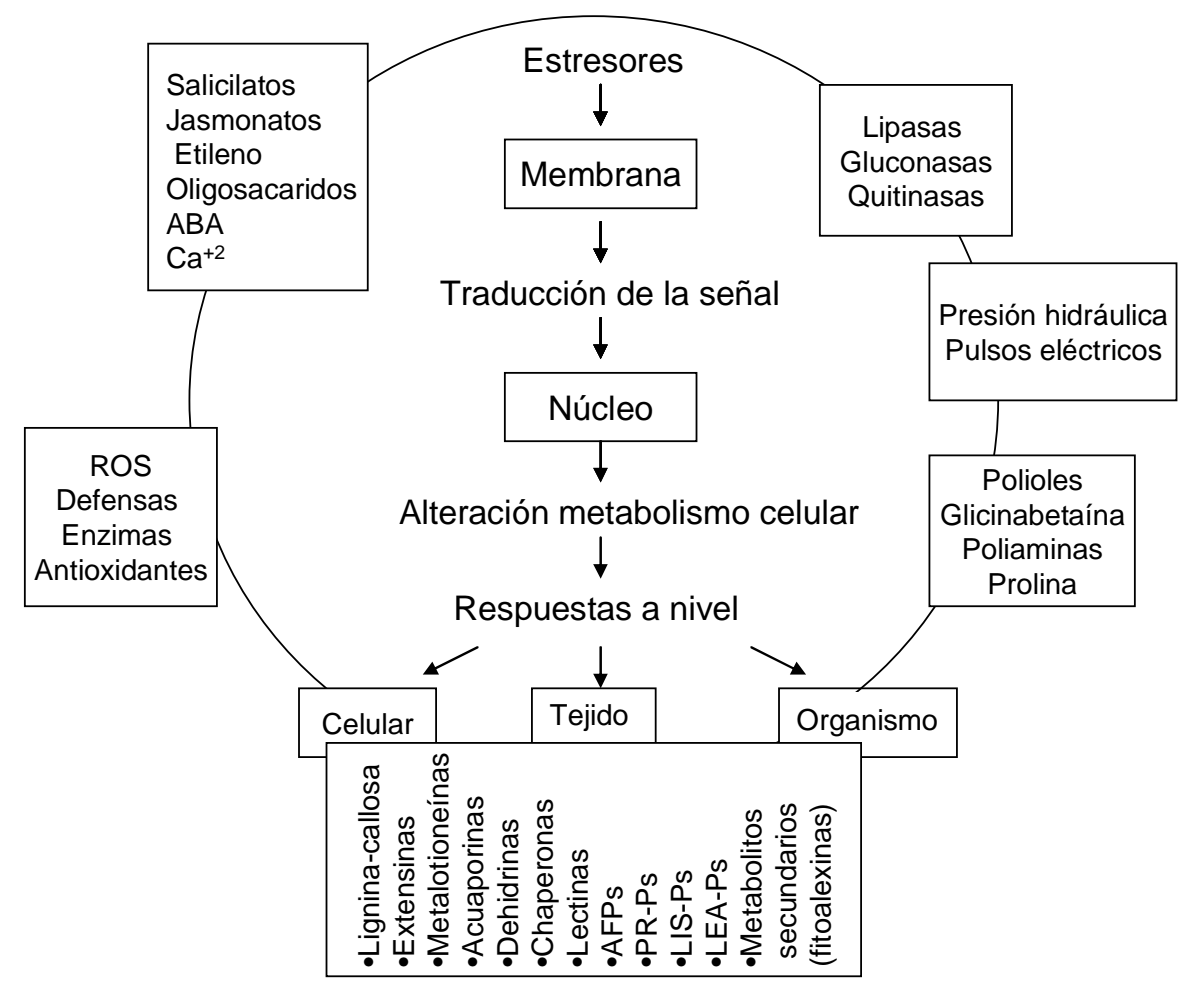

Figura 1.10. Mecanismo de respuesta de la planta ante un estrés. 


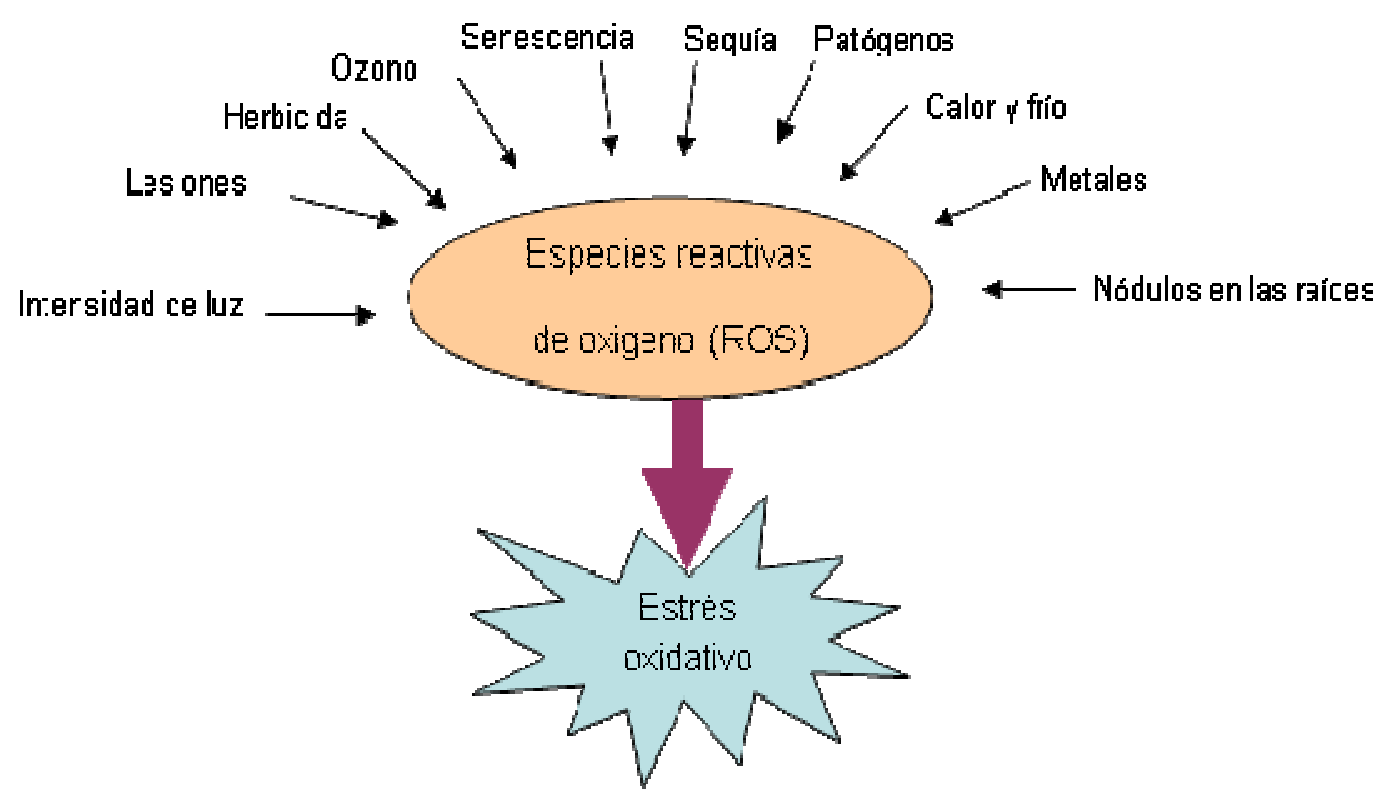

Figura 1.11. Factores que desencadenan un estrés oxidativo.

\subsection{Bioestimulantes y elicitores}

El término bioestimulante engloba cualquier sustancia o microorganismo aplicado a planta, semilla o sistema radicular que, independientemente de su contenido nutricional, es capaz de estimular procesos metabólicos en la planta, mejorando su eficiencia nutricional, sus atributos de calidad y/o su tolerancia a estreses abióticos (Le Mire y col., 2016). Estos compuestos no tienen efecto directo sobre plagas ni enfermedades. Son normalmente extractos de plantas, sustancias, microorganismos y/o mezclas heterogéneas de estos (Du Jardin, 2015). Esto hace difícil definir su mecanismo de acción y dificulta la reproducibilidad de sus efectos. En general, los bioestimulantes tienen efecto sobre funciones fisiológicas como el crecimiento radicular y el transporte de micronutrientes desde las raíces a los brotes, incrementando su concentración en los tejidos, además de estimular la expresión de genes que codifican dicho flujo de nutrientes (Billard y col., 2014). Existen evidencias de que los bioestimulantes, activan respuestas implicadas en el desarrollo y producción de la planta, bajo un amplio rango de condiciones ambientales adversas (estrés abiótico) aumentando la tolerancia de esta (Mejía-Teniente y col., 2010; Takatsuji y col., 2010). Como 
consecuencia de esta respuesta al estrés abiótico, se activa la síntesis de metabolitos secundarios con actividad biológica e interesantes propiedades para la salud, como son vitamina $\mathrm{C}$ y polifenoles. Por ello, los bioestimulantes pueden convertirse en una herramienta potencial para mejorar las características organolépticas y el valor nutricional de los frutos, aspecto muy valorados y demandados por el consumidor, a la vez que se mejora se productividad en condiciones ambientales adversas (Sudha y Ravishankar, 2003; Karuppusamy, 2009; Ramakrishna y Aswathanarayana, 2011).

El concepto tradicional de elicitor se refiere a moléculas capaces de inducir la síntesis de fitoalexinas en planta, en ausencia de agentes patógenos (Keen y col., 1972; Albersheim y Valent, 1978). En la actualidad, esta definición se ha extendido para cualquier molécula que puede activar mecanismos de defensa de la planta contra patógenos (Dzhavakhiya y Shcherbakova, 2016). Estas moléculas activadoras hacen referencia a un amplio rango de compuestos, los cuales pueden ser derivados a partir de plagas $u$ de otros microorganismos, así como a partir de preparados biológicos de origen vegetal o de análogos producidos sintéticamente (Tabla 1.2).

A menudo, una misma molécula puede tener propiedades elicitoras de la respuesta de la planta al estrés biótico, y propiedades bioestimulantes. Además, existe una correlación entre los mecanismos que desencadenan el estrés biótico y abiótico. Todo ello hace que la clasificación de una molécula en la categoría de elicitor o bioestimulante sea a menudo complicada, y se presente de forma confusa en la bibliografía.

\subsubsection{Modo de acción de elicitores}

Los elicitores son capaces de inducir los sistemas de defensa de la planta ante un estrés biótico. Así, pueden promover la síntesis de metabolitos con actividad biológica, tanto en ausencia de un estrés como en presencia de este, pudiendo mejorar la calidad funcional de los vegetales y su tolerancia a condiciones desfavorables (Figura 1.12). 
La principal aplicación de estas moléculas en agricultura ha sido promover, en plantas no infectadas, la resistencia inducida a diversas plagas y enfermedades (Shang y col., 2011). El estudio de estas moléculas ha cobrado gran importancia en los últimos años, ya que suponen una alternativa o permiten disminuir el uso de agroquímicos convencionales, evitando resistencias y así, cubrir la demanda de productos libres de residuos.

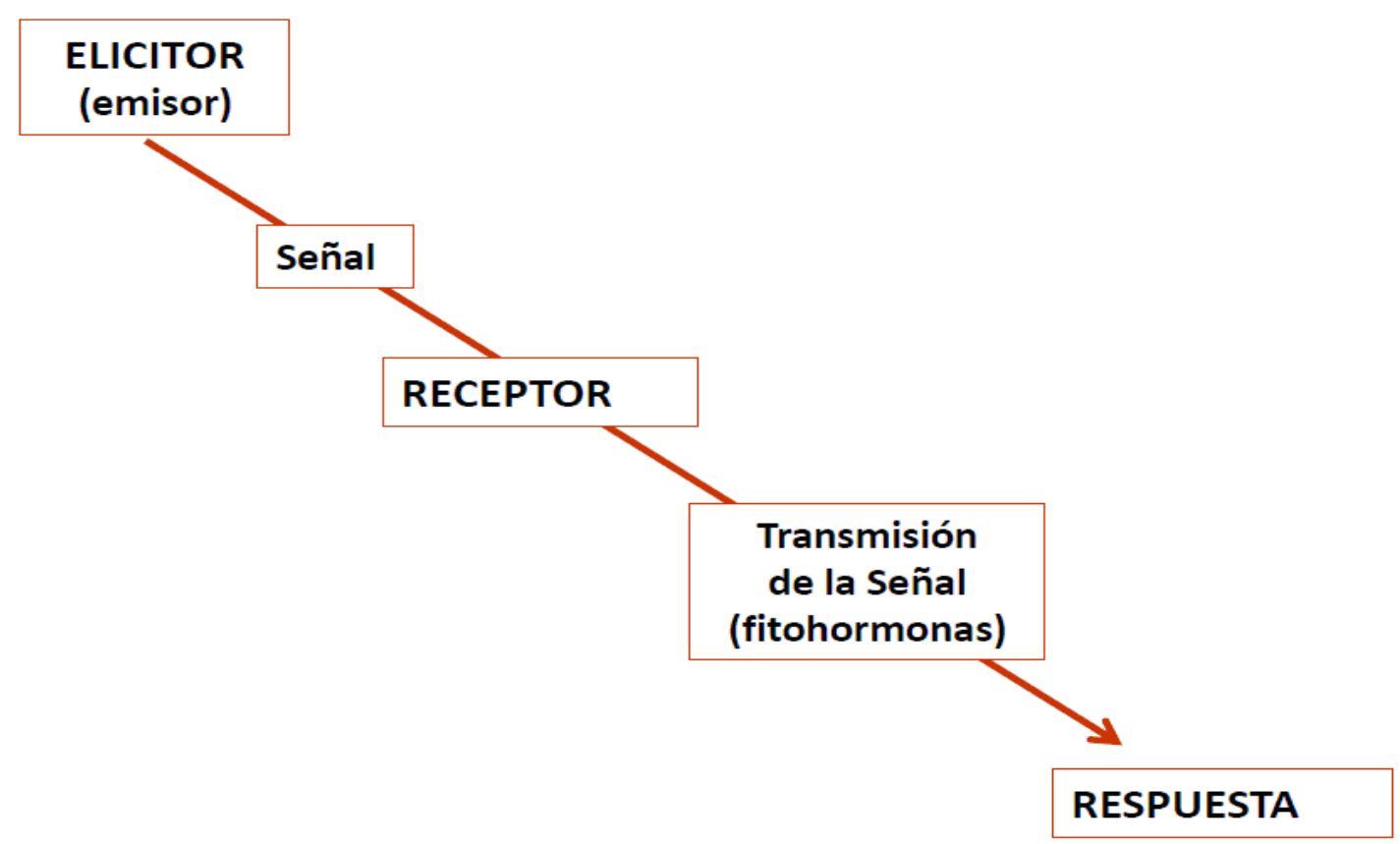

Figura 1.12. Modo de acción de un elicitor.

Existe una amplia gama de sustancias elicitoras capaces de inducir resistencia, que según su procedencia se pueden clasificar en: origen biótico y abiótico (Riveros, 2001) (Tabla 1.2). 
Tabla 1.2. Moléculas y agentes bióticos y abióticos, inductores de resistencia.

\section{Origen biótico}

Origen abiótico

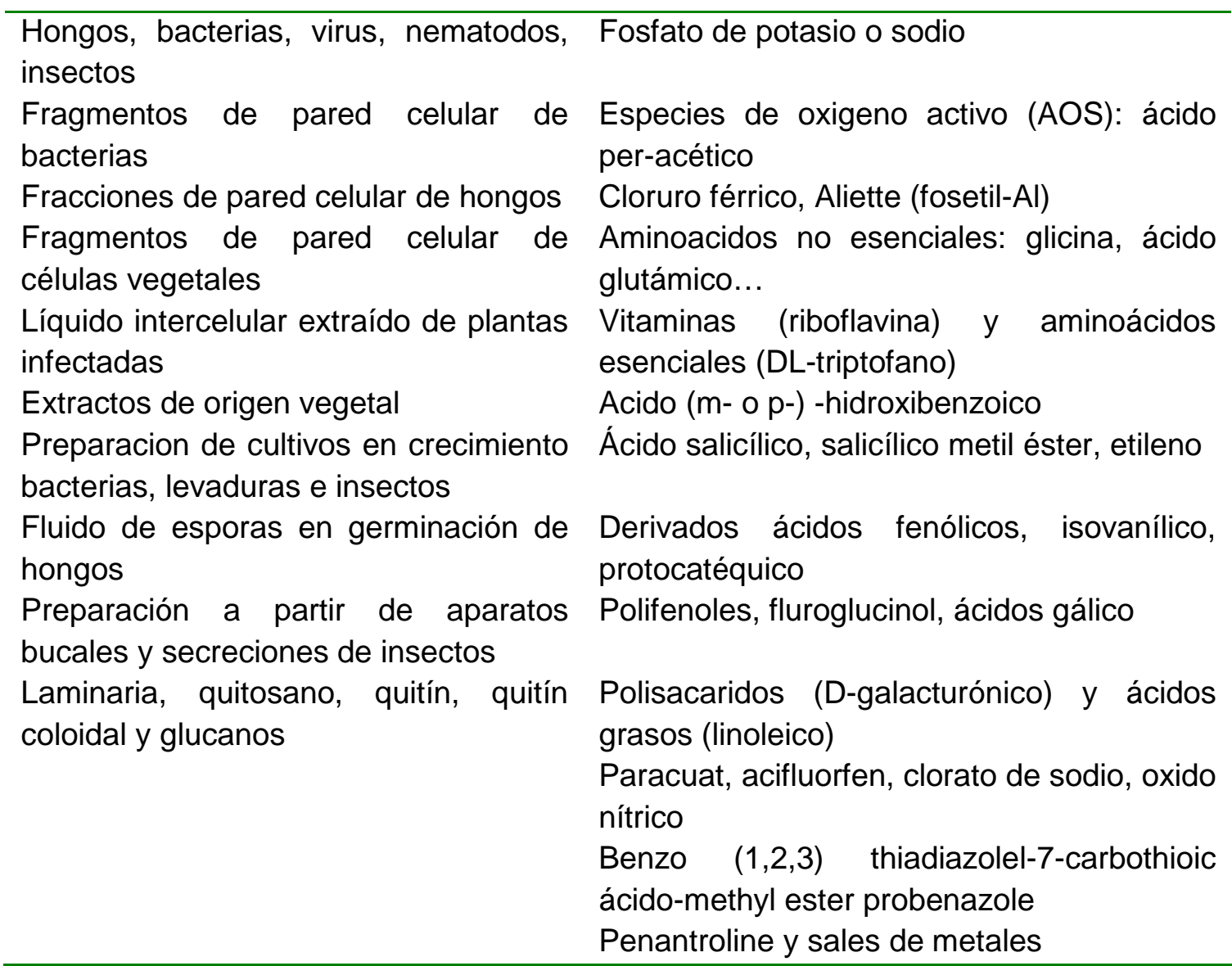

Esta tesis incluye un estudio sobre la respuesta de la planta a diferentes elicitores con efecto bioestimulante, en particular, ácido salicílico, metil jasmonato, quitosano y un brasinoesteroide (2,4-epibrassinolido).

\subsection{2. Ácido salicílico (AS)}

El ácido salicílico (AS), es un compuesto fenólico simple que deriva del ácido benzoico. El esqueleto del ácido salicílico está formado por fenilpropanoides que han perdido un fragmento de dos carbonos de la cadena lateral (Ávalos y Pérez-Urria, 2009) (Figura 1.14). En las plantas, los compuestos fenólicos están 
relacionados con el metabolismo secundario e incrementan su presencia como protección química en mecanismos de resistencia y defensa de la planta ante un estrés (Ramakrishna y Aswathanarayana, 2011). El AS, se encuentra en los tejidos de las plantas tanto en forma libre como conjugada. Las formas conjugadas son glucósidos, ésteres, amidas y ácidos dihidroxibenzóicos. Algunos autores describen que cuando se requiere de AS, una parte proviene de las reservas de las formas conjugadas (Hennig y col., 1993), mientras que otra parte proviene de la actividad de la PAL (síntesis de novo) (Raskin, 1992).

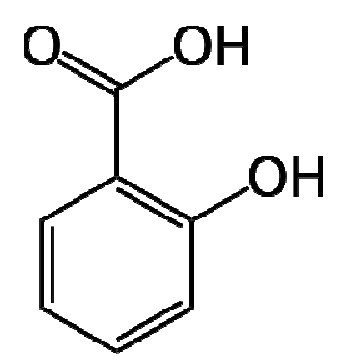

Figura 1.14. Estructura del ácido salić́lico.

Algunos autores han descrito que AS se encuentra involucrado en procesos relacionados con el retraso de la senescencia y la inducción de la floración y tuberización (Bourbouloux y col., 1998). Además, entre otras propiedades se ha definido su capacidad termogénica y alelopática (Raskin, 1992). Concretamente, en plantas sometidas a diversos estreses, este compuesto destaca por su papel en la respuesta celular relacionada con el daño oxidativo.

\subsubsection{Metil jasmonato (MJ)}

El ácido jasmónico, sus moléculas relacionadas y derivados, se denominan jasmonatos. Son compuestos de origen vegetal de naturaleza lipídica, con estructura molecular similar a la de las prostaglandinas animales. Los jasmonatos se sintetizan a través de la vía octadecanoide, a partir de los ácidos grasos no 
saturados linolénico o linoléico, que se liberan desde los fosfolípidos de las membranas celulares por la acción de lipasas (Schaller y col., 2005; Wasternack y col., 2006) (Figura 1.15). Concretamente, el metil jasmonato es un compuesto natural de carácter volátil, derivado del ácido jasmónico (Ruiz, 2014). Está catalogado como hormona, al igual que el AS, ya que en concentraciones bajas y distantes de su lugar de síntesis, pueden inducir respuesta en la planta.

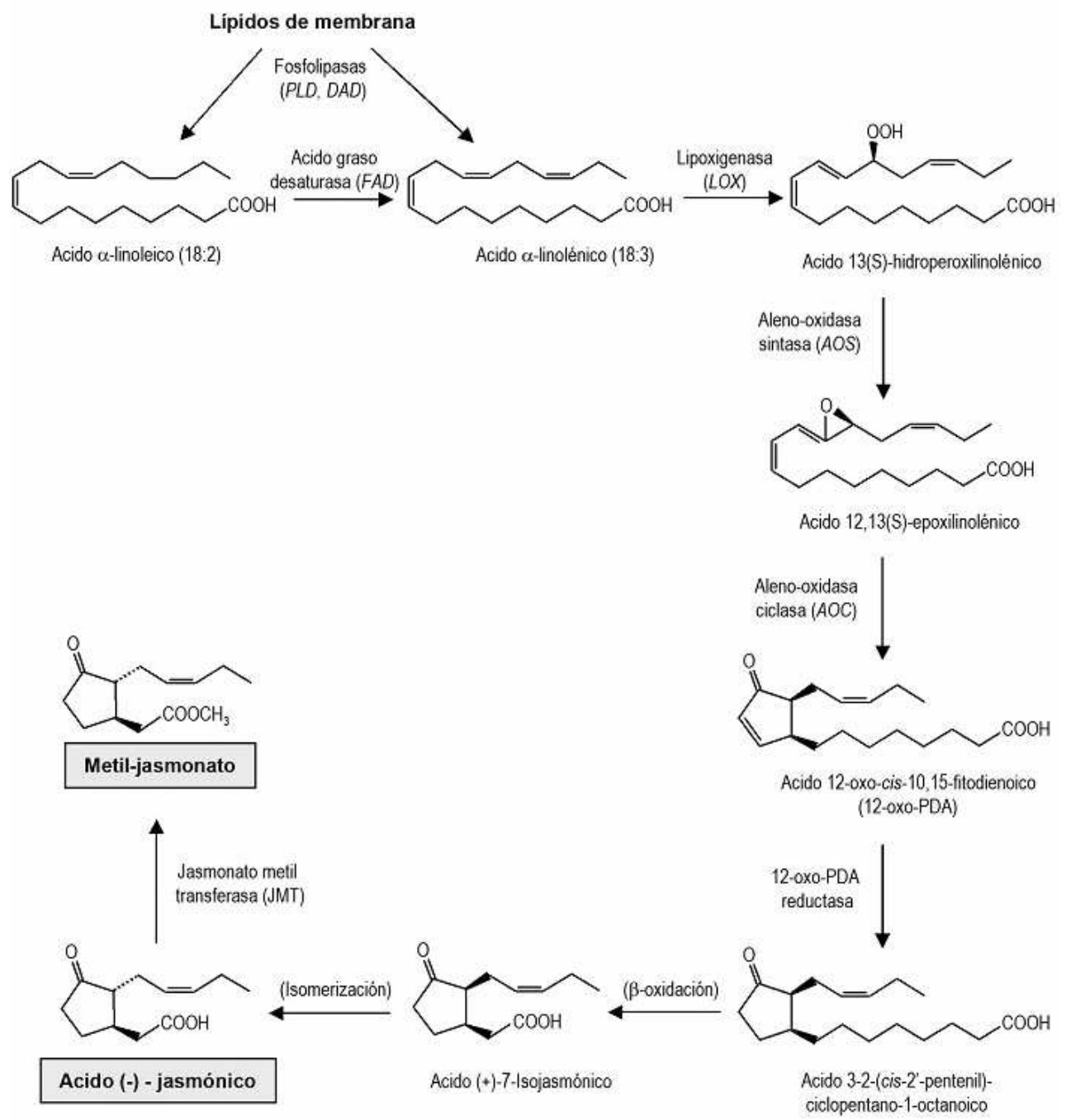

Figura 1.15. Ruta de biosíntesis de metil jasmonato.

Metil jasmonato (MJ) actúa como molécula señal de la respuesta de las plantas a diversas situaciones de estrés (heridas, ataque por patógenos y plagas, 
exposición a sequía, etc.) y participa en diversos procesos del crecimiento y desarrollo de las plantas (Creelman y Mullet, 1997; Farmer y col., 2003). Además está implicado en el metabolismo secundario y síntesis de pigmentos (Cheong y Choi, 2003; Rohwer y Erwin, 2008). MJ tiene una actividad similar al mediador químico del que deriva (ácido jasmónico), por lo que es capaz de activar las enzimas responsables de la biosíntesis de polifenoles, como la fenilalanina amino liasa en lichis (Yang y col., 2011), melocotones (Jin y col., 2009), manzanas, uva de mesa, fresas (Heredia y Cisneros-Zevallos, 2009), produciendo un aumento de los fenoles totales presentes en estas frutas.

La aplicación de MJ en tratamientos precosecha ha mostrado su capacidad de aumentar los niveles de flavonoides y producir cambios en la síntesis de compuestos volátiles (Percival y Mackenzie, 2007; Wang y col., 2008a). Numerosos estudios realizados en brasicas muestran que aplicaciones exógenas de AS y MJ, inducen la formación de flavonoides, fenilpropanoides y glucosinolatos, todos ellos relacionados con el metabolismo secundario e involucrados en gran cantidad de actividades de regulación en las planta (Liang y col., 2006a; Liang y col., 2006b; Mikkelsen y col., 2003). Por otra parte, tratamientos postcosecha con MJ aumentaron los niveles de antocianos y fenoles totales en diversos cultivos como tomate (Tzortzakis y Economakis, 2007), granada (Sayyari y col., 2011) y fresa (Moreno y col., 2010).

\subsubsection{Quitosano (Q)}

El quitosano es uno de los pocos polisacáridos catiónicos naturales. Se deriva de la quitina, mediante la desacetilación de la misma en condiciones muy alcalinas y a alta temperatura (Pastor e Higuera, 2004). Es un polisacárido lineal que está compuesto por dos tipos de unidades estructurales, distribuidas de manera aleatoria a lo largo de la cadena N-acetil-D-glucosamina y D-glucosamina, las cuales se encuentran unidas entre sí por enlaces del tipo $\beta$ (1-4) glicosídicos. Desarrolla carga positiva en medio ácido $(\mathrm{pH}<5,5)$, debido a la protonación del grupo amino presente en cada una de sus unidades glucosamina (Figura 1.16). Esto lo hace soluble en medio acuoso, a diferencia de su polímero matriz la 
quitina $\mathrm{y}$, según muchos autores, le confiere una mayor actividad biocida (Helander y col., 2001; Devlieghere y col., 2004).

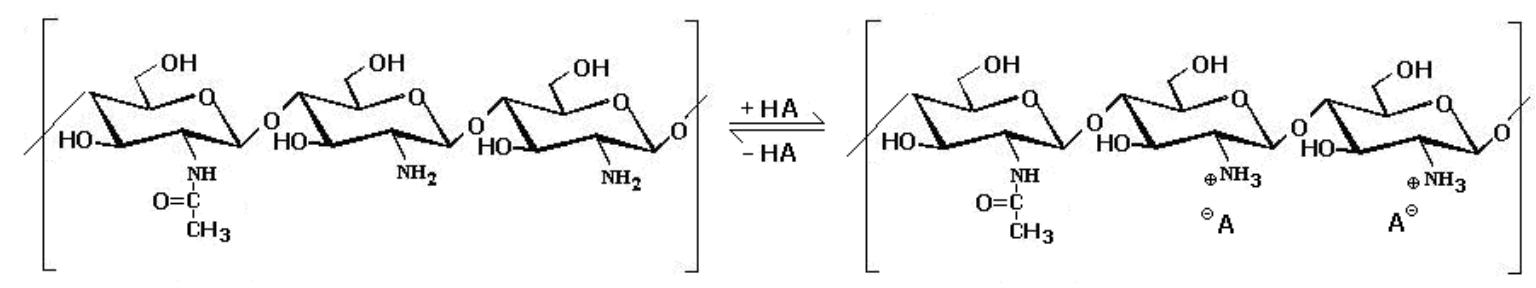

Figura 1.16. Estructura del quitosano en función del pH del medio.

Este biopolímero de origen natural se ha convertido rápidamente en una alternativa prometedora para la agricultura, debido a su excelente capacidad de formar películas, unido a que no produce contaminantes, es biocompatible, no presenta toxicidad, es naturalmente abundante y renovable y posee propiedades antimicrobianas (Khan y col., 2000). Según Chang y col. (1998), la aplicación de quitosano aumenta la producción de mentol en cultivos de menta. Además, incrementó la formación de barreras físicas y estimuló hidrolasas en raíces y hojas de pepino (El Ghaouth y col., 1994). En cacahuete, aplicaciones exógenas de quitosano aumentaron los niveles endógenos de ácido salicílico, quitinasa intracelular y gluconasa (Sathiyabama y Balasubramania, 1998). En tomate, el recubrimiento de semillas con quitosano, produjo la expresión de reacciones de defensa de la planta (Benhamou y col., 1994).

\subsubsection{Brasinoesteroides y análogos}

Los brasinoesteroides (BR) son compuestos esteroidales, que tienen la capacidad de estimular el crecimiento de las plantas. Derivan de la vía de los terpenoides, igual que otros grupos hormonales como citoquininas, giberelinas, ABA, etc. Los BR más comunes y abundantes corresponden a castasterona, brasinolida, tifasterol y teasterona. La estructura básica de un BR natural está constituida por varios anillos, existiendo formas con 27, 28 y 29 carbonos (Figura 
1.17). Se encuentran localizados principalmente en los plastidios almacenados en gránulos de almidón (Sasse, 1991; Taylor y col., 1993).

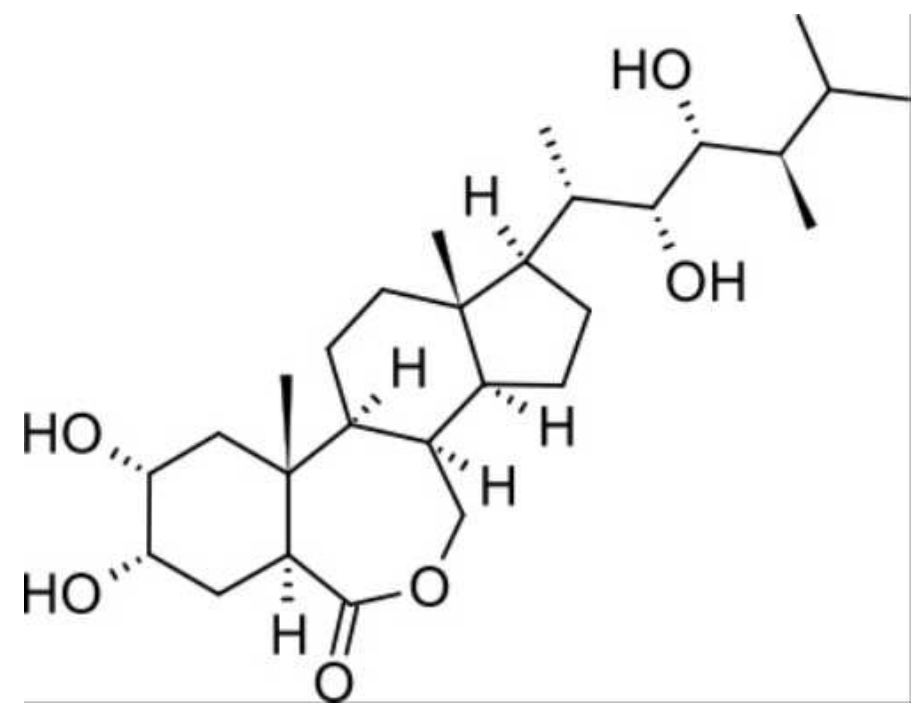

Figura 1.17. Estructura de 2,4-epibrassinolido

Se ha demostrado que los brasinoesteroides influyen en procesos como la germinación, rizogénesis, floración, senescencia, abscisión y en los procesos de maduración. Los brasinoesteroides también confieren resistencia a las plantas frente al estrés biótico y abiótico, por lo que se les considera como una nueva clase de hormonas vegetales con efectos pleiotrópicos (Figura 1.18). Algunos autores describen que la aplicación exógena de estos compuestos, provoca una inusual actividad promotora del crecimiento (Mitchell y col., 1970). Además, fortalecen la resistencia de las plantas a las plagas y a factores de estrés abiótico como la salinidad, la sequía y los cambios bruscos de temperatura, así como a agentes químicos agresivos como plaguicidas y herbicidas (Sasse, 1991, Fujioka y Sakurai, 1997). Estudios recientes muestran diversas propiedades fisiológicas de los brasinoesteroides (Salgado y col., 2008; Hernández y García-Martínez, 2016), lo que permite considerarlos como sustancias naturales, altamente promisorias, respetuosas con el ambiente, apropiados para aumentar la autoprotección de las plantas y aumento de la producción agrícola. 


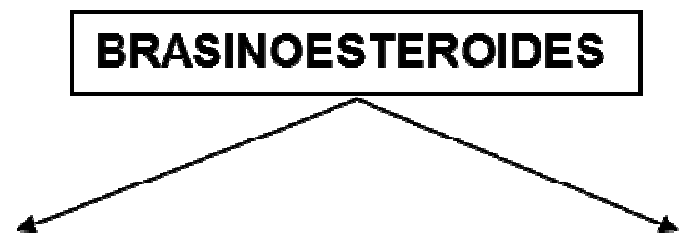

\section{ESTRÉS ABIÓTICO}

$$
\begin{aligned}
& \text { Estrés oxidativo, } \\
& \text { hídrico y salino }
\end{aligned}
$$

- Aumento de la actividad enzimática: SOD, CAT, APX

- Aumento de la tasa de fotosintesis neta

Estrés osmótico (sequía, salinidad, frío)

- Aumento del nivel de ABAy prolina

Estrés por metales pesados
ESTRÉS BIÓTICO

Hongos, bacterias y virus

- Estimulo de la sintesis de ABA y etileno

- Incremento del nivel AS

- Estímulo de la síntesis de proteinas de defensa

Aplicación de pesticidas

- Aumento de la asimilación de $\mathrm{CO}_{2}$

- Aumento de la tasa de fotosíntesis neta

- Aumento del nivel de glutatión y fitoquelatinas

- Aumento de la tasa de fotosíntesis neta

- Estímulo del metabolismo del nitrógeno

\section{Estrés térmico}

- Aumento del nivel de proteínas de defensa

Figura 1.18. Efecto de los BR en plantas sometidas a distintos tipos de estrés. 


\section{Capítulo 2}

\section{OBJETIVOS}

El tomate es la hortaliza más importante tanto en consumo como en producción a nivel mundial y su popularidad aumenta constantemente. En la Región de Murcia supone un elevado porcentaje de la producción agrícola, lo que la sitúa como una de las principales productoras en el ámbito nacional. Además de su gran importancia a nivel socio-económico, el tomate es considerado un producto de gran valor nutricional, con un alto contenido en compuestos bioactivos con propiedades beneficiosas para la salud. Entre los factores que limitan el cultivo de tomate en la Región, disminuyendo el rendimiento y en consecuencia, ocasionando importantes pérdidas económicas, destaca la alta temperatura. Este problema se ve acrecentado por el hecho de que la mayor parte de la producción se lleva a cabo bajo invernadero, durante los meses de primavera y verano en los que se alcanzan valores de temperatura muy superiores a los considerados óptimos para este cultivo. A este problema se le añade la escasez de recursos hídricos de buena calidad, resultado de la escasa pluviometría propia de zonas de clima semiárido. Los problemas de salinidad de suelos y aguas que se generan, pueden intensificar los efectos negativos de la alta temperatura sobre la producción y calidad de tomate.

El objetivo principal de esta tesis fue conocer la influencia de la alta temperatura sobre el rendimiento y la calidad de tomate, en particular sobre la acumulación de metabolitos relacionados con la calidad organoléptica y nutricional del fruto, y establecer diferentes estrategias agronómicas basadas en el manejo de la nutrición mineral, la utilización de mallas de sombreo y la aplicación de bioestimulantes, para minimizar los efectos negativos del estrés térmico. Para ello se plantearon los siguientes objetivos específicos: 
1. Evaluar la idoneidad de la variedad enana de tomate Micro-Tom, para ser utilizada como planta modelo en estudios de respuesta de tomate a diferentes estreses abióticos.

2. Estudiar el efecto del estrés por alta temperatura, sobre la acumulación de carotenoides y ácido ascórbico en tomate.

3. Conocer la influencia del sombreo y su interacción con la nutrición nitrogenada, sobre el rendimiento y la calidad del fruto, bajo condiciones de alta temperatura.

4. Evaluar el efecto de la interacción alta temperatura $x$ salinidad sobre el rendimiento y la calidad del fruto.

5. Estudiar la respuesta de tomate a nivel fisiológico, agronómico y bioquímico a la aplicación de bioestimulantes, bajo condiciones de alta temperatura. 


\section{Capítulo 3}

\section{TÉCNICAS ANALÍTICAS}

\subsection{Parámetros de intercambio gaseoso}

La asimilación neta de $\mathrm{CO}_{2}(\mathrm{~A})$, conductancia estomática $\left(\mathrm{g}_{\mathrm{s}}\right)$, transpiración (T), concentración de $\mathrm{CO}_{2}$ intercelular $\left(\mathrm{C}_{\mathrm{i}}\right)$ y eficiencia del uso de agua (WUE) se determinaron utilizando un analizador de intercambio gaseoso portátil LI-COR (LI6400XT, Lincoln, NE, EEUU) (Figura 3.1). Para ello, la cubeta (0,25 L), equipada con una fuente de luz externa, se mantuvo con una radiación fotosintéticamente activa (PAR) constante de $1500 \mu \mathrm{mol} \mathrm{m} \mathrm{m}^{-2} \mathrm{~s}^{-1}$ durante las mediciones, suficiente para saturar las hojas de tomate. Durante todas las mediciones, la temperatura de la hoja fue de $28 \pm 2 \stackrel{\circ}{\circ}$ y la concentración de $\mathrm{CO}_{2}$ en la cámara foliar de $400 \mu \mathrm{mol}$ $\mathrm{m}^{-2} \mathrm{~s}^{-1}$. El déficit de presión de vapor de la hoja-aire se mantuvo entre 1 y $1,3 \mathrm{kPa}$ dentro de la cubeta. Las condiciones se mantuvieron constantes durante todo el ensayo. Con el fin de evitar condiciones de alta temperatura y baja humedad, las medidas se realizaron a primera hora de la mañana sobre hojas jóvenes, situadas en el estrato superior de la planta, sin defectos y totalmente expandidas. Se realizaron 3 medidas por hoja.

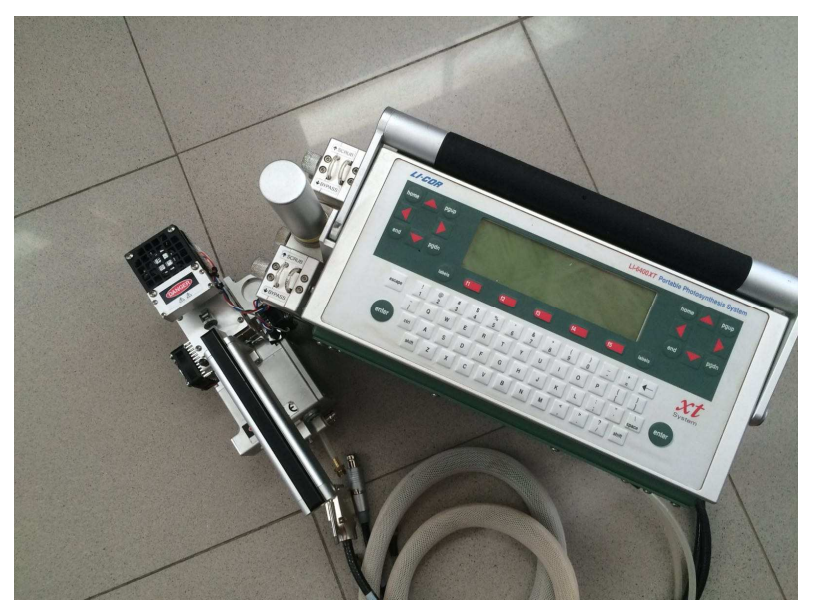

Figura 3.1. Analizador de parámetros de intercambio gaseoso. 


\subsection{Parámetros físicos}

\subsubsection{Peso}

El peso fresco del fruto se determinó en un granatario Mettler Toledo PG 6002-S (Uznach, Suiza), con una precisión de 0,01 g.

\subsubsection{Calibre ecuatorial y longitudinal}

El calibre ecuatorial y longitudinal de los frutos de tomate se determinó con un calibre milimétrico con lectura digital Mitutoyo (Andover, Reino Unido).

\subsubsection{Color}

El color de los frutos se midió por reflectancia utilizando un colorímetro Minolta CR-200 (Ramsey, NJ, EEUU) a través de la lectura directa en tres áreas diferentes de la superficie del fruto, seleccionadas al azar, tomando la media de las tres mediciones como la definitiva. Los datos se expresaron como CIEL ${ }^{*} a^{*} b^{*}$, donde $L^{*}$ indica la luminosidad (0, negro; 100 , blanco), y $a^{*}$ (+, rojo; -, verde) y $b^{*}$ (+, amarillo; -, azul) (Figura 3.2).
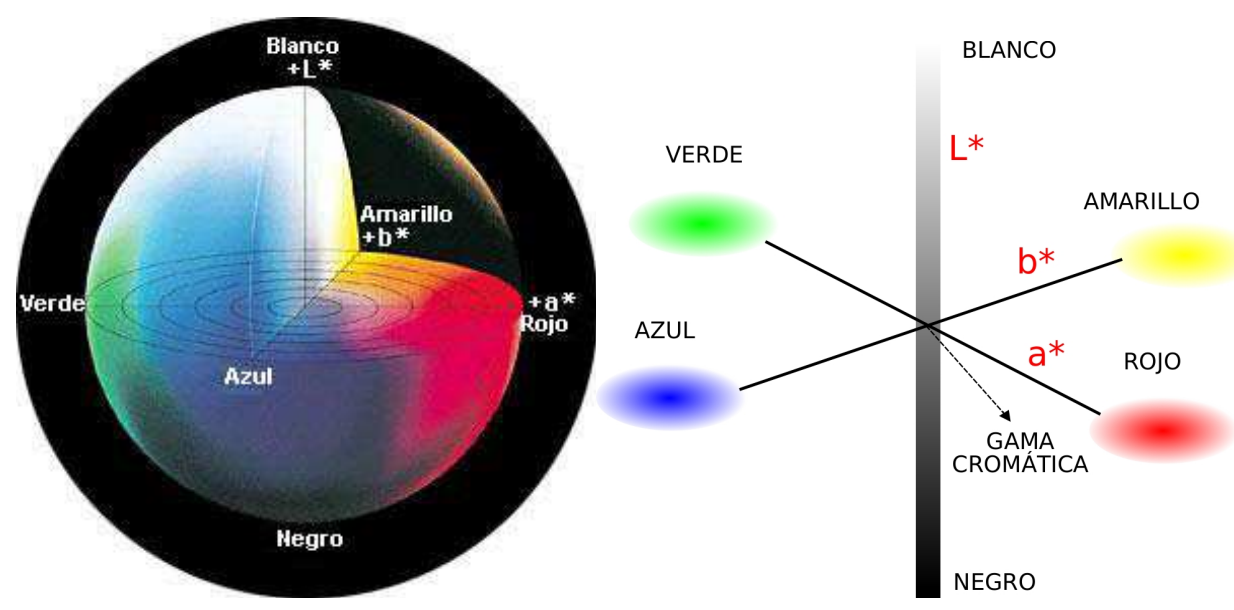

Figura 3.2. Espacio de color CIELab. 
Los valores numéricos de $a^{*}$ y $b^{*}$ se convirtieron en Hue $\left[H u e=\tan ^{-1}\left(b^{*} / a^{*}\right)\right]$ y Croma $\left[C=\left(a^{2}+b^{2}\right)^{1 / 2}\right]$. El valor de Hue (tono), que está relacionado con la longitud de onda del color dominante, se representa como una esfera y se asocia con el ángulo que forma $\left(0^{\circ}\right.$, rojo; $90^{\circ}$, amarillo; $180^{\circ}$, verde; $270^{\circ}$, azul; $360^{\circ}$, violeta). El valor de croma es la intensidad o la pureza del tono (McGuire, 1992).

\subsection{Análisis de metabolitos en fruto}

\subsubsection{Análisis de azúcares solubles y ácidos orgánicos}

\subsubsection{Extracción}

La extracción de azúcares y ácidos orgánicos se realizó homogeneizando 1 $\mathrm{g}$ de material vegetal, previamente congelado $\left(-80^{\circ} \mathrm{O}\right)$ ) y triturado, con agua desionizada (Millipore, Molsheim, Francia) a $50 \stackrel{\circ}{\mathrm{C}}$, mediante un homogenizador Polytron (PT-MR 3100, Kinematica, Lucerna, Suiza). Las muestras se centrifugaron en una centrífuga modelo 5810R (Eppendorf, Hamburgo, Alemania) durante 30 min a 10000 r.p.m. El sobrenadante se pasó por un filtro de nylon con un tamaño de poro de 0,45 $\mu \mathrm{m}$ (Millipore, Milford, MA, EEUU) y se enrasó a 50 $\mathrm{mL}$ con agua desionizada. La muestra fue purificada mediante extracción en fase sólida (EFS) con un cartucho $\mathrm{C}_{18}$ (Varian, Lake Forest, EEUU), previamente activado con $10 \mathrm{~mL}$ de metanol y $20 \mathrm{~mL}$ de agua desionizada.

\subsubsection{Determinación de azúcares}

La determinación de los azúcares solubles en la fracción hidrofílica se realizó mediante un cromatógrafo Agilent Serie 1100 (Waldbronn, Alemania) equipado con un detector de índice de refracción (RID), una columna analítica CARBOSep CHO 682, $300 \times 7,8$ mm (Transgenomic, San Jose, EEUU) con relleno polimérico y un cartucho precolumna $(0,5-2,0 \mu \mathrm{m})$ con el mismo relleno. La fase móvil consistió en agua desionizada a un flujo de $0,4 \mathrm{~mL} \mathrm{~min}^{-1}$. El volumen de inyección fue de $20 \mu \mathrm{L}$. La temperatura de la columna se mantuvo a $80{ }^{\circ} \mathrm{C}$ 
durante los 40 min que duró el análisis. Para cuantificar las muestras se prepararon curvas de calibración entre 1 a $10 \mathrm{~g} \cdot \mathrm{L}^{-1}$ de glucosa y fructosa en agua desionizada.

\subsubsection{Determinación de ácidos orgánicos}

El análisis de ácidos orgánicos se realizó según el método desarrollado por Flores y col. (2012), utilizando un cromatógrafo líquido Agilent serie 1200 (Santa Clara, CA, EEUU) equipado con un espectrómetro de masas triple cuadrupolo equipado con un sistema de ionización por electroespray (ESI) operando en modo negativo. La separación se realizó en una columna $\mathrm{C}_{18}$ Prontosil $250 \times 3 \mathrm{~mm}$ de, $3 \mu \mathrm{m}$ de tamaño de partícula (Bischoff, Alemania), utilizando ácido fórmico 0,1\% (v/v) como fase móvil y un flujo de 0,4 $\mathrm{mL} \mathrm{min}^{-1}$. Las transiciones MRM utilizadas para la identificación de cada uno de los compuestos fueron: ácido málico $(\mathrm{m} / \mathrm{z}$ $133 \rightarrow 115)$, cítrico $(\mathrm{m} / \mathrm{z} 191 \rightarrow 111)$, glutámico $(\mathrm{m} / \mathrm{z} 146 \rightarrow 128)$, quínico $(\mathrm{m} / \mathrm{z}$ $191 \rightarrow 85)$, succínico $(m / z 117 \rightarrow 73)$, y siquímico $(m / z 173 \rightarrow 93)$. Para la cuantificación de los ácidos orgánicos se construyeron rectas de calibrado matricial, utilizando estándares comerciales (Sigma, Steinheim, Alemania). El intervalo de linealidad estuvo comprendido entre 0,05-1200 $\mathrm{g} \mathrm{mL}^{-1}$ para cada ácido orgánico.

\subsubsection{Análisis de compuestos fenólicos}

\subsubsection{Extracción}

Los compuestos fenólicos libres se extrajeron con metanol/ácido fórmico (97/3, v/v) de acuerdo con el método descrito por Cantos y col. (2002). Se pesaron $4 \mathrm{~g}$ de tomate previamente triturado, al que se le añadió miricetina como estándar interno (15 ppm) y se homogenizaron con $10 \mathrm{~mL}$ de metanol/ácido fórmico (97:3). El homogenizado se centrifugó a 10000 r.p.m. (15 min, $4 \stackrel{\circ}{ } \mathrm{C}$ ). El sobrenadante se retiró y el proceso se repitió adicionando $10 \mathrm{~mL}$ de metanol/ácido fórmico. La combinación de ambos sobrenadantes se llevó a 
sequedad en un evaporador rotativo Büchi modelo R-205 (Flawil, Suiza) y el residuo se redisolvió en $2 \mathrm{~mL}$ de $\mathrm{MeOH}$ y se filtró $(0,45 \mu \mathrm{m})$ (Millipore, Milford, MA, EEUU) para su posterior análisis cromatográfico.

\subsubsection{Determinación}

El perfil de compuestos fenólicos se determinó utilizando un cromatógrafo líquido Agilent serie 1200 (Santa Clara, CA, EEUU) equipado con un detector de espectrometría de masas triple cuádruplo (MS/MS) y un sistema de ionización por electroespray (ESI) operando en modo negativo. La separación se realizó en una columna $\mathrm{C}_{18}$ Licrosphere, $250 \times 4 \mathrm{~mm}$ de $5 \mu \mathrm{m}$ de tamaño de partícula (Agilent Technologies, Waldbronn, Alemania) utilizando como fase móvil ácido fórmico 5\% $(\mathrm{v} / \mathrm{v})(\mathrm{A})$ y acetonitrilo (B), a un flujo de $1 \mathrm{~mL} \mathrm{~min}^{-1}$. Las condiciones del gradiente fueron las que se describen a continuación: el gradiente se inició con un $5 \%$ de $B$, hasta alcanzar el 10\% de B en 9 min, un $30 \%$ de B en 50 min y se incrementó a $100 \%$ de B en 2 min, se manteniéndose a 100\% durante $3 \mathrm{~min}$, volviendo a las condiciones iniciales en $1 \mathrm{~min}$ y permaneciendo en isocrático durante $6 \mathrm{~min}$. Las transiciones MRM utilizadas para la identificación de cada uno de los compuestos fueron: ácido caféico-O-hexósido $(m / z 341 \rightarrow 179)$, ácido caféico $(m / z 179 \rightarrow$ $135)$, ácido clorogénico $(m / z 353 \rightarrow 191)$, ácido coumaroilquínico $(m / z 337 \rightarrow$ $191)$, ácido cryptoclorogénico $(m / z 353 \rightarrow 173)$, dicafeoilquínico $(m / z 515 \rightarrow 191)$, ácido ferúlico-O-hexósido $(\mathrm{m} / z 355 \rightarrow 193)$, ácido ferúlico $(\mathrm{m} / \mathrm{z} 193 \rightarrow 134)$, ácido homovanílico-O-hexósido (kaempferol-3-O-rutinósido, $(m / z \quad 593 \rightarrow 285)$, naringenina $(m / z 271 \rightarrow 151)$, naringenina-O-hexósido $(m / z 433 \rightarrow 271)$, ácido $p$ cumárico $(m / z 163 \rightarrow 119)$, floretina- $C$-diglicósido $(m / z 597 \rightarrow 357)$, quercetina $(m / z 301 \rightarrow 151)$, rutína (quercetín 3-O-rutinósido) $(m / z 609 \rightarrow 300)$, rutín-Opentósido $(m / z 741 \rightarrow 609)$. En los casos de estar disponibles, los compuestos identificados se cuantificaron utilizando patrones comerciales (Sigma, Steinheim, Alemania), y el resto se cuantificó con respecto a su isómero, ácido hidroxicinámico o aglicona $m / z 343 \rightarrow 181)$, kaempferol $(m / z 285 \rightarrow 117$, correspondiente. En particular, ácido cafeico-O-hexósido fue cuantificado como ácido cafeico, los ácidos coumaroilquínico, dicafeoilquínico y criptoclorogénico 
como ácido clorogénico, ácido ferúlico-O-hexósido como ácido ferúlico, ácido homovanílico-O-hexósido como ácido homovanílico, kaempferol-3-O-rutinósido fue cuantificado como kaempferol, naringenin-O-hexósido como naringenina, floretina- $C$-diglicósido como floretina y rutin- $O$-pentósido como rutina. Para ello se construyó una recta matricial en un intervalo de linealidad comprendido entre $0,07-25,1 \mu \mathrm{gL}^{-1}$.

\subsubsection{Análisis de carotenoides y vitamina $E$}

\subsubsection{Extracción}

Los carotenoides y la vitamina $\mathrm{E}$ se extrajeron según el método descrito por Böhm (2001), con ligeras modificaciones. A $1 \mathrm{~g}$ de muestra y se le añadieron 200 mg de $\mathrm{MgO}$ y $500 \mu \mathrm{L}$ (25 ppm) de $\beta$-apo-8'-carotenal como estándar interno y se homogenizó en un Polytron PT-MR 3100 (Kinematica AG, Littau, Suiza) con una mezcla de metanol/tetrahidrofurano $(1 / 1, v / v)$ que contenía $0,1 \%(p / v)$ de butil hidroxitolueno (BHT). El homogenizado se centrifugó a 10000 r.p.m. durante 10 min a $4 \stackrel{\circ}{\circ} \mathrm{C}$ en una centrífuga Eppendorf 5810R (Hamburgo, Alemania). El sobrenadante se llevó a sequedad en un evaporador rotativo Büchi modelo R-205 (Flawil, Suiza). El residuo se redisolvió en $2 \mathrm{~mL}$ de metanol/metil tert-butil éter $(1 / 1, v / v)$ y se filtró $(0,45 \mu \mathrm{m})$ (Millipore, Milford, MA, EEUU) para su posterior análisis cromatográfico.

\subsubsection{Determinación}

La determinación se realizó en un cromatógrafo de líquido Agilent Serie 1200 (Santa Clara, CA, EEUU) equipado con un detectores diodos array (DAD) y de fluorescencia $(F L D)$. La separación se realizó en una columna Prontosil $C_{30}$, 250 x 4,6 mm, $3 \mu \mathrm{m}$ (Bischoff, Leonberg, Alemania) utilizando metanol (A) y metil tert-butil éter (B) como fase móvil. Las condiciones iniciales fueron $15 \%$ de $B$ durante $10 \mathrm{~min}$, seguido de un aumento lineal hasta $90 \%$ de B durante $20 \mathrm{~min}$. La elución se realizó a un flujo de $1,3 \mathrm{~mL} \mathrm{~min}^{-1}$ con un volumen de inyección de 20 
$\mu \mathrm{L}$. La detección se realizó a $287 \mathrm{~nm}$ para fitoeno, $347 \mathrm{~nm}$ para fitoflueno y 444 $\mathrm{nm}$ para luteína, violaxantina, $\zeta$-caroteno $\gamma$-caroteno, $\beta$-caroteno, licopeno y $\beta$ apo-8'-carotenal (estándar interno). La identificación de los compuestos se logró mediante la comparación de los tiempos de retención y espectros UV, utilizando estándares o referencias bibliográficas (Kimura y Rodriguez-Amaya, 2003) y sus valores de $\mathrm{m} / \mathrm{z}$ obtenidos mediante el análisis realizado en un cromatógrafo de líquidos Agilent 1200 (Waldbronn, Alemania), provisto de un detector espectrómetro de masas triple cuadrupolo (MS/MS), utilizando una fuente de ionización química a presión atmosférica (APCl) operando en modo positivo.

Los isómeros cis se identificaron de acuerdo a la absorción a 330 o $360 \mathrm{~nm}$ y los valores de Q-ratio, definido como la relación entre la altura del pico cis y la del pico de máxima absorción (pico base), descritos en la literatura (Schierle y col., 1997; Chen y col., 2004). Los principales compuestos se cuantificaron usando estándares externos comerciales de licopeno y $\beta$-caroteno (Sigma-Aldrich, Taufkirchen, Alemania) y luteína, violaxantina y neoxantina (DHI LAB, Hoersholm, Dinamarca). Los compuestos fitoeno y fitoflueno fueron expresados como equivalentes de $\beta$-caroteno.

El análisis de $\alpha$ - y $\gamma$-tocoferol se realizó en el mismo equipo y condiciones que los carotenoides utilizando un detector de fluorescencia $\left(E_{\text {excitación }}=250 \mathrm{~nm}\right.$ y $E_{\text {emisión }}=410 \mathrm{~nm}$ ) y estándares comerciales disponibles para su cuantificación (DHILAB, Hoersholm, Dinamarca). Para ello se construyeron dos rectas matriciales en un intervalo de linealidad comprendido entre 1-100 $\mathrm{g} \mathrm{mL}^{-1}$ para $\alpha$ tocoferol y $y$-tocoferol.

\subsubsection{Análisis de vitamina C}

\subsubsection{Extracción}

La determinación de vitamina $\mathrm{C}$ se realizó de acuerdo con la metodología desarrollada por Fenoll y col. (2011). Para la extracción se homogenizaron $3 \mathrm{~g}$ de muestra con $10 \mathrm{~mL}$ de EDTA 0,05\% (p/v) en un Polytron PT-MR 3100 (Kinematica 
AG, Littau, Suiza). El homogenizado se centrifugó (10000 r.p.m., 10 min, $4{ }^{\circ} \mathrm{C}$ ) utilizando una centrífuga Eppendorf 5810R (Hamburgo, Alemania). El sobrenadante se filtró a través de 0,45 $\mu \mathrm{m}$ (Millipore, Milford, MA, EEUU). Para inducir la reducción de ácido dehidroascórbico (ADHA) a ácido ascórbico (AA), al extracto se le añadió DL-1,4-ditiotreitol (DTT) $5 \mathrm{mM}$, incubándolo durante $30 \mathrm{~min}$ a $30 \stackrel{\circ}{C}$ y procediendo al análisis cromatográfico inmediatamente.

\subsubsection{Determinación}

La determinación y cuantificación de vitamina $C$ se llevó a cabo utilizando un cromatógrafo líquido Agilent serie 1200 (Santa Clara, CA, EEUU) equipado con una columna $\mathrm{C}_{18}$ Prontosil $250 \times 3 \mathrm{~mm}, 3 \mu \mathrm{m}$ tamaño de partícula (Bischoff, Leonberg, Alemania), utilizando ácido fórmico $0,2 \%(\mathrm{v} / \mathrm{v})$ como fase móvil a un flujo de 0,4 mL $\mathrm{min}^{-1}$. El análisis espectral de masas se realizó en un espectrómetro de masas triple cuadrupolo (MS/MS) de Agilent equipado con un sistema de ionización por electroespray (ESI) operando en modo negativo. La cuantificación se realizó por comparación con un estándar de AA (Sigma-Aldrich, St. Louis, MO, EEUU), usando la transición $m / z 175 \rightarrow 115$. Para ello se construyó una recta matricial en un intervalo de linealidad comprendido entre 0,05-2000 $\mu \mathrm{g} \mathrm{mL}^{-1}$. 


\section{Capítulo 4}

\section{RESPUESTA DE LA VARIEDAD ENANA DE TOMATE MICRO-TOM AL ESTRÉS SALINO Y NUTRICIONAL}

Además de su importancia económica, el tomate es considerado una excelente fuente de compuestos bioactivos y nutrientes esenciales, en particular, carotenoides, compuestos fenólicos, ácido ascórbico y $\alpha$-tocoferol (Erge y Karadeniz, 2011). La acumulación de estos metabolitos y la de otros compuestos relacionados con las características organolépticas de los frutos (azúcares y ácidos orgánicos) depende, además de factores genéticos, de factores agronómicos y ambientales (Rosello y col., 2011). Una de las mayores limitaciones para la producción de los cultivos en gran parte del planeta, es la escasez de recursos hídricos de buena calidad. El riego con agua salina tiene un efecto negativo sobre el desarrollo y rendimiento de las plantas debido, por un lado, a la disminución del potencial osmótico en el medio de cultivo (efecto osmótico) y por otro, a la presencia de iones salinos (efecto específico). El efecto primario de toxicidad inducido por la presencia de sales en el medio de cultivo, especialmente a concentraciones moderadas, es un efecto osmótico, el cual se traduce en una disminución de la disponibilidad de agua para las raíces como consecuencia de la disminución de la energía libre del agua en el suelo (Yuan y col., 2004). Para contrarrestar esta limitación, la planta acumula, en el citosol y en diferentes orgánulos celulares, iones y solutos compatibles tales como azúcares simples (glucosa y fructosa) y complejos (manitol), alcoholes, aminoácidos (prolina) y compuestos de amonio cuaternario (glicina betaina) (Yokoi y col., 2002). La acumulación de estos compuestos permite a las células disminuir su potencial osmótico y mejorar la absorción de agua por las raíces. Por otro lado, la concentración de compuestos antioxidantes tales como ácido ascórbico, carotenoides y compuestos fenólicos, también aumentan bajo condiciones salinas, como un mecanismo no enzimático para la detoxificación de especies 
reactivas de oxígeno (ROS) generadas por un estrés oxidativo inducido por la salinidad (Abogadallah, 2010). De manera indirecta, el aumento de la concentración de estos metabolitos primarios y secundarios, como respuesta de la planta al estrés abiótico, puede mejorar la calidad organoléptica, nutricional y funcional de tomate (Flores y col., 2003).

Respecto al efecto de la nutrición mineral sobre la composición del los frutos de tomate, el aumento de la dosis de nitrógeno $(\mathrm{N})$ se ha correlacionado con una disminución del contenido en azúcares solubles y vitamina C (Wang y col., 2008b). Por otro lado, la fertilización potásica (K) también puede afectar a la concentración de metabolitos relacionados con la calidad del fruto. Según Lee y Kader (2000), un aumento del aporte de K aumenta la concentración de azúcares en tomate, como consecuencia de un incremento en la tasa fotosintética de la planta. La concentración de licopeno, uno de los principales carotenoides presentes en tomate con importantes propiedades beneficiosas para la salud, también se ve incrementada con el aumento de aporte de K (Serio y col., 2007; Liu y col., 2011). Respecto al calcio (Ca), su relación con la incidencia de la podredumbre apical o blossom end rot (BER) ha sido ampliamente estudiada (Saure, 2001; Taylor y Locascio, 2004). Este desorden fisiológico ha sido relacionado con una alteración en la translocación de Ca hacia la parte distal del fruto (Olle y Bender, 2009), como consecuencia de diferentes factores, entre ellos, salinidad, alta temperatura, solubilidad de sales de Ca en la disolución del suelo y presencia de elementos antagonistas como magnesio $(\mathrm{Mg})$ y amonio $\left(\mathrm{NH}_{4}\right)$. Aunque el efecto del $\mathrm{Ca}$ sobre la aparición del BER ha sido ampliamente estudiado, aún existe escasa información sobre la incidencia que este nutriente puede tener sobre la calidad organoléptica y nutricional de los frutos.

Basándose en la capacidad de los factores externos para modificar el perfil $y$ el contenido de metabolitos primarios y secundarios en los frutos, diversos autores han propuesto diferentes aproximaciones agronómicas con el fin de aumentar su calidad organoléptica y nutricional (Poiroux-Gonord y col., 2010). En particular, la aplicación de un estrés salino moderado y la optimización de la nutrición mineral, son estrategias que se han utilizado para mejorar la calidad del tomate. Sin embargo, aunque los enfoques agronómicos ofrecen buenas 
perspectivas, se requieren más estudios que permitan identificar, de forma precisa, el efecto del manejo del cultivo y de las condiciones medioambientales, así como la interacción entre estos factores, sobre la composición de los frutos. Para ello se requieren diseños experimentales bajo condiciones controladas, como los que ofrece el cultivo en cámaras de crecimiento. Este tipo de ensayos plantea el inconveniente del espacio reducido, especialmente en el caso de estudios realizados sobre fruto, en los que plantas como las de tomate alcanzan un mayor tamaño. Con el fin de solventar este problema, algunos autores han utilizado la variedad de tomate enano Micro-Tom como planta modelo (Carvalho y col., 2011).

El fenotipo del cultivar Micro-Tom es debido a la presencia de dos mutaciones recesivas, dwarf (d) y self-pruning ( $s p)$, y al menos a una tercera mutación que reduciría también la altura de la planta (Marti y col., 2006). Este mutante, que fue desarrollado inicialmente como un cultivar ornamental, tiene un tamaño reducido (aproximadamente $10-20 \mathrm{~cm}$ altura) y un ciclo de vida corto (7090 días desde la siembra hasta la maduración de los primeros frutos) (Scott y Harbaug, 1989). Estas características le confieren evidentes ventajas para el estudio de la respuesta fisiológica de la planta, ya que puede ser cultivado en cámaras de crecimiento bajo condiciones controladas, en espacios limitados y con una alta densidad de plantación.

Sin embargo, el perfil de metabolitos de este mutante y su respuesta a factores agronómicos y medioambientales no han sido bien estudiados. El objetivo de este trabajo es utilizar la variedad enana de tomate Micro-Tom para estudiar el perfil de compuestos bioactivos (carotenoides y compuestos fenólicos) y la viabilidad de dicha variedad mutante como planta modelo en estudios de la respuesta de tomate al estrés salino y nutricional, mediante la comparación de su respuesta con la de una variedad no mutante. 


\subsection{MATERIALES Y MÉTODOS}

\subsubsection{Sitio de estudio y material vegetal}

El ensayo se realizó, durante los meses de febrero y julio, en la finca experimental "La Matanza", perteneciente al Centro de Edafología y Biología Aplicada del Segura (CEBAS-CSIC), situada en Santomera (Murcia). Se llevó a cabo en un invernadero de policarbonato tipo capilla, de superficie $462,5 \mathrm{~m}^{2}$ ( $25 \mathrm{x}$ $18,5 \mathrm{~m}$ ), con una altura de $5 \mathrm{~m}$ a la canal y de $7,7 \mathrm{~m}$ a la cumbrera. El material vegetal utilizado fue tomate del cultivar enano Micro-Tom, y de la variedad comercial Optima (Seminis).

\subsubsection{Diseño experimental y manejo del cultivo}

El diseño experimental consistió en cinco tratamientos: control (14 mM N, 6 $\mathrm{mM} \mathrm{K}$ y $4 \mathrm{mM} \mathrm{Ca})$, bajo en nitrógeno $(1,4 \mathrm{mM} \mathrm{N})$, bajo en potasio $(0,7 \mathrm{mM} \mathrm{K})$, bajo en calcio $(0,4 \mathrm{mM} \mathrm{Ca})$ y salinidad (control $+100 \mathrm{mM} \mathrm{NaCl})$, distribuidos al azar con cuatro repeticiones por tratamiento. En la Tabla 4.1 se muestra la composición de la disolución nutritiva del tratamiento control. Los demás tratamientos se obtuvieron mediante sustitución total o parcial de $\mathrm{KNO}_{3}$ y $\mathrm{Ca}\left(\mathrm{NO}_{3}\right)_{2} \cdot 4 \mathrm{H}_{2} \mathrm{O}$, añadiendo $\mathrm{Cl}_{2} \mathrm{Ca}$ y $\mathrm{K}_{2} \mathrm{SO}_{4}$ en caso necesario, con el fin de mantener las concentraciones del resto de elementos al mismo nivel que en la disolución Hoagland. Las plántulas de tomate, inicialmente germinadas en vermiculita y regadas con disolución 1/10 de Hoagland, se transfirieron a cubas de polivinilo negro de $120 \mathrm{~L}$ de capacidad, cada una de ellas constituyendo una repetición. Cada cuba se tapó con una plancha de polietileno negro que evitaba, por una parte, la evaporación del agua y por otra, la exposición de la disolución nutritiva a la luz. En el caso de la variedad Micro-Tom, se colocaron dos plantas por cuba, y en el caso de la variedad Optima, una planta por cuba, en ambos casos sujetas mediante adaptadores de poliuretano expandido y algodón hidrófobo. En la Figura 4.1 se muestra una vista general de la distribución de las plantas en el invernadero. El agua utilizada para la preparación de las disoluciones nutritivas provenía del trasvase del Taibilla y se desionizó mediante 
un sistema de ósmosis inversa KP-HWL. Las disoluciones nutritivas estaban permanentemente aireadas y su volumen se mantuvo constante mediante la adición diaria de agua desionizada. Las disoluciones se analizaron semanalmente y se repusieron los nutrientes absorbidos por la planta. El pH se controló cada dos días y se mantuvo en el rango 5,5-6,5 mediante la adición de $\mathrm{KOH} \circ \mathrm{H}_{2} \mathrm{SO}_{4}$ cuando fue necesario. La recolección se realizó gradualmente conforme los frutos alcanzaban el tamaño y estado de maduración adecuado.

Tabla 4.1. Composición de la disolución nutritiva Hoagland modificada.

\begin{tabular}{cccccc}
\hline \multicolumn{7}{c}{ Macronutrientes $(\mathrm{mM})$} \\
\hline $\mathrm{NO}_{3}{ }^{-}$ & $\mathrm{H}_{2} \mathrm{PO}_{4}{ }^{-}$ & $\mathrm{SO}_{4}{ }^{2-}$ & $\mathrm{Ca}$ & $\mathrm{K}$ & $\mathrm{Mg}$ \\
14 & 2 & 2 & 4 & 8 & 2 \\
\hline \multicolumn{7}{c}{ Micronutrientes $(\mu \mathrm{M})$} \\
\hline $\mathrm{B}$ & $\mathrm{Mn}$ & $\mathrm{Zn}$ & $\mathrm{Cu}$ & $\mathrm{Mo}$ & $\mathrm{Cl}$ \\
25 & 2 & 2 & 0,5 & 0,5 & 50 \\
\hline
\end{tabular}

Las muestras destinadas al análisis de los diferentes parámetros de calidad se recolectaron una vez que los frutos habían alcanzado el estado de madurez requerido (totalmente rojo), descartando aquellos que presentaban cualquier defecto. Para evitar la sobre-maduración de los frutos, estos se revisaron diariamente y se recolectaron inmediatamente una vez que habían alcanzado un color homogéneo. En la variedad Optima, la recolección de las muestras para el análisis de la calidad se realizó sobre frutos del tercer al quinto racimo, mientras que en la variedad Micro-Tom se muestrearon todos los frutos de la planta. Los tomates pertenecientes a una misma repetición se cortaron en trozos pequeños y se mezclaron. La mitad de cada muestra se licuó y se centrifugó para la determinación del contenido en sólidos solubles totales (SST) con un refractómetro Atago modelo PAL-1 (Tokio, Japón), el pH con un pHmetro modelo GLP21 (Crison, Alella, Barcelona) y la acidez total con un valorador modelo 702 SM Titrino (Metrohm, Herisau, Suiza). La otra mitad de la muestra se homogeneizó con nitrógeno líquido y se conservó a $-80 \stackrel{\circ}{\circ} \mathrm{C}$ para el posterior análisis de azúcares solubles, ácidos orgánicos, compuestos fenólicos, 
carotenoides y vitamina $\mathrm{C}$, según los procedimientos descritos en los apartados 3.3.1., 3.3.2., 3.3.3 y 3.3.4 del capítulo 3. Cada muestra se analizó por triplicado.

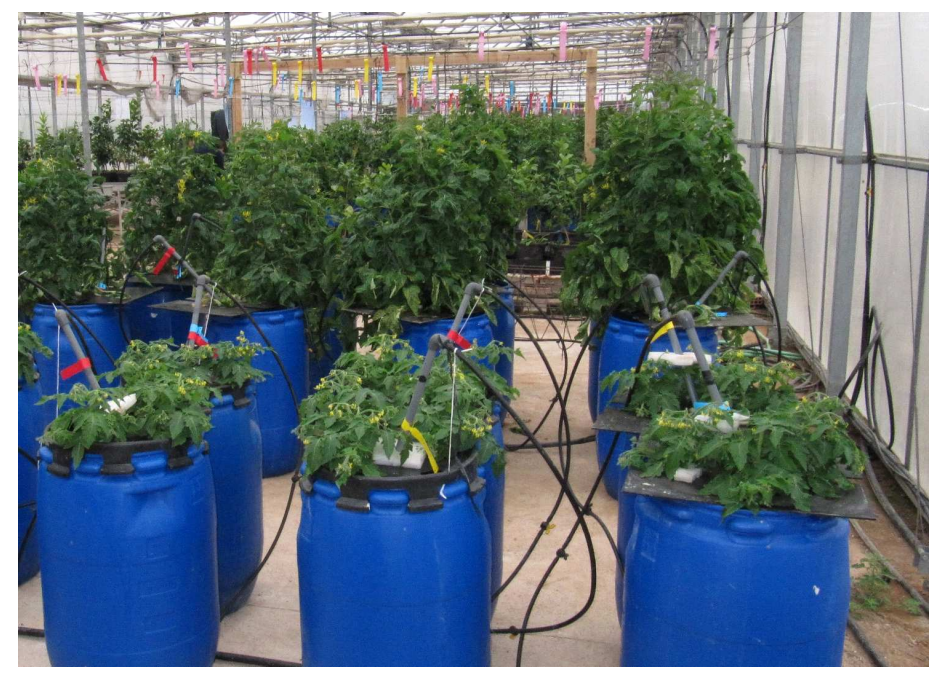

Figura 4.1. Vista general de las plantas de tomate cvs. Micro-Tom y Optima, cultivadas en sistema hidropónico.

\subsubsection{Análisis estadístico}

Los resultados fueron analizados estadísticamente mediante el análisis de la varianza (ANOVA) usando IBM SPSS Statistic 21. Los valores se compararon con el test de diferencia entre medias de Duncan.

\subsection{RESULTADOS Y DISCUSIÓN}

\subsubsection{Perfil de compuestos fenólicos en la variedad Micro-Tom}

La identidad de los compuestos fenólicos detectados se confirmó mediante comparación con los patrones disponibles o, en el caso de compuestos en los que no se disponía de dichos patrones, mediante técnicas LC-QqQ, utilizando una fuente de ionización por electrospray (ESI), operando en modo negativo. Para ello se realizó, en primer lugar, un barrido de iones totales (Full scan), donde se 
obtuvo una información general del perfil de los metabolitos en la muestra. Posteriormente, se utilizaron diferentes modos de adquisición: barrido de pérdidas neutras (Neutral Loss Scan), barrido de iones precursor (Precursor Ion Scan) y barrido de iones producto (Product Ion Scan). El análisis de LC-QqQ del cultivar Micro-Tom, permitió identificar 28 compuestos fenólicos, incluyendo derivados hidroxicinámicos y benzoicos (ácidos cafeico, cafeico-O-hexósido, clorogénico, criptoclorogénico, p-cumárico, coumaroilquínico, ferúlico-O-hexósido, homovanílico-O-hexósido, dicafeoilquínico y ferúlico), flavonoles (kaempferol, kaempferol-3-O-rutinósido, quercetina, rutina y rutina-O-pentósido), flavanonas (naringenina y naringenina- $O$-hexósido) y floretina- $C$-diglicósido (derivado de dihidrochalcona) (Tabla 4.2). Los espectros generados por estos compuestos en modo negativo, dieron lugar a la molécula desprotonada $[\mathrm{M}-\mathrm{H}]^{-}$y a otros fragmentos característicos. La presencia de ácidos cafeico, ferúlico y $p$-cumárico se confirmó por comparación con los espectros de masas y los tiempos de retención de los patrones de referencia. La pérdida de $\mathrm{CO}_{2}[\mathrm{M}-\mathrm{H}-44]$ ] se confirmó en los tres ácidos hidroxicinámicos y en el ácido ferúlico, se confirmó la pérdida del grupo metilo [M-H-15] . Por otro lado, se detectaron tres ácidos dicafeoilquínicos que presentaron, como iones fragmento, una molécula de ácido cafeico $(m / z 179)$ y la resultante de la pérdida de una molécula de ácido quínico [M-H-162] . Además, el análisis Full Scan mostró tres ácidos cafeico-O-hexósidos, cuyas identidades fueron confirmadas por la pérdida neutra de $162 \mathrm{u}$ (correspondiente a la pérdida de la hexosa) y la detección de la $\mathrm{m} / \mathrm{z} 179$ (correspondiente a la molécula de ácido cafeico) en el barrido de iones precursores. La pérdida neutra de 162 u también se utilizó para la identificación de otros glucósidos/galactósidos tales como ácido homovanílico-O-hexósido, ácido ferúlico-O-hexósido y naringenina-O-hexósido, este último también confirmado por barrido de iones precursores $(m / z 271)$. De forma similar, el barrido de la pérdida neutra de 308 u confirmó la presencia de rutina y kaempferol-3-O-rutinósido y la pérdida neutra de 132 u y el barrido de iones precursor $m / z$ 301, revelaron la presencia de rutina-O-pentósido. La presencia de tres isómeros de ácido cafeoilquínico se confirmó por la pérdida de $162 \mathrm{u}$, correspondiente a una molécula de ácido cafeico. Los tres isómeros fueron identificados como clorogénico, un isómero like-clorogénico y criptoclorogénico. 
Tabla 4.2. Compuestos fenólicos identificados en tomate Micro-Tom y resultado de los ensayos LC-QqQ.

\begin{tabular}{|c|c|c|c|c|c|c|c|}
\hline & Compuestos & $\operatorname{Tr}(\min )$ & {$[\mathrm{M}-\mathrm{H}]^{-}$} & Iones MS/MS & $\mathbf{P N}^{*}$ & PRE $^{\star \star}$ & Patrón \\
\hline 1 & Ác. cafeico-O-hexósido 1 & 12,91 & 341 & 179,135 & 162 & 179 & \\
\hline 2 & Ác. homovanílico-O-hexósido1 & 13,60 & 343 & 181,121 & 162 & & \\
\hline 3 & Ác. cafeico-O-hexósido 2 & 14,27 & 341 & 179,135 & 162 & 179 & \\
\hline 4 & Ác. homovanílico-O-hexósido2 & 14,87 & 343 & 181,121 & 162 & & \\
\hline 5 & Ác. ferúlico-O-hexósido 1 & 15,63 & 355 & 193,178 & 162 & & \\
\hline 6 & Ác. cafeico-O-hexósido 3 & 16,14 & 341 & 179,135 & 162 & 179 & \\
\hline 7 & Ác. clorogénico & 16,82 & 353 & 191,179 & 162 & & Si \\
\hline 8 & Ác. Criptoclorogénico & 17,24 & 353 & $179,173,135$ & 162 & & \\
\hline 9 & Ác. ferúlico-O-hexósido 2 & 19,11 & 355 & 193,178 & 162 & & \\
\hline 10 & Ác. cafeico & 19,23 & 179 & 135 & & & Si \\
\hline 11 & Like-clorogénico & 20,16 & 353 & 191,179 & 162 & & \\
\hline 12 & Ác. coumaroilquínico & 22,23 & 337 & 191,163 & & & \\
\hline 13 & Ác. $p$-coumárico & 26,28 & 163 & 119 & & & $\mathrm{Si}$ \\
\hline 14 & Ác. ferúlico & 29,36 & 193 & 149,134 & & & $\mathrm{Si}$ \\
\hline 15 & Rutina-O-pentósido & 29,65 & 741 & 609,300 & 132 & 301 & \\
\hline 16 & Rutina & 32,57 & 609 & 301 & 308 & & $\mathrm{Si}$ \\
\hline 17 & Floretina-C-diglicósido & 33,16 & 597 & $477,417,387,357$ & 120 & & \\
\hline 18 & Dicafeoilquínico 1 & 35,01 & 515 & 353,191 & 162 & & \\
\hline 19 & Dicafeoilquínico 2 & 36,50 & 515 & 353,191 & 162 & & \\
\hline 20 & Kaempferol-3-O-rutinósido & 36,75 & 593 & 285 & 308 & & \\
\hline 21 & Naringenina-O-hexósido 1 & 36,92 & 433 & 271 & 162 & 271 & \\
\hline 22 & Naringenina-O-hexósido 2 & 37,75 & 433 & 271 & 162 & 271 & \\
\hline 23 & Dicafeoilquínico 3 & 39,51 & 515 & 191 & 162 & & \\
\hline 24 & Naringenina-O-hexósido 3 & 40,50 & 433 & 271 & 162 & 271 & \\
\hline 25 & Naringenina-O-hexósido 4 & 43,15 & 433 & 271 & 162 & 271 & \\
\hline 26 & Naringenina-O-hexósido 5 & 44,79 & 433 & 271 & 162 & 271 & \\
\hline 27 & Quercetina & 49,98 & 271 & 179,151 & & & $\mathrm{Si}$ \\
\hline 28 & Naringenina & 53,71 & 301 & 151,119 & & & $\mathrm{Si}$ \\
\hline
\end{tabular}

*PN: barrido de pérdidas neutras; ${ }^{* *}$ PRE: barrido de iones precursores. 
El ácido clorogénico fue identificado por comparación del espectro de masas y el tiempo de retención, respecto al del patrón de referencia. En el barrido de iones producto, el isómero identificado como like-clorogénico presentó un espectro similar al del ácido clorogénico, detectándose los iones fragmento $\mathrm{m} / \mathrm{z}$ 191 (correspondiente al quínico) y $\mathrm{m} / z 179$ (correspondiente al ácido cafeico). Este isómero no pudo ser identificado como ácido neoclorogénico debido a que su tiempo de retención y la intensidad del ión fragmento $\mathrm{m} / \mathrm{z} 179$ (menor del 5\%) no correspondió con los descritos en la bibliografía (Khachik y col., 2002). El tercer isómero fue identificado como ácido criptoclorogénico de acuerdo con su pico base $\mathrm{m} / \mathrm{z} 173$ [quínico- $\mathrm{H}-\mathrm{H}_{2} \mathrm{O}$ ] y los iones fragmento $\mathrm{m} / \mathrm{z} 179$ y 135 , típicamente menos abundantes en este isómero. El ácido cumaroilquínico, presentó los iones fragmento $m / z 191$ y 163 , correspondiente a los ácidos quínico y p-cumárico, respectivamente. El espectro generado por floretina-C-diglicósido $(\mathrm{m} / \mathrm{z} 597)$, mostró los iones fragmento esperados 477, 417, 387 y 357 como resultado de las pérdidas de 120 y/o 90 (Slimestad y Verheul, 2009). Finalmente, quercetina y naringenina fueron identificados por comparación de sus espectros y tiempos de retención con el de sus patrones. Quercetina fue confirmada por la fragmentación típica de los flavonoles en 179 y 151, correspondientes a la ruptura del anillo central y naringenina mostró, además del ión fragmento 151, la $\mathrm{m} / \mathrm{z} 119$ característica de este compuesto y de otras flavanonas (Böhm, 2001).

\subsubsection{Perfil de carotenoides en la variedad Micro-Tom}

El análisis cromatográfico de carotenoides realizado sobre las muestras de Micro-Tom permitió identificar 21 compuestos (Figura 4.2). En la Tabla 4.3, se muestran las características espectrales de los carotenoides detectados. Los picos de 1, 2, 8 y 20 fueron identificados como all trans-violaxantina, all transluteína, all trans- $\beta$-caroteno y all trans-licopeno, respectivamente, por comparación de los tiempos de retención y el espectro de absorción UV/Vis con los de sus correspondientes patrones.

La identificación de fitoeno, fitoflueno, $\zeta$-caroteno, $\delta$-caroteno y $\gamma$-caroteno se realizó por comparación del orden de elución y de los espectros UV/Vis 
obtenidos, con la información disponible en la literatura (Fabre y col., 2001; Khachik y col., 2002). Para la identificación de los isómeros cis se consideraron las variaciones de la estructura fina y la intensidad de la banda de absorción en la región UV (pico cis). Los picos 6 y 9 fueron identificados como 13 cis y 9 cis- $\beta$ caroteno, respectivamente, por comparación con los resultados descritos en la bibliografía de orden de elución en una columna $\mathrm{C}_{30}$ de fase reversa (Lacker y col., 1999), desplazamiento hipsocrómico de 9 y $5 \mathrm{~nm}$ y valores de Q-ratio (Chen y col., 2004). Los picos 16, 17, 18, 19 y 21 fueron identificados como 13 cis-, 9 cis-, 9' cis-, 5 cis- y 5' cis-licopeno, en base a los datos cromatográficos, al desplazamiento hipsocrómico observado de $6,6,6,0$ y $0 \mathrm{~nm}$, respectivamente, y a los valores de Q-ratio descritos por Schierle y col. (1997) y por Lin y Chen (2003). Finalmente, los picos 12 y 13 presentaron el espectro de absorción típico de $\alpha$-caroteno, pero no pudieron ser confirmados como isómeros cis debido a la ausencia de banda de absorción en la región UV (pico cis) y de variación hipsocrómica. 


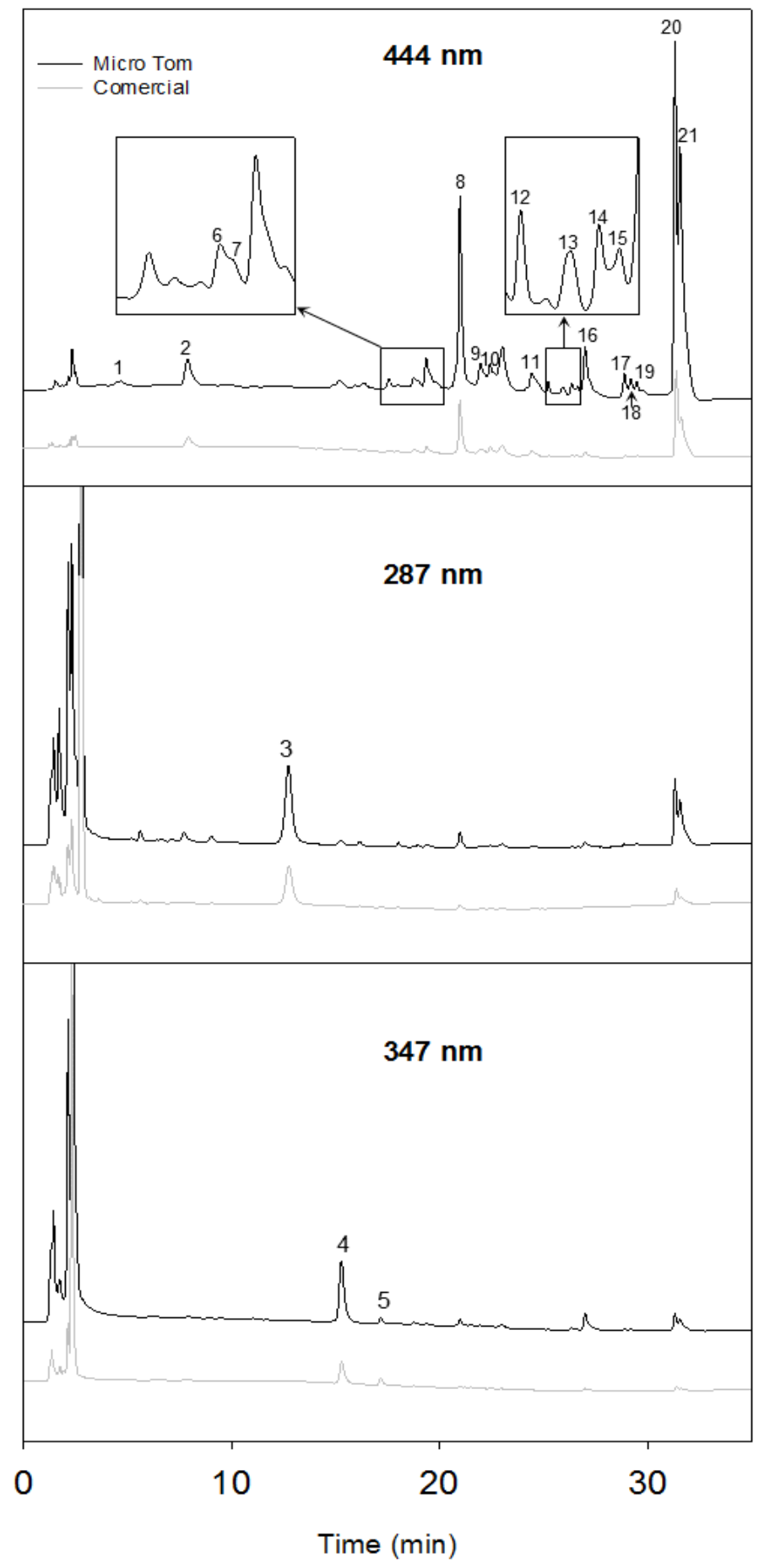

Figura 4.2. Cromatogramas correspondientes al análisis de carotenoides en muestras de tomate de las variedades Micro-Tom y Optima. La identificación de los picos y su caracterización están reflejados en la Tabla 4.3. 
Tabla 4.3. Carotenoides identificados en la variedad de tomate Micro-Tom, tiempo de retención (Tr) y características espectrales: longitud de onda $(\boldsymbol{\lambda})$, $Q$-ratio encontrado en nuestro ensayo (Q-ratio encontrado) y $Q$-ratio descrito en la bibliografía ( $Q$-ratio referencia).

\begin{tabular}{|c|c|c|c|c|c|c|c|c|}
\hline \multirow{2}{*}{$\begin{array}{c}\text { Pico } \\
1\end{array}$} & \multirow{2}{*}{$\begin{array}{l}\text { Compuestos } \\
\text { All trans-violaxantina }\end{array}$} & \multirow{2}{*}{$\begin{array}{c}\operatorname{Tr}(\min ) \\
4,68\end{array}$} & \multicolumn{4}{|c|}{$\lambda(\mathrm{nm})$} & \multirow[t]{2}{*}{$\begin{array}{c}\text { Q-ratio } \\
\text { encontrado }\end{array}$} & \multirow[t]{2}{*}{$\begin{array}{l}\text { Q-ratio } \\
\text { referencia }\end{array}$} \\
\hline & & & & 416 & 439 & 469 & & \\
\hline 2 & All trans-luteína & 7,89 & & 422 & 445 & 474 & & \\
\hline 3 & Fitoeno & 12,73 & & 276 & 286 & 297 & & \\
\hline 4 & Cis-fitoflueno & 15,27 & 258 & 331 & 348 & 367 & & \\
\hline 5 & Fitoflueno & 17,54 & & 331 & 348 & 367 & & \\
\hline 6 & 13 cis- $\beta$-caroteno & 18,75 & 338 & 421 & 443 & 470 & 0,39 & $0,35^{\mathrm{a}}$ \\
\hline 7 & All trans- $\zeta$-caroteno & 18,95 & & 380 & 400 & 424 & & \\
\hline 8 & All trans- $\beta$-caroteno & 20,97 & & 426 & 452 & 478 & & \\
\hline 9 & 9 cis- $\beta$-caroteno & 21,95 & 350 & 422 & 447 & 473 & 0,08 & $0,10^{b}$ \\
\hline 10 & Cis- $\delta$-caroteno & 22,41 & 350 & 431 & 456 & 489 & 0,11 & $0,13^{c}$ \\
\hline 11 & All trans- $\delta$-caroteneo & 24,40 & 346 & 431 & 456 & 489 & & \\
\hline 12 & Like- $\alpha$-caroteno & 25,21 & & 420 & 446 & 474 & & \\
\hline 13 & Like- $\alpha$-caroteno & 25,92 & & 420 & 446 & 474 & & \\
\hline 14 & Cis- $\gamma$-caroteno & 26,33 & 360 & 436 & 462 & 492 & 0,29 & $0,30^{c}$ \\
\hline 15 & All trans- $\gamma$-caroteno & 26,62 & & 436 & 462 & 492 & & \\
\hline 16 & 13 o $13^{\prime}$ cis-licopeno & 26,97 & 362 & 439 & 466 & 496 & 0,57 & $0,55^{d}$ \\
\hline 17 & 9 o 9' cis-licopeno & 28,87 & 362 & 440 & 466 & 496 & 0,13 & $0,12^{d}$ \\
\hline 18 & 9 o 9' cis-licopeno & 29,18 & 362 & 438 & 466 & 496 & 0,13 & $0,12^{d}$ \\
\hline 19 & 5 o 5' cis-licopeno & 29,44 & 362 & 446 & 472 & 504 & 0,06 & $0,06^{d}$ \\
\hline 20 & All trans-licopeno & 31,25 & 362 & 446 & 472 & 504 & & \\
\hline 21 & 5 o 5' cis-licopeno & 31,52 & 362 & 444 & 472 & 504 & 0,06 & $0,06^{d}$ \\
\hline
\end{tabular}




\subsubsection{Respuesta varietal al estrés nutricional y salino}

\subsubsection{Rendimiento y composición de los frutos}

La variedad de tomate Micro-Tom ha sido utilizada como planta modelo en diferentes estudios sobre el metabolismo de carbohidratos (Obiadalla-Ali y col., 2004), la regulación hormonal del cuajado y desarrollo del fruto (Meissner y col., 1997; Eyal y Levi, 2002), el efecto tóxico de metales (Gratao y col., 2008) y el comportamiento postcosecha bajo condiciones subóptimas (Gómez y col., 2009). Sin embargo, según Marti y col. (2006), las mutaciones que dan lugar al fenotipo enano, pueden causar efectos pleiotrópicos, por lo que su empleo como planta modelo puede verse limitado. Sin embargo, existe escasa información sobre el perfil de metabolitos y la respuesta comparativa de esta variedad enana a diferentes estreses bióticos respecto a la de variedades comerciales de tomate.

En nuestro ensayo, los frutos de la variedad Micro-Tom alcanzaron valores más bajos de $\mathrm{pH}$, mayor acidez total y mayor concentración de sólidos solubles totales (SST) que los frutos correspondientes a la variedad Optima (Tabla 4.4) y a otras variedades comerciales cuyos valores han sido descritos en la bibliografía (Busch y col., 2008).

Los principales metabolitos primarios determinados en ambas variedades, fueron, glucosa y fructosa (azúcares solubles) y los ácidos orgánicos, cítrico, glutámico, málico, y quínico (Tabla 4.5). Para todos estos compuestos, excepto el ácido glutámico, la variedad Micro-Tom presentó concentraciones entre 2 y 4 veces superiores a las determinadas en la variedad comercial. Por su parte, el ácido glutámico, alcanzó valores superiores en la variedad comercial (1,5 veces superior). Por otro lado, Micro-Tom mostró una mayor relación fructosa/glucosa $(1,62)$ que Optima $(1,14)$. 
Tabla 4.4. Producción total $\left(\mathrm{kg}_{\text {planta }}{ }^{-1}\right)$, sólidos solubles totales (SST; Brix), $\mathrm{pH}$ y acidez total ( $\mathrm{g}$ ácido cítrico $\mathrm{L}^{-1}$ ) de las variedades de tomate Micro-Tom (MT) y Optima, cultivadas bajo condiciones de salinidad y limitación de nutrientes $(\mathrm{N}, \mathrm{K}$ y $\mathrm{Ca})$.

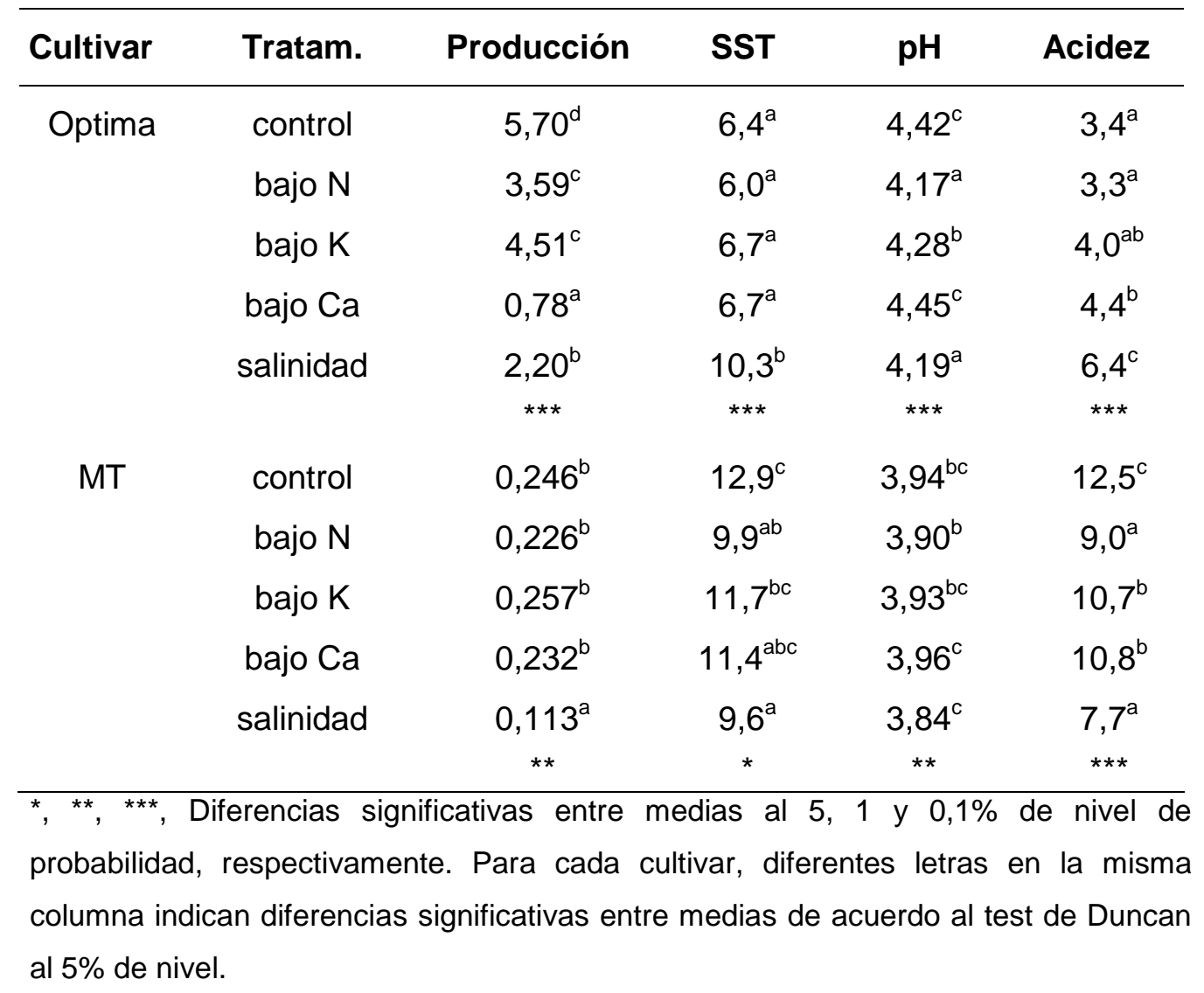

Respecto a la respuesta del rendimiento de tomate al estrés abiótico, la salinidad disminuyó la producción total de frutos en un porcentaje similar en ambas variedades (Tabla 4.4). Sin embargo, los diferentes estreses nutricionales (bajo $\mathrm{N}, \mathrm{K}$ y $\mathrm{Ca}$ ) solo afectaron a la producción en la variedad Optima. Por otro lado, el estrés salino aumentó significativamente la concentración SST en los frutos la variedad Optima y disminuyó el pH de los mismos, con respecto al control. Este tratamiento también aumentó significativamente la acidez de los frutos, al igual que el tratamiento bajo en $\mathrm{Ca}$ Por el contrario, en la variedad Micro-Tom, el estrés salino y el tratamiento bajo en $\mathrm{N}$, diminuyeron la concentración de SST con respecto al control. Además, la acidez en la variedad enana disminuyó significativamente en todos los tratamientos y el pH no se vio 
afectado. Los resultados encontrados en nuestro ensayo, sobre la variedad Optima, coinciden con el aumento del contenido de sólidos solubles totales y de la acidez observados por otros autores en variedades de tomate comercial, cultivadas bajo condiciones salinas (Petersen y col., 1998; Fernández-García y col., 2004).

Tabla 4.5. Concentración de glucosa (Gluc) y fructosa (Fruct) ( $\mathrm{mg} \mathrm{g}^{-1} \mathrm{PF}$ ), ácidos cítrico, glutámico, málico y quínico ( $\mathrm{mg} \mathrm{g}^{-1} \mathrm{PF}$ ) y vitamina $\mathrm{C}($ Vit $\mathrm{C})\left(\mu \mathrm{g} \mathrm{g}^{-1} \mathrm{PF}\right)$, en frutos de tomate Optima y Micro-Tom (MT), cultivados bajo condiciones de salinidad y limitación de nutrientes $(\mathrm{N}, \mathrm{K}$ y $\mathrm{Ca})$.

\begin{tabular}{|c|c|c|c|c|c|c|c|c|}
\hline Cultivar & Tratam. & Gluc & Fruct & Cítrico & Glutámico & Málico & Quínico & Vit C \\
\hline \multirow[t]{6}{*}{ Optima } & control & $12,6^{a}$ & $14,2^{\mathrm{a}}$ & $7,9^{\mathrm{a}}$ & $2,19^{\mathrm{ab}}$ & $0,70^{\mathrm{a}}$ & $0,10^{\mathrm{a}}$ & $288,7^{a}$ \\
\hline & bajo $\mathrm{N}$ & $18,8^{b}$ & $21,3^{b}$ & $9,7^{b}$ & $1,88^{a}$ & $0,88^{\mathrm{b}}$ & $0,14^{b}$ & $340,9^{b}$ \\
\hline & bajo $\mathrm{K}$ & $17,2^{\mathrm{b}}$ & $20,2^{b}$ & $9,7^{b}$ & $2,36^{b}$ & $0,84^{\mathrm{b}}$ & $0,13^{b}$ & $340,8^{b}$ \\
\hline & bajo $\mathrm{Ca}$ & $18,2^{b}$ & $20,6^{b}$ & $12,2^{c}$ & $3,58^{d}$ & $0,82^{b}$ & $0,14^{b}$ & $293,4^{a}$ \\
\hline & salinidad & $31,2^{c}$ & $34,9^{c}$ & $13,4^{d}$ & $3,08^{c}$ & $1,10^{c}$ & $0,19^{c}$ & $430,1^{c}$ \\
\hline & & $* \star *$ & $\star \star * *$ & $\star * \star$ & $* \star *$ & $* * *$ & $* \star \star$ & $\star \star \star \star$ \\
\hline \multirow[t]{6}{*}{ MT } & control & $26,3^{a}$ & $43,6^{a}$ & $21,4^{\mathrm{a}}$ & $1,44^{b}$ & $1,22^{\mathrm{bc}}$ & 0,45 & 480,6 \\
\hline & bajo $\mathrm{N}$ & $29,8^{\mathrm{ab}}$ & $48,8^{\mathrm{ab}}$ & $20,1^{a}$ & $1,08^{\mathrm{ab}}$ & $1,11^{\mathrm{ab}}$ & 0,44 & 510,2 \\
\hline & bajo $\mathrm{K}$ & $27,6^{a}$ & $44,0^{a}$ & $21,4^{a}$ & $1,47^{b}$ & $1,28^{\mathrm{c}}$ & 0,42 & 496,3 \\
\hline & bajo Ca & $27,4^{\mathrm{a}}$ & $44,5^{a}$ & $24,9^{b}$ & $2,10^{c}$ & $1,34^{\mathrm{C}}$ & 0,47 & 515,6 \\
\hline & salinidad & $33,8^{b}$ & $52,5^{b}$ & $21,1^{a}$ & $0,91^{a}$ & $1,05^{\mathrm{a}}$ & 0,53 & 496,3 \\
\hline & & * & * & * & $* * *$ & $* *$ & n.s. & n.s. \\
\hline $\begin{array}{l}{ }^{*},{ }^{* *},{ }^{* *} \\
\text { respectiv } \\
\text { misma cc } \\
\text { de nivel. }\end{array}$ & nte; n.s. & . & 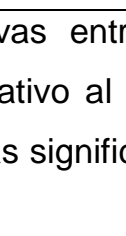 & - & 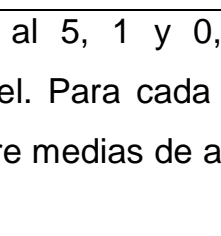 & $\%$ de & $\begin{array}{l}\text { de } \mathrm{p} \\
\text { rentes }\end{array}$ & $\begin{array}{l}\text { abilidad, } \\
\text { as en la }\end{array}$ \\
\hline
\end{tabular}

En la variedad comercial, los diferentes estreses nutricionales $(\mathrm{N}, \mathrm{K}$ y Ca) y, en mayor medida, el estrés salino, produjeron un aumento de la concentración de azúcares y ácidos orgánicos, excepto de ácido glutámico en el tratamiento bajo en N (Tabla 4.5). Sin embargo, en la variedad Micro-Tom, la concentración de azúcares solo se vio significativamente afectada por el estrés salino, y en este 
caso, en menor medida que la variedad comercial; mientras que en Micro-Tom la salinidad aumentó un $29 \%$ y $28 \%$ la concentración de glucosa y la fructosa, en Optima provocó un aumento del $148 \%$ y el $146 \%$ de ambos azúcares, respectivamente. Respecto a la concentración de ácidos orgánicos, en MicroTom, la salinidad produjo una disminución de las concentraciones de los ácidos glutámico y málico pero no tuvo ningún efecto sobre los ácidos quínico y cítrico. Por último, el tratamiento bajo en Ca aumentó la concentración de ácido glutámico y ácido cítrico en la variedad enana. La acumulación de azúcares solubles en frutos de tomate como consecuencia del estrés salino se debe a la activación de enzimas metabólicos relacionados con la biosíntesis de carbohidratos (Saito y col., 2009). Además del aumento en la concentración de azúcares solubles, en un estudio previo realizado sobre plantas de tomate Micro-Tom se observó, una acumulación de otros metabolitos, entre ellos ácidos orgánicos, como respuesta al estrés salino (Yin y col., 2010).

\subsubsection{Contenido del fruto en compuestos bioactivos}

De acuerdo con los resultados obtenidos de azúcares y ácidos orgánicos, la concentración total de vitamina $\mathrm{C}$, medida como la suma de los ácidos ascórbico y deshidroascórbico, también fue superior (1,5 veces) en Micro-Tom que en Optima (Tabla 4.5). Además, mientras que en la variedad comercial la concentración de vitamina $\mathrm{C}$ se incrementó a causa de la salinidad y mediante la reducción de $\mathrm{N}$ y $\mathrm{K}$ en la solución nutritiva, en Micro-Tom no se observó efecto significativo de ninguno de los estreses aplicados. Los resultados obtenidos en la variedad Optima concuerdan con los descritos anteriormente por otros autores en estudios realizados sobre tomate, en los que el nivel de ácido ascórbico aumentó al reducir el aporte de N o al aplicar salinidad (Bènard y col., 2009; Sgherri y col., 2007). El aumento del contenido de ácido ascórbico como resultado de la reducción del suministro de $\mathrm{N}$ ha sido correlacionado con una modificación del microclima del fruto como consecuencia de un aumento de la irradiancia (Bènard y col., 2009). Por otro lado, el aumento del ácido ascórbico observado en las plantas sometidas a estrés salino, puede ser atribuido a un mecanismo de 
adaptación de la planta a dicho estrés, el cual promueve de nuevo la síntesis de este metabolito o su regeneración a partir de ácido dihidrolipoico (Sgherri y col., 2007). El efecto del $\mathrm{K}$ sobre la concentración de vitamina $\mathrm{C}$ ha sido menos estudiado, encontrándose resultados contradictorios en la bibliografía; mientras que en pimiento algunos autores sugieren que variaciones de la dosis de $\mathrm{K}$ dentro de un amplio rango, no afectan a la concentración de ascórbico en fruto (Flores y col., 2004; Asri y Sonmez, 2010), en tomate, Javaria y col. (2012) describieron un aumento progresivo de la concentración de vitamina $C$ en fruto, al aumentar la dosis de $\mathrm{K}$ hasta $450 \mathrm{~kg} \mathrm{ha}^{-1} \mathrm{~K}_{2} \mathrm{O}$, a partir de la cual se observó una disminución. El aumento de vitamina $\mathrm{C}$ descrito como consecuencia del aumento del aporte de $\mathrm{K}$, es debido al papel que este elemento juega en el metabolismo de los carbohidratos y su relación con la formación de ácido ascórbico (Majumdar y col., 2000; Ananthi y col., 2004).

Los principales compuestos fenólicos identificados en ambas variedades fueron los ácidos clorogénico, cafeico, dicafeoilquínico, ferúlico-O-hexósido y cafeico-O-hexósido, además de kaemperol-3-O-rutinósido, rutina, naringenina- $O$ hexósido y naringenina. Las concentraciones de estos compuestos fueron aproximadamente entre 2 y 10 veces superiores en Micro-Tom que en la variedad comercial y aproximadamente entre 40 y 50 veces mayor en el caso de kaempferol-3-O-rutinósido (Tabla 4.6).

En general, el efecto de los estreses nutricionales y el estrés salino sobre la concentración de los compuestos fenólicos, fue mayor en la variedad Optima, que en Micro-Tom. En la variedad comercial, el $\mathrm{N}$ fue el nutriente mineral que afectó en mayor medida al contenido en estos metabolitos, aumentando la concentración de clorogénico, dicafeoilquínico, kaempferol-3-O-rutinósido, rutina y naringeninaO-hexósido y disminuyendo la de los ácidos cafeico y cafeico-O-hexósido. Por otra parte, la salinidad aumentó los valores de clorogénico, dicafeoilquínico, ácido ferúlico-O-hexósido, kaempferol-3-O-rutinósido, rutina y naringenina y disminuyó las concentraciones de cafeico y naringenina-O-hexósido. Aunque el efecto de la salinidad sobre la concentración fenólica de los frutos parece estar altamente condicionado por el genotipo y la estacionalidad, se ha demostrado que la concentración de estos compuestos varia como respuesta de defensa de la planta 
a las condiciones de estrés (Sgherri y col., 2007; Krauss y col., 2006). Según Sgherri y col. (2008), el aumento de ácido clorogénico en frutos que provienen de plantas regadas con agua salina, afecta significativamente a la actividad antioxidante de la fracción hidrosoluble del fruto debido a su naturaleza polihidroxilada. Al contrario de lo observado en Optima, los estreses nutricionales no afectaron a las concentraciones de compuestos fenólicos en Micro-Tom, excepto a la concentración de ácido cafeico-O-hexósido, que aumentó como consecuencia de un bajo suministro de $\mathrm{Ca}$. Por otra parte, la salinidad sólo afectó a la concentración de ácido clorogénico, la cual disminuyó en Micro-Tom, a diferencia de lo observado en la variedad comercial. 
Tabla 4.6. Concentraciones de los principales compuestos fenólicos, ácidos clorogénico, cafeico, dicafeoilquínico, ferúlico-O-hexosido (F-O-h) y cafeico-O-hexósido (C-O-h), kaemferol-3-O-rutinosido (K-O-r), rutina (R), naringenina-O-hexósido ( $\mathrm{N}-\mathrm{O}$-h) y naringenina ( $\mathrm{N}$ ), expresados como $\mathrm{\mu g} \mathrm{g}^{-1} \mathrm{PF}$, en frutos de tomate de las variedades Optima y Micro-Tom (MT), cultivadas bajo condiciones salinas y limitación de nutrientes $(\mathrm{N}, \mathrm{K}, \mathrm{Ca})$.

\begin{tabular}{|c|c|c|c|c|c|c|c|c|c|c|}
\hline Cultivar & Tratamiento & Clorogénico & Cafeico & Dicafeico & F-O-h & C-O-h & $\mathrm{K}-\mathrm{O}-\mathrm{r}$ & $\mathbf{R}$ & N-O-h & $\mathbf{N}$ \\
\hline \multirow[t]{6}{*}{ Optima } & control & $5,6^{a}$ & $0,79^{b}$ & $0,27^{\mathrm{a}}$ & $2,5^{b}$ & $2,5^{b}$ & $2,5^{\mathrm{a}}$ & $3,3^{a}$ & $2,2^{b}$ & $6,0^{b}$ \\
\hline & bajo $N$ & $9,9^{b}$ & $0,50^{\mathrm{a}}$ & $0,41^{b}$ & $2,4^{b}$ & $1,6^{\mathrm{a}}$ & $4,2^{b}$ & $6,3^{b}$ & $3,8^{c}$ & $7,4^{b c}$ \\
\hline & bajo $\mathrm{K}$ & $6,5^{\mathrm{a}}$ & $0,49^{a}$ & $0,22^{a}$ & $2,2^{a b}$ & $1,6^{\mathrm{a}}$ & $1,6^{\mathrm{a}}$ & $2,7^{\mathrm{a}}$ & $1,1^{\mathrm{a}}$ & $3,6^{a}$ \\
\hline & bajo $\mathrm{Ca}$ & $5,2^{\mathrm{a}}$ & $0,52^{\mathrm{a}}$ & $0,20^{a}$ & $1,6^{\mathrm{a}}$ & $1,6^{\mathrm{a}}$ & $3,0^{\mathrm{ab}}$ & $3,6^{a}$ & $2,3^{b}$ & $7,5^{b c}$ \\
\hline & salinidad & $9,4^{b}$ & $0,52^{\mathrm{a}}$ & $0,57^{c}$ & $5,7^{\mathrm{c}}$ & $3,0^{b}$ & $7,2^{\mathrm{c}}$ & $10,5^{c}$ & $0,2^{\mathrm{a}}$ & $9,3^{c}$ \\
\hline & & $* * *$ & * & $* * *$ & $* * *$ & $* * *$ & $* * *$ & $* * *$ & $* * *$ & $* *$ \\
\hline \multirow[t]{6}{*}{ MT } & control & $28,9^{b}$ & 0,45 & $3,5^{\mathrm{ab}}$ & 11,7 & $3,8^{a}$ & 132 & 39,5 & 17,1 & 16,5 \\
\hline & bajo $N$ & $28,0^{b}$ & 0,65 & $4,1^{b}$ & 11,3 & $4,0^{a}$ & 123 & 40,9 & 14,0 & 15,3 \\
\hline & bajo $\mathrm{K}$ & $26,8^{b}$ & 0,50 & $3,1^{\mathrm{a}}$ & 12,1 & $4,3^{\mathrm{ab}}$ & 158 & 41,7 & 18,4 & 15,7 \\
\hline & bajo $\mathrm{Ca}$ & $25,8^{\mathrm{b}}$ & 0,82 & $3,1^{\mathrm{a}}$ & 12,3 & $4,8^{b}$ & 133 & 35,6 & 11,6 & 14,4 \\
\hline & salinidad & $18,7^{\mathrm{a}}$ & 0,20 & $2,9^{\mathrm{a}}$ & 11,2 & $4,1^{\mathrm{a}}$ & 127 & 36,3 & $7,6^{\mathrm{a}}$ & 13,0 \\
\hline & & $* *$ & n.s. & * & n.s. & $* *$ & n.s. & n.s. & * & n.s. \\
\hline
\end{tabular}

${ }^{*},{ }^{* *},{ }^{* \star}$, Diferencias significativas entre medias al 5,1 y $0,1 \%$ de nivel de probabilidad, respectivamente; n.s., no significativo al $5 \%$ de nivel. Para cada cultivar, diferentes letras en la misma columna indican diferencias significativas entre medias de acuerdo al test de Duncan al $5 \%$ de nivel. 
Los principales carotenoides identificados en ambas variedades (fitoeno, fitoflueno, all trans-luteína, all trans- $\beta$-caroteno y all trans-licopeno) se encontraron en concentraciones aproximadamente dos veces superiores en la variedad MicroTom respecto a la variedad Optima, a excepción de luteína, que mostró valores similares en ambos cultivares bajo condiciones control (Tabla 4.7).

Tabla 4.7. Concentraciones de fitoeno, fitoflueno, all trans-luteína (luteína), all trans- $\beta$-caroteno ( $\beta$-carot) y all trans-licopeno (Licop), expresado como $\mu \mathrm{g} \mathrm{g} \mathrm{g}^{-1} \mathrm{PF}$, en frutos de tomate de las variedades Optima y Micro-Tom (MT) cultivados bajo condiciones de salinidad y limitación de nutrientes $(\mathrm{N}, \mathrm{K}$ y Ca).

\begin{tabular}{llccccc}
\hline Cultivar & Tratam. & Fitoeno & Fitoflueno & Luteina & $\beta$-carot & Licop \\
\hline \multirow{2}{*}{ Optima } & control & $15,1^{\mathrm{a}}$ & $6,3^{\mathrm{a}}$ & $0,57^{\mathrm{ab}}$ & $11,5^{\mathrm{a}}$ & $53,1^{\mathrm{ab}}$ \\
& bajo N & $15,2^{\mathrm{a}}$ & $6,3^{\mathrm{a}}$ & $0,44^{\mathrm{a}}$ & $10,2^{\mathrm{a}}$ & $38,7^{\mathrm{a}}$ \\
& bajo K & $17,0^{\mathrm{ab}}$ & $7,0^{\mathrm{a}}$ & $0,52^{\mathrm{ab}}$ & $10,4^{\mathrm{a}}$ & $53,1^{\mathrm{ab}}$ \\
& bajo Ca & $20,4^{\mathrm{b}}$ & $8,8^{\mathrm{bc}}$ & $0,75^{\mathrm{b}}$ & $11,8^{\mathrm{a}}$ & $69,1^{\mathrm{bc}}$ \\
& salinidad & $17,5^{\mathrm{ab}}$ & $9,8^{\mathrm{c}}$ & $0,68^{\mathrm{ab}}$ & $15,8^{\mathrm{b}}$ & $83,8^{\mathrm{c}}$ \\
& & $*$ & $* *$ & $*$ & $* *$ & $* *$ \\
& MT & 24,0 & 13,8 & $0,55^{\mathrm{ab}}$ & $24,2^{\mathrm{a}}$ & $110,8^{\mathrm{ab}}$ \\
& control & 26,1 & 14,8 & $0,95^{\mathrm{c}}$ & $32,1^{\mathrm{ab}}$ & $130,6^{\mathrm{ab}}$ \\
& bajo N & 25,9 & 14,8 & $0,45^{\mathrm{a}}$ & $23,7^{\mathrm{a}}$ & $99,8^{\mathrm{a}}$ \\
& bajo K & 28,8 & 16,5 & $0,81^{\mathrm{bc}}$ & $25,6^{\mathrm{ab}}$ & $108,3^{\mathrm{a}}$ \\
& bajo Ca & 28,5 & 16,3 & $0,95^{\mathrm{c}}$ & $35,4^{\mathrm{b}}$ & $167,4^{\mathrm{c}}$ \\
& salinidad & 28,5 & $* *$ & $*$ & $*$
\end{tabular}

${ }^{*},{ }^{* *},{ }^{* * *}$, Diferencias significativas entre medias al 5,1 y $0,1 \%$ de nivel de probabilidad, respectivamente; n.s., no significativo al $5 \%$ de nivel. Para cada cultivar, diferentes letras en la misma columna indican diferencias significativas entre medias de acuerdo al test de Duncan al $5 \%$ de nivel.

El tratamiento salino aumentó la concentración de la mayoría de carotenoides en ambos cultivares, excepto fitoeno y fitoflueno en Micro-Tom y luteína en Optima. Otros autores han descrito una mejora de la calidad 
organoléptica y nutricional de tomate como consecuencia de un incremento moderado de la salinidad, aumentando no solo el contenido de metabolitos primarios (azúcares y ácidos orgánicos) en el fruto, sino también el de licopeno (Goykovic y col., 2007). Respecto a la respuesta al estrés nutricional, la disminución de $\mathrm{K}$ no afectó a la concentración de ninguno de los carotenoides en Optima y Micro-Tom, el tratamiento bajo en Ca aumentó los valores de fitoeno y fitoflueno en Optima y el tratamiento bajo en $\mathrm{N}$ aumentó la concentración de luteína respecto al control en la variedad Micro-Tom.

\subsection{CONCLUSIONES}

Las variedades enana (Micro-Tom) y comercial (Optima) presentaron perfiles de metabolitos similares, diferenciándose principalmente en la concentración de los compuestos individuales. Estos resultados indican que las mutaciones de Micro-Tom causantes del fenotipo enano no alteran significativamente la biosíntesis de los metabolitos primarios y secundarios relacionados con la calidad nutricional y funcional de tomate. Sin embargo, el uso de Micro-Tom como planta modelo para el estudio del efecto de la salinidad sobre la composición de tomate, podría estar limitado por la menor respuesta de la variedad enana respecto a variedades comerciales (Optima y otras variedades estudiadas previamente en la literatura) a la salinidad, lo que se tradujo en una menor acumulación de metabolitos primarios (azúcares y ácidos orgánicos) bajo condiciones salinas. Además en Micro-Tom, al contrario que en la variedad comercial, no se observó la acumulación de metabolitos secundarios relacionados con la respuesta de la planta al estrés oxidativo causado por la salinidad, tales como compuestos fenólicos y vitamina C. Sin embargo en ambas variedades, el estrés salino provocó un aumento de las concentraciones de los principales carotenoides. Por último, Micro-Tom mostró una mayor tolerancia a la limitación de nutrientes que la variedad Optima. Así, al contrario de lo observado en la variedad comercial, el rendimiento del cultivo y la concentración de la mayoría de metabolitos primarios y secundarios en fruto de Micro-Tom no se vieron afectados por la limitación nutricional N, K o Ca. 
Respuesta de Micro-Tom al estrés salino y nutricional 


\section{Capítulo 5}

\section{VARIACIÓN DEL CONTENIDO DE COMPUESTOS BIOACTIVOS EN TOMATE COMO RESPUESTA AL AUMENTO DE LA TEMPERATURA}

El aumento de la temperatura ambiental es la causante de grandes pérdidas en el rendimiento y la calidad de frutas y hortalizas. En particular, en tomate se ha descrito que el estrés térmico provoca el aborto de flores y limita el cuajado del fruto (Bita y col., 2011). Respecto a la calidad nutricional, Gautier y col., 2008 mostraron que el aumento de temperatura afecta a la concentración de metabolitos secundarios del fruto (carotenoides, compuestos fenólicos, vitaminas, etc.) en mayor medida que a la de metabolitos primarios (azúcares y ácidos orgánicos). Según estos autores, un aumento de la temperatura hasta $32{ }^{\circ} \mathrm{C}$ provoca, en tomate, un aumento de la concentración de compuestos fenólicos, aunque disminuye las concentraciones de ascorbato y de carotenoides. Además, dependiendo de cual sea el metabolito estudiado, la respuesta ante el estrés también depende del estado de desarrollo del fruto, así como de la duración de la exposición al mismo. Sin embargo, la información acerca de la influencia del estado de desarrollo sobre dicha respuesta es muy limitada. Esta información es necesaria para poder evaluar el impacto del estrés térmico sobre el rendimiento y la calidad nutricional de tomate en zonas cálidas, como la Región de Murcia, especialmente bajo condiciones de invernadero, así como en otras zonas, en las que se prevé un aumento de temperatura como resultado del calentamiento global (IPCC, 2001). En este ensayo se estudia el efecto del aumento de la temperatura diurna sobre la calidad de tomate, dependiendo del estado de desarrollo del fruto en el momento en el que se impone el estrés. 


\subsection{MATERIALES Y MÉTODOS}

\subsubsection{Material vegetal y manejo del cultivo}

Se cultivaron plantas de tomate (Solanum lycopersicum L. CV. Velasco) en cámaras de crecimiento, utilizando macetas de $15 \mathrm{~L}$ rellenas de fibra de coco y perlita (85:15) (Figura 5.1). Las plantas se regaron con disolución nutritiva Hoagland conteniendo $14 \mathrm{~N}, 6 \mathrm{~K}, 4 \mathrm{Ca}, 2 \mathrm{P}, 1 \mathrm{~S}$, y $1 \mathrm{Mg}(\mathrm{mM})$ y $50 \mathrm{Cl}, 25 \mathrm{~B}, 2$ $\mathrm{Mn}, 2 \mathrm{Zn}, 0,5 \mathrm{Cu}, 0,5 \mathrm{Mo}$, y $20 \mathrm{Fe}(\mu \mathrm{M})$. Durante el ensayo, las plantas se podaron quitando los brotes laterales y la polinización se propició de forma manual.

\subsubsection{Diseño experimental}

Se estableció un fotoperiodo de 16/8 h día/noche, con una intensidad de luz durante el día por encima de $550 \mu \mathrm{mol} \mathrm{m} \mathrm{m}^{-2} \mathrm{~s}^{-1}$ y una humedad relativa del $70 \%$. Inicialmente se establecieron las condiciones de temperatura consideradas óptimas para el cultivo de tomate $\left(24 / 12,5{ }^{\circ} \mathrm{C}\right.$, día/noche), hasta que se pudieron diferenciar seis estadios diferentes de desarrollo del fruto dentro de una misma planta (53 días después del transplante). En este momento, la temperatura ambiental se incrementó hasta $32 / 19 \stackrel{\circ}{ } \mathrm{C}$ (día/noche) (Figura 5.2). Además, un grupo de plantas se mantuvo bajo las condiciones de temperatura iniciales hasta el final del ensayo (tratamiento control).

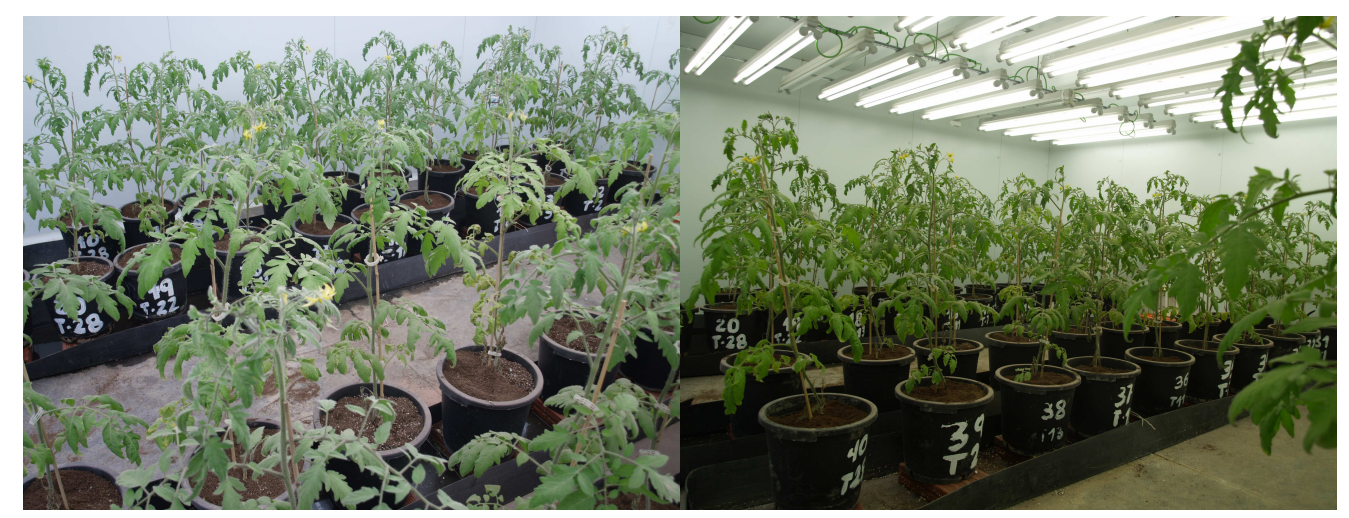

Figura 5.1. Plantas de tomate cultivadas en cámara de crecimiento bajo condiciones controladas de luz y temperatura. 
En la Tabla 5.1 se muestran los criterios establecidos para la clasificación de los estadios, así como los días que dichos frutos se mantuvieron bajo condiciones de alta temperatura (DAT) antes de ser recolectados.

Tabla 5.1. Criterios elegidos para establecer los diferentes estadios de desarrollo del fruto y días a los que dichos frutos estuvieron expuestos a alta temperatura (DAT).

\begin{tabular}{ccc}
\hline Estadios de desarrollo & Descripción & DAT* $^{*}$ \\
\hline estadio 1 & floración & 44 \\
estadio 2 & $\varnothing \leq 30 \mathrm{~mm}$ & 36 \\
estadio 3 & $\varnothing \leq 40 \mathrm{~mm}$ & 27 \\
estadio 4 & $\varnothing \leq 50 \mathrm{~mm}$ & 22 \\
estadio 5 & $\varnothing \leq 60 \mathrm{~mm}$ & 16 \\
estadio 6 & Frutos verdes totalmente desarrollados & 6
\end{tabular}

${ }^{*}$ DAT son medias de los valores de cada tratamiento, con un máximo de variabilidad de \pm 3 días.

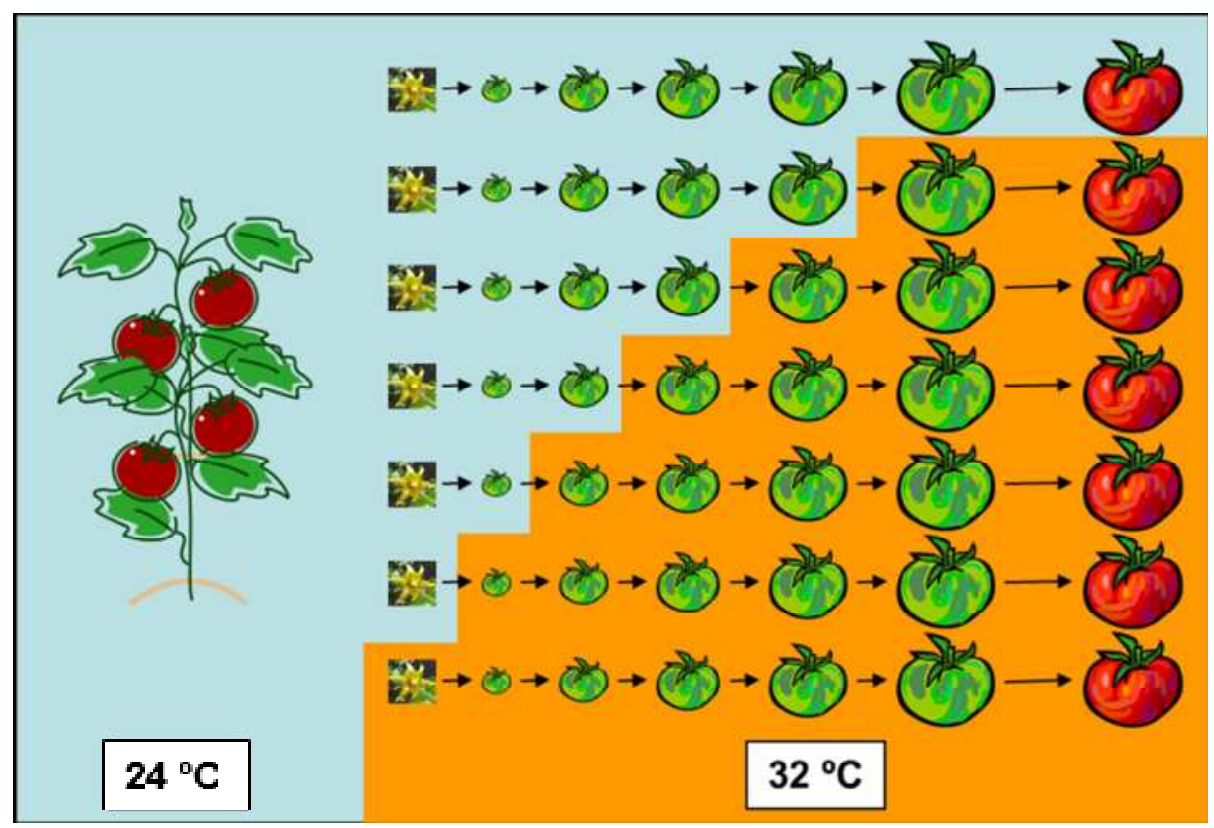

Figura 5.2. Representación gráfica de los diferentes estadios de desarrollo del fruto en los que se impuso el aumento de temperatura. 
Se seleccionaron diez plantas por tratamiento, considerando como tales los estadios a partir de los cuales se impuso el estrés térmico. No se utilizaron las mismas plantas para muestrear frutos pertenecientes a diferentes tratamientos. Las flores correspondientes al estadio 1 se seleccionaron de entre las disponibles en el racimo 6 y los frutos correspondientes a los tratamientos de estadios 2-6 se seleccionaron de los racimos 3-5. En las plantas bajo tratamiento control (24/12,5 ${ }^{\circ} \mathrm{C}$, día/noche durante todo el cultivo), los frutos fueron seleccionados de los racimos 3-6. En todos los tratamientos, los frutos se recolectaron en estado de maduración rojo, lo que correspondió a 0, 6, 16, 22, 27, 36 y 44 DAT para el tratamiento control y los estadios $6,5,4,3,2$ y 1 , respectivamente. Para evitar la sobre-maduración de los frutos, estos se revisaron diariamente y se recolectaron inmediatamente una vez que habían alcanzado un color rojo homogéneo. Se muestrearon seis repeticiones por tratamiento, cada una de ellas constituida por diez frutos procedentes de diez plantas diferentes. El análisis de los parámetros físicos (peso medio, diámetro ecuatorial y longitudinal y los parámetros de color $L^{*}, a^{*}, b^{*}$ ) se realizó en todos los frutos. Posteriormente, los frutos pertenecientes a una misma repetición se juntaron y la mitad de cada muestra se licuó y se centrifugó para la determinación del contenido en sólidos solubles totales (SST). La otra mitad se homogeneizó con $\mathrm{N}_{2}$ líquido y se conservó a $-80{ }^{\circ} \mathrm{C}$ hasta su análisis. Los metabolitos analizados fueron carotenoides y vitamina $\mathrm{C}$, según los procedimientos descritos en los apartados 3.3.3. y 3.3.4.

\subsubsection{Análisis estadístico}

El análisis estadístico de los resultados se realizó mediante el análisis de la varianza (ANOVA), usando IBM SPSS Statistic 21. Los valores se compararon con el test de diferencia entre medias de Tukey. 


\subsection{RESULTADOS Y DISCUSIÓN}

\subsubsection{Rendimiento y parámetros físicos de los frutos}

Como resultado del aumento de la temperatura, se observó una disminución del peso medio y de los diámetros ecuatorial y longitudinal de los frutos respecto a los cultivados a temperatura óptima (Tabla 5.2). Estas pérdidas de peso y tamaño fueron proporcionales al período de exposición al estrés por alta temperatura (a mayor duración de la exposición a alta temperatura, mayor pérdida de peso y calibre), excepto en el caso de las frutos expuestos a $32{ }^{\circ} \mathrm{C}$ desde floración (estadio 1), los cuales mostraron pesos y tamaños similares a los de los frutos control. Los resultados obtenidos en este primer estadio, pudieron ser debidos a una mayor incidencia de aborto de flores, como mecanismo control de la planta por retroalimentación para evitar una excesiva relación sumidero/fuente (de Koning, 1996), y el consiguiente aumento del peso de los frutos restantes en dicho racimo. Así, en los racimos expuestos a alta temperatura desde floración, el número de fruto fue menor (2-3) que en los mismos racimos correspondientes a plantas control (5-6 frutos). Según Hedhly y col. (2009), la etapa reproductiva de tomate es más sensible al estrés por alta temperatura que la de crecimiento vegetativo. Además, dentro de las diferentes etapas de desarrollo del fruto, ciertos estadios son más sensibles. Así, el estrés térmico por alta temperatura aumenta la tendencia a abortar en las flores más jóvenes, debido a un encogimiento del grano de polen, a fallos en la dehiscencia de la antera y a una disposición irregular del endotecio y la epidermis (Sato y col., 2002).Todo ello explicaría la mayor incidencia de aborto de flores observada en el racimo 6 , correspondiente a frutos bajo alta temperatura desde el estadio 1 , y el consiguiente aumento del peso de los frutos restantes. Además, también explicaría el aumento del contenido de sólidos solubles totales en los frutos restantes (Tabla 5.2), como resultado de una concentración de solutos, debido a una disminución de la relación sumidero/fuente. No se observó efecto del tratamiento en el contenido de agua de los frutos. 
El valor de $\mathrm{a}^{*}$, directamente correlacionado con el color rojo del fruto, disminuyó, como resultado del aumento de temperatura en frutos expuestos al estrés desde el estadio 6 (frutos verdes totalmente desarrollados, 6 DAT). De acuerdo con estos resultados, en un estudio anterior realizado por Gautier y col. (2008) sobre frutos recolectados en verde y madurados posteriormente a diferentes temperaturas, se observó una pérdida de color rojo como consecuencia del aumento de la temperatura de 24 a $32^{\circ} \mathrm{C}$, como c onsecuencia de la inhibición de la síntesis de licopeno. En nuestro estudio, el efecto negativo de la alta temperatura sobre el color, disminuyó al aumentar el tiempo de exposición al estrés térmico, e incluso, los frutos desarrollados bajo condiciones de alta temperatura durante periodos más largos (36 y 44 días), llegaron a aumentar el valor de a * por encima del obtenido en los frutos del tratamiento control.

Tabla 5.2. Peso medio, diámetro ecuatorial ( $\varnothing$ ecuat.), diámetro longitudinal ( $\varnothing$ long.) parámetros de color Hunter $\left(L^{*}, a^{*}\right.$ y $\left.b^{*}\right)$, sólidos solubles totales (SST) y contenido en agua de frutos de tomate bajo diferentes periodos de exposición a alta temperatura $\left(32^{\circ} \mathrm{C}\right)$.

\begin{tabular}{lccccccc}
\hline & \multicolumn{6}{c}{ Días de exposición a altas temperatura (DAT) } \\
\cline { 2 - 7 } & $\mathbf{0}$ & $\mathbf{6}$ & $\mathbf{1 6}$ & $\mathbf{2 2}$ & $\mathbf{2 7}$ & $\mathbf{3 6}$ & $\mathbf{4 4}$ \\
\hline Peso (g) & $83,5^{\mathrm{cd}}$ & $85,7^{\mathrm{d}}$ & $78,1^{\mathrm{abcd}}$ & $67,2^{\mathrm{abc}}$ & $60,9^{\mathrm{a}}$ & $63,5^{\mathrm{ab}}$ & $79,5^{\mathrm{bcd}}$ \\
Ø ecuat. (mm) & $60,1^{\mathrm{bc}}$ & $60,7^{\mathrm{bc}}$ & $57,1^{\mathrm{bc}}$ & $55,4^{\mathrm{ab}}$ & $50,5^{\mathrm{a}}$ & $55,5^{\mathrm{a}}$ & $60,0^{\mathrm{c}}$ \\
Ø long. (mm) & $42,0^{\mathrm{b}}$ & $42,1^{\mathrm{b}}$ & $41,7^{\mathrm{b}}$ & $39,1^{\mathrm{ab}}$ & $37,5^{\mathrm{a}}$ & $37,7^{\mathrm{ab}}$ & $43,8^{\mathrm{b}}$ \\
L $^{*}$ & $35,5^{\mathrm{a}}$ & $36,5^{\mathrm{a}}$ & $35,3^{\mathrm{a}}$ & $36,2^{\mathrm{a}}$ & $36,1^{\mathrm{a}}$ & $36,5^{\mathrm{a}}$ & $38,2^{\mathrm{b}}$ \\
$\mathrm{a}^{*}$ & $15,1^{\mathrm{ab}}$ & $13,0^{\mathrm{a}}$ & $13,6^{\mathrm{a}}$ & $15,8^{\mathrm{b}}$ & $16,4^{\mathrm{b}}$ & $18,6^{\mathrm{c}}$ & $26,3^{\mathrm{d}}$ \\
b $^{*}$ & $13,3^{\mathrm{a}}$ & $14,5^{\mathrm{ab}}$ & $13,5^{\mathrm{a}}$ & $14,6^{\mathrm{ab}}$ & $14,2^{\mathrm{ab}}$ & $15,0^{\mathrm{b}}$ & $17,1^{\mathrm{c}}$ \\
SST (o Brix) & $4,2^{\mathrm{ab}}$ & $4,0^{\mathrm{a}}$ & $4,1^{\mathrm{ab}}$ & $4,0^{\mathrm{ab}}$ & $4,2^{\mathrm{ab}}$ & $4,6^{\mathrm{bc}}$ & $4,8^{\mathrm{c}}$ \\
Agua (\%) & 94,1 & 94,6 & 94,87 & 94,9 & 95,5 & 93,5 & 94,0 \\
\hline
\end{tabular}

Diferentes letras en la misma columna indican diferencias entre medias de acuerdo con el test de Tukey. 


\subsubsection{Contenido en compuestos bioactivos}

Los compuestos sobre los que se estudió el efecto del aumento de la temperatura ambiental fueron carotenoides y vitamina $\mathrm{C}$. En el tratamiento control, el análisis de estos compuestos se realizó sobre frutos de los racimos 3, 4, 5 y 6 de forma independiente. Sin embargo, no se observaron diferencias significativas entre los racimos analizados para ninguno de los metabolitos, probablemente debido, por un lado, al sistema de muestreo elegido en el que los frutos eran recolectados de diferentes plantas, y por lo tanto no se modificaba la relación sumidero/fuente, y por otro, al hecho de que, en la cámara de crecimiento, el fotoperiodo se mantuvo constante durante todo el desarrollo del cultivo (a diferencia de lo que ocurre bajo condiciones naturales). Por lo tanto, los resultados se presentan como la media de los valores de concentración de carotenoides y vitamina $\mathrm{C}$ obtenidos para los diferentes racimos.

El efecto de la alta temperatura sobre la concentración de vitamina $C$ dependió del estadio en el que se impuso el estrés y la duración del mismo (Figura 5.3). En los frutos sometidos a $32^{\circ} \mathrm{C}$ desde estadios de desarrollo avanzados (estadios 6 y 5 , equivalentes a 6 y 16 DAT, respectivamente), la concentración de vitamina $\mathrm{C}$ disminuyó con respecto a la alcanzada en los frutos control. Al aumentar el período de exposición al estrés, el efecto negativo de la alta temperatura sobre el contenido de vitamina $C$ disminuyó de forma proporcional. Así, los frutos bajo alta temperatura durante 36 días (estadio 4) alcanzaron una concentración de vitamina $C$ similar al observado en los frutos control. Por otra parte, el aumento del período de exposición a 44 días, resultó en un aumento de la concentración de vitamina $C$ por encima de los valores obtenidos en los frutos del tratamiento control. 


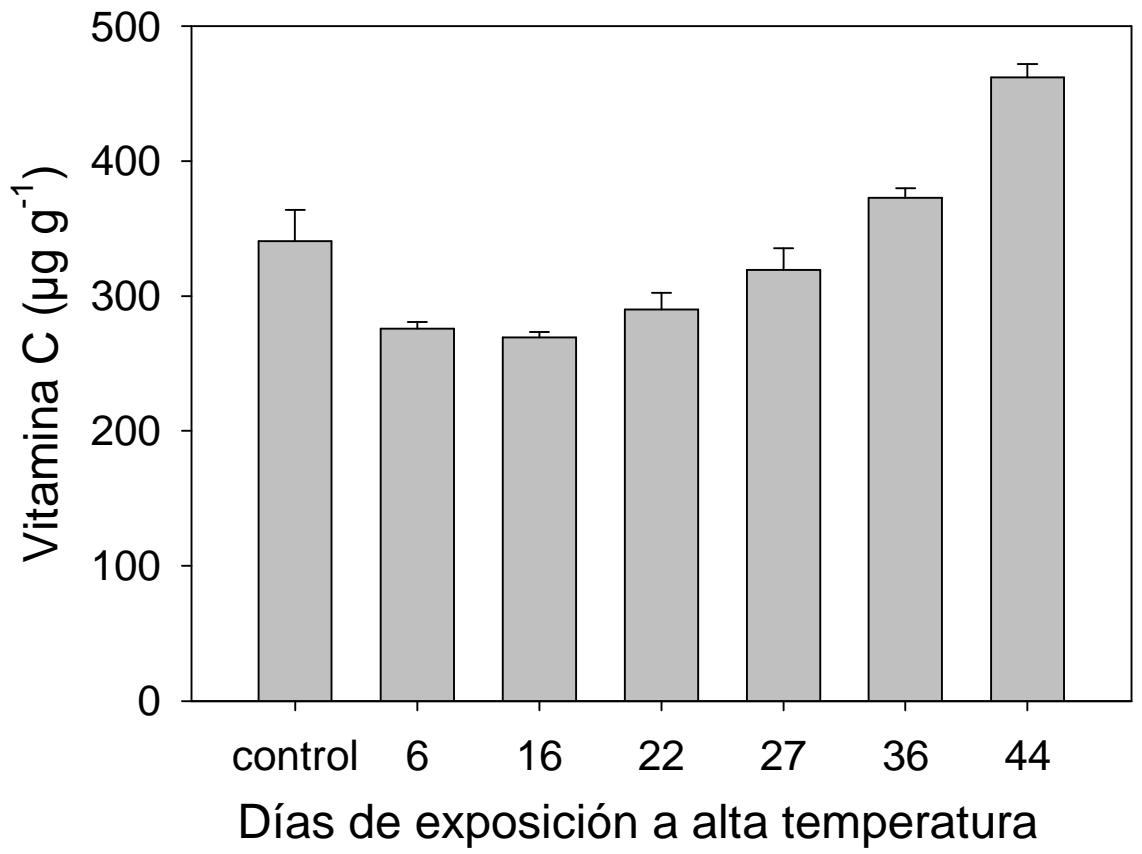

Figura 5.3. Concentración de vitamina $C$ en frutos bajo condiciones de alta temperatura $(32 \stackrel{\circ}{\circ})$ durante diferentes periodos. Las barras son medias de los valores \pm error estándar $(n=6)$.

El estrés causado por la alta temperatura conduce a una alteración de la composición de los frutos, a través de modificaciones a nivel fisiológico, bioquímico y molecular. A nivel de la planta, el aumento de la temperatura puede alterar la distribución de fotoasimilados entre los diferentes órganos de la planta, así como aumentar la producción de frutos, a expensas del crecimiento vegetativo (de Koning, 1996). Por otro lado, temperaturas superiores a los valores óptimos, pueden alterar directamente los procesos de síntesis/degradación de ciertos metabolitos en la planta. En particular, la acumulación de ascorbato se ve limitada bajo condiciones de alta temperatura, al reducir la síntesis de ascorbato y/o favorecer la degradación del mismo por oxidación, debido al aumento de las actividades ascorbato peroxidasa y ascorbato oxidasa y a una disminución de la actividad dehidroascorbato reductasa (Rosales y col., 2006). Por otro lado, el aumento proporcional de la concentración de vitamina $\mathrm{C}$ al aumentar el periodo de exposición a alta temperatura, sugiere una adaptación del metabolismo de la 
planta al estrés y/o una restauración de los procesos de síntesis de ascorbato durante los intervalos de tiempo en que disminuye la temperatura a lo largo del fotoperiodo (noche). Finalmente, el contenido de vitamina C fue mayor en los frutos expuestos a alta temperatura desde la floración que en los frutos control, probablemente debido a un efecto de concentración, como resultado de una disminución de la relación sumidero/fuente, debido a su vez a un incremento de aborto floral. Dicho efecto de concentración no puede ser atribuido a un menor contenido en agua en el fruto, ya que en los análisis no se vieron diferencias entre los diferentes tratamientos.

Respecto a los carotenoides, los compuestos identificados en tomate fueron fitoeno, fitoflueno, all trans-licopeno, 13 cis-licopeno, 5 cis-licopeno, luteína, all trans- $\gamma$-caroteno, all trans- $\beta$-caroteno, 9 cis- $\beta$-caroteno, 13 cis- $\beta$-caroteno y violaxantina. El aumento de temperatura en el estadio 6 (frutos verdes totalmente desarrollados), provocó una disminución de la concentración de licopeno total, calculado como la suma de isómeros all trans, 13 cis, y 5 cis- licopeno (Figura 5.4 A). Esta disminución estuvo acompañada de una disminución en la concentración de fitoeno y fitoflueno (precursores de licopeno) y de un aumento de la concentración de luteína (producto) (Tabla 5.3 y Figura 5.5).

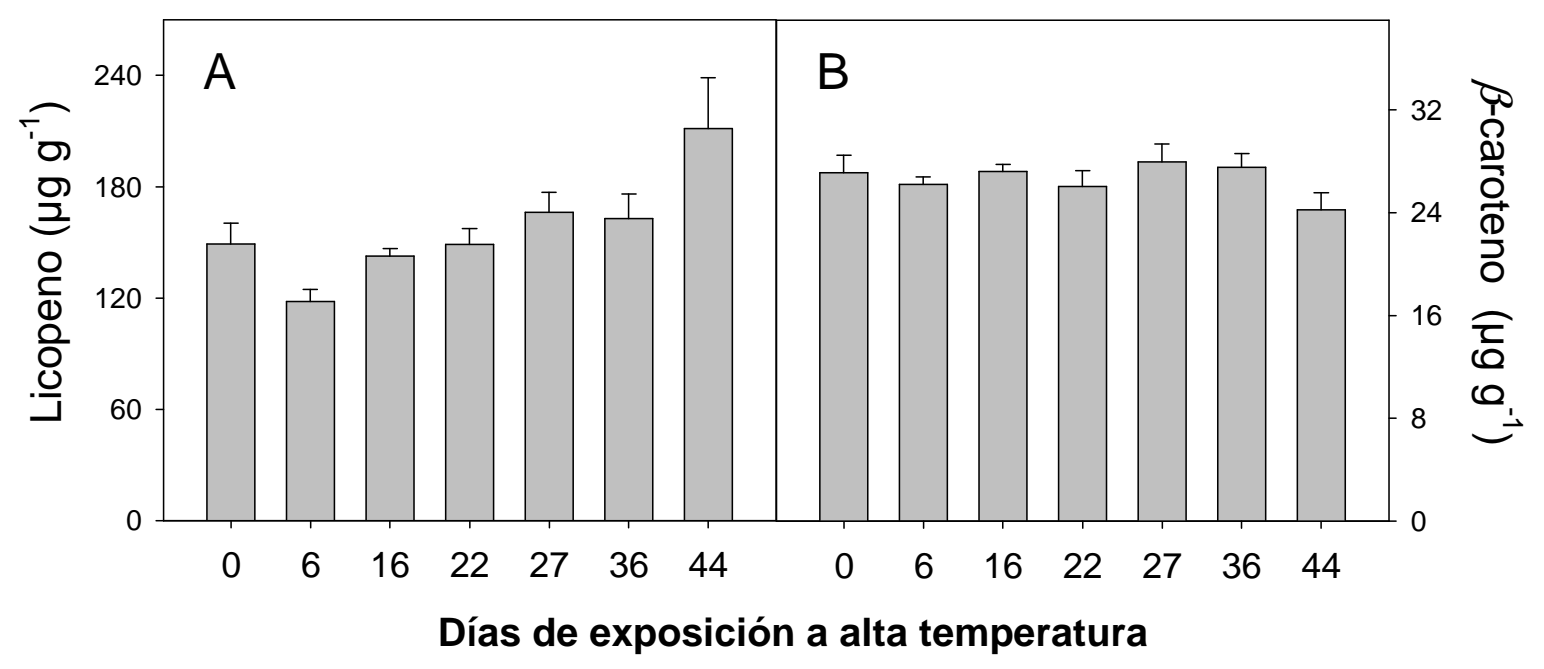

Figura 5.4. Concentración total de licopeno total $(A)$ y $\beta$-caroteno total $(B)$ en frutos expuestos a estrés térmico (32 ํㅡ) durante diferentes tiempos de exposición. Las barras son medias de los valores \pm error estándar $(n=6)$. 
Tabla 5.3. Concentración de carotenoides $\left(\mu \mathrm{g} \mathrm{g}^{-1}\right)$ en frutos de tomate expuestos a alta temperatura $\left(32^{\circ} \mathrm{C}\right)$ durante diferentes periodos de tiempo.

\begin{tabular}{|c|c|c|c|c|c|c|c|}
\hline \multirow[b]{2}{*}{ Compuestos } & \multicolumn{7}{|c|}{ Días de exposición a alta temperatura (DAT) } \\
\hline & 0 & 6 & 16 & 22 & 27 & 36 & 44 \\
\hline Fitoeno & $16,8^{b}$ & $8,5^{\mathrm{e}}$ & $9,9^{\mathrm{de}}$ & $11,4^{\text {cd }}$ & $13,5^{c}$ & $22,7^{\mathrm{a}}$ & $24,4^{\mathrm{a}}$ \\
\hline Fitoflueno & $7,8^{b}$ & $4,2^{d}$ & $5,1^{\mathrm{cd}}$ & $5,4^{\mathrm{cd}}$ & $6,2^{\mathrm{bc}}$ & $6,3^{b c}$ & $6,7^{\mathrm{a}}$ \\
\hline All trans-licopeno & $100,4^{b}$ & $78,5^{c}$ & $94,9^{\mathrm{bc}}$ & $99,3^{b c}$ & $111,3^{b}$ & $107,2^{b}$ & $143,6^{a}$ \\
\hline 13 cis-licopeno & $4,8^{e}$ & $5,2^{\text {de }}$ & $6,6^{\mathrm{cd}}$ & $6,4^{\mathrm{cd}}$ & $7,1^{\mathrm{bc}}$ & $8,5^{\mathrm{b}}$ & $9,3^{\mathrm{a}}$ \\
\hline 5 cis-licopeno & $3,3^{\mathrm{a}}$ & $1,9^{b c}$ & $1,8^{\mathrm{c}}$ & $2,2^{b c}$ & $1,8^{\mathrm{c}}$ & $2,2^{b c}$ & $1,9^{a b}$ \\
\hline Luteína & $11,2^{\mathrm{c}}$ & $12,8^{\mathrm{abc}}$ & $13,8^{\mathrm{ab}}$ & $13,2^{\mathrm{ab}}$ & $13,4^{\mathrm{ab}}$ & $13,7^{\mathrm{a}}$ & $12,2^{\mathrm{bc}}$ \\
\hline All trans-y-caroteno & $3,2^{\mathrm{a}}$ & $2,8^{b}$ & $2,8^{b}$ & $2,3^{\mathrm{c}}$ & $2,1^{\mathrm{c}}$ & $1,9^{c}$ & $2,0^{c}$ \\
\hline All trans- $\beta$-caroteno & 25,7 & 24,6 & 25,2 & 24,2 & 25,9 & 24,5 & 21,6 \\
\hline 9 cis- $\beta$-caroteno & 0,6 & 0,6 & 0,7 & 0,6 & 0,7 & 0,7 & 0,5 \\
\hline 13 cis- $\beta$-caroteno & $0,9^{d}$ & $1,0^{\text {cd }}$ & $1,3^{\mathrm{ab}}$ & $1,2^{b c}$ & $1,4^{\mathrm{ab}}$ & $1,4^{\mathrm{ab}}$ & $1,3^{\mathrm{a}}$ \\
\hline Violaxantina & $3,1^{\mathrm{a}}$ & $3,0^{\mathrm{a}}$ & $2,5^{\mathrm{b}}$ & $2,5^{\mathrm{b}}$ & $2,2^{\mathrm{bc}}$ & $1,8^{c}$ & $1,1^{d}$ \\
\hline
\end{tabular}

Diferentes letras en la misma columna indican diferencias entre medias de acuerdo con el test de Tukey.

En los estadios más tempranos, el efecto de la temperatura (inhibiendo la acumulación de licopeno y sus precursores y aumentando la de luteína), disminuyó proporcionalmente con el tiempo de exposición a $32^{\circ} \mathrm{C}$. Incluso, en el caso de los frutos sometidos a altas temperaturas desde la floración, las concentraciones de fitoeno y licopeno, alcanzaron niveles superiores a los observados en los frutos control. A diferencia de licopeno, la concentración total de $\beta$-caroteno (calculada como la suma de isómeros all trans, 9 cis y 13 cis- $\beta$ caroteno) no se vio afectada por el aumento de la temperatura (Figura 7.4 B). Además, las concentraciones de $\gamma$-caroteno y violaxantina disminuyeron proporcionalmente a la duración de la exposición al estrés. Según Gautier y col. (2008), la enzima fitoeno sintetasa (PSY), responsable de la formación de fitoeno a partir de dos moléculas de geranilgeranil difosfato (GGPP), juega un papel fundamental en la regulación de la biosíntesis de carotenoides. PSY es inhibida por el aumento de la temperatura, principalmente al nivel transcripcional (Bramley, 2002; Fraser y Bramley, 2004). Esto podría explicar la disminución observada en 
la concentración de fitoeno, fitoflueno, y de su producto licopeno, en frutos sometidos a elevada temperatura durante un corto período de tiempo. Algunos autores sugieren que la disminución de licopeno como resultado de un aumento de la temperatura puede ser debido a la degradación de este compuesto hacia la formación de $\beta$-caroteno (Gautier y col., 2008). Sin embargo, nuestros resultados también sugieren una degradación de licopeno hacia la formación de luteína.

Los mecanismos de control de retroalimentación y canalización metabólica entre cada rama de la ruta de los isoprenoides, desempeñan un papel clave en la concentración final de cada compuesto (Poiroux-Gonord y col., 2010). Así el hecho de que la concentración de $\beta$-caroteno se mantuviera estable bajo condiciones de estrés, podría estar relacionado, por una parte, con el aumento de la degradación de licopeno y $y$-caroteno y, por otra, con la disminución del catabolismo de $\beta$-caroteno hacia la formación de violaxantina, lo cual también explicaría la disminución observada en la concentración de este último compuesto.

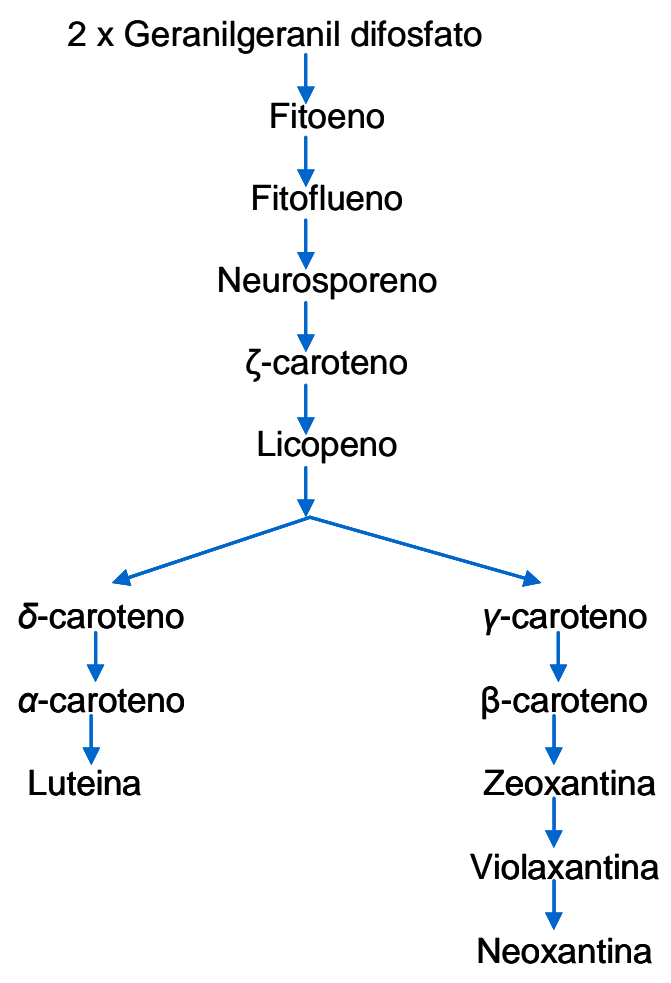

Figura 5.5. Ruta de biosíntesis de carotenoides 
El aumento de la duración del estrés térmico, redujo el efecto negativo del mismo sobre la concentración de fitoeno, fitoflueno, licopeno y luteína, lo que sugiere, de manera similar a lo observado en el caso de la vitamina $C$, una adaptación del metabolismo de la planta a la alta temperatura y/o a la restauración de los procesos de síntesis de los carotenoides durante intervalos de tiempo en el que la temperatura disminuye a lo largo del fotoperiodo. El aumento en el contenido de carotenoides observado en frutos correspondientes al estadio 1 (Tabla 5.3), podría también atribuirse a un efecto de concentración, resultante de una disminución en la relación sumidero/fuente.

Además de estos cambios metabólicos en la ruta de biosíntesis de los isoprenoides, el estrés por alta temperatura condujo a un aumento en la concentración de los isómeros 13 cis- $\beta$-caroteno y 13 cis-licopeno. La formación de isómeros cis a partir de su correspondiente forma all trans, como resultado de un aumento de la temperatura, ha sido previamente estudiada por otros autores que describieron la estabilidad de los diferentes isómeros de licopeno, de acuerdo a su energía molecular, según el orden 5 cis $\geq$ all trans $\geq 9$ cis $\geq 13$ cis $>15$ cis $>7$ cis > 11 cis (Boileau y col., 2002; Chasse y col., 2001). Sin embargo, a pesar de que las formas cis son más inestables, se ha demostrado que los isómeros cislicopeno son más biodisponibles que sus correspondientes isómeros trans, probablemente debido a su menor longitud y a su baja tendencia de formar agregados, lo cual les confiere una mayor solubilidad (Nguyen y Schwartz, 1998; Boileau y col., 1999).

\subsection{CONCLUSIONES}

El efecto del aumento de la temperatura sobre el desarrollo del fruto y sobre las concentración de vitamina $\mathrm{C}$ y de carotenoides dependió de la etapa de desarrollo del fruto en la que se impuso el estrés. En general, el aumento de temperatura afectó negativamente al tamaño y al peso del fruto proporcionalmente al tiempo de exposición a altas temperaturas. Sin embargo, los frutos sometidos a altas temperaturas desde floración, mostraron tamaño y pesos similares que los frutos del tratamiento control, debido a una mayor incidencia de 
aborto floral y al aumento de peso de los frutos restantes. Respecto a la calidad nutricional, los frutos expuestos a $32^{\circ} \mathrm{C}$ durante un corto período de tiempo, disminuyeron la concentración de vitamina $\mathrm{C}$ y también la de licopeno, pero no se observó ningún efecto de la temperatura sobre la concentración de $\beta$-caroteno. Los cambios observados en las concentraciones de otros carotenoides pueden ser explicados por la canalización metabólica entre las diferentes ramas de la ruta de biosíntesis de los isoprenoides. Por último, el efecto negativo de la alta temperatura sobre la concentración de vitamina C y de licopeno, disminuye a medida que aumenta el tiempo de exposición al estrés, alcanzando valores similares a los obtenidos en los frutos control, o incluso mayor, si los frutos estaban bajo estrés térmico desde la floración. Estos resultados muestran la capacidad de las plantas de tomate para adaptarse a condiciones de estrés térmico, pudiendo incluso restaurar las concentraciones de estos metabolitos después de largos períodos de exposición a alta temperatura. 


\section{Capítulo 6}

\section{INFLUENCIA DE LA NUTRICIÓN NITROGENADA Y SU INTERACCIÓN CON EL SOMBREO, EN EL RENDIMIENTO Y LA CALIDAD DE TOMATE}

El uso de fertilizantes de nitrógeno $(\mathrm{N})$ contribuye en gran medida al correcto crecimiento y desarrollo de las plantas, pudiendo aumentar de forma significativa el rendimiento de los cultivos. Sin embargo, un manejo incorrecto de la nutrición nitrogenada puede ocasionar efectos negativos sobre los mismos, entre otros, mayor riesgo de sufrir problemas fitosanitarios (Parisi y col., 2006), mayor sensibilidad a condiciones medioambientales adversas (Amancio y Stulen, 2007) y disminución de la vida útil de los frutos en postcosecha al aumentar el riesgo de rotura de los tejidos, produciendo alteraciones fisiológicas y senescencia (Hewett, 2006). Por otro lado, la aplicación excesiva de $\mathrm{N}$ en sistemas de producción intensivos, incrementa la lixiviación de nitratos a lo largo del perfil del suelo (Flores y col., 2005), provocando serios problemas medioambientales, como la contaminación de aguas subterráneas y eutrofización del medio (Cameron y col., 2013).

Respecto al cultivo de tomate, el aumento de la dosis de $\mathrm{N}$ provoca, en general, un aumento de la producción de fruto hasta cierto límite, en el que se favorece el crecimiento vegetativo en detrimento del productivo (Zotarelli y col., 2009; Elia y Conversa, 2012). Este aumento del rendimiento conlleva, en muchos casos, una disminución de la calidad, como consecuencia de la disminución de su contenido en azúcares y ácidos orgánicos (Parisi y col., 2006; Wang y col., 2007). Respecto al efecto de la nutrición nitrogenada sobre la calidad funcional, los estudios se han centrado mayoritariamente en los principales compuestos bioactivos de tomate: carotenoides, vitamina $\mathrm{C}$ y compuestos fenólicos. En una revisión de la literatura existente, Poiroux-Gonord y col. (2010) concluyeron que altas dosis de $\mathrm{N}$ favorecen la acumulación de carotenoides en el fruto. Sin embargo, los resultados obtenidos por Bènard y 
col. (2009) sugieren que el efecto del $\mathrm{N}$ sobre el contenido de licopeno y $\beta$ caroteno no es significativo y depende en gran medida de la estación de cultivo. Respecto al contenido de vitamina C, la mayoría de los autores coinciden en que el aumento de la disponibilidad de $\mathrm{N}$ provoca una disminución del contenido de vitamina $C$ en el fruto (Lee y Kader, 2000; Reboucas y col., 2015). De acuerdo con esto, el contenido en compuestos antioxidantes hidrofílicos (vitamina C y compuestos fenólicos) aumentó al disminuir la dosis de N, como mecanismo de defensa inducido por el estrés por deficiencia de N (OchoaVelasco y col., 2016). A pesar del aumento del contenido de compuestos fenólicos descrito en hoja como respuesta a una disminución del aporte de $\mathrm{N}$ (Stout y col., 1998), otros estudios no encuentran un incremento de dichos compuestos en fruto, probablemente debido a que se trata de un órgano más protegido (Stewart y col., 2001; Bènard y col., 2009).

El efecto del $\mathrm{N}$ sobre el rendimiento y la calidad final de los frutos, puede estar influenciado por otros factores externos que han de ser considerados con el fin de optimizar el manejo de la nutrición mineral, procurando mejorar la calidad de tomate, sin grandes pérdidas en el rendimiento. En particular, el uso de mallas de sombreo es una práctica agrícola muy extendida como medida económica para paliar el efecto de la alta radiación y el consecuente aumento de temperatura en zonas cálidas. Dicho aumento de temperatura se encuentra entre los factores ambientales que más afectan al rendimiento y la calidad de los frutos en climas semiáridos, llegando a ser un factor limitante durante los meses de verano, especialmente para los cultivos desarrollados bajo invernadero. El objetivo de este trabajo es conocer la influencia de la dosis de $\mathrm{N}$ y su interacción con el uso de mallas de sombreo, sobre la calidad de tomate, considerando su contenido en compuestos relacionados con el sabor y el valor funcional del fruto. 


\subsection{MATERIALES Y MÉTODOS}

En primer lugar se planteó un ensayo en el que se estudió la interacción $\mathrm{N}$ $x$ sombreo sobre el rendimiento y la calidad de tomate. Para ello se contemplaron tratamientos con o sin sombreo, combinados con diferentes dosis de $\mathrm{N}$ impuestas desde el trasplante. A la vista de los resultados obtenidos y de los resultados contradictorios encontrados en la bibliografía sobre el efecto de la disminución de la dosis de $\mathrm{N}$ sobre la producción y composición de tomate, se planteó un segundo ensayo en el que se comparó el efecto de la reducción de $\mathrm{N}$ a partir de dos estadios de crecimiento diferentes: trasplante y floración.

\subsubsection{Material vegetal y sitio de estudio}

Se cultivaron plantas de tomate (Solanum lycopersicum L.) en macetas de $20 \mathrm{~L}$ rellenas con una mezcla de fibra de coco y perlita (85:15), en un invernadero de policarbonato localizado en las instalaciones del Instituto Murciano de Investigación y Desarrollo Agrario y Alimentario (IMIDA) en La Alberca (Murcia). EI riego se realizó mediante control automatizado con disolución nutritiva Hoagland (Tabla 6.1), la cual se modificó para alcanzar las diferentes dosis de $\mathrm{N}$ mediante sustitución total o parcial de $\mathrm{KNO}_{3}$ y $\mathrm{Ca}\left(\mathrm{NO}_{3}\right)_{2} \cdot 4 \mathrm{H}_{2} \mathrm{O}$, añadiendo $\mathrm{Cl}_{2} \mathrm{Ca}$ y $\mathrm{K}_{2} \mathrm{SO}_{4}$ en caso necesario.

Tabla 6.1. Composición de la disolución nutritiva Hoagland modificada

\begin{tabular}{cccccc}
\hline \multicolumn{5}{c}{ Macronutrientes $(\mathrm{mM})$} \\
\hline $\mathrm{NO}_{3}^{-}$ & $\mathrm{H}_{2} \mathrm{PO}_{4}^{-}$ & $\mathrm{SO}_{4}{ }^{-2}$ & $\mathrm{Ca}^{2+}$ & $\mathrm{K}^{+}$ & $\mathbf{M g}^{2+}$ \\
14 & 2 & 2 & 4 & 8 & 2 \\
\hline \multicolumn{7}{c}{ Micronutrientes $(\mu \mathrm{M})$} \\
\hline $\mathrm{B}$ & $\mathrm{Mn}$ & $\mathrm{Zn}$ & $\mathrm{Cu}$ & $\mathrm{Mo}$ & $\mathrm{Cl}^{-}$ \\
25 & 2 & 2 & 0,5 & 0,5 & 50 \\
\hline
\end{tabular}




\subsubsection{Diseño experimental}

6.1.2.1. Interacción $\mathrm{N}$ x sombreo sobre la producción y calidad

En este primer ensayo, los tratamientos consistieron en tres niveles de $\mathrm{N}$, 14, 7 y $3 \mathrm{mM}$ (T1, T2 y T3, respectivamente), combinados con dos niveles de intensidad luminosa: control (100\% luz) y sombreo $(60 \%$ luz) mediante la utilización de pantalla térmica ( $\mathrm{AOL} S \mathrm{40}$ ). Los seis tratamientos resultantes se distribuyeron en un diseño de bloques al azar con dos bloques por tratamiento y cinco repeticiones por bloque (10 repeticiones por tratamiento) (Figura 6.1).

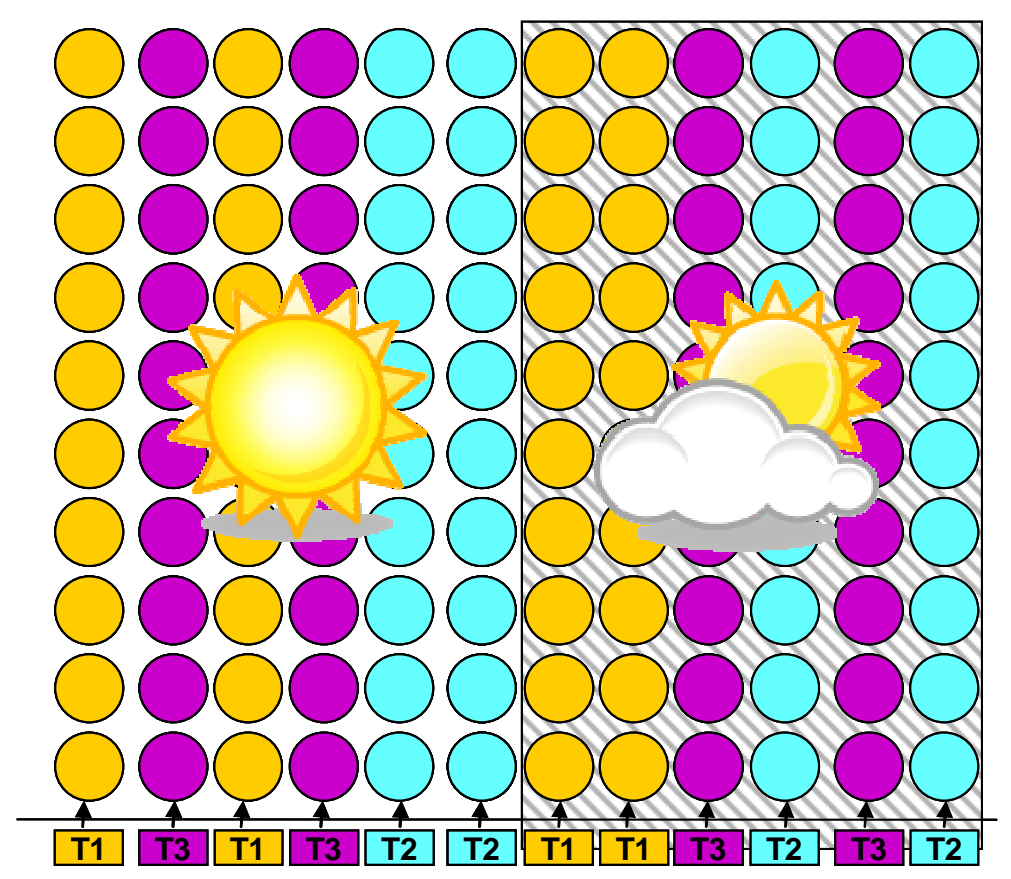

Figura 6.1. Diseño experimental del estudio de la interacción $\mathrm{N}$ x sombreo.

La colocación de la pantalla térmica provocó una disminución de la temperatura máxima, de aproximadamente de $5{ }^{\circ} \mathrm{C}$, respecto a la de la zona no sombreada, llegándose a alcanzar de manera puntual diferencias de hasta $9 \stackrel{\circ}{\circ}$ entre ambas zonas (Figura 6.2). La temperatura mínima nocturna no se vio alterada por el sombreo. 


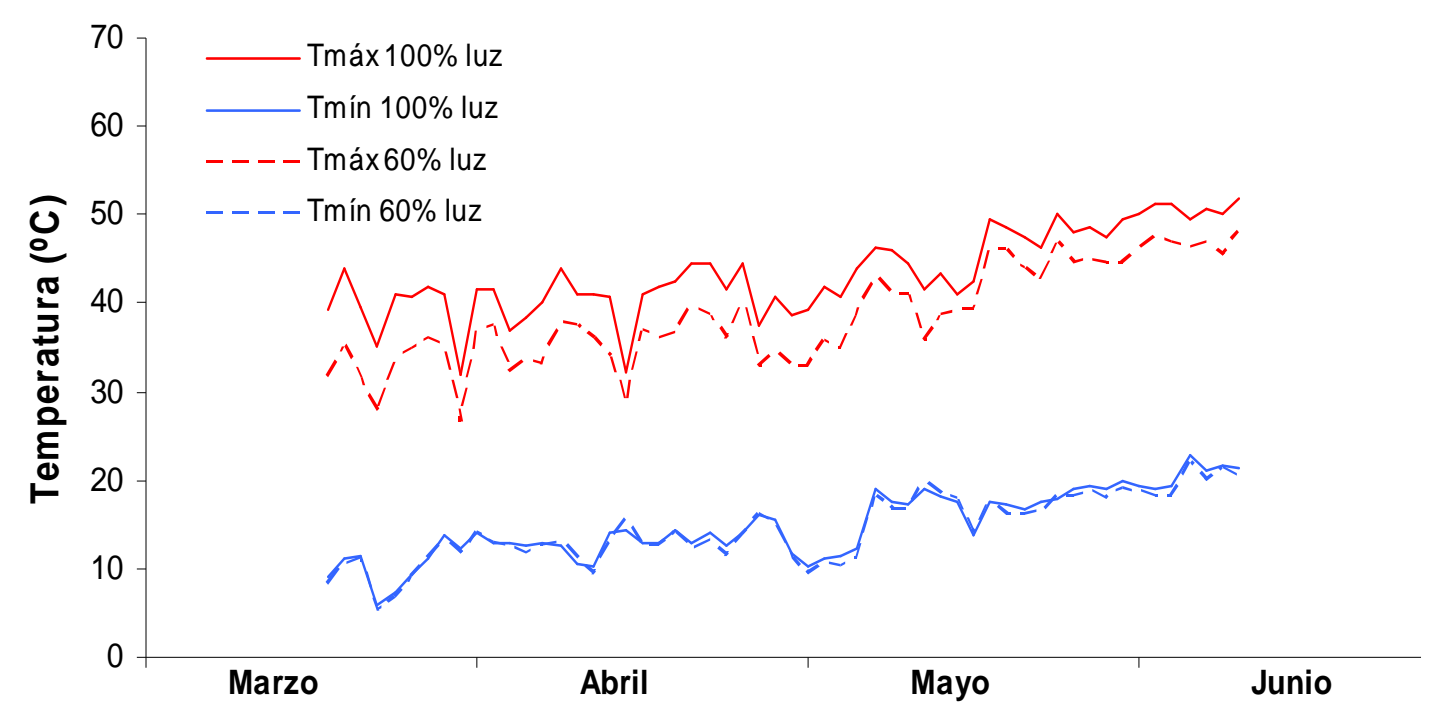

Figura 6.2. Evolución de las temperaturas máximas y mínimas en las zonas 100\% luz y $60 \%$ luz a lo largo del ciclo de cultivo.

6.1.2.2. Reducción de la dosis de $\mathrm{N}$ en diferentes fases de desarrollo

En este ensayo, los tratamientos consistieron en la aplicación de diferentes dosis de $\mathrm{N}(14,7,3 \mathrm{mM} \mathrm{N})$ a partir de dos estadios de desarrollo de la planta. Un primer grupo de plantas fue cultivado bajo dichos tratamientos desde el trasplante (plántulas con cuatro hojas verdaderas, de altura aproximada de 10-15 cm). El segundo grupo fue cultivado inicialmente con una dosis $14 \mathrm{mM} \mathrm{N}$ y a partir de la floración de los primeros tres racimos, se impusieron las tres dosis de N. Los tratamientos se dispusieron en el invernadero según un diseño de bloques al azar con dos bloques y 6 repeticiones por bloque, cada repetición formada por tres plantas (Figura 6.3). 


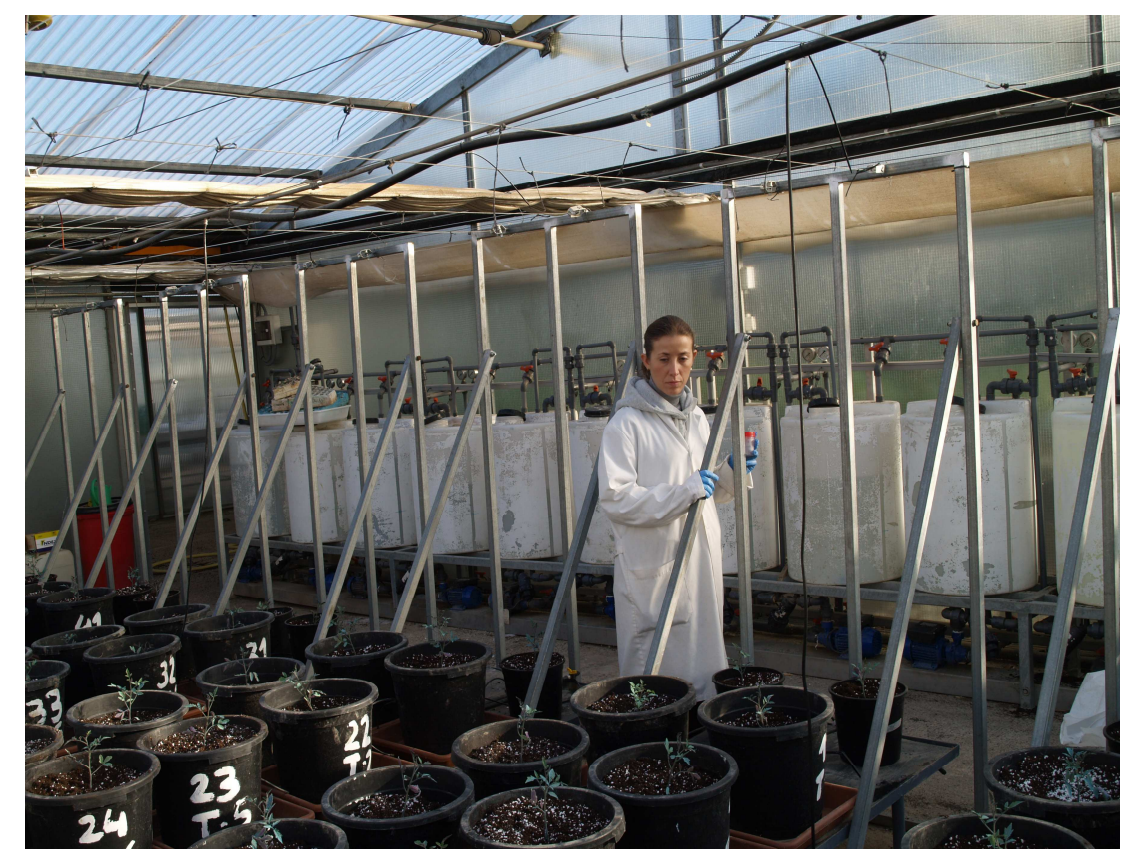

Figura 6.3. Vista parcial del invernadero donde se realizaron los ensayos con diferentes tratamientos de $\mathrm{N}$.

\subsubsection{Muestreo y parámetros analizados}

Para la determinación de la producción total, número y peso medio de los frutos, se recolectaron y pesaron todos los frutos de forma individual. Para el análisis de los parámetros de calidad, se seleccionaron frutos de los racimos 2-4, en estado de maduración totalmente rojo, descartando aquellos que no tenían un color homogéneo o presentaban algún defecto. El estado de maduración de los frutos se supervisaba diariamente para evitar la sobremaduración de los mismos. El análisis de metabolitos relacionados con la calidad organoléptica y nutricional se realizó según la metodología descrita en los apartados: parámetros físicos (3.2), análisis de azúcares (3.3.1.), análisis de compuestos fenólicos (3.3.2.), análisis de carotenoides y vitamina $E$ (3.3.3.) y análisis de vitamina $C$ (3.3.4.) del capítulo 3. 


\subsubsection{Análisis estadístico}

Los resultados se analizaron estadísticamente mediante el análisis de la varianza (ANOVA), utilizando el programa estadístico SPSS 18. Los valores se compararon con el test de diferencia entre medias de Tukey.

\subsection{RESULTADOS Y DISCUSIÓN}

\subsubsection{Interacción $\mathbf{N}$ x sombreo sobre la producción y calidad}

\subsubsection{Producción}

La nutrición nitrogenada tiene un fuerte impacto en el desarrollo de los cultivos y la obtención de rendimientos óptimos. Requiere por tanto, un adecuado manejo que permita conseguir un equilibrio entre el desarrollo vegetativo y reproductivo (Warner y col., 2004). Además, el efecto del N sobre la producción depende de otros factores externos como es la luz. Así, se ha comprobado que el uso de mallas de sombreo en invernadero afecta a la producción y la absorción de nutrientes en plantas de tomate (Gent, 2008). En nuestro ensayo, la aplicación de sombreo ( $60 \%$ luz) solo disminuyó significativamente la producción total de frutos en el tratamiento $14 \mathrm{mM} \mathrm{N}$ (Tabla 6.2). Independientemente de la intensidad luminosa, la disminución de la dosis de $\mathrm{N}$ provocó una reducción del número de frutos, lo que se atribuyó a que las restricciones de $\mathrm{N}$ establecidas en los tratamientos 7 y $3 \mathrm{mM} \mathrm{N}$ se impusieron desde el trasplante, limitando el cuajado de los frutos. Por otro lado, mientras que en condiciones de $100 \%$ luz, la disminución del número de frutos como consecuencia de la disminución de la dosis de $\mathrm{N}$, no modificó el peso medio de los mismos, bajo condiciones de sombreo, la disminución de la dosis de $\mathrm{N}$ (y consecuente disminución del número de frutos) provocó un aumento significativo del peso medio. Según Gent (2008), las condiciones de sombreo favorecen el crecimiento de los frutos en detrimento del crecimiento vegetativo. Por tanto, el aumento del peso medio, observado bajo condiciones de sombreo, como consecuencia de la disminución del número de frutos al disminuir la dosis de N, podría explicarse por una movilización de las 
reservas de carbohidratos acumuladas en tallos y hojas hacia los frutos restantes. Por el contrario, bajo condiciones $100 \%$ luz, la disminución de la dosis de $\mathrm{N}$ podría favorecer el mantenimiento del crecimiento vegetativo a expensas del crecimiento de los frutos. Como resultado del aumento de peso de los frutos cultivados bajo sombreo, al disminuir la concentración de $\mathrm{N}$ de 14 a $7 \mathrm{mM}$, en este tratamiento se alcanzó un valor de producción similar al obtenido en el tratamiento $100 \%$ luz y $14 \mathrm{mM} \mathrm{N}$.

Tabla 6.2. Producción ( $k g$ planta $\left.{ }^{-1}\right)$, número, peso medio $(g)$ y color $\left(L y a^{*}\right)$ de frutos cultivado bajo diferentes intensidades de luz (100\% y $60 \%$ ) y dosis de $\mathrm{N}$ $(14,7$ y $3 \mathrm{mM} \mathrm{N})$.

\begin{tabular}{|c|c|c|c|c|c|c|}
\hline & & Producción & № frutos & Peso & $\mathbf{L}$ & $a^{*}$ \\
\hline \multicolumn{7}{|c|}{ EFECTOS PRINCIPALES } \\
\hline \multirow[t]{4}{*}{ Dosis } & 14 & $2,67^{b}$ & $36,5^{c}$ & $73,1^{\mathrm{a}}$ & 39,0 & $14,8^{\mathrm{c}}$ \\
\hline & 7 & $2,48^{b}$ & $30,1^{b}$ & $84,4^{b}$ & 38,8 & $13,9^{b c}$ \\
\hline & 3 & $1,68^{\mathrm{a}}$ & $20,1^{\mathrm{a}}$ & $84,7^{b}$ & 38,4 & $12,8^{a}$ \\
\hline & & $* * *$ & $* * *$ & ** & n.s. & * \\
\hline \multirow[t]{3}{*}{ Luz } & $100 \%$ & 2,27 & 30,6 & 74,7 & 39,2 & 14,9 \\
\hline & $60 \%$ & 2,29 & 27,7 & 86,9 & 38,4 & 12,8 \\
\hline & & n.s. & n.s. & ** & * & $* * *$ \\
\hline
\end{tabular}

\section{INTERACCIÓN}

\begin{tabular}{ccccccc} 
Luz & Dosis & & & & \\
$100 \%$ & 14 & $2,96^{\mathrm{c}}$ & 39,0 & $76,2^{\mathrm{ab}}$ & $38,9^{\mathrm{b}}$ & 15,4 \\
& 7 & $2,33^{\mathrm{b}}$ & 33,6 & $70,0^{\mathrm{a}}$ & $39,0^{\mathrm{b}}$ & 15,1 \\
& 3 & $1,50^{\mathrm{a}}$ & 19,2 & $77,9^{\mathrm{ab}}$ & $39,6^{\mathrm{b}}$ & 13,1 \\
$60 \%$ & 14 & $2,38^{\mathrm{b}}$ & 34,0 & $70,1^{\mathrm{a}}$ & $39,1^{\mathrm{b}}$ & 14,0 \\
& 7 & $2,62^{\mathrm{bc}}$ & 26,6 & $98,9^{\mathrm{c}}$ & $38,6^{\mathrm{ab}}$ & 12,2 \\
& 3 & $1,87^{\mathrm{a}}$ & 21,0 & $91,7^{\mathrm{bc}}$ & $37,6^{\mathrm{a}}$ & 12,0 \\
& $* *$ & n.s. & $* * *$ & $* * *$ & n.s. \\
\hline & \multicolumn{7}{c}{, indican diferencias significativas entre medias con un nivel de probabilidad del $0,1,1 \mathrm{y}$}
\end{tabular}


Respecto al color, no se observaron diferencia significativas en la luminosidad del fruto $(\mathrm{L})$ entre los diferentes tratamientos de $\mathrm{N}$ y luz, excepto en el caso de frutos cultivados con $3 \mathrm{mM} \mathrm{N}$ y $60 \%$ luz, que presentaron un valor más bajo que el resto de tratamientos (Tabla 6.2). El valor de la coordenada $a^{*}$ (contribución del rojo) fue significativamente mayor en el tratamiento $100 \%$ luz y aumentó con el incremento de la dosis de $\mathrm{N}$, debido a un aumento de la concentración de los compuestos responsables del color rojo en tomate, licopeno y en menor medida $\beta$-caroteno (ver apartado 6.2.1.2), como resultado del aumento de la intensidad luminosa (Jarquin-Enriquez y col., 2013) y la disponibilidad de N (Poiroux-Gonord y col., 2010).

\subsubsection{Calidad}

Respecto al contenido en azúcares solubles, no se observó interacción entre los efectos del $\mathrm{N}$ y la luz (Tabla 6.3). La concentración de glucosa disminuyó al disminuir la concentración de $\mathrm{N}$ en el medio, independientemente de la intensidad de luz, aunque esta disminución sólo fue significativa en el tratamiento con 3 mM N (Tabla 6.3). Por otro lado, la dosis de $\mathrm{N}$ y la intensidad luminosa no afectaron significativamente a la concentración de fructosa. La mayoría de los estudios correlacionan la disminución de la disponibilidad de $\mathrm{N}$, con un aumento de la concentración de azúcares en frutos (Ono y col., 1996; Wingler y col., 2006). Sin embargo, a diferencia de estos estudios, nuestras condiciones experimentales incluyeron la restricción de $\mathrm{N}$ (tratamientos 3 y $7 \mathrm{mM}$ ) durante un largo periodo (desde trasplante), lo que supone una limitación más severa. Esta limitación podría afectar a la fotosíntesis disminuyendo el contenido de clorofila y deteriorando las membranas fotosintéticas como consecuencia de la acumulación de almidón (Guidi y col., 1998), afectando de esta manera la acumulación de glucosa en frutos. 
Tabla 6.3. Concentración de glucosa y fructosa en frutos de tomate cultivado con diferentes intensidades de luz (100\% y $60 \%)$ y diferentes dosis de $N(14,7$ y 3 $\mathrm{mMN}$ ).

\begin{tabular}{cccc}
\hline & & Glucosa & Fructosa \\
\hline \multicolumn{2}{c}{ EFECTOS PRINCIPALES } & & \\
Dosis & 14 & $20,9^{\mathrm{b}}$ & 19,7 \\
& 7 & $18,0^{\text {ab }}$ & 19,6 \\
& 3 & $16,7^{\mathrm{a}}$ & 18,3 \\
& & $*$ & n.s. \\
Luz & $100 \%$ & 17,9 & 19,3 \\
& $60 \%$ & 18,7 & 18,9 \\
& & n.s. & n.s.
\end{tabular}

\section{INTERACCIÓN}

\begin{tabular}{cccc} 
Luz & Dosis & & \\
$100 \%$ & 14 & 20,3 & 20,2 \\
& 7 & 18,0 & 19,7 \\
& 3 & 15,5 & 18,0 \\
$60 \%$ & 14 & 19,0 & 20,3 \\
& 7 & 19,0 & 19,5 \\
& 3 & 17,7 & 18,7 \\
& n.s. & n.s. \\
\hline${ }^{*},{ }^{* *},{ }^{* * *}$, indican diferencias significativas entre medias con un \\
nivel de probabilidad del $0,1,1$ y $5 \%$, respectivamente. n.s., no \\
significativo.
\end{tabular}

Entre los compuestos fenólicos detectados en los frutos de tomate, el mayoritario fue el ácido clorogénico con una concentración media de $7,2 \mu \mathrm{g} \mathrm{g}^{-1}$, seguido de ácido homovanílico-O-hexósido $\left(3,5 \mu \mathrm{g} \mathrm{g} \mathrm{g}^{-1}\right)$, rutina $\left(3,7 \mu \mathrm{g} \mathrm{g}{ }^{-1}\right)$, kaempferol-3-O-rutinósido $\left(3,2 \mu \mathrm{g} \mathrm{g}^{-1}\right)$, floretina- $C$-diglucósido $\left(1,3 \mu \mathrm{g} \mathrm{g}^{-1}\right)$, naringenina $\left(0,77 \mu \mathrm{g} \mathrm{g}^{-1}\right)$, ácido criptoclorogénico $\left(0,76 \mu \mathrm{g} \mathrm{g}^{-1}\right)$, ácido cafeíco- $O$ hexósido $\left(0,57 \mu \mathrm{g} \mathrm{g}^{-1}\right)$, naringenina-O-hexósido $\left(0,34 \mu \mathrm{g} \mathrm{g}^{-1}\right)$, ácido ferúlico-Ohexósido $\left(0,27 \mu \mathrm{g} \mathrm{g}^{-1}\right)$, ácido coumaroilquínico $\left(0,20 \mu \mathrm{g} \mathrm{g}^{-1}\right)$, ácido cafeíco $(0,08$ $\left.\mu \mathrm{g} \mathrm{g}^{-1}\right)$, rutina-O-pentósido $\left(0,05 \mu \mathrm{g} \mathrm{g}^{-1}\right)$, ácido rutina-O-hexosido $\left(0,05 \mu \mathrm{g} \mathrm{g}^{-1}\right)$, quercetina $\left(0,04 \mu \mathrm{g} \mathrm{g}^{-1}\right)$, ácido ferúlico $\left(0,04 \mu \mathrm{g} \mathrm{g}^{-1}\right)$, ácido dicafeoilquínico $(0,03$ 
$\left.\mu \mathrm{g}^{-1}\right)$ y ácido $p$-cumárico $\left(0,01 \mu \mathrm{g} \mathrm{g}^{-1}\right)$. La concentración de compuestos fenólicos totales, calculada como suma de todos los compuestos fenólicos individuales detectados, aumentó significativamente como resultado del aumento de la intensidad luminosa y de la disminución de la dosis de N (Tabla 6.4 y Figura 6.4). El aumento observado como consecuencia de la disminución de la concentración de N, fue más pronunciado en el tratamiento $100 \%$ luz, por lo que ANOVA detectó una interacción significativa entre los factores principales estudiados ( $\mathrm{N}$ y sombreo).

Tabla 6.4. Significancia de los efectos principales (intensidad de luz y dosis de nitrógeno) sobre el contenido de licopeno, $\beta$-caroteno, compuestos fenólicos totales, vitaminas $\mathrm{C}$ y $\mathrm{E}$.

\section{Fenólicos Vitamina C Vitamina E Licopeno $\beta$-caroteno}

\begin{tabular}{lccccc}
\hline$\%$ Luz $(\mathrm{L})$ & $* * *$ & $* * *$ & n.s. & $*$ & n.s. \\
$\begin{array}{l}\text { Nitrógeno }(\mathrm{N}) \\
\mathrm{N} \times \text { sombreo }\end{array}$ & $* * *$ & $* *$ & $* *$ & n.s. & n.s. \\
& & n.s. & n.s. & $*$ & $*$ \\
${ }^{*},{ }^{* *},{ }^{* * *}$, indican diferencias significativas entre medias con un nivel de probabilidad del $0,1,1$ y \\
$5 \%$, respectivamente. n.s., no significativo.
\end{tabular}




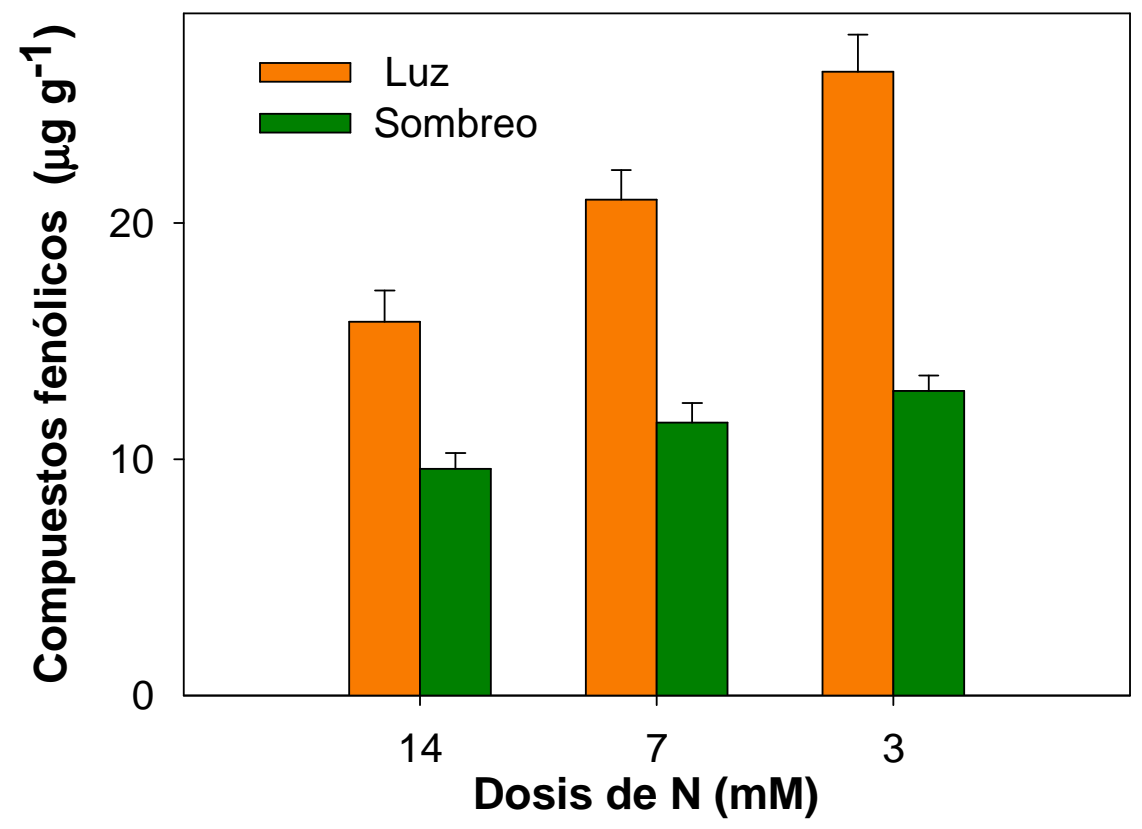

Figura 6.4. Concentración de compuestos fenólicos totales $\left(\mu \mathrm{g} \mathrm{g}^{-1} \mathrm{PF}\right)$ en frutos de tomate cultivados bajo los diferentes tratamientos de luz y N. Los valores son medias \pm SE $(n=10)$.

Al igual que en el caso de los compuestos fenólicos, la concentración de vitamina $C$ en fruto fue mayor bajo condiciones de $100 \%$ luz y aumentó significativamente al disminuir la concentración de $\mathrm{N}$ en el medio de cultivo, aunque de forma menos acusada (Tabla 6.4, Figura 6.5). Sin embargo, a diferencia de lo observado para compuestos fenólicos, el efecto de ambos factores ( $\mathrm{N}$ y sombreo) sobre la concentración de vitamina $\mathrm{C}$, fue independiente el uno del otro (interacción $\mathrm{N}$ x sombreo no significativa). 


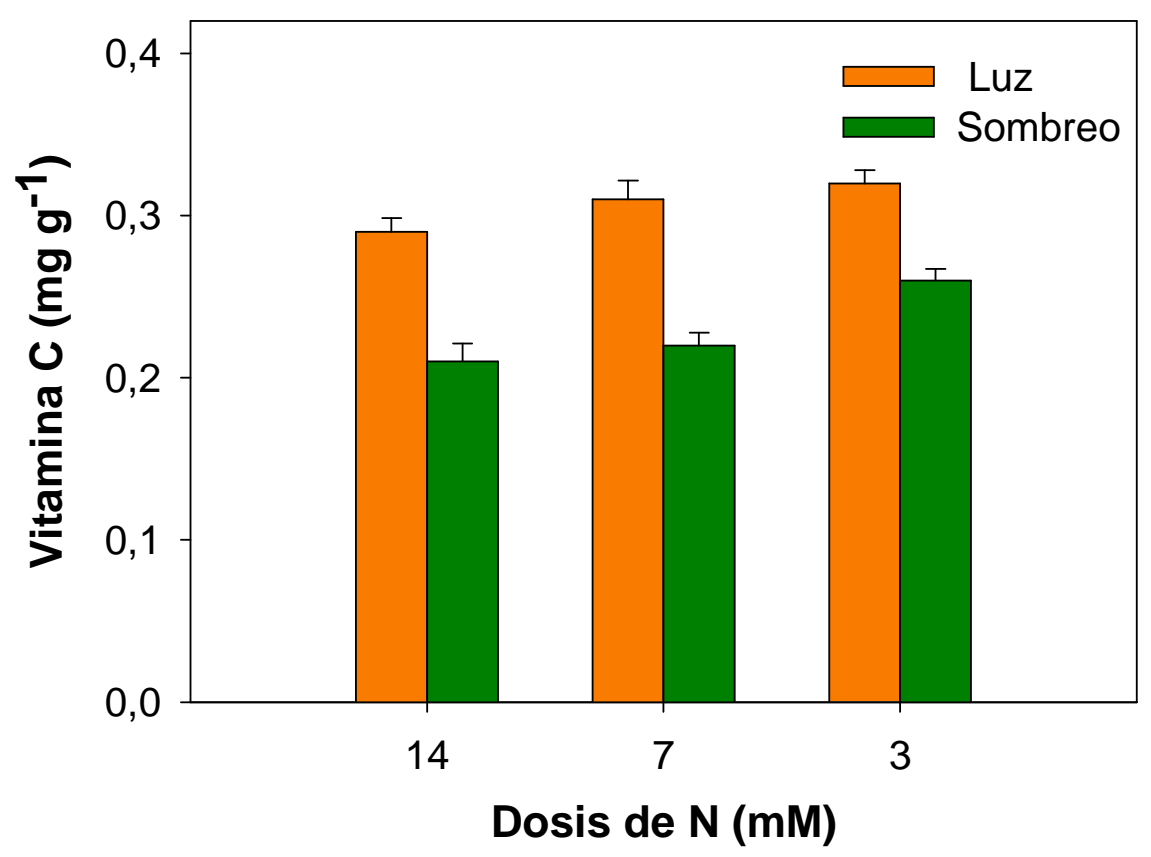

Figura 6.5. Concentración de vitamina $C\left(\mu \mathrm{g} \mathrm{g}^{-1} \mathrm{PF}\right)$ en frutos de tomate cultivados bajo los diferentes tratamientos de luz y $\mathrm{N}$. Los valores son medias \pm SE $(n=10)$.

Según Bènard y col. (2009), la disminución de la dosis de $\mathrm{N}$ provoca un aumento de la concentración de ácido ascórbico y compuestos fenólicos en tomate al disminuir la producción, aumentando la relación fuente/sumidero, lo que se traduce en un mayor contenido de estos metabolitos en fruto (efecto de concentración). Por otro lado, en un estudio realizado por Stewart y col. (2001), el estrés por déficit de $\mathrm{N}$ provocó un aumento del contenido de flavonoides en tomate, lo que se atribuyó al aumento de la actividad fenilalanina amonio liasa (PAL) que, bajo dichas condiciones, libera $\mathrm{N}$ hacia la ruta de síntesis de aminoácidos, a la vez que se derivan los esqueletos de carbono, vía 4-cumaroilCoA, hacia la síntesis de flavonoides (Margna, 1977). De acuerdo con Lovdal y col. (2010), la privación de $N$ en plantas de tomate provoca un aumento de la expresión de genes estructurales que regulan las enzimas PAL (fenilalanina amonio liasa), CHS (chalcona sintasa), F3H (flavanona-3-hidroxilasa), y FLS (flavonol sintasa), de las rutas de fenilpropanoides y flavononides, aumentando así la concentración de flavonoides. 
La síntesis de compuestos fenólicos puede estar inducida por un amplio rango de estímulos ambientales, entre los que destaca la luz (Li y col., 1993). Así, el aumento de la intensidad luminosa se ha correlacionado con la acumulación de compuestos fenólicos, además de vitamina $\mathrm{C}$, en tomate, probablemente debido al papel fotoprotector que juegan estos compuestos (Dumas y col., 2003; Gautier y col., 2008). En concreto, los flavonoles que se acumulan en la piel de los frutos de tomate, filtran las longitudes de onda dañinas de la radiación (Stewart y col., 2000) y proporcionan protección contra el daño oxidativo inducido por la luz (Guidi y col., 1998). Debido a la dependencia entre los factores luz y temperatura, el aumento de la concentración de compuestos fenólicos observada en fruto cultivados sin sombreo, puede también atribuirse a la mayor temperatura alcanzada en dicha zona (Gautier y col., 2008), probablemente debido a un mecanismo de defensa de la planta ante la situación de estrés (Karipcin y col., 2016). Por otro lado, se ha descrito una estrecha correlación entre las condiciones de luz y el contenido de ácido ascórbico en tomate y otros vegetales de forma que, en general, a menor intensidad luminosa, menor concentración de vitamina $\mathrm{C}$ en los tejidos, debido a un menor suministro de fotoasimilados necesarios para la síntesis de este metabolito (Gruda, 2005).

Existe escasa información sobre como el sombreo afecta al contenido de compuestos fenólicos en función del manejo de la nutrición nitrogenada (interacción $\mathrm{N}$ x sombreo). En general, la mayoría de los trabajos que estudian el efecto de diferentes factores ambientales y/o agronómicos sobre la composición de fruto, se centran en cada uno de estos factores de forma individual. Aunque esta información es muy valiosa para entender los mecanismos de respuesta de los cultivos a cada situación, estos estudios se alejan de lo que ocurren en condiciones de campo, donde normalmente se dan combinaciones de diferentes estreses y los resultados pueden diferir de los esperados. Así, se ha demostrado que el patrón de expresión génica en plantas cultivadas bajo la combinación de diferentes tipos de estrés, puede ser diferente del patrón de expresión observado cuando estos estreses son aplicados individualmente (Riszhsky y col., 2004; Mittler, 2006). En un estudio realizado por Mestre (2014), sobre tomate cultivado bajo una combinación de estreses (salinidad y alta temperatura), se observó que 
mientras que a $25^{\circ} \mathrm{C}$ la concentración de compuestos fenólicos aumentó como resultado del aumento de la concentración de $\mathrm{NaCl}$ por encima de $30 \mathrm{mM}$, a $35 \stackrel{\circ}{\circ} \mathrm{C}$ ocurrió el efecto contrario. En nuestro caso, el incremento de los compuestos fenólicos como resultado de la disminución de la dosis de $\mathrm{N}$, fue mucho más evidente bajo condiciones de $100 \%$ luz que con sombreo.

Respecto al contenido de vitamina $\mathrm{E}$ de los frutos, la respuesta a los tratamientos de $\mathrm{N}$ fue independiente de la intensidad luminosa (interacción $\mathrm{N}$ x sombreo no significativa) (Tabla 6.4) y muy diferente a la observada en el caso de compuestos fenólicos y vitamina C. En primer lugar, la reducción de la intensidad luminosa no afectó significativamente a la concentración de vitamina $E$ en el fruto, aunque se observó una ligera tendencia a disminuir (Tabla 6.4, Figura 6.6). Por otro lado, la disminución de la dosis de $\mathrm{N}$ disminuyó la concentración de esta vitamina. De acuerdo con nuestros resultados, se ha descrito una disminución de la concentración de vitamina $E$ en lechuga, como consecuencia de la aplicación de sombreo (Zhou y col., 2009). Según dichos autores, el mayor contenido de vitamina $\mathrm{E}$ y otros metabolitos como carotenoides, glutatión y ascorbato, encontrados en plantas crecidas bajo alta intensidad de luz, puede ser debido a su papel fotoprotector mediante la absorción del exceso de energía.

Licopeno y $\beta$-caroteno representaron el $74 \%$ y un $16 \%$, respectivamente, de los carotenoides totales detectados en fruto. En general, el sombreo provocó un aumento de la concentración de licopeno en tomate (Tabla 6.4, Figura 6.7). Según Gautier y col. (2008), el aumento de la temperatura del fruto de 27 a $32{ }^{\circ} \mathrm{C}$, inhibe la síntesis de precursores de licopeno y, a partir de $32 \stackrel{\circ}{C}$, se produce una reducción de la acumulación de este metabolito. Por lo tanto, el mayor contenido de licopeno encontrado en frutos cultivados bajo sombreo, podría atribuirse a la disminución de la temperatura máxima alcanzada en dicho tratamiento, y al aumento del tiempo en el que los frutos permanecieron por debajo de la temperatura crítica para la síntesis de licopeno, dentro de cada fotoperiodo. Por otro lado, el efecto del $\mathrm{N}$ sobre la concentración de licopeno, dependió de la intensidad luminosa; mientras que bajo condiciones de 100\% luz, la disminución de la dosis de $\mathrm{N}$ provocó una disminución de la concentración de este compuesto, bajo condiciones de $60 \%$ luz no se observó este efecto. Con respecto a $\beta$ - 
caroteno, también se detectó una interacción entre los factores $\mathrm{N}$ y sombreo, de forma que la disminución de $\mathrm{N}$, provocó una disminución de su concentración, la cual fue más pronunciada en condiciones de $100 \%$ de luz que en sombreo (Tabla 6.4, Figura 6.8).

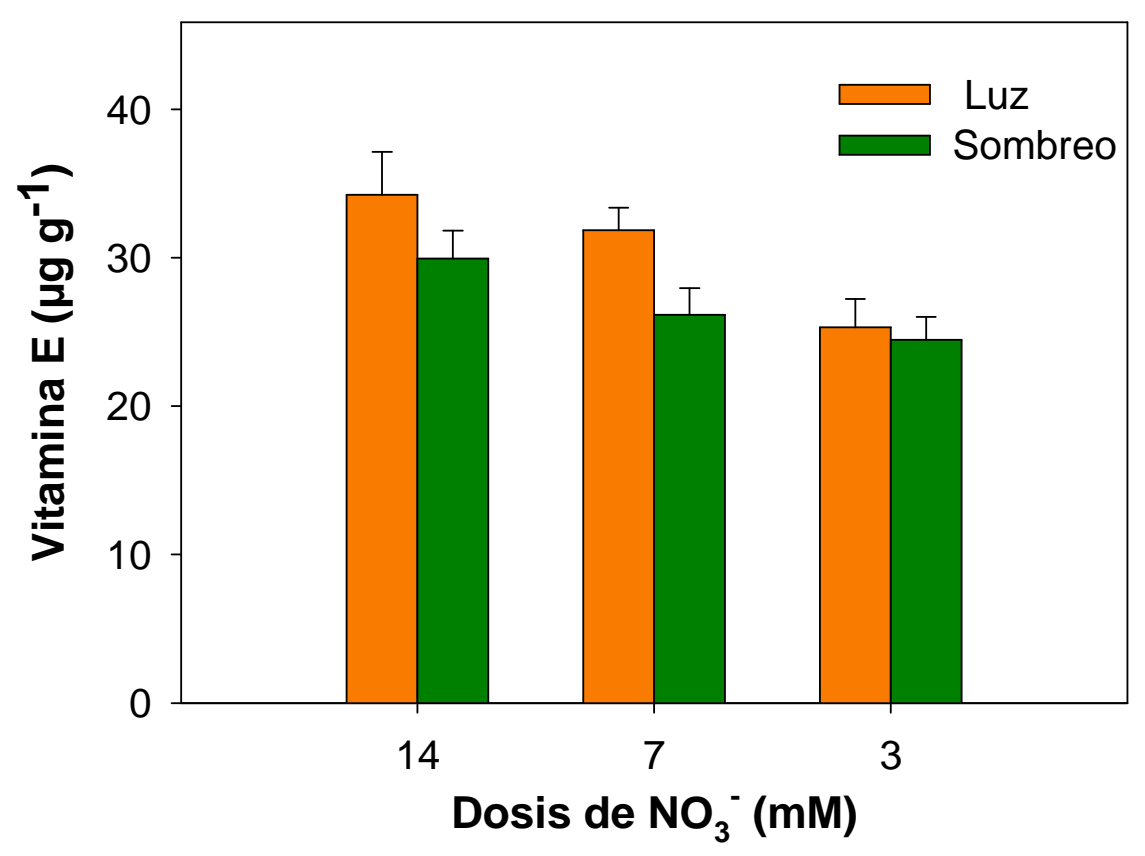

Figura 6.6. Concentración de vitamina $E\left(\mu g g^{-1} P F\right)$ en frutos de tomate cultivados bajo los diferentes tratamientos de luz y N. Los valores son medias \pm SE $(n=10)$. 


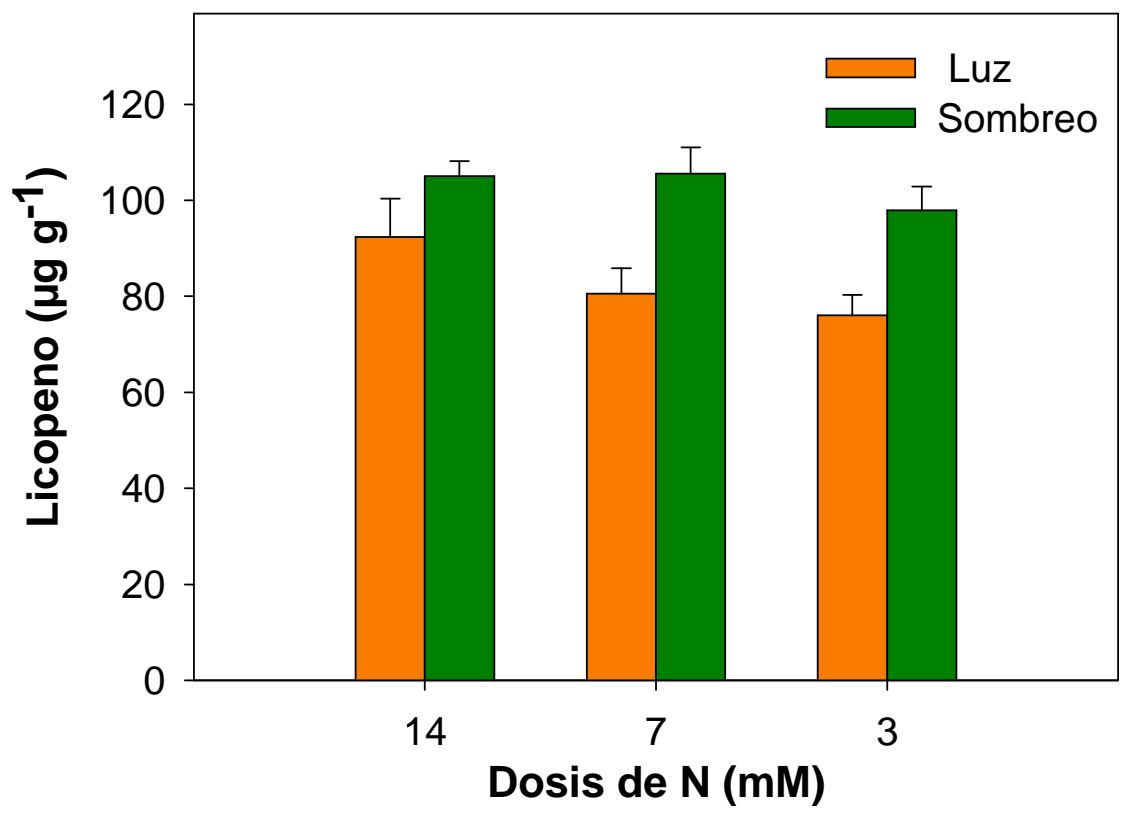

Figura 6.7. Concentración de licopeno ( $\mu \mathrm{g} \mathrm{g}^{-1} \mathrm{PF}$ ) en frutos de tomate cultivados bajo los diferentes tratamientos de luz y N. Los valores son medias \pm SE $(n=10)$.

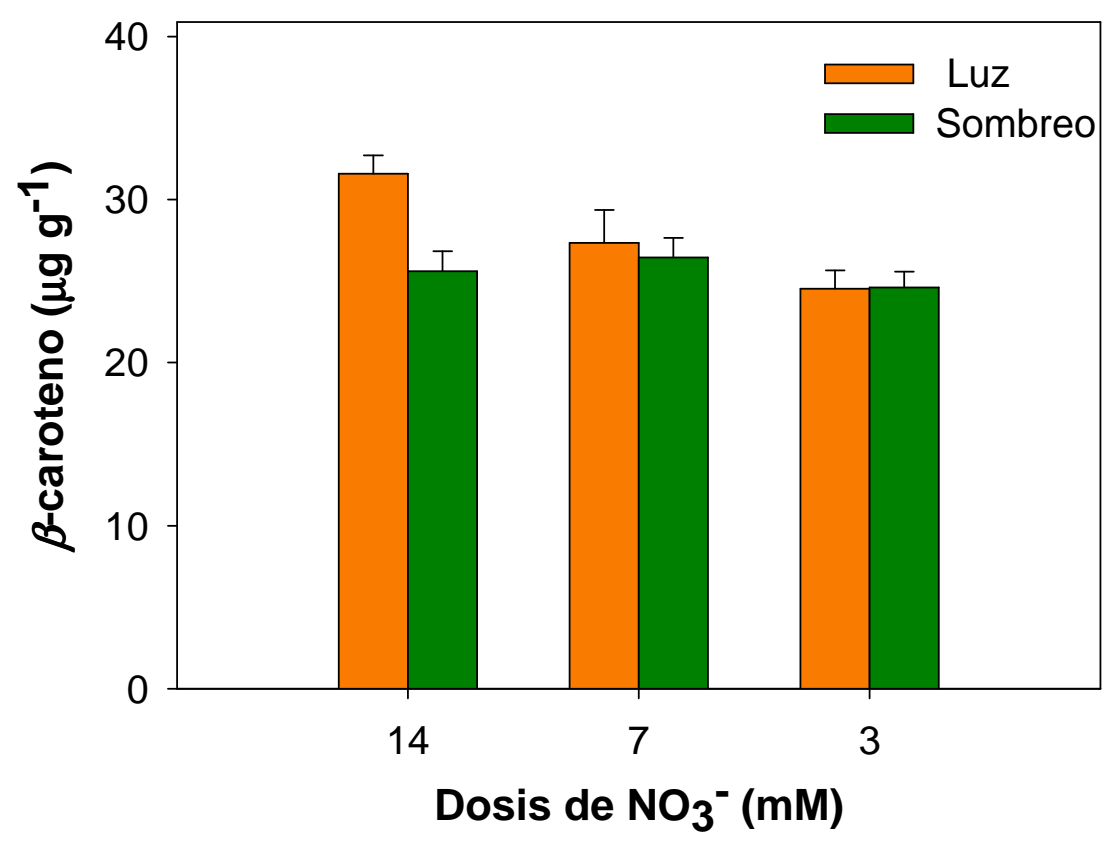

Figura 6.8. Concentración de $\beta$-caroteno $\left(\mu \mathrm{g} \mathrm{g}^{-1} \mathrm{PF}\right)$ en frutos de tomate cultivados bajo los diferentes tratamientos de luz y $N$. Los valores son medias \pm SE $(n=10)$. 
En resumen, la aplicación de mallas de sombreo disminuyó significativamente la producción total de frutos en las plantas cultivadas con 14 $\mathrm{mM} \mathrm{N}$, pero no afectó a la producción en los tratamientos con 7 y $3 \mathrm{mM}$. La disminución de la dosis de $\mathrm{N}$, provocó una reducción del número de frutos independientemente de la intensidad luminosa. Sin embargo, bajo condiciones de sombreo la disminución de la dosis de $\mathrm{N}$ favoreció el aumento del tamaño de los frutos. El sombreo no afectó a la concentración de azúcares en los frutos. La disminución de la dosis de $\mathrm{N}$, solo disminuyó la concentración de azúcares en el caso de glucosa en frutos cultivados con $3 \mathrm{mM} \mathrm{N}$, independientemente de la intensidad luminosa. Respecto al contenido de compuestos bioactivos, la aplicación de sombreo disminuyó la concentración de la mayoría de los compuestos estudiados (vitamina $\mathrm{C}$, compuestos fenólicos, vitamina $\mathrm{E}$ y $\beta$ caroteno). Mientras que la disminución de la dosis de $\mathrm{N}$ aumentó la concentración de vitamina $\mathrm{C}$ y compuestos fenólicos, dicha reducción tuvo el efecto contrario sobre vitamina $E$ y $\beta$-caroteno. Sin embargo, en ambos casos, el efecto de la dosis de $\mathrm{N}$ se vio amortiguado en condiciones de sombreo. Al contrario de lo observado para otros metabolitos, el sombreo aumentó la concentración de licopeno, probablemente debido a la disminución asociada de la temperatura. Además, bajo dichas condiciones, la disminución de la dosis de $\mathrm{N}$ no afectó significativamente a su concentración.

\subsubsection{Reducción de la dosis de $\mathbf{N}$ en diferentes fases de desarrollo}

\subsubsection{Producción}

La disminución del aporte de $\mathrm{N}$ suele estar relacionada con una disminución en el crecimiento vegetativo de la planta, pero si la disminución no se produce de manera muy drástica, no suele tener gran impacto en la cosecha comercial e incluso puede producirse un incremento del contenido de materia seca y de la calidad del fruto (Bénard y col., 2009). En nuestro ensayo, cuando los tratamientos de $\mathrm{N}$ se aplicaron desde el trasplante, la disminución de la dosis de $\mathrm{N}$ de 14 a 7 mM no afectó significativamente a la producción total (Figura 6.9 A). Sin embargo, las plantas fertilizadas con las dosis más baja (3 mM) obtuvieron un 
menor rendimiento que las plantas control (14 mM). Dicha merma del rendimiento fue debida a una disminución en el número de frutos. Por otro lado, las disminuciones en los aportes de $\mathrm{N}$ a partir de la floración del primer racimo, no afectaron a la producción total, ya que la disminución en el peso medio al disminuir la concentración $\mathrm{N}$ de 14 a $3 \mathrm{mM}$, fue compensada con un aumento del número de frutos (Figura 6.10 y Figura 6.11). Dicho aumento puede atribuirse a una menor caída de flores y por lo tanto a una menor relación fuente/sumidero, que justifica la disminución del peso de los frutos.

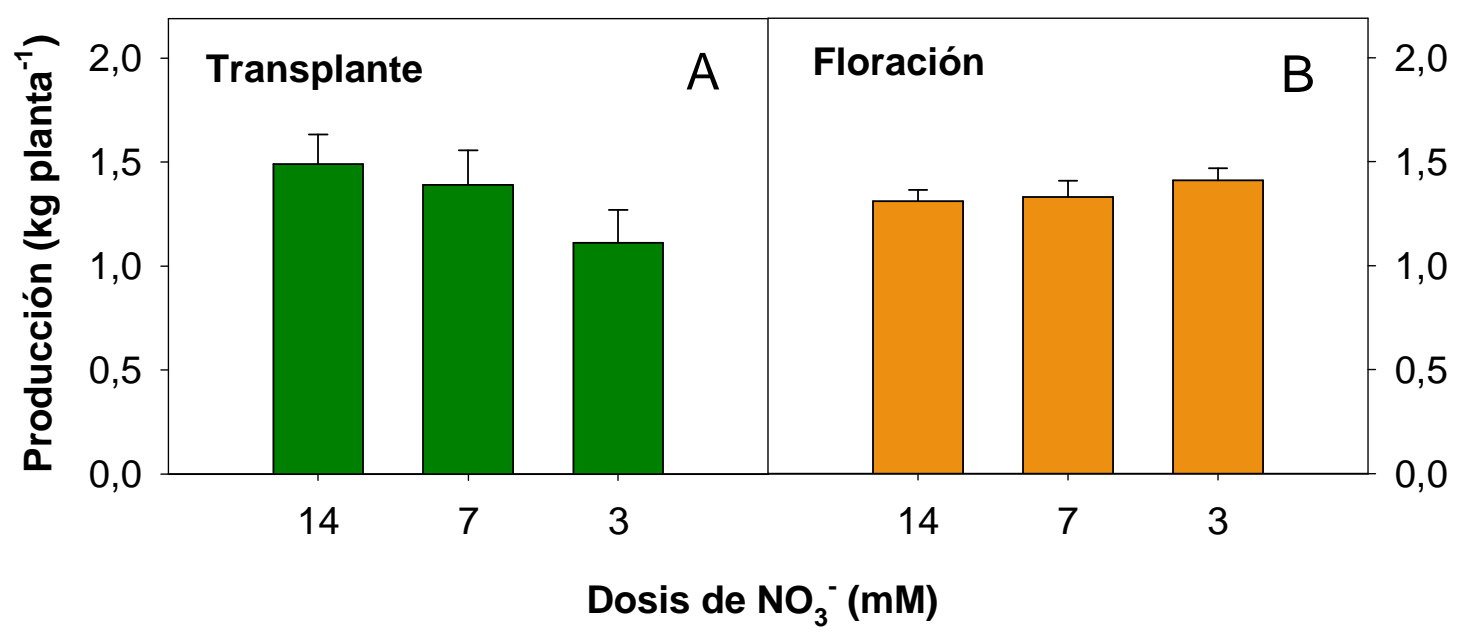

Figura 6.9. Efecto de diferentes dosis de $\mathrm{N}$ aplicadas desde el trasplante (A) y desde la floración (B) sobre la producción total. Los valores son medias $\pm \mathrm{SE}$ $(n=6)$. 


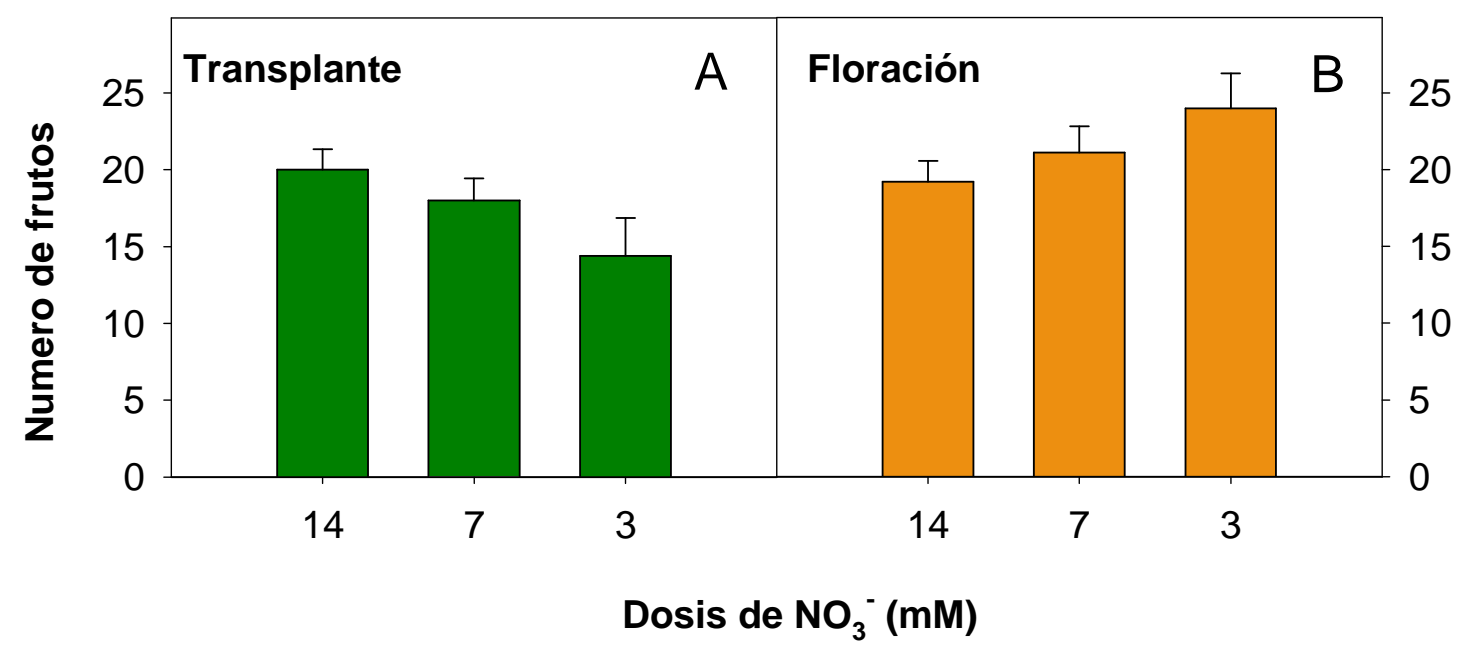

Figura 6.10. Representación de diferentes dosis de nitrógeno aplicadas desde trasplante $(A)$ y desde floración $(B)$ sobre el número de frutos. Los valores son medias $\pm \operatorname{SE}(n=6)$.

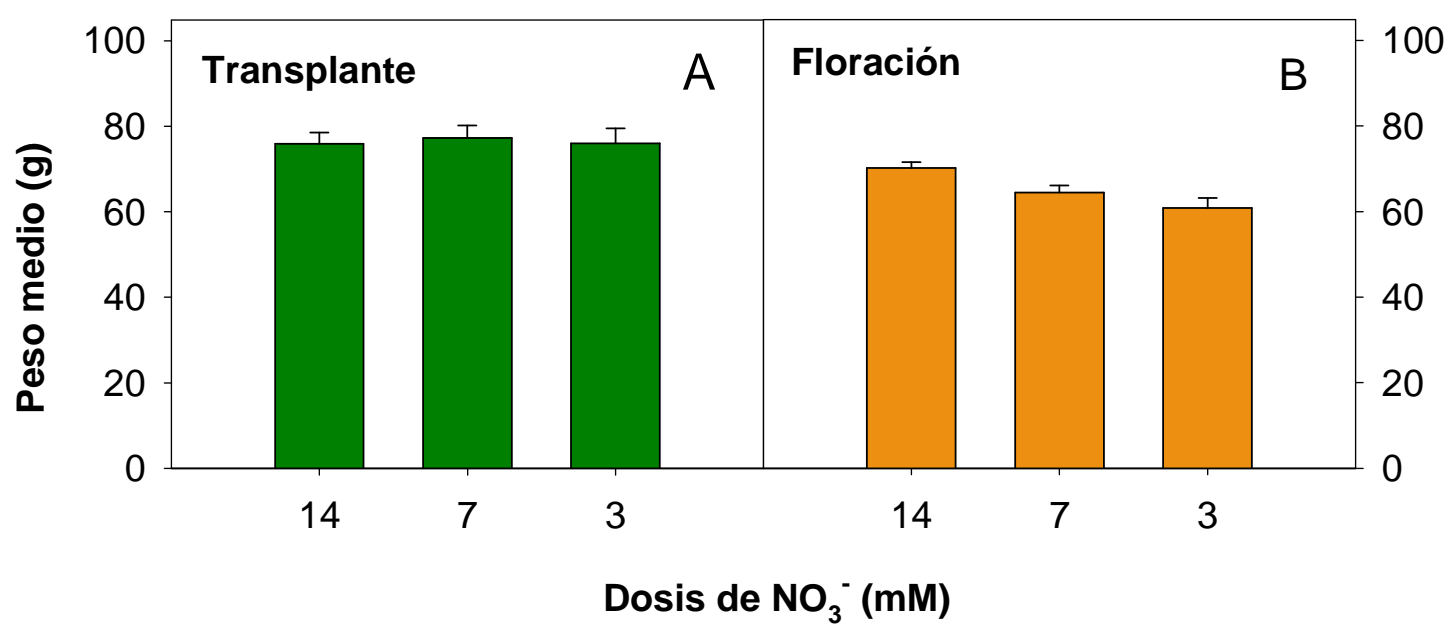

Figura 6.11. Efecto de diferentes dosis de $\mathrm{N}$, aplicadas desde trasplante (A) y desde floración (B) sobre el peso medio de los frutos. Los valores son medias \pm SE $(n=6)$. 


\subsubsection{Calidad}

Los azúcares solubles mayoritarios detectados en tomate fueron glucosa y fructosa. En el grupo de plantas donde los diferentes tratamientos de $\mathrm{N}$ se aplicaron desde el trasplante, se observó una disminución significativa tanto de la concentración de glucosa como de fructosa, al disminuir la dosis de $\mathrm{N}$ de 14 a 7 $\mathrm{mM}$ (Tabla 6.5). Por el contrario, en plantas donde los tratamientos se aplicaron a partir del periodo de floración, se observó un aumento significativo de la concentración de azúcares, en las plantas fertilizadas con la menor concentración de N (3 mM). La mayoría de los estudios previos, describen una acumulación de azúcares en frutos de tomate, como consecuencia de la restricción del aporte de N (Wang y col., 2007). Según Bènard y col. (2009), dicha acumulación es debida la disminución del crecimiento vegetativo que a su vez provoca un aumento de la irradiancia del fruto, aumentando así su actividad fotosintética y por lo tanto, su contenido en azúcares. Además, la disminución del crecimiento vegetativo también provocaría un aumento de la temperatura de los frutos y como consecuencia, del flujo de $\mathrm{C}$ y del contenido de hexosas en los mismos (Walker y Ho, 1997). Por último, Wingler y col. (2006) atribuyeron la acumulación de azúcares bajo restricciones de $\mathrm{N}$ a una disminución de la demanda de esqueletos de carbono para la síntesis de aminoácidos y proteínas. Estos resultados coinciden con los obtenidos en nuestro ensayo cuando las limitaciones de $\mathrm{N}$ se impusieron desde la floración de los primeros racimos. Sin embargo, en los tratamientos de $\mathrm{N}$ impuestos desde el trasplante se observó el efecto contrario, probablemente debido a que la restricción de $\mathrm{N}$, prolongada durante un mayor periodo de tiempo, resultó muy drástica, pudiendo afectar a la fotosíntesis durante los primeros estadios de desarrollo de la planta, interfiriendo así en el proceso de acumulación de reservas y por lo tanto, a la distribución posterior de fotoasilmilados hacia los frutos. 
Tabla 6.5. Contenido de glucosa y fructosa $\left(\mathrm{mg} \mathrm{g}^{-1}\right)$ en tomates sometidos a los diferentes tratamientos de $\mathrm{N}$ desde el trasplante o desde la floración del primer racimo.

\begin{tabular}{|c|c|c|c|}
\hline Estadio & Dosis N (mM) & Glucosa & Fructosa \\
\hline \multirow[t]{4}{*}{ Trasplante } & 14 & $20,4^{b}$ & $18,2^{b}$ \\
\hline & 7 & $17,7^{\mathrm{a}}$ & $16,0^{\mathrm{a}}$ \\
\hline & 3 & $\begin{array}{c}17,9^{\mathrm{a}} \\
\star \star *\end{array}$ & $\begin{array}{c}15,9^{\mathrm{a}} \\
x^{2}\end{array}$ \\
\hline & & $* *$ & \\
\hline \multirow[t]{3}{*}{ Floración } & 14 & $20,4^{a}$ & $18,2^{\mathrm{a}}$ \\
\hline & 7 & $20,9^{\mathrm{ab}}$ & $18,7^{\mathrm{a}}$ \\
\hline & 3 & $\begin{array}{c}22,3^{b} \\
*\end{array}$ & $\underset{* \star}{20,3^{b}}$ \\
\hline
\end{tabular}

En cuanto a la concentración de vitamina $\mathrm{C}$, la disminución de la dosis de $\mathrm{N}$ aumentó la concentración de este metabolito, independientemente del momento de desarrollo en el que se aplicó la restricción (Figura 6.12). Estos resultados coinciden con los encontrados en el estudio previo sobre una variedad comercial y el mutante enano Micro-Tom (Flores y col., 2015), y los descritos por Wang y col. (2008b). Algunos autores relacionan dicho incremento, al igual que en el caso de azúcares, con un aumento de la irradiancia en fruto (Dumas y col., 2003; Simone y col., 2007). Por otro lado, ascorbato es un metabolito secundario cuya síntesis puede aumentar bajo condiciones medioambientales adversas, como respuesta de la planta a un estrés abiótico (Gill y Tuteja, 2010; Gallie, 2013). Así, la restricción de $\mathrm{N}$ y el aumento de la temperatura de los frutos como consecuencia del menor crecimiento vegetativo, podría provocar la acumulación de este metabolito en fruto. 


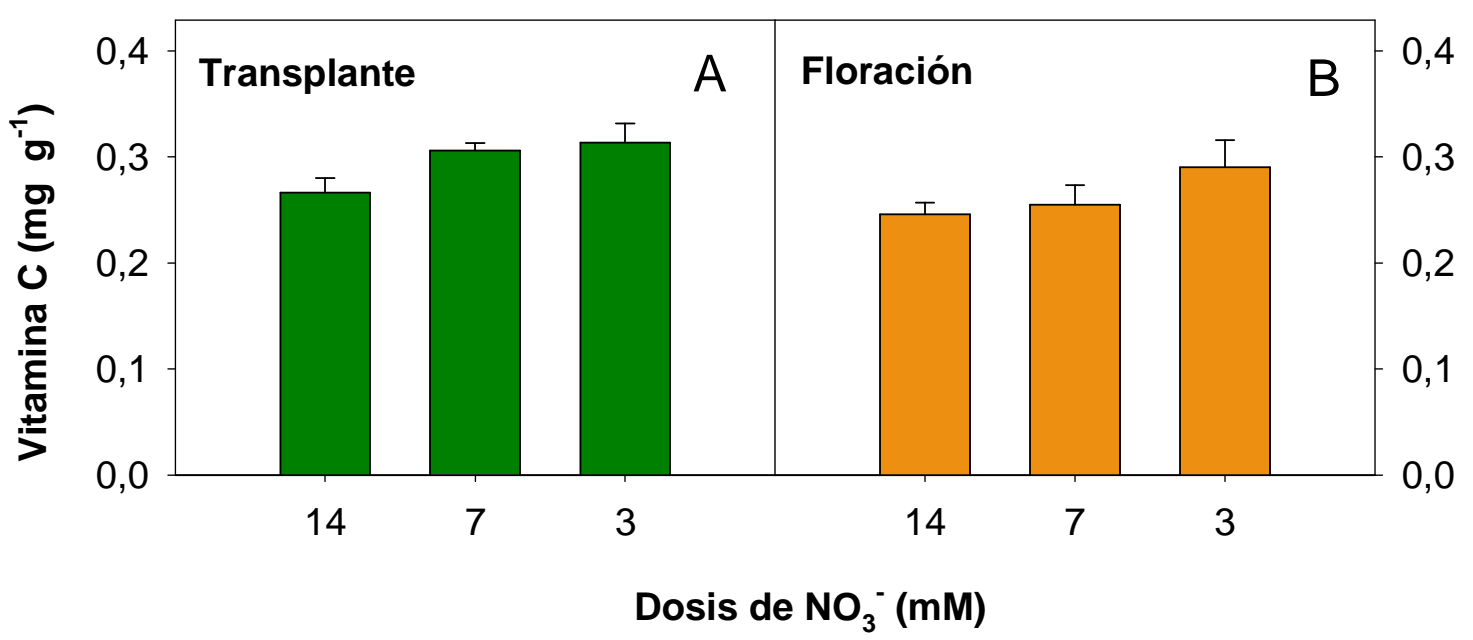

Figura 6.12. Efecto de diferentes dosis de $\mathrm{N}$ aplicadas desde trasplante (A) y desde floración (B) sobre el contenido de vitamina $\mathrm{C}\left(\mathrm{mg} \mathrm{g}^{-1}\right)$. Los valores son medias \pm SE $(n=6)$.

El efecto de la dosis de $\mathrm{N}$ sobre el contenido de los principales carotenoides, dependió de cada metabolito y de la etapa de desarrollo de la planta o del fruto en la que se impusieron los tratamientos. El compuesto mayoritario fue licopeno, seguido de $\beta$-caroteno, luteína, fitoeno, fitoflueno, violaxantina y $\gamma$-caroteno. La concentración de la mayoría de carotenoides disminuyó como resultado de una reducción de las dosis de $\mathrm{N}$, en las plantas en las que los tratamientos se impusieron desde trasplante (Figuras 6.13 y 6.14 y Tabla 6.6). Los resultados obtenidos cuando los tratamientos se impusieron desde floración fueron diferentes y dependieron del metabolito estudiado. Mientras que la concentración de licopeno y su precursor fitoeno aumentaron como consecuencia de la reducción de N (Figura 6.13), la mayoría de los carotenoides no se vieron afectados, excepto luteína cuya concentración fue menor en el tratamiento con $3 \mathrm{mM} \mathrm{N}$ respecto al resto (Figura 6.14). La disminución de $\mathrm{N}$ y el consecuente aumento de la temperatura del fruto provocarían dos efectos contrarios sobre la síntesis de carotenoides. Por un lado, el aumento de la irradiancia en el fruto estimularía su síntesis y por otro, el aumento de temperatura podría provocar el efecto contrario (Dumas y col., 2003). De acuerdo con Hernández y col. (2015), la temperatura afecta de distinta forma a la concentración de los diferentes carotenoides, dependiendo de la canalización 
metabólica entre las diferentes ramas de la ruta de biosíntesis de los isoprenoides. Así, los resultados obtenidos podrían explicarse por la combinación de los efectos contrarios que provocan el aumento de la irradiancia y de la temperatura, y por otro lado, por el diferente efecto de la temperatura dependiendo del metabolito estudiado.

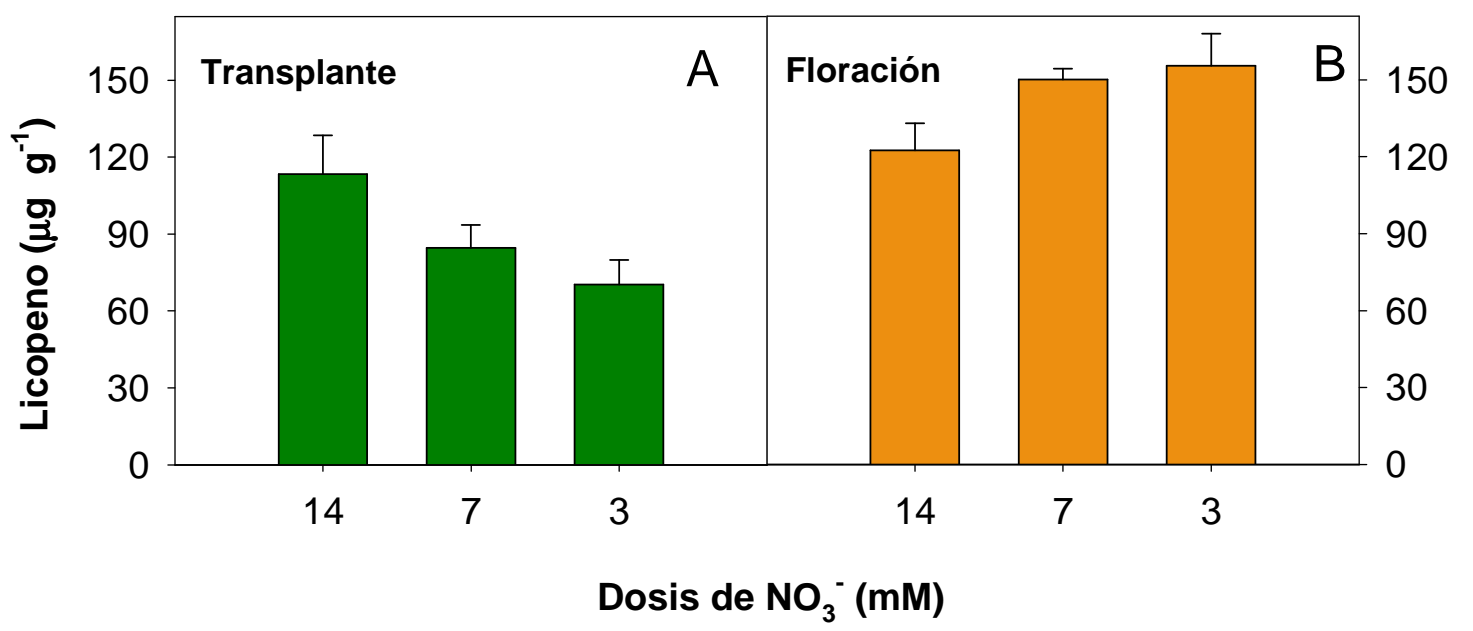

Figura 6.13. Efecto de diferentes dosis de $\mathrm{N}$ aplicadas desde trasplante (A) y desde floración (B) sobre el contenido de licopeno $\left(\mu \mathrm{g} \mathrm{g}^{-1}\right)$. Los valores son medias $\pm S E(n=6)$.

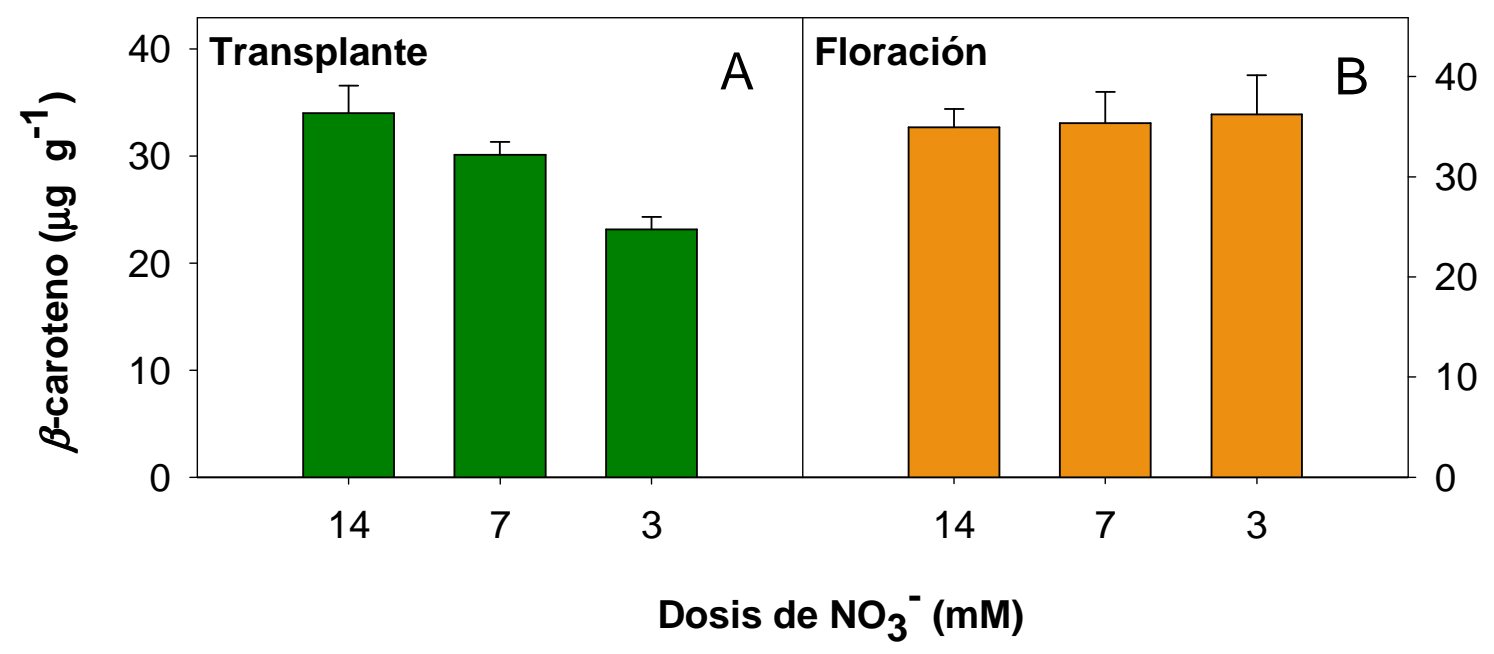

Figura 6.14. Efecto de diferentes dosis de $N$ aplicadas desde el trasplante $(A) \circ$ desde floración (B) sobre el contenido de $\beta$-caroteno $\left(\mu \mathrm{g} \mathrm{g}^{-1}\right)$. Los valores son medias $\pm \operatorname{SE}(n=6)$. 
Tabla 6.6. Contenido de luteína, violaxantina (viol), fitoeno, fitoflueno (fitof) y ycaroteno ( $\mathrm{\gamma}$-car) (expresados en $\mu \mathrm{g} \mathrm{g}^{-1}$ ), según el momento de aplicación en el que se aplicaron las diferentes dosis de nitrógeno ( $\mathrm{N} \mathrm{mM})$.

\begin{tabular}{ccccccc}
\hline Estadio & Dosis & Luteína & Viol & Fitoeno & Fitof & V-car \\
\hline \multirow{3}{*}{ Trasplante } & 14 & $14,1^{\mathrm{b}}$ & $2,5^{\mathrm{b}}$ & $24,9^{\mathrm{b}}$ & $6,0^{\mathrm{b}}$ & $2,4^{\mathrm{b}}$ \\
& 7 & $9,0^{\mathrm{a}}$ & $1,4^{\mathrm{ab}}$ & $20,8^{\mathrm{ab}}$ & $5,5^{\mathrm{ab}}$ & $1,9^{\mathrm{ab}}$ \\
& 3 & $8,1^{\mathrm{a}}$ & $1,0^{\mathrm{a}}$ & $16,5^{\mathrm{a}}$ & $3,6^{\mathrm{a}}$ & $1,6^{\mathrm{a}}$ \\
& & $*$ & $*$ & $*$ & $*$ & $*$ \\
Floración & 14 & $14,2^{\mathrm{b}}$ & 2,5 & $24,9^{\mathrm{a}}$ & 6,0 & 2,1 \\
& 7 & $14,4^{\mathrm{b}}$ & 2,9 & $26,4^{\mathrm{b}}$ & 7,1 & 2,6 \\
& 3 & $12,5^{\mathrm{a}}$ & 2,4 & $26,9^{\mathrm{b}}$ & 6,9 & 1,9 \\
& & $*$ & n.s. & $*$ & n.s. & n.s.
\end{tabular}

${ }^{*},{ }^{* *},{ }^{* * *}$, indican diferencias significativas entre medias con un nivel de probabilidad del $0,1,1$ y $5 \%$, respectivamente. n.s., no significativo. Los valores son medias \pm error estándar $(n=10)$.

En resumen, desde el trasplante, la disminución de la dosis de $\mathrm{N}$ de 14 a 7 $\mathrm{mM}$ no afectó a la producción, pero la disminución hasta $3 \mathrm{mM}$ provocó una pérdida de rendimiento, debido a un menor número de frutos. Sin embargo, la disminución en el aporte de $\mathrm{N}$ a partir de la floración del primer racimo, no afectó a la producción total, ya que la disminución en el peso medio al disminuir la concentración $\mathrm{N}$ de 14 a $3 \mathrm{mM}$, fue compensada con un aumento del número de frutos. Por otro lado, la reducción de $\mathrm{N}$ desde el trasplante, disminuyó la concentración de azúcares y de la mayoría de carotenoides. Por el contrario, cuando los tratamientos se aplicaron a partir de floración, la concentración de azúcares, licopeno y fitoeno aumentaron al disminuir la concentración de N. La mayoría de los carotenoides no se vieron afectados, excepto luteína. Por último, la concentración de vitamina C aumentó al disminuir la dosis de $\mathrm{N}$, independientemente del momento de aplicación de los tratamientos. 


\subsection{CONCLUSIONES}

El efecto negativo del sombreo sobre la producción de tomate pudo compensarse mediante la optimización de la nutrición nitrogenada de forma que, con una disminución de la dosis de $\mathrm{N}$, se consiguieron los rendimientos alcanzados sin sombreo. Además, el sombreo no afectó a la concentración de azúcares, aunque disminuyó la de muchos de los metabolitos relacionados con la calidad funcional (vitamina $\mathrm{C}, \beta$-caroteno, compuestos fenólicos y vitamina $\mathrm{E}$ ). Sin embargo, aumentó la concentración de licopeno, principal carotenoide de tomate responsable de su color y con reconocidas propiedades beneficiosas para la salud.

El efecto de la disminución de la dosis de $\mathrm{N}$ sobre la producción y calidad de tomate dependió en gran medida del momento fenológico en que se realizó dicha disminución. Al contrario de lo observado desde el trasplante, la disminución del aporte de $\mathrm{N}$ desde floración no afectó a la producción ni al contenido de $\beta$ caroteno y aumentó el contenido en azúcares y licopeno en fruto. Por otro lado, la concentración de vitamina $\mathrm{C}$ en fruto aumentó como consecuencia de la disminución del aporte de $\mathrm{N}$, independientemente del momento fenológico. 


\section{Capítulo 7}

\section{INFLUENCIA DE LA TEMPERATURA Y LA SALINIDAD SOBRE EL CONTENIDO DE TOMATE EN COMPUESTOS BIOACTIVOS}

La producción hortofrutícola en zonas áridas o semiáridas está condicionada por su climatología y escasez de recursos hídricos. En particular, la alta temperatura ambiental en estas zonas es un factor limitante para los cultivos, sobre todo cuando se desarrollan bajo invernadero (López, 2001). Este problema se ve acrecentado por la salinidad que presentan los suelos y las aguas de estas zonas. Todos estos factores tienen un efecto directo sobre la calidad de los frutos y en particular, sobre su contenido en compuestos antioxidantes (Dumas y col., 2003). Su estudio ha cobrado gran relevancia en los últimos años, debido a las variaciones de las condiciones ambientales ocasionadas por el llamado cambio climático y a su repercusión sobre la agricultura. Conocer la influencia de dichos factores, así como su interacción, sobre la calidad de los frutos, nos da herramientas para poder optimizar el manejo del cultivo con el fin de conseguir frutos de alto valor antioxidante y nutricional en condiciones ambientales adversas. La mayoría de los estudios presentes en la bibliografía, se basan en la respuesta de las plantas a un determinado tipo de estrés, pero los problemas de salinidad se suelen dar en regiones áridas donde la influencia del estrés por salinidad se agrava por la acción simultánea de factores xerotérmicos (Kuznestov y Shevyakova, 1997), como son las altas temperaturas y la sequía. En un estudio realizado en plántulas de tomate sometidas a una combinación de estrés salino y alta temperatura, se observó una respuesta específica de la planta a la combinación de ambos estreses de forma que, en contra de lo esperado, dicha combinación le confirió una protección frente a los efectos de la salinidad, que se tradujo en una mejora de la concentración de potasio en el tejido, del estado hídrico de las células y de la fotosíntesis, respecto al tratamiento con salinidad exclusivamente (Rivero y col., 2014). A pesar de la existencia de estudios a nivel 
fisiológico y agronómico que demuestran que la interacción de diferentes estreses no puede ser directamente extrapolada a la respuesta de la planta a cada uno de los estreses aplicados de manera individual (Mitller, 2006; Colmenero-Flores y Rosales, 2014), existe escasa información sobre el efecto de dicha combinación sobre la composición final del fruto. El objetivo de este trabajo fue estudiar el efecto del aumento de la temperatura y su interacción con el estrés salino, sobre las propiedades físicas (peso y color) de tomate y su contenido en compuestos bioactivos, en particular, licopeno, $\beta$-caroteno, vitamina $C$ y vitamina $E$.

\subsection{MATERIALES Y MÉTODOS}

\subsubsection{Material vegetal y manejo del cultivo}

El ensayo se llevó a cabo en un invernadero de policarbonato, formado por dos naves tipo capilla, con control automatizado de temperatura y humedad. Se cultivaron plantas de tomate (Solanum lycopersicum L. cV. Anairis) en un sistema hidropónico formado por cubas de $120 \mathrm{~L}$, provistas de un sistema de aireación permanente y de una plancha de polietileno negro para evitar la evaporación del agua y la exposición de la disolución nutritiva (Hoagland) a la luz (Figura 7.1). El volumen de las disoluciones se mantuvo constante mediante la adición de agua desionizada y las disoluciones se analizaron semanalmente para reponer los nutrientes absorbidos por la planta. El pH se controló cada tres días y se mantuvo en el rango de 5,5 a 6,5 .

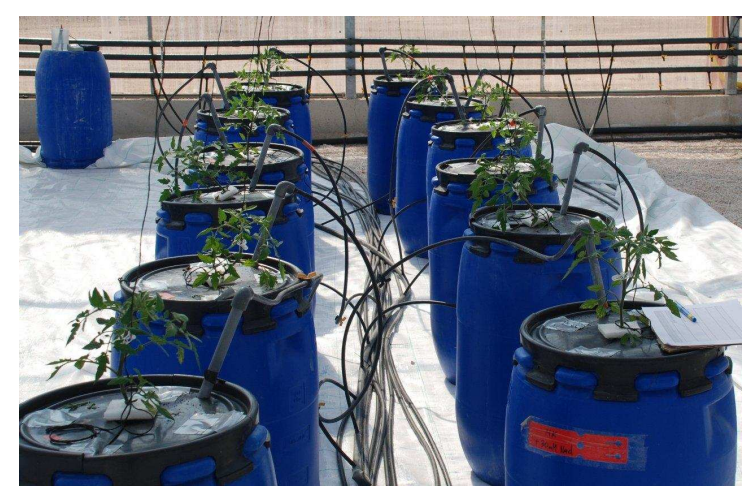

Figura 7.1. Detalle del sistema del cultivo hidropónico de tomate 


\subsubsection{Diseño experimental}

El ensayo consistió en ocho tratamientos resultado de la combinación de dos temperaturas máximas, $25{ }^{\circ} \mathrm{C}$ (óptima) y $35 \stackrel{\circ}{\circ} \mathrm{C}$, cada una de ellas fijada en una de las naves, y cuatro niveles salinos (10, 30,60 y $90 \mathrm{mM} \mathrm{NaCl}$ ), distribuidos según un diseño de bloques al azar, con dos bloques y 3 repeticiones por bloque. Los frutos se recolectaron progresivamente durante el mes de junio, a medida que alcanzaban el índice de madurez fisiológico fijado (fruto totalmente rojo, exento de zonas verdes, manchas amarillas y marrones). Se determinó la producción total, el número de frutos, el peso medio y los parámetros de color $\mathrm{L}^{*}$ (luminosidad) y a* (posición de rojo a verde) de los frutos y se trocearon y congelaron a $-80 \stackrel{\circ}{\mathrm{C}}$ para su posterior análisis. Los carotenoides principales (licopeno y $\beta$-caroteno), vitamina $E$ y vitamina $C$, se analizaron según las técnicas analíticas descritas en los apartados 3.3.3. y 3.3.4.

\subsubsection{Análisis estadístico}

Los resultados se analizaron estadísticamente mediante el análisis de la varianza (ANOVA), utilizando el programa estadístico SPSS 18. Los valores se compararon con el test de diferencia entre medias de Tukey.

\subsection{RESULTADOS Y DISCUSIÓN}

\subsubsection{Rendimiento}

Independientemente de la temperatura máxima alcanzada, la salinidad provocó una disminución de la producción total de fruto (Tabla 7.1). En el tratamiento de temperatura óptima $\left(25^{\circ} \mathrm{C}\right)$, esta pérdida de producción fue debida a la disminución del peso medio de los frutos. En el tratamiento a $35{ }^{\circ} \mathrm{C}$ fue atribuida, además de a la disminución del peso, a un menor número de frutos, en los tratamientos de 60 y $90 \mathrm{mM}$ de $\mathrm{NaCl}$. En lo referente al color, la luminosidad del fruto $\left(L^{*}\right)$ no se vio afectada por la salinidad ni por la temperatura. Sin 
embargo, el valor de la coordenada a* (contribución del rojo) aumentó tanto por el incremento de la concentración de $\mathrm{NaCl}$ en el medio, como por el aumento de la temperatura ambiental.

Tabla 7.1. Parámetros físicos de frutos de tomate cultivados bajo diferentes temperaturas ambientales y niveles salinos.

\begin{tabular}{|c|c|c|c|c|c|c|}
\hline $\mathbf{T}$ & $\begin{array}{l}\mathrm{NaCl} \\
(\mathrm{mM})\end{array}$ & $\begin{array}{c}\text { Producción } \\
\left.\text { (kg planta }^{-1}\right)\end{array}$ & $\begin{array}{c}\text { Peso medio } \\
(\mathrm{g})\end{array}$ & № frutos & $\mathbf{L}^{*}$ & $a^{*}$ \\
\hline \multirow{5}{*}{$25^{\circ} \mathrm{C}$} & 10 & $13,4^{d}$ & $248,6^{d}$ & $54,1^{\mathrm{ab}}$ & 38,3 & $11,6^{\mathrm{a}}$ \\
\hline & 30 & $11,9^{c}$ & $221,2^{c}$ & $53,7^{\mathrm{ab}}$ & 37,8 & $11,4^{\mathrm{a}}$ \\
\hline & 60 & $8,4^{b}$ & $146,4^{b}$ & $57,2^{b}$ & 37,7 & $12,9^{\mathrm{ab}}$ \\
\hline & 90 & $5,2^{a}$ & $103,5^{a}$ & $50,0^{a}$ & 38,0 & $14,0^{b}$ \\
\hline & & $* * *$ & $* * *$ & * & n.s. & ** \\
\hline \multirow{5}{*}{$35^{\circ} \mathrm{C}$} & 10 & $12,0^{c}$ & $198,0^{c}$ & $61,2^{b}$ & 37,5 & $12,6^{a}$ \\
\hline & 30 & $11,6^{c}$ & $194,4^{c}$ & $59,5^{b}$ & 38,3 & $13,2^{a}$ \\
\hline & 60 & $7,8^{\mathrm{b}}$ & $152,2^{b}$ & $51,3^{a}$ & 38,3 & $15,0^{b}$ \\
\hline & 90 & $4,6^{a}$ & $103,0^{a}$ & $44,8^{a}$ & 38,4 & $16,9^{c}$ \\
\hline & & $* * *$ & $\star * *$ & $* * *$ & n.s. & $* * *$ \\
\hline
\end{tabular}

Diferentes letras en la misma columna y para cada una de las temperaturas ( 25 y $35^{\circ} \mathrm{C}$ ) indican diferencias entre medias de acuerdo con el test de Tukey.

\subsubsection{Calidad}

La intensidad del color rojo en tomate se debe principalmente a su contenido en licopeno y, en menor medida, al de $\beta$-caroteno (Britton y col., 1995; Arias y col., 2000). De acuerdo con esto, en nuestro ensayo la intensidad del color rojo estuvo correlacionada con la concentración de licopeno, la cual aumentó significativamente con el aumento de la concentración de $\mathrm{NaCl}(P<0,05)$ en el medio de cultivo, tanto a $25^{\circ} \mathrm{C}$ como a $35^{\circ} \mathrm{C}$ (Figura 7.2). 


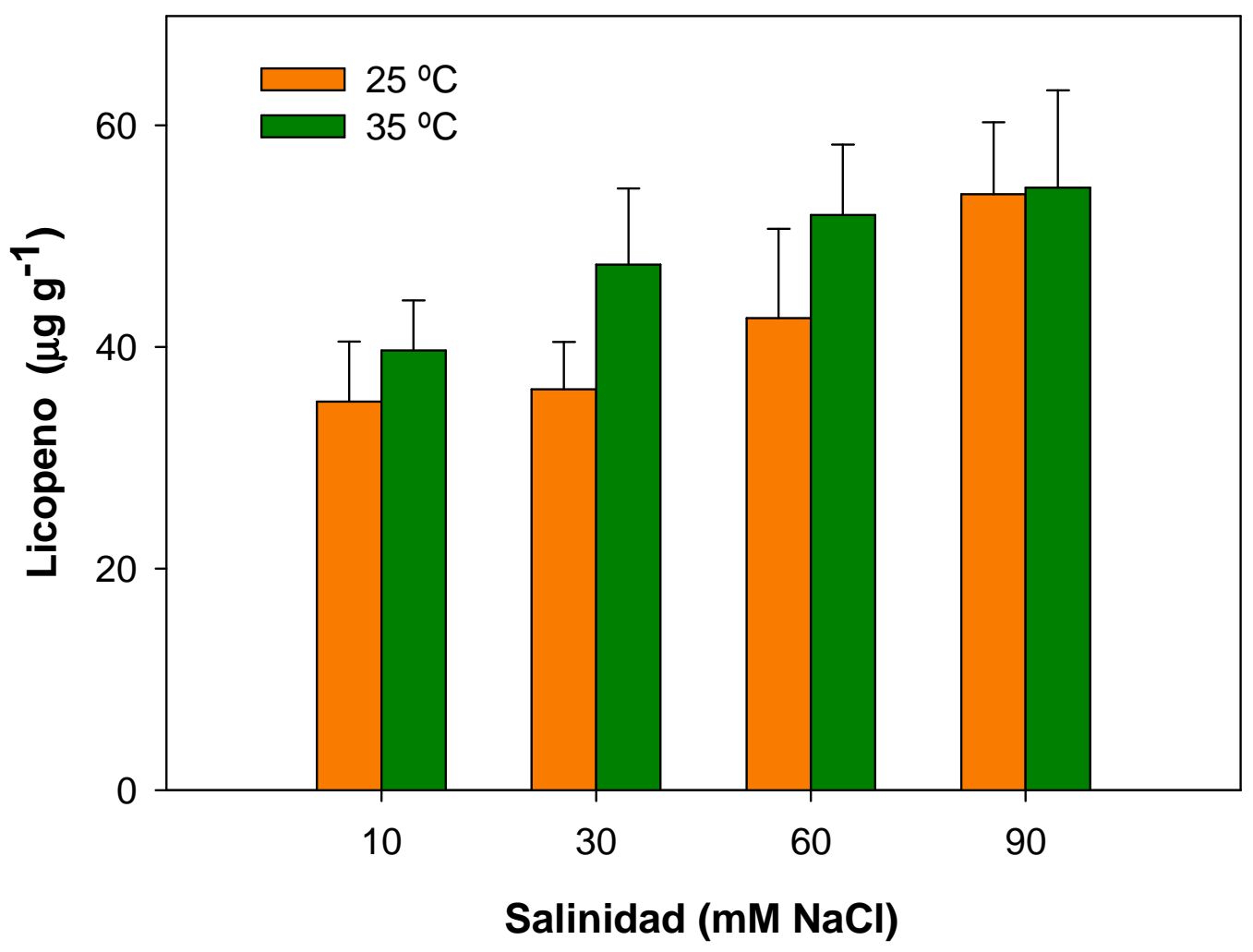

Figura 7.2. Concentración de licopeno ( $\mu \mathrm{g} \mathrm{g}^{-1} \mathrm{PF}$ ) en frutos de tomate cultivados a diferentes temperaturas $(25 \stackrel{\circ}{\circ}$ y $35 \stackrel{\circ}{\circ})$ y con distintos niveles salinos $(10,30$, 60 y $90 \mathrm{mM} \mathrm{NaCl}$. Las barras son media \pm error estándar $(n=6)$.

Por otro lado, la concentración de $\beta$-caroteno aumentó con la salinidad en el tratamiento a $25{ }^{\circ} \mathrm{C}$ (Figura 7.3 ). Sin embargo, a $35{ }^{\circ} \mathrm{C}$ no se observó la influencia del estrés salino. 


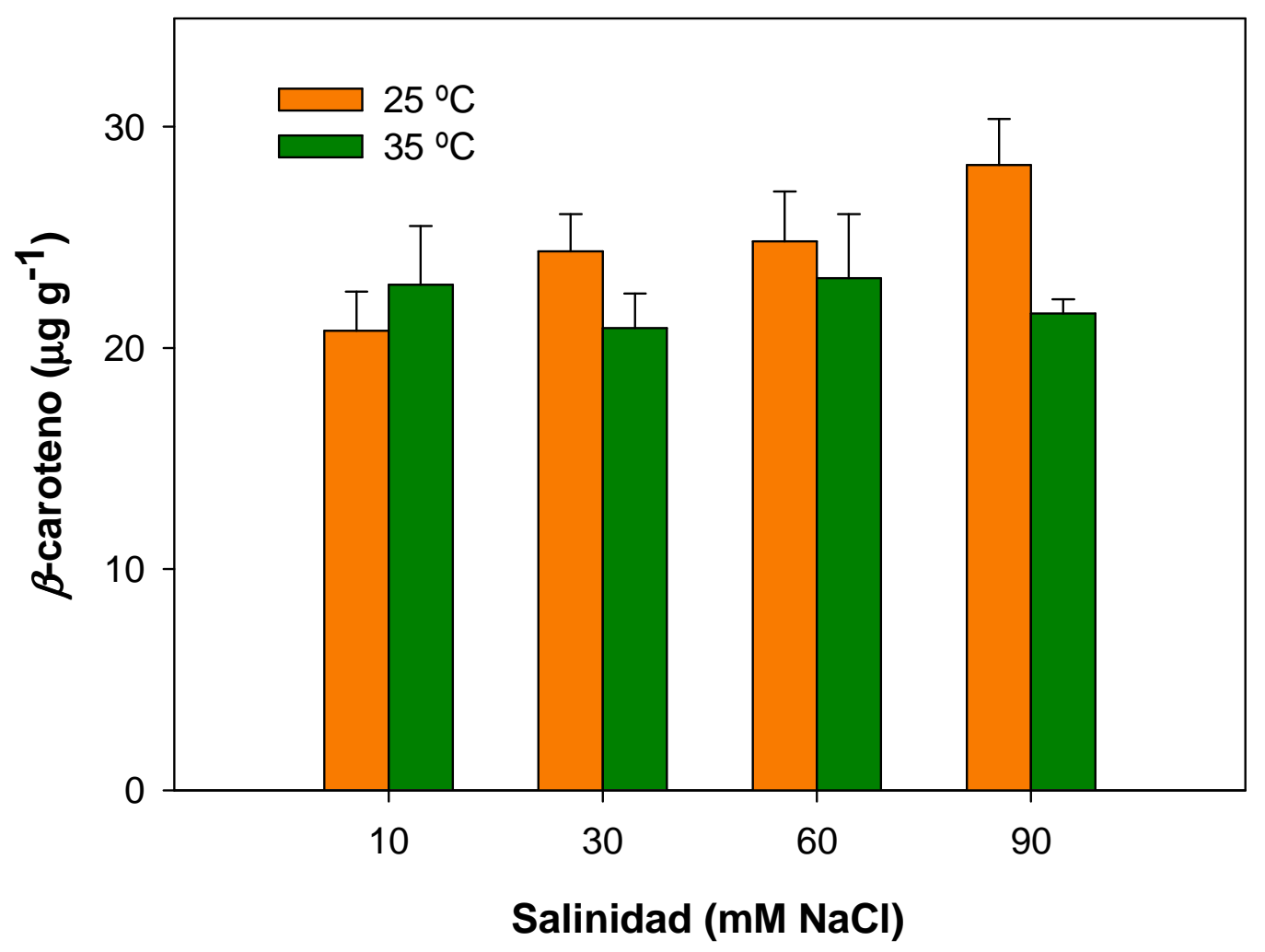

Figura 7.3. Concentración de $\beta$-caroteno $\left(\mu \mathrm{g} \mathrm{g} \mathrm{g}^{-1} \mathrm{PF}\right.$ ) en frutos de tomate cultivados a diferentes temperaturas $\left(25{ }^{\circ} \mathrm{C}\right.$ y $\left.35 \stackrel{\circ}{\circ} \mathrm{C}\right)$ y bajo distintos niveles salinos $(10,30,60$ y $90 \mathrm{mM} \mathrm{NaCl})$. Las barras son media \pm error estándar $(n=6)$.

Algunos autores atribuyen el aumento de la concentración de carotenoides en frutos cultivados bajo estrés salino, a la reducción de la carga productiva (Borghesi y col., 2011) y/o a la reducción de agua en el fruto (Krauss y col., 2006). En el caso concreto de licopeno, es más probable que la causa sea la menor relación fuente/sumidero, más que el resultado de una concentración provocada por la reducción del contenido de agua en el fruto, ya que apenas se modifica el contenido de sólidos solubles totales (Wu y Kubota, 2008). Además, Botella y col. (2000), encontraron que el riego de plantas de tomate con disoluciones que contenían 40-60 mM de NaCl, aumentaba el color rojo y la producción de etileno, lo que se traducía en un aumento de licopeno en los tomates y en una aceleración de la maduración. En nuestro estudio, el aumento de la concentración de licopeno en respuesta a la salinidad, estuvo acompañado de una disminución de la 
producción de fruto. Sin embargo, las diferencias encontradas en la respuesta de licopeno y $\beta$-caroteno frente al estrés salino, sugieren la posible influencia de la salinidad sobre los mecanismos involucrados directa o indirectamente en la síntesis de carotenoides en fruto.

El efecto del aumento de la temperatura sobre el contenido de carotenoides también dependió del compuesto estudiado. Mientras que la concentración de licopeno no se modificó significativamente al aumentar la temperatura, en $\beta$ caroteno se observó una disminución de su concentración en el tratamiento salino más elevado. Otros autores han descrito que un aumento de la temperatura ambiental a $32 \stackrel{\circ}{\mathrm{C}}$ no afecta a la concentración de $\beta$-caroteno en tomate (Lester, 2006). Por otro lado, en un estudio realizado sobre tomate cortado, la síntesis de licopeno durante la maduración del fruto disminuyó a partir de 27 ํ $\mathrm{C}$ y se observó una inhibición del compuesto a $32{ }^{\circ} \mathrm{C}$ (Gautier y col., 2008). Las diferencias encontradas con respecto a nuestros resultados, pueden deberse al hecho de que en el presente estudio, la maduración del fruto tuvo lugar en la planta y la temperatura máxima de $35^{\circ} \mathrm{C}$ sólo se alcanzó en horas puntuales del fotoperiodo. De nuevo, licopeno y $\beta$-caroteno presentaron respuestas diferentes al estrés, en este caso térmico, indicando la posibilidad de una modificación del metabolismo de biosíntesis de carotenoides como resultado del aumento de la temperatura.

La salinidad también provocó un aumento significativo $(P<0,05)$ de la concentración de vitamina $\mathrm{C}$ en tomates cultivados a $25^{\circ} \mathrm{C}$ y a $35^{\circ} \mathrm{C}$ (Figura 7.4). Diversos autores han descrito resultados similares atribuyéndolos a la respuesta de la planta ante una situación de estrés y a una concentración de este compuesto como consecuencia de la reducción del número de frutos y/o de su peso medio (Petersen y col., 1998; De Pascale y col., 2001; Krauss y col., 2006). Por otro lado, el aumento de temperatura produjo un aumento significativo $(P<0,001)$ de la concentración de esta vitamina, independientemente del nivel salino aplicado. El aumento de temperatura ambiental se ha correlacionado con una disminución de la acumulación de ascorbato en fruto de tomate, como consecuencia de la inhibición de la síntesis de este compuesto y el aumento de su oxidación (Rosales y col., 2006; Ehret y col., 2013). Sin embargo, los resultados obtenidos en nuestro estudio del efecto del aumento de la temperatura diurna 
sobre la calidad de tomate, dependiendo del estado de desarrollo del fruto (capítulo 5), muestran como la acumulación de ácido ascórbico en frutos se recupera a partir de 27 días después del aumento de temperatura, alcanzando posteriormente valores superiores a los de frutos cultivados bajo condiciones de temperatura óptima.

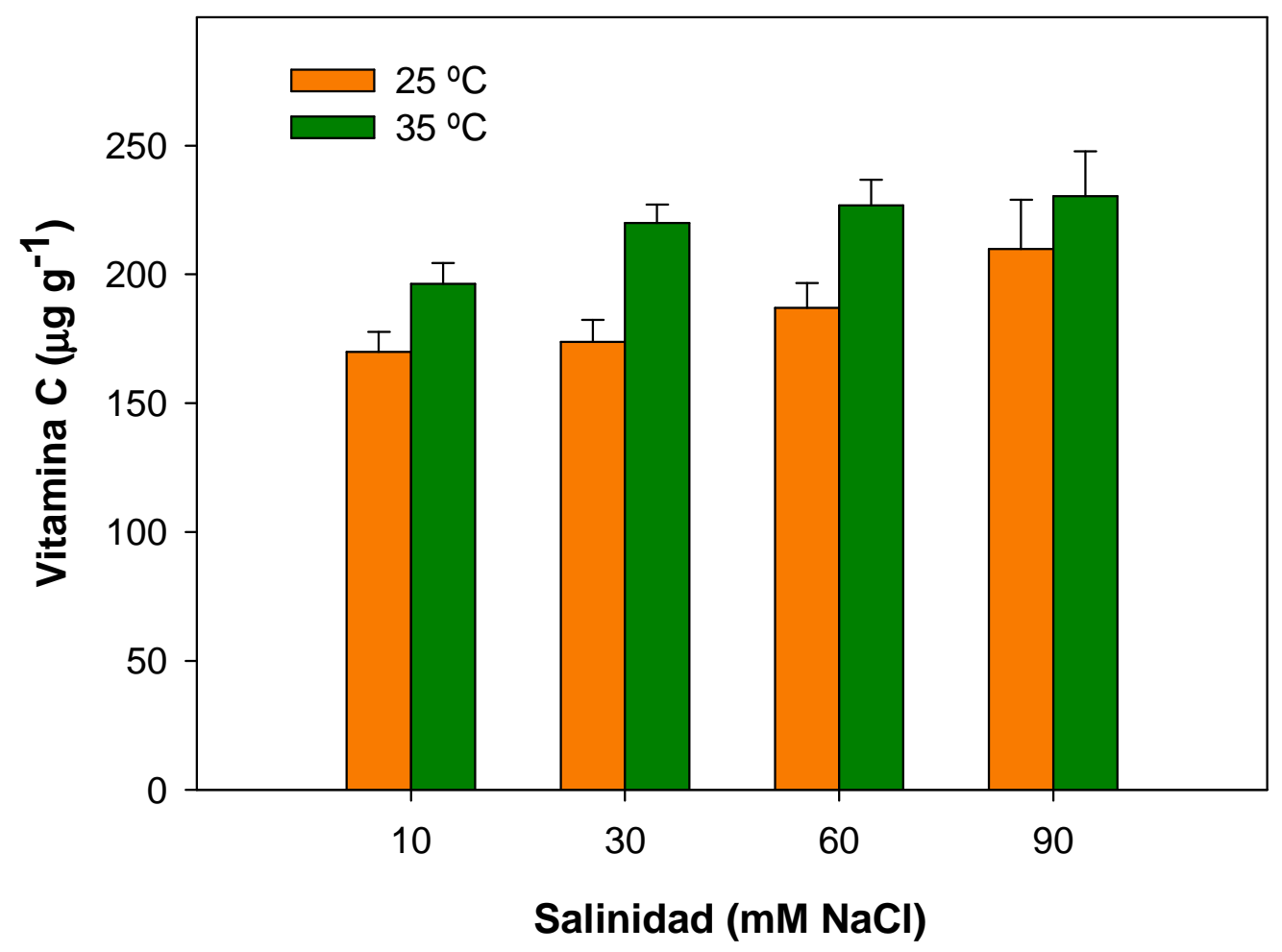

Figura 7.4. Concentración de vitamina $C\left(\mu \mathrm{g} \mathrm{g}^{-1} \mathrm{PF}\right)$ en frutos de tomate cultivados a diferentes temperaturas $\left(25{ }^{\circ} \mathrm{C}\right.$ y $\left.35 \stackrel{\circ}{\circ} \mathrm{C}\right)$ y bajo distintos niveles salinos $(10,30,60$ y $90 \mathrm{mM} \mathrm{NaCl})$. Las barras son media \pm error estándar $(n=6)$.

Por último, el contenido de vitamina $\mathrm{E}$ (calculado como suma de $\alpha$ - y $\gamma^{-}$ tocoferol) aumentó progresivamente $(P<0,001)$ con el incremento de la concentración de $\mathrm{NaCl}$ en el medio de cultivo (Figura 7.5). Sin embargo, el efecto de la temperatura sobre su concentración en fruto no fue significativo. El aumento de la concentración de tocoferol en condiciones de alta salinidad, al igual que el de otros compuestos como vitamina $\mathrm{C}$, es atribuido a su contribución como 
antioxidante para la protección de la planta frente a condiciones de estrés (Sgherri y col., 2007).

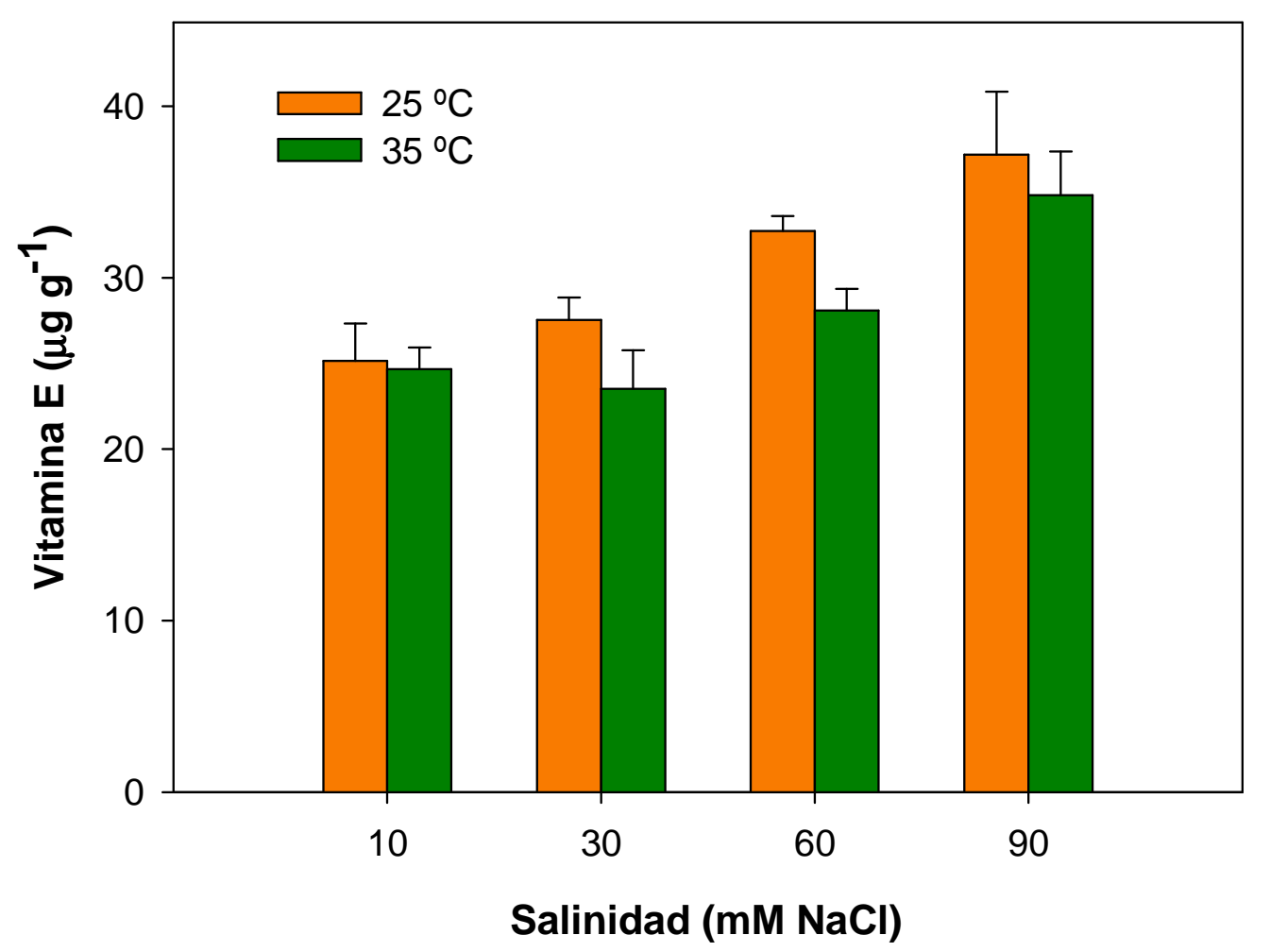

Figura 7.5. Concentración de vitamina $E\left(\mu g g^{-1} \mathrm{PF}\right)$ en frutos de tomate cultivados a diferentes temperaturas $\left(25{ }^{\circ} \mathrm{C}\right.$ y $\left.35{ }^{\circ} \mathrm{C}\right)$ y bajo distintos niveles salinos $(10,30,60$ y $90 \mathrm{mM} \mathrm{NaCl})$. Las barras son media \pm error estándar $(n=6)$.

\subsection{CONCLUSIONES}

El aumento de la salinidad en el medio de cultivo provocó una disminución de la producción de tomate, como consecuencia de la disminución del peso medio de los frutos. Este problema se agravó cuando la temperatura máxima ambiental ascendió hasta $35^{\circ} \mathrm{C}$, debido a una disminución del número de frutos. La pérdida de productividad como consecuencia del estrés salino y su combinación con un aumento de la temperatura, pudo ser en parte compensada, en términos de valor nutritivo, por el incremento de la concentración de licopeno y vitamina $C$ en el fruto. Por otro lado, la salinidad mostró como efecto positivo el aumento de la 
concentración de vitamina $\mathrm{E}$, aunque el aumento de temperatura no contribuyó a mejorar su contenido en el fruto. Por último, la salinidad también aumentó el contenido de $\beta$-caroteno, pero sólo en el tratamiento de $25^{\circ} \mathrm{C}$. Estos resultados ponen de manifiesto que, a pesar del efecto negativo que pueden ocasionar sobre la producción el estrés salino y el aumento de la temperatura, dichos factores ambientales contribuyen a aumentar los niveles de compuestos bioactivos en tomate. 


\section{Capítulo 8}

\section{RESPUESTA DE LA PLANTA DE TOMATE A LA APLICACIÓN DE BIOESTIMULANTES EN CONDICIONES DE ALTA TEMPERATURA}

El uso de bioestimulantes vegetales en agricultura ha experimentado un notable incremento en los últimos años. Algunos de estos compuestos, como por ejemplo ácido salicílico y metil jasmonato, se encuentran de forma natural en las plantas, actuando como señales internas que regulan la respuesta de defensa ante el estrés (Yang y col., 2004a). La aplicación exógena de bioestimulantes induce, los mecanismos de defensa de la planta (Mejía-Teniente y col., 2010; Takatsuji y col., 2010), de forma similar a lo que ocurre bajo condiciones de estrés. De esta forma, los bioestimulantes favorecen procesos fisiológicos, como la fotosíntesis y la producción de biomasa (Katiyar y col., 2015; Ghaderi y col., 2015), aumentando así el rendimiento y la calidad de las cosechas (Ambuludi, 2015). Además, la respuesta de la planta ante el estrés o como consecuencia de la aplicación exógena de ciertos bioestimulantes, implica el aumento de la síntesis de metabolitos secundarios, como es el caso de resveratrol o antocianos en uva, furanocumarinas en perejil o isoflavonoides en leguminosas (Cantos y col., 2003; Iriti y col., 2005; Camarena-Gutiérrez y de la Torre-Almaráz, 2007). Muchos de estos compuestos tienen propiedades antioxidantes y aportan beneficios para la salud cuando son ingeridos a través de la dieta. De esta forma, la aplicación de bioestimulantes ofrece una ventaja frente a otras prácticas agronómicas encaminadas a aumentar el rendimiento de los cultivos, como por ejemplo el manejo de la nutrición mineral, en las que un aumento de la producción puede provocar, en determinados casos, una disminución del contenido de compuestos bioactivos en los frutos (Gènard y col., 2003).

La capacidad que presentan ciertos bioestimulantes de inducir la respuesta de la planta frente al estrés, hace que su uso en agricultura sea de gran interés, cuando se pretende mejorar el rendimiento de los cultivos bajo condiciones 
adversas. En zonas cálidas, el estrés por alta temperatura es uno de los factores ambientales que mayor repercusión tiene sobre la productividad y la calidad de los cultivos. En concreto, en tomate, el aumento de la temperatura causa aborto floral y problemas en el cuaje de los frutos, produciendo importantes pérdidas en las cosechas (Bita y col., 2011; Bita y Gerats, 2013). Además, el aumento de la temperatura puede modificar la composición de los frutos, alterando sus propiedades físicas y la calidad sensorial y nutricional de estos (Dumas y col., 2003).

Existe una amplia gama de sustancias con propiedades bioestimulantes y, a pesar de las evidencias aportadas sobre los beneficios de su aplicación sobre el rendimiento de las cosechas, la información sobre las peculiaridades de cada compuesto, su idoneidad para cultivos específicos y el modo de aplicación más adecuado, sigue siendo escasa y confusa. El objetivo de este estudio es conocer la respuesta a nivel fisiológico, agronómico y bioquímico de tomate, cultivado bajo condiciones de alta temperatura, a la aplicación de bioestimulantes (metil jasmonato (MJ), ácido salicílico (AS), quitosano (Q), y 2,4-epibrasinolido (BR)), considerando diferentes concentraciones y modos de aplicación.

\subsection{MATERIALES Y MÉTODOS}

\subsubsection{Material vegetal y sitio de estudio}

Se cultivaron plantas de tomate (Solanum lycopersicum L. CV. Velasco) bajo invernadero, durante los meses de enero a julio en la finca "Torreblanca" propiedad del IMIDA, situada en Torrepacheco, Murcia (37은 $46^{\prime} 26.43^{\prime \prime}$ N y $0^{\circ} 53^{\prime}$ 26.43" O), con un clima mediterráneo y un suelo clasificado como franco-arcilloso. El ensayo se llevó a cabo en un invernadero de polietileno de tipo capilla con una superficie de $300 \mathrm{~m}^{2}$. 


\subsubsection{Manejo del cultivo}

Para la preparación del suelo, se realizaron labores para romper el horizonte superior endurecido (pase de cultivador a una profundidad de $30 \mathrm{~cm}$ y fresadora a una profundidad de $15-20 \mathrm{~cm}$ ) y así mejorar la estructura y porosidad del mismo, aumentando la retención de agua. Posteriormente el suelo se desinfectó mediante biosolarización, para lo que se aplicó y enterró materia orgánica de oveja bien fermentada, a razón de $4 \mathrm{~kg} \cdot \mathrm{m}^{-2}$. Finalmente se regó abundantemente, el suelo se cubrió con plástico y el invernadero se cerró durante tres meses para conseguir que las elevadas temperaturas y la emisión de gases redujeran las poblaciones de patógenos y la viabilidad de semillas de malas hierbas. Tras la desinfección del suelo, se instaló la red de riego por goteo y se diseñó la distribución parcelaria. El marco de plantación adoptado fue de $1 \mathrm{~m}$ entre filas y 0,4 $\mathrm{m}$ entre plantas, con una densidad de cultivo de 25000 plantas $\cdot \mathrm{ha}^{-1}$. La parcela estaba abastecida por un cabezal con un tanque de abonado y una tubería secundaria que alimentaba a dieciséis líneas porta goteros. Se colocó un gotero interlínea de $2 \mathrm{~L} \cdot \mathrm{h}^{-1}$ por planta.

El manejo de la fertilización se realizó siguiendo las Normas Técnicas recomendadas por la Dirección General de Agricultura e Industrias Agrarias para la Producción Integrada de tomate, reguladas en la Orden de la Consejería Agricultura y Agua del 10 de mayo de 2012 (BORM, 2012). El riego se realizó teniendo en cuenta las necesidades hídricas totales, calculadas en función de la evapotranspiración del cultivo. Al tratarse de un suelo franco, se optó por un riego de alta frecuencia, disminuyendo la duración de los riegos. Las necesidades hídricas se estimaron aproximadamente en 0,5-1,5 $\mathrm{L} \mathrm{m}^{-2} \mathrm{dia}^{-1}$ en función del desarrollo del cultivo y de los requerimientos climáticos. Para el manejo de la nutrición mineral se emplearon fertilizantes inorgánicos $\left(\mathrm{Ca}_{2} \mathrm{NO}_{3}, \mathrm{KNO}_{3}\right.$ y $\mathrm{K}_{2} \mathrm{H}_{2} \mathrm{PO}_{4}$ ) y microelementos ( $\mathrm{Fe}, \mathrm{Zn}$ y $\mathrm{Mn}^{\text {) }}$, atendiendo a las necesidades nutricionales del tomate $\left(210 \mathrm{~kg} \mathrm{ha}^{-1} \mathrm{~N}, 120 \mathrm{~kg} \mathrm{ha}^{-1}\right.$ de $\mathrm{P}_{2} \mathrm{O}_{5}$ y $\left.525 \mathrm{~kg} \mathrm{ha}^{-1} \mathrm{~K}_{2} \mathrm{O}\right)$

Durante el cultivo, la principal plaga para la que se estableció un programa de control fue Tuta absoluta. Para ello se utilizaron trampas de monitoreo y se 
introdujeron enemigos naturales (Nesidiocoris spp). Cuando el umbral de la plaga superó los límites establecidos, se realizaron tratamientos puntuales con clorantraniliprol (35 $\left.\mathrm{mg} \mathrm{L}^{-1}\right)$ o flubendiamida $\left(0,2 \mathrm{~g} \mathrm{~L}^{-1}\right)$, ambos compatibles con los enemigos naturales introducidos. Además, se utilizaron sublimadores de azufre, como medida de prevención de enfermedades fúngicas.

Otras prácticas utilizadas durante el desarrollo del cultivo fueron, la colocación colmenas de Bombus spp para favorecer una adecuada polinización y el empleo de datalogger (Onset HOBO, modelo H08-006-04) para el registro de la temperatura y la humedad en el interior del invernadero. Cada semana se hizo un mantenimiento de la plantación podando los brotes laterales. Finalmente se despuntaron las plantas una vez cuajado el racimo 10.

\subsubsection{Diseño experimental}

La aplicación de los tratamientos se realizó mediante pulverización de los bioestimulantes, de dos formas diferentes: sobre la parte aérea de la planta (ensayo 1) o directamente sobre los frutos (entre los racimos 2 y 7 ). Ambos ensayos se realizaron en el mismo invernadero de forma simultánea. En el primer ensayo, los tratamientos consistieron en pulverizaciones con $100 \mu \mathrm{M} \mathrm{MJ}, 200 \mu \mathrm{M}$ AS, $1 \mathrm{~g} \mathrm{~L}^{-1} \mathrm{Q}$ y $30 \mu \mathrm{M} \mathrm{BR}$, utilizando un volumen de $80 \mathrm{~mL}$ por planta. De cada tratamiento bioestimulante se realizaron tres aplicaciones consecutivas, 110, 115 y 125 días después del transplante (DDT). En el segundo ensayo, los tratamientos consistieron en aplicaciones de cuatro elicitores ( $M J, S A, Q$ y $B R$ ), a dos dosis diferentes cada uno: 100 y $1000 \mu \mathrm{M}$ MJ, 50 y $200 \mu \mathrm{M}$ AS, 0,1 y $1 \mathrm{~g} \mathrm{~L}-1 \mathrm{Q}$, y 10 y $30 \mu \mathrm{M}$ BR. La aplicación de los tratamientos se realizó mediante pulverizaciones directas sobre los frutos ( $80 \mathrm{~mL}$ por planta), 15, 7 y 4 días antes de la recolección de los frutos del racimo 2 y de nuevo, antes de la recolección del racimo 7 . (Figura 8.1). En ambos ensayos se incluyeron controles en los que se realizaron pulverizaciones con el mismo agente mojante utilizado en los tratamientos (etanol $0,2 \% \mathrm{v} / \mathrm{v}$ para $\mathrm{MJ}$ y $\mathrm{AS}$, ácido acético $1 \%$ para $\mathrm{Q}$ y agua para $\mathrm{BR}$ ). Dada la naturaleza volátil del $\mathrm{MJ}$, los tratamientos con este bioestimulante se aplicaron bajo plástico, el cual se mantuvo durante los dos días posteriores a la aplicación. 
Además, se dejó una fila sin tratar a ambos lados de la fila correspondiente a los tratamientos con MJ. El diseño experimental de los ensayos 1 y 2 fue de bloques al azar, con 2 bloques y tres repeticiones por bloque, cada una de ellas constituida por tres (ensayo 1) o dos plantas (ensayo 2). Los frutos se recolectaron durante los meses de mayo a julio. Durante este periodo, la temperatura máxima en el invernadero alcanzó valores de $42 \stackrel{\circ}{\mathrm{C}}$ (Figura 8.2), lo que se considera condiciones de alta temperatura para el cultivo de tomate, cuyos valores críticos para la fructificación se establecen a partir de $26{ }^{\circ} \mathrm{C}$ (Stevens y Rudich, 1978). Para los muestreos se seleccionaron frutos homogéneos, totalmente rojos, con ausencia de defectos y recién virados para evitar la sobremaduración.

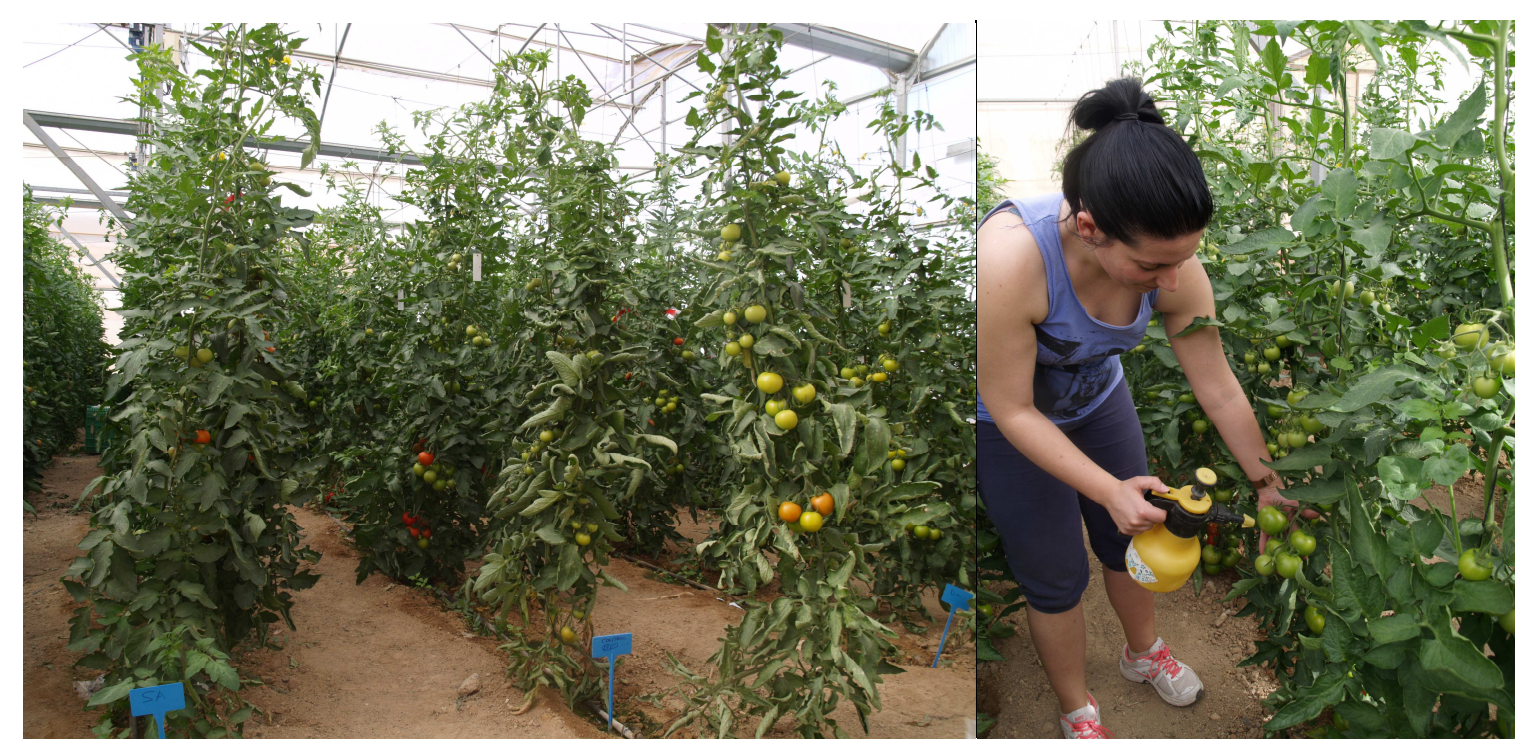

Figura 8.1. Vista parcial del invernadero y detalle de la aplicación de los tratamientos bioestimulantes. 


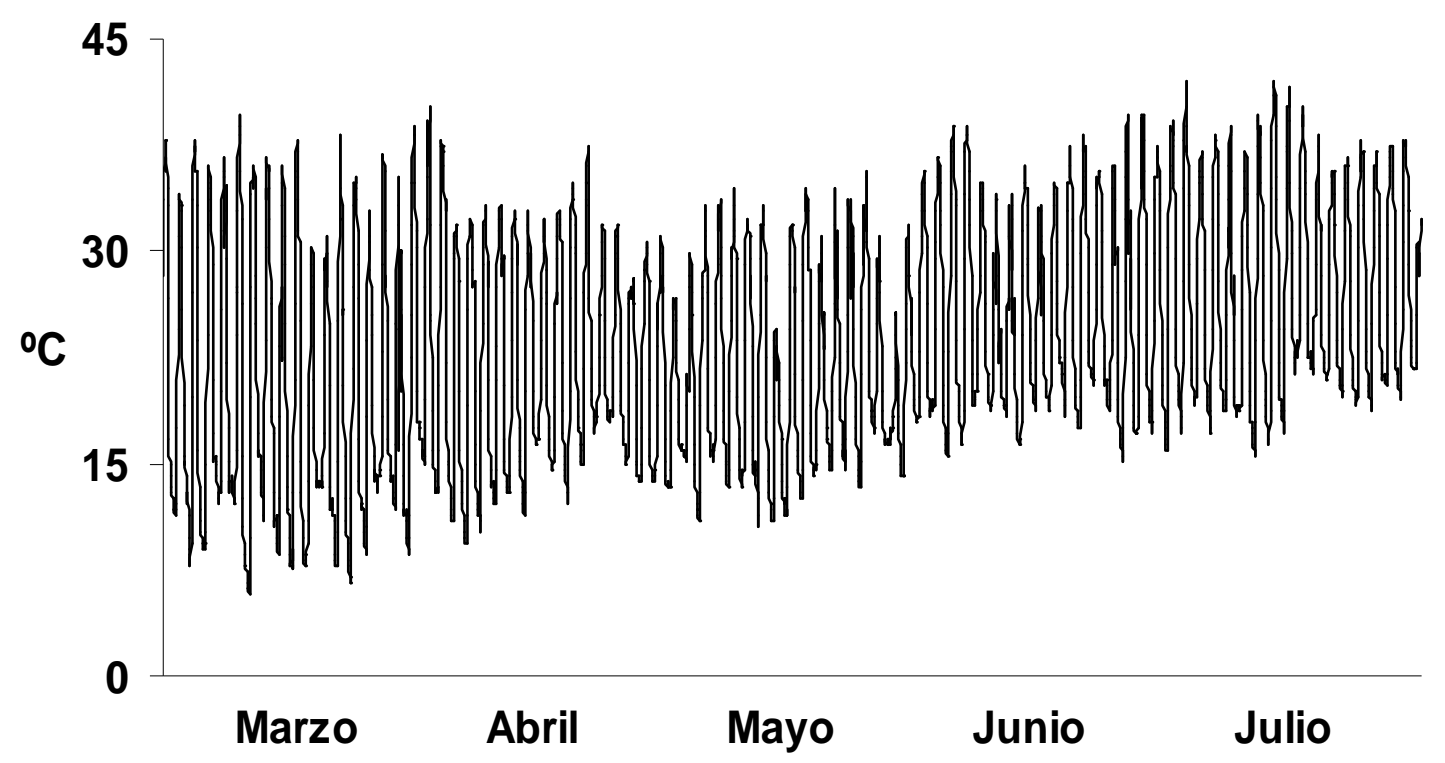

Figura 8.2. Evolución de las temperaturas medias a lo largo del ciclo de cultivo.

\subsubsection{Parámetros analizados}

Las medidas de los parámetros de intercambio gaseoso se realizaron en las plantas correspondientes al ensayo 1, 139, 142, 148 y 163 DDT, coincidiendo con 14, 17, 23 y 48 días después de la primera aplicación de los diferentes tratamientos (DDA). El efecto de los tratamientos sobre el rendimiento se evaluó en los ensayos 1 y 2 , determinando la producción total, el número de fruto y el peso medio de los mismos. A la vista de los resultados de rendimiento obtenidos en ambos ensayos, se decidió evaluar la calidad de fruto en las muestras correspondientes al ensayo 2. Los parámetros de calidad evaluados fueron color (ver apartado 3.2.3) y contenido en metabolitos primarios (azúcares) (apartado 3.3.1) y secundarios (compuestos fenólicos, carotenoides y vitamina C) (apartado 3.3.2, 3.3.3 y 3.3.4, respectivamente) correlacionados con el sabor y la calidad funcional de los frutos. 


\subsubsection{Análisis estadístico}

Los resultados se analizaron estadísticamente mediante el análisis de la varianza y el Test de Rango múltiple de Tukey, para la separación de medias, utilizando el programa informático IBM SPSS Statistic 21.

\subsection{RESULTADOS y DISCUSIÓN}

\subsubsection{Respuesta fisiológica de la planta a los bioestimulantes}

Las medidas de los parámetros de intercambio gaseoso se realizaron durante el mes de junio, 139, 142, 148 y 163 días después del trasplante (DDT), coincidiendo con 14, 17, 23 y 48 días después de la aplicación del último tratamiento, respectivamente. Las temperaturas máximas, diurnas y nocturnas, alcanzadas estos días fueron 30 y $15 \stackrel{\circ}{\circ} \mathrm{C}, 29$ y $17 \stackrel{\circ}{\circ} \mathrm{C}, 36$ y $16 \stackrel{\circ}{\circ}$ y 39 y $17 \stackrel{\circ}{ } \mathrm{C}$, respectivamente (Figura 8.3). Las temperaturas diurnas superaron los $30^{\circ} \mathrm{C}$, valor considerado crítico para el cultivo de tomate ya que, por encima de este valor, se produce la caída de la flor y se limita el cuajado, lo que se traduce en una disminución del rendimiento (Stevens y Rudich, 1978). Además, temperaturas por encima de $32 \stackrel{\circ}{\circ} \mathrm{C}$ durante la maduración de los frutos, provocan una disminución de la síntesis de licopeno o una degradación del mismo, y por lo tanto, una disminución de la calidad (Gautier y col., 2008). Bajo condiciones de alta temperatura, como las alcanzadas durante la formación y desarrollo del fruto en este ensayo, la capacidad fotosintética de las planta se ve reducida por una alteración de las reacciones que tienen lugar en los tilacoides de la membrana de los cloroplastos, así como del transporte de electrones y de los sistemas enzimáticos (Ristic y col., 2008, Rexrhot y col., 2012). Además, temperaturas entre 30 y $40 \stackrel{\circ}{\circ}$, favorecen los procesos respiratorios en detrimento de los procesos fotosintéticos, se incrementa el $\mathrm{CO}_{2}$ interno y se cierran los estomas (Morales y col., 2003). 
Diversos autores afirman que la aplicación de elicitores puede aumentar la tolerancia de las plantas al estrés por altas temperaturas en diferentes cultivos (Muns y Tester, 2008), lo que se ha atribuido a su capacidad de inducir la síntesis de proteínas y otras sustancias con actividad biológica, como ácido salicílico y ácido abcísico (Poór y col., 2011; Yoon y col., 2009; Basit y col., 2016). En nuestro estudio, los tratamientos con MJ, AS, BR y $Q$ no afectaron significativamente a ninguno de los parámetros de intercambio gaseoso estudiados: fotosíntesis (Figura 8.3), conductancia estomática (Figura 8.4) y eficiencia del uso del agua (Figura 8.5). Los resultados que se encuentran en la bibliografía respecto al efecto de los elicitores sobre los procesos fotosintéticos de la planta, son contradictorios. Por un lado, se ha descrito la capacidad de ciertos bioestimulantes de proteger dichos procesos ante diferentes tipos de estrés abiótico. Así, Mimouni y col. (2016) describieron que la aplicación de ácido salicílico, sobre plantas de tomate, redujo el impacto negativo de la salinidad sobre la fotosíntesis, la transpiración y la conductancia estomática. Popova y col. (2003) observaron un efecto positivo de metil jasmonato y ácido salicílico sobre el proceso de fotosíntesis en plantas de cebada tratadas con paracuat, mejorando el rendimiento de la cadena de electrones y la actividad de enzimas antioxidantes en los cloroplastos. Sin embargo, la aplicación de metil jasmonato, en plantas de tomate cultivadas bajo condiciones de sequía, indujo el cierre estomático, evitando la evapotranspiración excesiva y por lo tanto, reduciendo la fotosíntesis neta (Suhita y col., 2004). Además, bajo condiciones favorables (sin estrés), otros estudios mostraron que la aplicación de bioestimulantes puede provocar, tanto una pérdida de pigmentos fotosintéticos, y por lo tanto, de energía absorbida por el aparato fotosintético (Yang y col., 2004; Khan y col., 2010; Kazemi, 2014), como por el contrario, un incremento del contenido de clorofila (Yildirim y Dursun, 2009), dependiendo de la dosis empleada. 


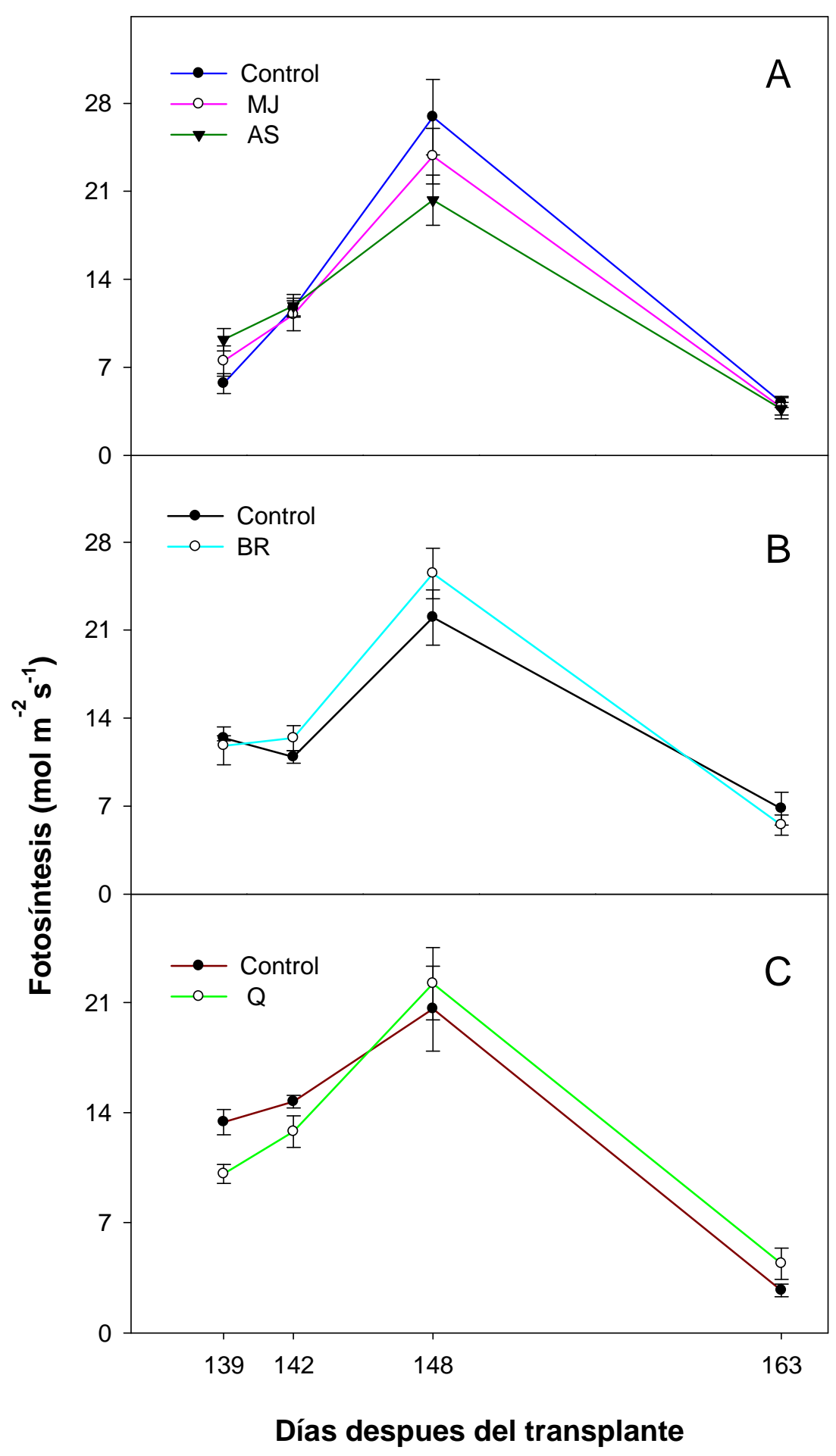

Figura 8.3. Fotosíntesis neta $\left(\mu \mathrm{mol} \mathrm{m} \mathrm{m}^{-2} \mathrm{~s}^{-1}\right)$ en plantas tratadas con los diferentes bioestimulantes (ensayo 1), a los 14, 17, 23 y 48 DDA, coincidiendo con 139, 142, 148 y 163 DDT. Los valores son medias \pm SE $(n=6)$. 


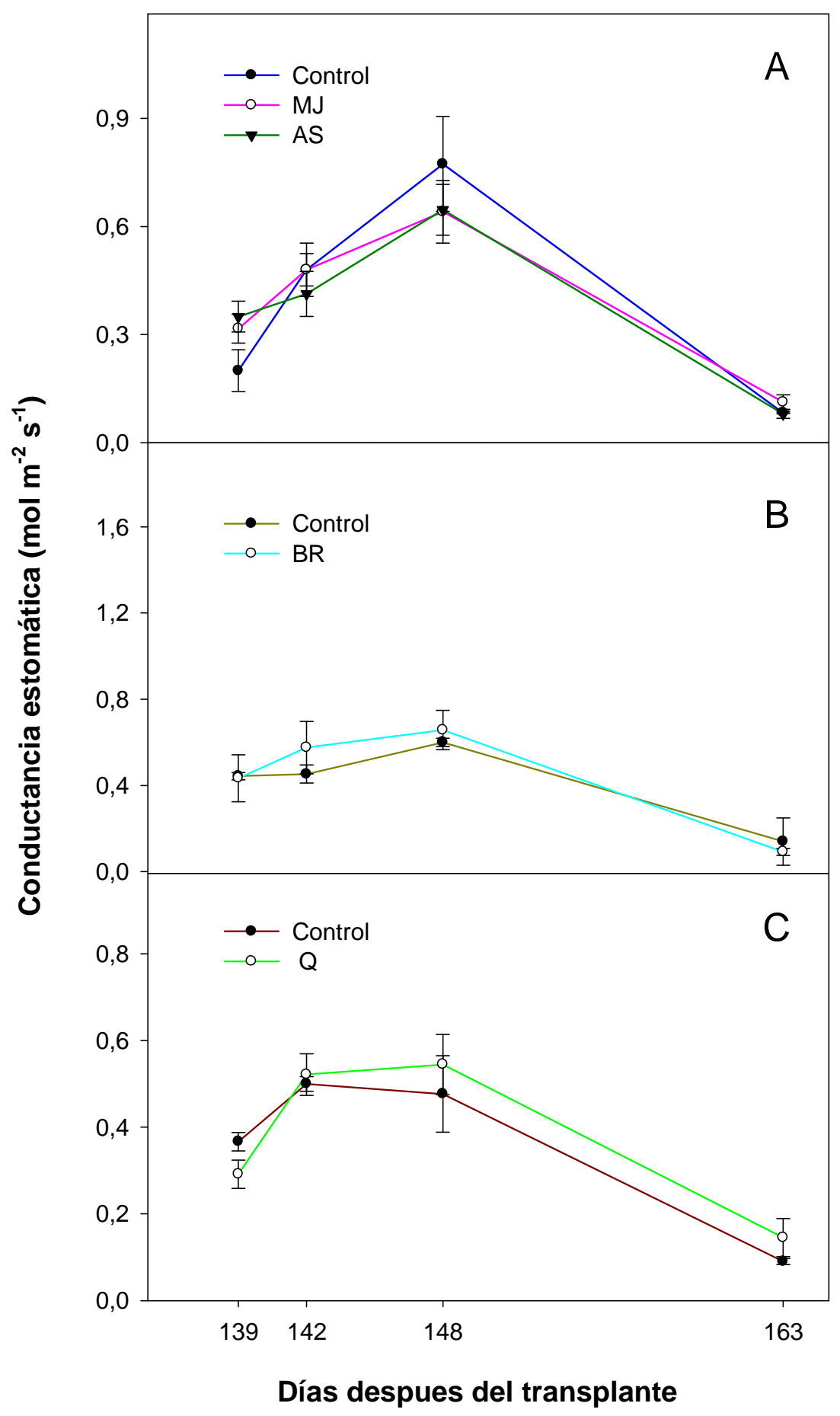

Figura 8.4. Conductancia estomática $\left(\mathrm{mol} \mathrm{m}^{-2} \mathrm{~s}^{-1}\right)$ en plantas tratadas con los diferentes bioestimulantes (ensayo 1), a los 14, 17, 23 y 48 DDA, coincidiendo con $139,142,148$ y 163 DDT. Los valores son medias \pm SE $(n=6)$. 


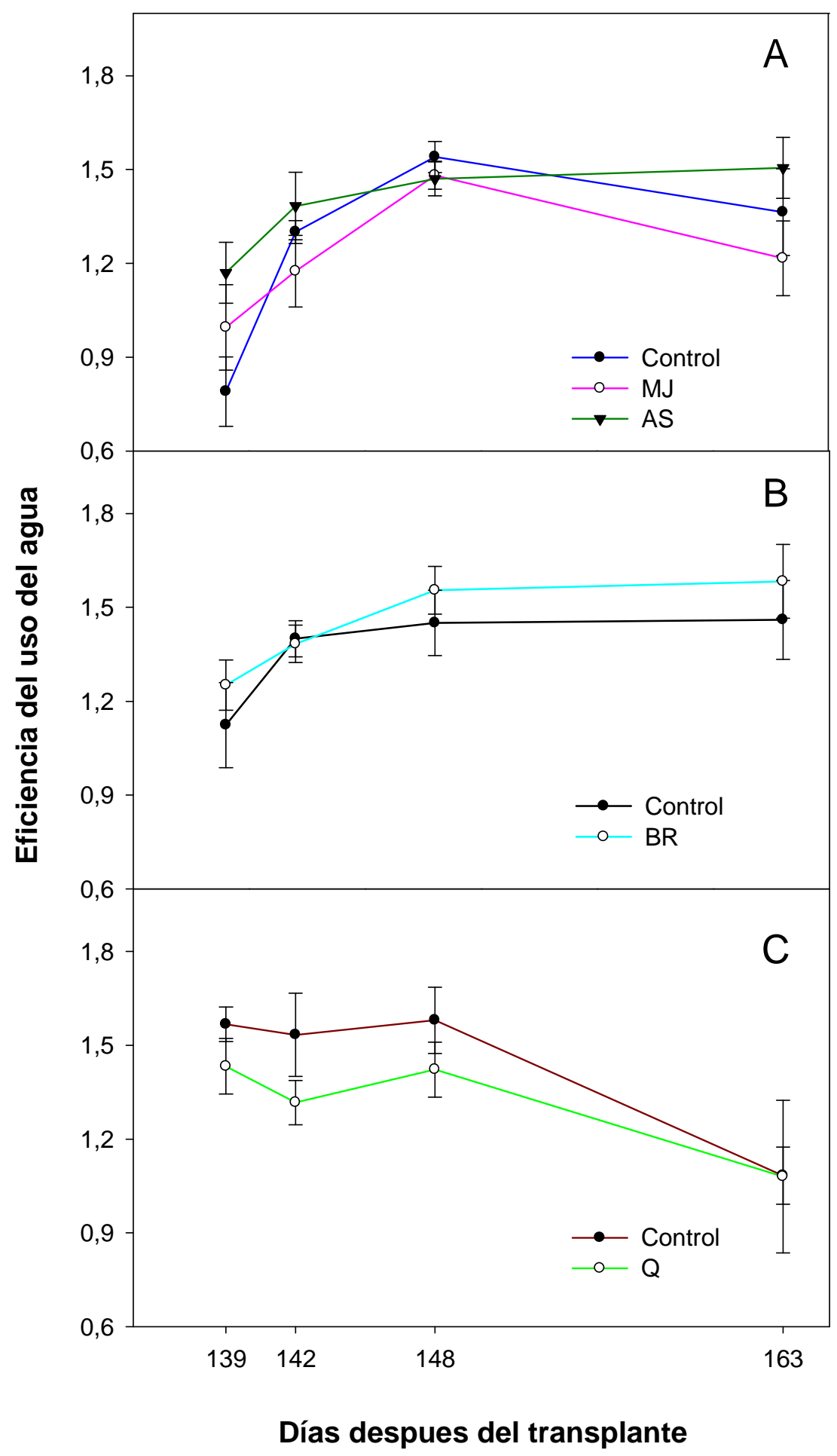

Figura 8.5. Eficiencia del uso del agua ( $\mu \mathrm{mol} \mathrm{CO}_{2} \mathrm{mmol}_{2} \mathrm{O}^{-1}$ ) en plantas tratadas con los diferentes bioestimulantes (ensayo 1), a los 14, 17, 23 y 48 DDA, coincidiendo con 139, 142, 148 y 163 DDT. Los valores son medias \pm SE $(n=6)$. 


\subsubsection{Respuesta agronómica de la planta a los bioestimulantes}

Para conocer el efecto de los bioestimulantes sobre el rendimiento de fruto, y comparar la eficiencia de las aplicaciones sobre la parte aérea (ensayo 1) y sobre los frutos (ensayo 2), se evaluaron los resultados de producción obtenidos con los dos tipos de aplicación, considerando las concentraciones de bioestimulantes comunes a ambos ensayos: control, $100 \mu \mathrm{M}$ MJ, $200 \mu \mathrm{M}$ AS, $1 \mathrm{~g}$ $\mathrm{L}^{-1} \mathrm{Q}$ y $30 \mu \mathrm{M}$ BR (Tabla 8.1).

Respecto al ensayo 1, solo los tratamientos con AS y BR aumentaron significativamente la producción total con respecto a su control (Tabla 8.1). Este aumento fue debido al mayor número de frutos alcanzado en dichos tratamientos. En el caso de $Q$, se observó un aumento del peso medio de los frutos con respecto a su control, aunque esto no se tradujo en un aumento significativo de la producción. Comparando entre sí el efecto de todos los tratamientos sobre la producción total y el número de frutos, se encontraron diferencias significativas $(P<0,01)$ entre ellos, siendo las plantas tratadas con BR y AS, las que alcanzaron valores mayores, seguidas de las tratadas con $Q$ y por último las correspondientes al tratamiento con MJ. Finalmente, no se observaron diferencias significativas entre bioestimulantes en el peso medio de los frutos.

Cuando la aplicación se realizó directamente sobre los racimos 2 y 7 (ensayo 2), los tratamientos con $\mathrm{MJ}, \mathrm{AS}, \mathrm{Q}$ y $\mathrm{BR}$ aumentaron el número de frutos respecto al control, aunque la producción solo aumentó significativamente en el caso de AS, Q y BR (Tabla 8.1). El peso medio aumentó significativamente en los tratamientos con $Q$ y $B R$. En el caso de MJ, la falta de respuesta en la producción total, a pesar del aumento observado en el número de frutos, fue debido a una disminución del peso medio de los mismos. Comparando entre sí el efecto de todos los tratamientos, se encontraron diferencias significativas entre ellos, tanto en la producción final como en el peso medio de los frutos $(P<0,05)$, siendo las plantas tratadas con $Q$ las que obtuvieron valores más altos, seguidas de las tratadas con AS, BR y por último las tratadas con MJ. De acuerdo con nuestros resultados, algunos autores han descrito que la aplicación de quitosano aumenta, 
además de la producción de biomasa, el número de flores y por lo tanto el de frutos (Bautista-Baños y col., 2006).

Tabla 8.1. Producción total $\left(\mathrm{kg}\right.$ planta $\left.{ }^{-1}\right)$, número y peso medio de fruto de plantas de tomate tratadas mediante pulverizaciones sobre toda la parte aérea (ensayo 1) o sobre los frutos de los racimos 2 y 7 (ensayo 2), con metil jasmonato (MJ), ácido salicílico (AS), quitosano (Q) y 2,4-epibrasinolido (BR).

\begin{tabular}{ccccc}
\hline ENSAYO 1 & Dosis & Producción & No de frutos & Peso medio \\
\hline \multirow{2}{*}{ MJ } & control & 3,37 & 15,2 & 73,7 \\
& $100 \mu \mathrm{M}$ & 3,59 & 15,7 & 78,4 \\
& & n.s. & n.s. & n.s. \\
\multirow{2}{*}{ AS } & control & 3,37 & 15,2 & 73,7 \\
& $200 \mu \mathrm{M}$ & 4,44 & 18,7 & 78,5 \\
& & $* *$ & $*$ & n.s. \\
Q & control & 4,07 & 17,5 & 76,0 \\
& $1 \mathrm{~g} \mathrm{~L}^{-1}$ & 4,24 & 16,8 & 85,6 \\
& & n.s. & n.s. & $*$ \\
BR & control & 3,47 & 14,1 & 82,0 \\
& $30 \mu \mathrm{M}$ & 4,59 & 19,1 & 80,3 \\
& & $*$ & $* *$ & n.s.
\end{tabular}

\begin{tabular}{|c|c|c|c|c|}
\hline ENSAYO 2 & Dosis & Producción & № de frutos & Peso medio \\
\hline MJ & $\begin{array}{l}\text { control } \\
100 \mu \mathrm{M}\end{array}$ & $\begin{array}{c}3,98 \\
4,03 \\
\text { n.s. }\end{array}$ & $\begin{array}{c}22,3 \\
27,2 \\
* *\end{array}$ & $\begin{array}{c}93,5 \\
82,1 \\
*\end{array}$ \\
\hline AS & $\begin{array}{l}\text { control } \\
200 \mu \mathrm{M}\end{array}$ & $\begin{array}{c}3,98 \\
4,78 \\
\star \star \star\end{array}$ & $\begin{array}{c}22,3 \\
26,08 \\
\star \star\end{array}$ & $\begin{array}{c}93,5 \\
94,3 \\
\text { n.s. }\end{array}$ \\
\hline Q & $\begin{array}{l}\text { control } \\
1 \mathrm{~g} \mathrm{~L}^{-1}\end{array}$ & $\begin{array}{c}4,08 \\
5,15 \\
\star *\end{array}$ & $\begin{array}{c}23,9 \\
28,0 \\
\star \star\end{array}$ & $\begin{array}{c}86,5 \\
95,5 \\
*\end{array}$ \\
\hline $\mathrm{BR}$ & $\begin{array}{l}\text { control } \\
30 \mu \mathrm{M}\end{array}$ & $\begin{array}{c}3,78 \\
4,66 \\
\star * \star\end{array}$ & $\begin{array}{c}21,9 \\
28,8 \\
* *\end{array}$ & $\begin{array}{c}73,6 \\
83,6 \\
*\end{array}$ \\
\hline
\end{tabular}

En general, el efecto beneficioso de los bioestimulantes sobre el rendimiento, fue más acusado cuando los tratamientos se realizaron directamente sobre los frutos (ensayo 2). Esto podría deberse a que, aunque la aplicación de 
los tratamientos se realizó a la misma dosis (concentración y volumen) que en el caso de los tratamientos realizados sobre la planta (ensayo 1), el área de aplicación fue mucho más reducida y por lo tanto, la concentración aplicada por superficie, mucho mayor.

\subsubsection{Calidad de tomate tratado con bioestimulantes}

Debido a los resultados obtenidos en al apartado anterior, donde los tratamientos realizados directamente sobre los frutos dieron mayor respuesta respecto al rendimiento, se decidió realizar los análisis de color y contenido en metabolitos primarios (azúcares) y secundarios (vitamina C, carotenoides y compuestos fenólicos) relacionados con la calidad funcional, sobre los frutos procedentes del ensayo 2. En este ensayo se aplicaron dos concentraciones diferentes (dosis 1 y 2) de cada uno de los bioestimulantes, además de sus respectivos controles.

\subsubsection{Producción}

El aumento de la producción alcanzado con los tratamientos AS y BR a las dosis más elevadas (200 $\mu \mathrm{M}$ AS y $30 \mu \mathrm{M}$ BR), también se alcanzó con las dosis más bajas (50 $\mu \mathrm{M}$ AS y $10 \mu \mathrm{M}$ BR) (Figura 8.6A). Sin embargo, en el tratamiento con $Q$ con la dosis más baja $\left(0,1 \mathrm{~g} \mathrm{~L}^{-1}\right)$, no se observó el aumento de la producción respecto al control, alcanzado con la dosis mayor $\left(1 \mathrm{~g} \mathrm{~L}^{-1}\right)$. Por último, el tratamiento con MJ $100 \mu \mathrm{M}$ no resultó en un aumento significativo de la producción respecto al control, como el observado en la dosis más elevada (1000 $\mu \mathrm{M})$ ya que, a pesar del aumento del número de frutos, con la dosis más baja se produjo una disminución muy acusada del peso de los mismos (Figuras 8.6 B y $8.6 \mathrm{C}$ ). 


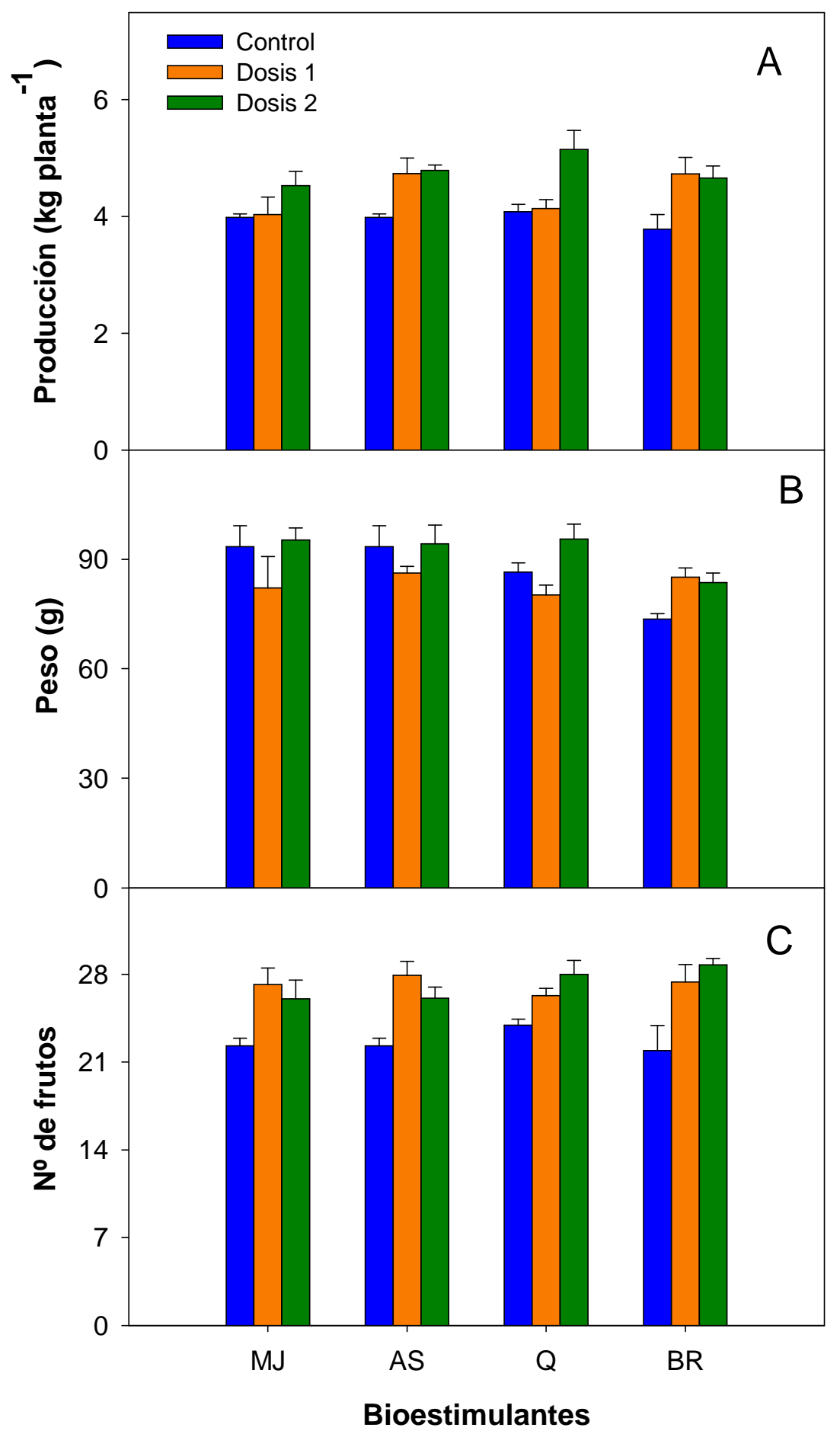

Figura 8.6. Producción total $\left(\mathrm{kg} \mathrm{planta}^{-1}\right)(\mathrm{A})$, número $(\mathrm{B})$ y peso medio $(\mathrm{g})(\mathrm{C})$ de fruto, en plantas tratadas con metil jasmonato (MJ), ácido salicílico (AS), quitosano (Q) y 2,4-epibrasinolido (BR). Las dosis (control, dosis 1 y dosis 2) corresponden a: MJ $(0,100$ y $1000 \mu \mathrm{M}), A S(0,50$ y $200 \mu \mathrm{M}), \mathrm{Q}\left(0,0,1\right.$ y $\left.1 \mathrm{~g} \mathrm{~L}^{-1}\right)$ y $\operatorname{BR}(0,10$ y $30 \mu M)$. Los valores son medias \pm SE $(n=6)$. 
En general, todos los bioestimulantes estudiados mejoraron la producción total de tomate cultivado bajo condiciones de alta temperatura, dependiendo de la dosis aplicada. Por un lado, el aumento de la producción por $\mathrm{MJ}$ y $\mathrm{Q}$ solo se alcanzó cuando dichos bioestimulantes se aplicaron a las dosis más elevadas (1000 $\mu \mathrm{M}$ y $1 \mathrm{~g} \mathrm{~L}^{-1}$, respectivamente), mientras que BR y AS, consiguieron mejorar el rendimiento con las dosis más bajas (50 y $10 \mu \mathrm{M}$, respectivamente). Para todos los bioestimulantes ensayados, el aumento de la producción fue resultado de un aumento del número de frutos y además, en el caso de $B R$ y $Q$, también se produjo un aumento del peso medio de los mismos.

\subsubsection{Color de los frutos}

El color es uno de los atributos que más afecta a la percepción de la calidad de los frutos por parte del consumidor. Estudios previos muestran que, aplicaciones exógenas de ácido jasmónico durante el proceso de maduración del fruto de tomate, pueden modular los cambios de color a través de dos vías: una interaccionando con la síntesis de etileno y otra independientemente del etileno (Fan y col., 1998). Otros autores describen la influencia de los jasmonatos sobre la degradación de la clorofila y la acumulación de $\beta$-caroteno en tomate y manzana (Saniewski y col., 1987a; Saniewski y col., 1987b; Pérez y col., 1993), afectando al color final de los frutos. Mientras que los tratamientos con MJ, AS y $B R$ no alteraron el valor de Hue, los frutos tratados con $Q$ presentaron un color más rojo (mayor Hue) que su respectivo control (Figura 8.7). Este aumento fue significativo $(P<0,01)$ en los frutos del racimo 2 y para el tratamiento con la dosis más elevada $\left(1 \mathrm{~g} \mathrm{~L}^{-1}\right)$. Respecto al valor de Croma, los frutos tratados con Q $(1 \mathrm{~g}$ $\mathrm{L}^{-1}$ ) presentaron un color menos intenso (menor Croma) que los del tratamiento control, siendo significativo en los frutos del racimo $2(P<0,05)$ (Figura $8.8 \mathrm{~A}$ ), lo que se atribuyó a un efecto de dilución, como consecuencia de un aumento de la producción total. Por el contrario, los frutos tratados con MJ $100 \mu \mathrm{M}$ presentaron un valor de Croma mayor que su respectivo control, en los frutos pertenecientes a ambos racimos, asociado a un menor peso de los frutos (Figuras $8.8 \mathrm{~A}$ y B). 


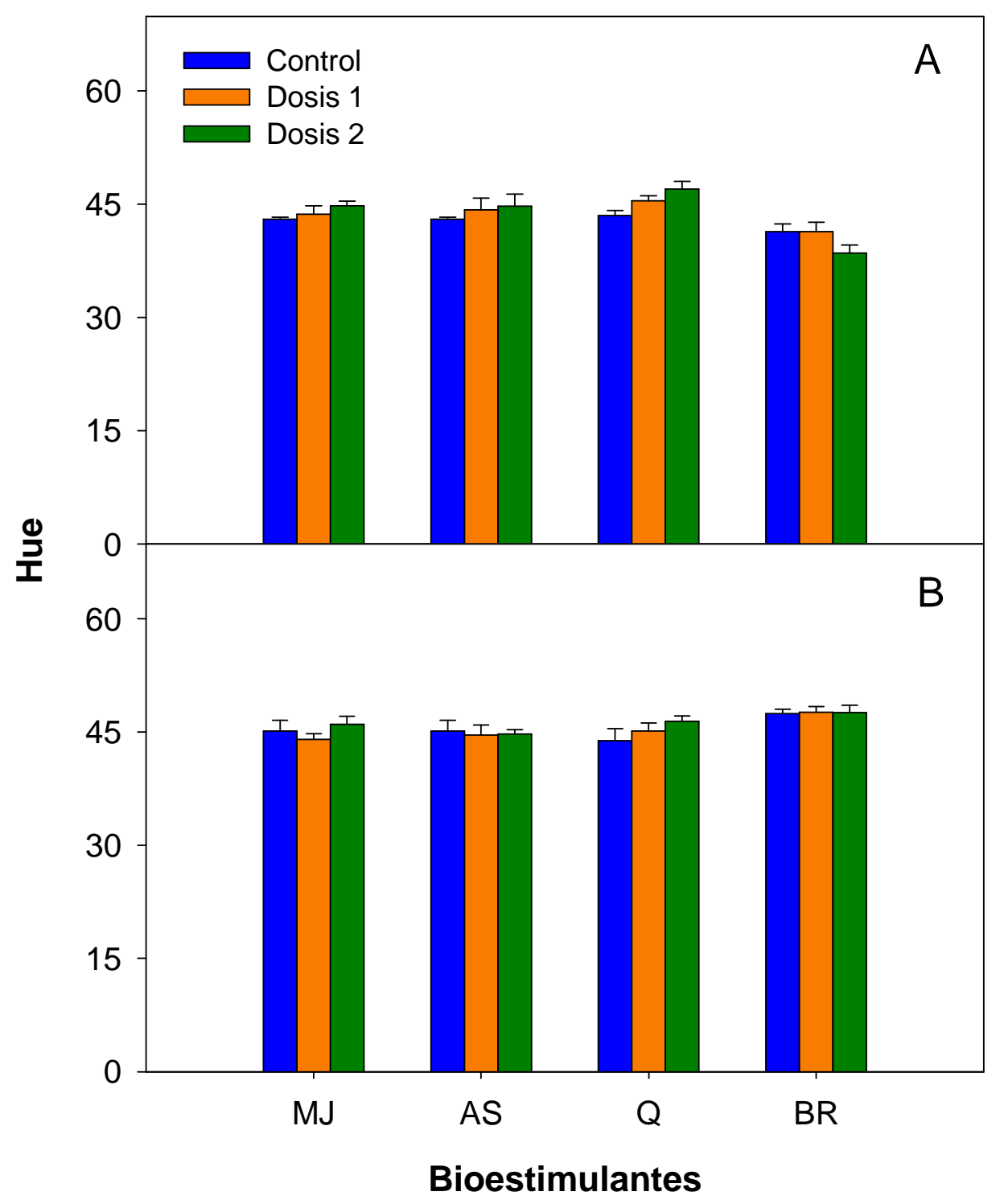

Figura 8.7. Valores de Hue (tono) de frutos procedentes de los racimos 2 (A) y 7 (B), en plantas tratadas con metil jasmonato (MJ), ácido salicílico (AS), quitosano (Q) y 2,4-epibrasinolido (BR). Las dosis (control, dosis 1 y dosis 2) corresponden a: $\mathrm{MJ}(0,100$ y $1000 \mu \mathrm{M}), \mathrm{AS}(0,50$ y $200 \mu \mathrm{M}), \mathrm{Q}\left(0,0,1\right.$ y $\left.1 \mathrm{~g} \mathrm{~L}^{-1}\right)$ y BR $(0,10$ y $30 \mu \mathrm{M})$. Los valores son medias \pm SE $(n=6)$. 


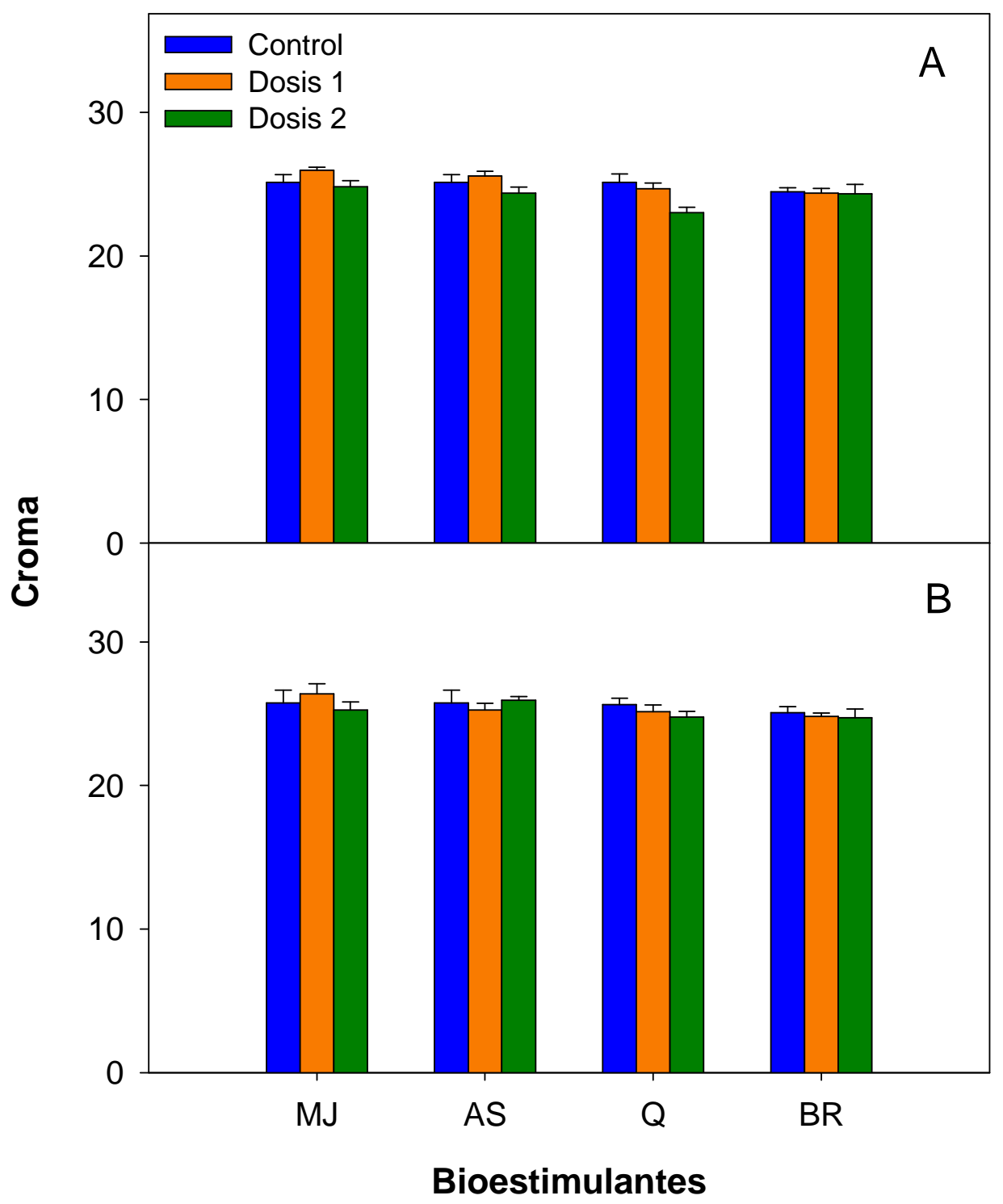

Figura 8.8. Valores de Croma (intensidad de color) de frutos procedentes de los racimos $2(A)$ y $7(B)$, en plantas tratadas con metil jasmonato $(M J)$, ácido salicílico (AS), quitosano (Q) y 2,4-epibrasinolido (BR). Las dosis (control, dosis 1 y dosis 2) corresponden a: MJ (0, 100 y $1000 \mu \mathrm{M})$, AS $(0,50$ y $200 \mu \mathrm{M}), \mathrm{Q}(0,0,1$ y $\left.1 \mathrm{~g} \mathrm{~L}^{-1}\right)$ y $B R(0,10$ y $30 \mu M)$. Los valores son medias \pm SE $(n=6)$. 


\subsubsection{Azúcares solubles}

El contenido en azúcares solubles está directamente relacionado con las propiedades organolépticas de los frutos. Glucosa y fructosa fueron los azúcares solubles mayoritarios detectados en tomate. En nuestro ensayo, los tratamientos con MJ tendieron a aumentar la concentración de azúcares en fruto (Figuras 8.9 y 8.10), aunque solo de forma significativa $(P<0,05)$ en el caso de glucosa. En el caso de los tratamientos con AS y $Q$, a pesar de las ligeras variaciones encontradas entre las diferentes dosis, dependiendo del racimo, no se detectaron diferencias significativas en la concentración de azúcares por efecto de los tratamientos. Con respecto a BR, se observó una interacción significativa entre el efecto de la dosis y el del racimo, tanto sobre la concentración de glucosa como de fructosa $(P<0,001$ y $P<0,01$, respectivamente); mientras que en los frutos del racimo 2 se observó una disminución del contenido en azúcares en los frutos tratados con la dosis más elevada $(30 \mu \mathrm{M})$, en los frutos del racimo 7 se observó el efecto contrario. En un estudio previo, realizado sobre frutos de tomate cortado, se mostró la capacidad de los brasinólidos para regular la maduración de los frutos, incrementando la concentración de azúcares y licopeno, como resultado de la inducción de la expresión de genes relacionados con la síntesis de etileno (Zhu y col., 2015). En pimiento dulce, la aplicación de una mezcla de quitosano y ácido jasmónico, provocó un aumento del contenido en azúcares en el fruto, principalmente cuando dicha aplicación se realizó en estado de maduración avanzado (García-Mier y col., 2015). Las diferencias encontradas en nuestro estudio, como consecuencia de los diferentes tratamientos, muestran la influencia que tienen factores como la dosis, el momento de aplicación y el efecto de dichos bioestimulantes sobre el contenido de azúcares en el fruto. 


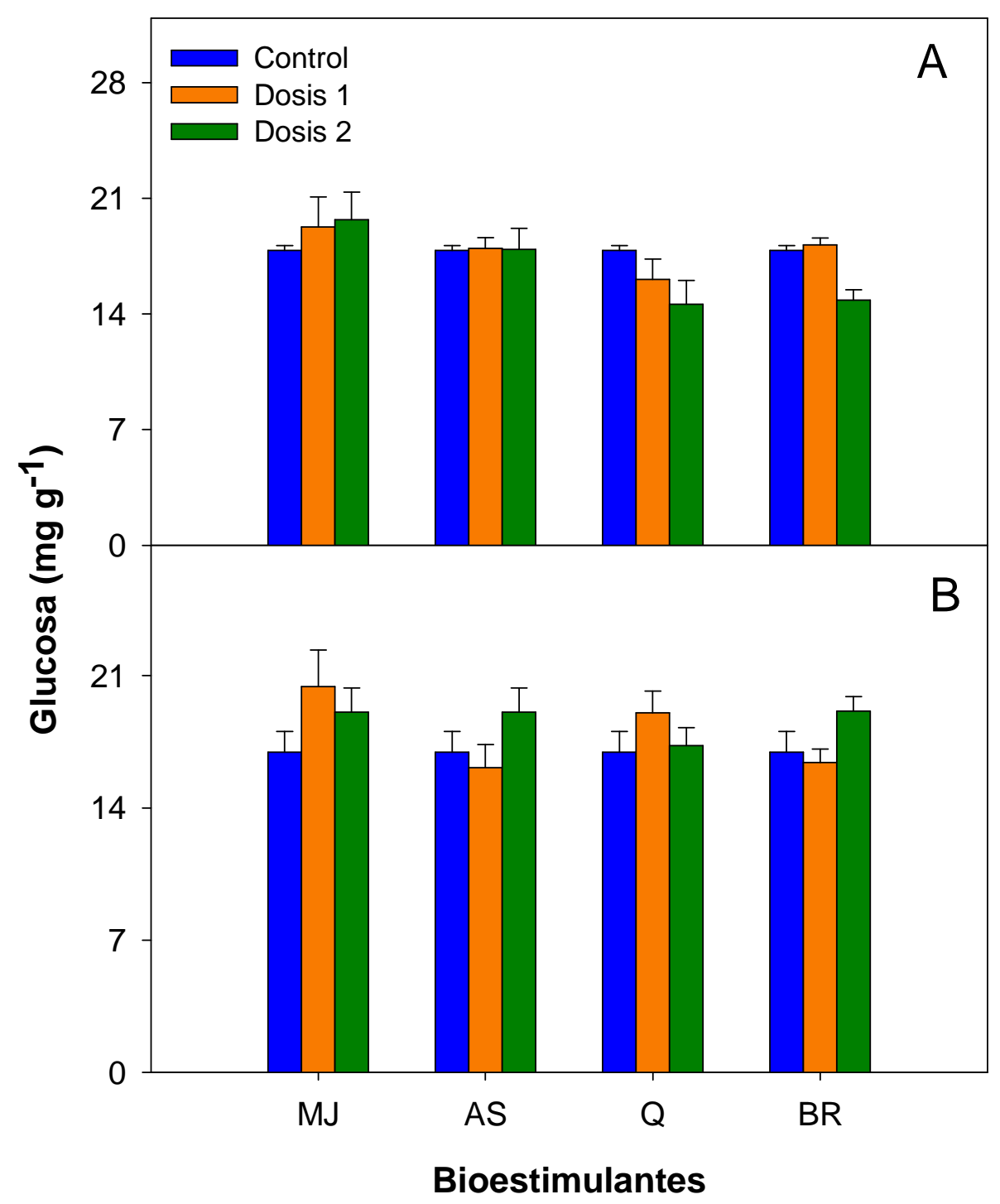

Figura 8.9. Contenido de glucosa $\left(\mathrm{mg} \mathrm{g}^{-1}\right)$ en frutos procedentes de los racimos 2 (A) y 7 (B), en plantas tratadas con metil jasmonato (MJ), ácido salicílico (AS), quitosano (Q) y 2,4-epibrasinolido (BR). Las dosis (control, dosis 1 y dosis 2) corresponden a: $\mathrm{MJ}(0,100$ y $1000 \mu \mathrm{M})$, AS (0, 50 y $200 \mu \mathrm{M}), \mathrm{Q}\left(0,0,1\right.$ y $\left.1 \mathrm{~g} \mathrm{~L}^{-1}\right)$ y $\operatorname{BR}(0,10$ y $30 \mu M)$. Los valores son medias \pm SE $(n=6)$. 


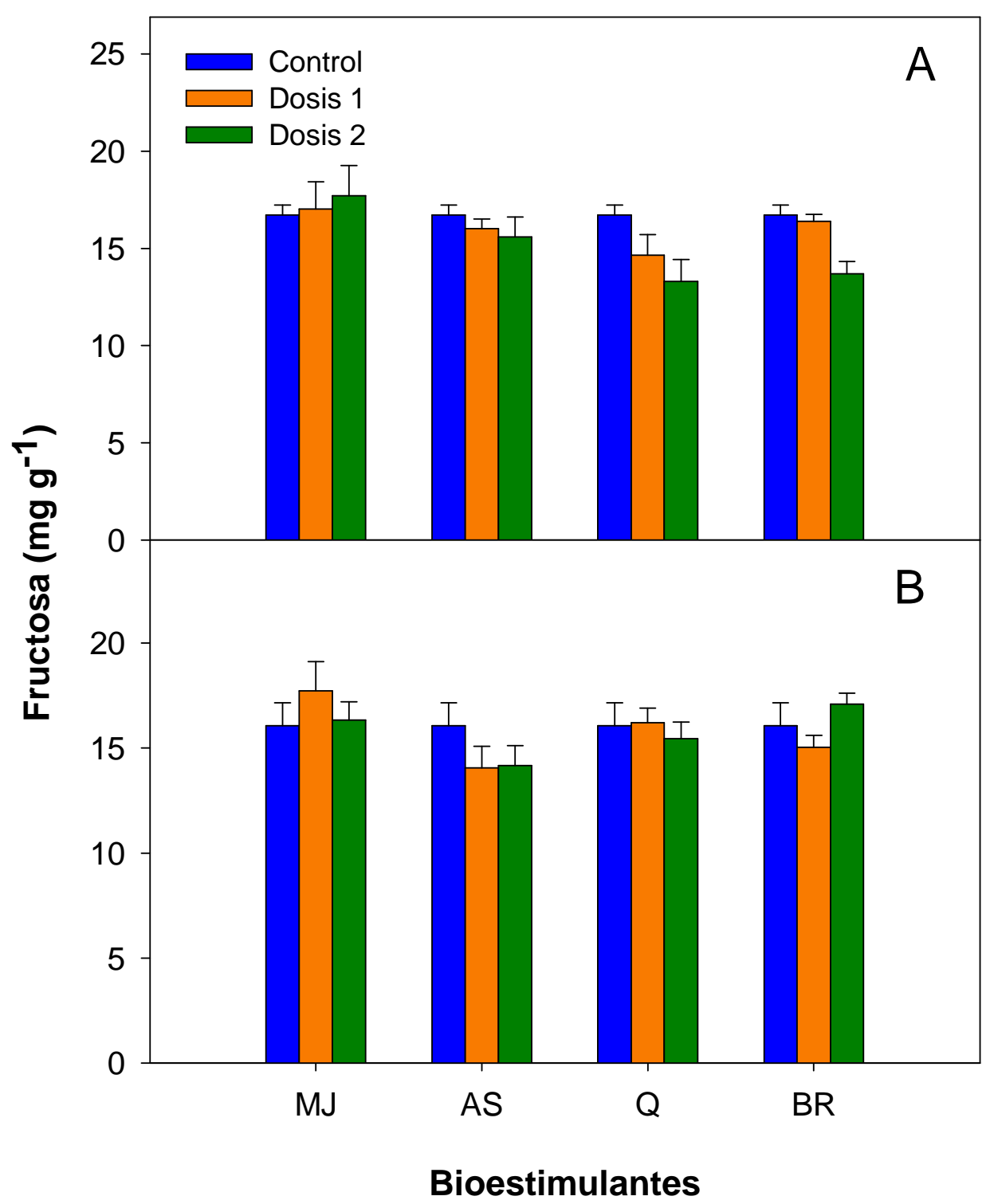

Figura 8.10. Contenido de fructosa $\left(\mathrm{mg} \mathrm{g}^{-1}\right)$ en frutos procedentes de los racimos 2 (A) y 7 (B), en plantas tratadas con metil jasmonato (MJ), ácido salicílico (AS), quitosano (Q) y 2,4-epibrasinolido (BR). Las dosis (control, dosis 1 y dosis 2) corresponden a: MJ (0, 100 y $1000 \mu \mathrm{M})$, AS (0, 50 y $200 \mu \mathrm{M}), \mathrm{Q}\left(0,0,1\right.$ y $\left.1 \mathrm{~g} \mathrm{~L}^{-1}\right)$ y $\mathrm{BR}(0,10$ y $30 \mu \mathrm{M})$. Los valores son medias \pm SE $(n=6)$. 


\subsubsection{Vitamina C}

Aunque la principal forma activa de la vitamina $C$ es ácido ascórbico (AA), su forma oxidada, el ácido dehidroascórbico (ADHA) también presenta actividad biológica, ya que se convierte fácilmente en ácido ascórbico en el cuerpo humano, de ahí el interés en el análisis simultáneo de AA y ADHA (Lee y Kader, 2000). En nuestro estudio se midió el contenido de vitamina $C$ como la suma de ácido ascórbico y dehidroascórbico, previa reducción de este, mediante el uso de ditiotreitol (DTT). El efecto de los tratamientos con MJ y AS sobre este compuesto, dependió del racimo analizado. Mientras que en frutos del racimo 2 la concentración de vitamina $\mathrm{C}$ disminuyó, independientemente de la dosis aplicada (Figura 8.11A), en el racimo 7 , se observó el efecto contrario (Figura 8.11B). Respecto al tratamiento con $\mathrm{Q}$, la concentración de vitamina $\mathrm{C}$ disminuyó significativamente, pero solo en los frutos tratados con la dosis más alta $\left(1 \mathrm{~g} \mathrm{~L}^{-1}\right)$. Esta disminución fue más evidente en el racimo 7, coincidiendo con un importante aumento de la producción. Por otro lado, los tratamientos con BR disminuyeron drásticamente la concentración de vitamina $C$ en ambos racimos, probablemente debido a un efecto de dilución, consecuencia del aumento significativo de la producción observado en este tratamiento. Al contrario de lo observado en nuestro estudio, Zhu y col. (2015) describieron un aumento de la concentración de ácido ascórbico en frutos de tomate cortado, como consecuencia de un tratamiento con brasinoesteroides. En otro estudio, la aplicación de quitosano sobre semillas de brócoli incrementó el contenido de vitamina $C$ en la pella (Pérez-Balibrea y col., 2011). Las discrepancias encontradas entre estos resultados y los nuestros pueden atribuirse a que, a diferencia de lo observado en nuestro estudio, dichos autores no describen un aumento en la producción y por lo tanto no es probable un efecto de dilución. 


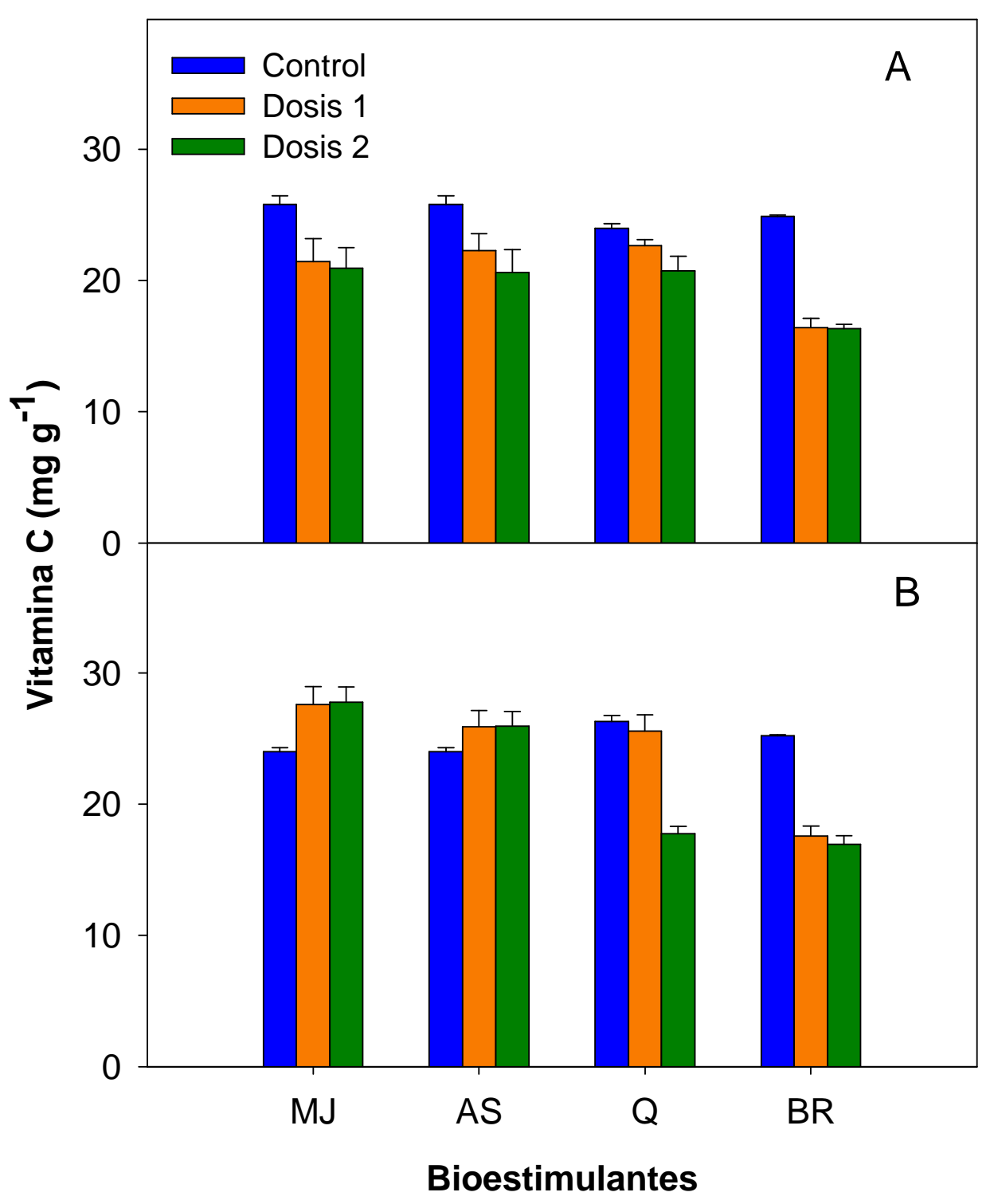

Figura 8.11. Contenido de vitamina $C\left(\mathrm{mg} \mathrm{g}^{-1}\right)$ en frutos procedentes de los racimos $2(A)$ y $7(B)$, en plantas tratadas con metil jasmonato $(M J)$, ácido salicílico (AS), quitosano (Q) y 2,4-epibrasinolido (BR). Las dosis (control, dosis 1 y dosis 2) corresponden a: MJ (0, 100 y $1000 \mu \mathrm{M})$, AS (0, 50 y $200 \mu \mathrm{M}), \mathrm{Q}(0,0,1$ y $\left.1 \mathrm{~g} \mathrm{~L}^{-1}\right)$ y $B R(0,10$ y $30 \mu \mathrm{M})$. Los valores son medias $\pm \mathrm{SE}(\mathrm{n}=6)$. 


\subsubsection{Carotenoides}

Los carotenoides detectados en tomate mediante análisis cromatográfico fueron, en orden de elución, violaxantina, luteína, fitoeno, fitoflueno, all trans- $\beta$ caroteno, all trans-licopeno, $\zeta$-caroteno, $\gamma$-caroteno, 13 cis- $\beta$-caroteno, 9 cis- $\beta$ caroteno, 13 cis-licopeno, 9 cis-licopeno y 5 cis-licopeno. En general e independientemente del tratamiento bioestimulante aplicado, se observó una disminución de la concentración de carotenoides en los frutos del racimo 7 respecto a los del racimo 2 (Tablas 8.2-8.5). La concentración de licopeno, principal carotenoide que se encuentra en tomate, puede disminuir como consecuencia de un aumento de temperatura ambiental por encima de $32{ }^{\circ} \mathrm{C}$ (Gautier y col., 2008). En nuestro ensayo, este valor de temperatura fue superado durante el periodo de maduración de los frutos, principalmente de los racimos superiores (Figura 8.4). Bajo dichas condiciones de alta temperatura, los tratamientos con MJ no afectaron a la concentración de los carotenoides mayoritarios encontrados en tomate (all trans-licopeno, $\beta$-caroteno, fitoeno, fitoflueno y luteína) independientemente de la dosis aplicada (Tabla 8.2). Tampoco afectaron a la concentración de $\zeta$-caroteno y $\gamma$-caroteno. Sin embargo, las concentraciones de otros carotenoides minoritarios (violaxantina, 13 cis- $\beta$ caroteno, 9 cis- $\beta$-caroteno, 13 cis-licopeno y 9 cis-licopeno) disminuyeron como consecuencia de la aplicación de MJ. Por último, los tratamientos con este bioestimulante, provocaron un aumento de la concentración de 5 cis-licopeno en fruto.

Respecto a los tratamientos con AS, la aplicación de la dosis más baja (50 $\mu \mathrm{M})$ dio lugar a un aumento del contenido de all trans-licopeno y 5 cis-licopeno en los dos racimos analizados (Tabla 8.3). El efecto de los tratamientos sobre la concentración de fitoeno, fitoflueno, luteína y violaxantina dependió del racimo analizado; mientras que la aplicación de AS (50 y $200 \mu \mathrm{M})$ disminuyó la concentración de estos carotenoides en frutos procedentes del racimo 2 , no se observó ningún efecto en los correspondientes al racimo 7. All trans- $\beta$-caroteno, $\zeta$ caroteno y $\gamma$-caroteno no se vieron afectados por los tratamientos. Por último, las concentraciones de otros isómeros cis de $\beta$-caroteno y licopeno disminuyeron tanto en el racimo 2 como en el 7, como consecuencia de la aplicación de AS. 
En general, el tratamiento con $\mathrm{Q}$ a la dosis más elevada $\left(1 \mathrm{~g} \mathrm{~L}^{-1}\right)$, provocó una disminución de la concentración de los carotenoides analizados, aunque esta disminución no fue significativa en el caso de violaxantina y, en el caso de fitoeno, fitoflueno y 5 cis-licopeno, solo se observó en frutos procedentes del racimo 2 (Tabla 8.4). Esta disminución general se atribuyó a un efecto de dilución, consecuencia del aumento observado en la producción total, tanto por el mayor número de frutos como, en el caso de plantas tratadas con $1 \mathrm{~g} \mathrm{~L}^{-1} \mathrm{Q}$, por el mayor peso medio de los mismos.

Los tratamientos con BR, no afectaron a la concentración de la mayoría de los carotenoides (fitoeno, fitoflueno, all trans- $\beta$-caroteno, y all trans-licopeno, $\zeta$ caroteno, $\mathrm{y}$-caroteno y 5 ' cis-licopeno) independientemente de la dosis utilizada (Tabla 8.5). Por el contrario, las concentraciones de violaxantina, luteína e isómeros cis de $\beta$-caroteno y licopeno disminuyeron con los tratamientos aunque, en el caso de violaxantina y luteína, esta disminución solo fue significativa en el racimo 2 . 
Tabla 8.2. Efecto de metil jasmonato (MJ) sobre las concentraciones ( $\mu \mathrm{g} \mathrm{g}^{-1} \mathrm{PF}$ ) de violaxantina (1), luteína (2), fitoeno (3), fitoflueno (4), all trans- $\beta$-caroteno (5), all trans-licopeno (6), $\zeta$-caroteno (7), $\gamma$-caroteno (8), 13 cis- $\beta$-caroteno (9), 9 cis- $\beta$-caroteno (10), 13 cis-licopeno (11), 9 cis-licopeno (12), 5 cis-licopeno (13), suma de cis- $\beta$-caroteno (14) y suma de cis-licopeno (15).

\begin{tabular}{|c|c|c|c|c|c|c|c|c|c|c|c|c|c|c|c|c|}
\hline & & 1 & 2 & 3 & 4 & 5 & 6 & 7 & 8 & 9 & 10 & 11 & 12 & 13 & 14 & 15 \\
\hline Dosis & 0 & $1,16^{\mathrm{b}}$ & 2,2 & 4,6 & 3,5 & 8,8 & 17,7 & 0,28 & 0,43 & $0,43^{b}$ & $0,36^{b}$ & $2,3^{b}$ & $0,46^{b}$ & $4,9^{\mathrm{a}}$ & $0,78^{\mathrm{b}}$ & 8,1 \\
\hline \multirow[t]{3}{*}{$(\mu \mathrm{M})$} & 100 & $0,77^{\mathrm{a}}$ & 2,2 & 4,5 & 3,3 & 8,9 & 21,0 & 0,28 & 0,38 & $0,28^{a}$ & $0,19^{a}$ & $1,2^{\mathrm{a}}$ & $0,19^{a}$ & $7,6^{\mathrm{b}}$ & $0,47^{\mathrm{a}}$ & 7,8 \\
\hline & 1000 & $0,82^{\mathrm{a}}$ & 2,0 & 4,0 & 3,0 & 8,8 & 21,0 & 0,27 & 0,38 & $0,24^{a}$ & $0,18^{a}$ & $1,3^{\mathrm{a}}$ & $0,20^{a}$ & $7,1^{\mathrm{b}}$ & $0,42^{\mathrm{a}}$ & 9 \\
\hline & & ** & n.s. & n.s. & n.s. & n.s. & n.s. & n.s. & n.s. & $* * *$ & $* * *$ & $* * *$ & $* * *$ & $* * *$ & $* * *$ & n.s. \\
\hline \multirow[t]{2}{*}{ Racimo } & 2 & 0,95 & 2,3 & 5,6 & 4,2 & 9,4 & 21,0 & 0,26 & 0,4 & 0,28 & 0,21 & 1,8 & 0,33 & 7,3 & 0,49 & 9,7 \\
\hline & 7 & 0,89 & 1,9 & 3,0 & 2,2 & 8,3 & 18,5 & 0,30 & 0,39 & 0,35 & 0,29 & 1,6 & 0,24 & 5,5 & 0,64 & 6,8 \\
\hline \multicolumn{16}{|c|}{ INTERACCIÓN } & $* *$ \\
\hline \multicolumn{17}{|c|}{ Racimo Dosis } \\
\hline \multirow[t]{3}{*}{2} & 0 & $1,32^{b}$ & 2,5 & 6,1 & 4,6 & 9,4 & 18,1 & 0,25 & 0,44 & 0,37 & 0,32 & 2,33 & 0,47 & 5,2 & 0,69 & 8,5 \\
\hline & 100 & $0,84^{\mathrm{a}}$ & 2,4 & 5,8 & 4,3 & 10,0 & 23,1 & 0,29 & 0,41 & 0,29 & 0,18 & 1,27 & 0,28 & 9,0 & 0,47 & 10,9 \\
\hline & 1000 & $0,69^{a}$ & 2,1 & 5,0 & 3,8 & 8,7 & 22,0 & 0,23 & 0,36 & 0,19 & 0,13 & 1,58 & 0,24 & 7,7 & 0,32 & 9,7 \\
\hline \multirow[t]{4}{*}{7} & 0 & $0,99^{a b}$ & 1,9 & 3,1 & 2,3 & 8,2 & 17,2 & 0,30 & 0,42 & 0,49 & 0,39 & 2,20 & 0,46 & 4,6 & 0,88 & 7,7 \\
\hline & 100 & $0,65^{\mathrm{a}}$ & 1,9 & 2,5 & 1,9 & 7,3 & 18,1 & 0,26 & 0,33 & 0,25 & 0,21 & 0,99 & 0,14 & 5,6 & 0,46 & 6,9 \\
\hline & 1000 & $0,95^{\mathrm{ab}}$ & 1,9 & 3,1 & 2,3 & 8,9 & 20,0 & 0,32 & 0,40 & 0,29 & 0,24 & 1,41 & 0,16 & 6,4 & 0,52 & 8,2 \\
\hline & & $\star *$ & n.s. & n.s. & n.s. & n.s. & n.s. & n.s. & n.s. & n.s. & n.s. & n.s. & n.s. & n.s. & n.s. & n.s. \\
\hline
\end{tabular}


Tabla 8.3. Efecto de ácido salicílico (AS) sobre las concentraciones ( $\mu \mathrm{g} \mathrm{g} \mathrm{g}^{-1} \mathrm{PF}$ ) de violaxantina (1), luteína (2), fitoeno (3), fitoflueno (4), all trans- $\beta$-caroteno (5), all trans-licopeno (6), $\zeta$-caroteno (7), $\gamma$-caroteno (8), 13 cis- $\beta$-caroteno (9), 9 cis- $\beta$-caroteno (10), 13 cis-licopeno (11), 9 cis-licopeno (12), 5 cis-licopeno (13), suma de cis- $\beta$-caroteno (14) y suma de cis-licopeno (15).

\begin{tabular}{|c|c|c|c|c|c|c|c|c|c|c|c|c|c|c|c|c|}
\hline & & 1 & 2 & 3 & 4 & 5 & 6 & 7 & 8 & 9 & 10 & 11 & 12 & 13 & 14 & 15 \\
\hline Dosis & 0 & $1,16^{b}$ & $2,2^{b}$ & 4,6 & 3,5 & 8,8 & $17,6^{\mathrm{a}}$ & 0,28 & 0,43 & $0,43^{b}$ & $0,36^{b}$ & $2,3^{b}$ & $0,46^{b}$ & $4,9^{a}$ & $0,78^{\mathrm{b}}$ & $8,1^{\mathrm{ab}}$ \\
\hline \multirow[t]{3}{*}{$(\mu \mathrm{M})$} & 50 & $0,78^{a}$ & $1,9^{a}$ & 4,0 & 2,9 & 8,0 & $22,3^{b}$ & 0,25 & 0,38 & $0,26^{a}$ & $0,20^{\mathrm{a}}$ & $1,7^{\mathrm{a}}$ & $0,31^{a}$ & $7,0^{b}$ & $0,45^{a}$ & $9,3^{b}$ \\
\hline & 200 & $0,82^{\mathrm{a}}$ & $1,9^{a}$ & 3,7 & 2,8 & 7,9 & $15,9^{a}$ & 0,24 & 0,35 & $0,26^{a}$ & $0,20^{\mathrm{a}}$ & $1,4^{\mathrm{a}}$ & $0,23^{a}$ & $4,7^{\mathrm{a}}$ & $0,46^{\mathrm{a}}$ & $6,4^{\mathrm{a}}$ \\
\hline & & $\star \star \star *$ & * & n.s. & n.s. & n.s. & * & n.s. & n.s. & $\star \star *$ & $* * *$ & $\star \star \star *$ & $* \star *$ & $* *$ & $* * *$ & * \\
\hline \multirow[t]{3}{*}{ Racimo } & 2 & 0,97 & 2,1 & 5,1 & 3,8 & 8,4 & 20,3 & 0,22 & 0,36 & 0,27 & 0,21 & 1,9 & 0,34 & 6,1 & 0,48 & 8,6 \\
\hline & 7 & 0,87 & 2,0 & 3,1 & 2,3 & 8,2 & 16,7 & 0,29 & 0,42 & 0,37 & 0,30 & 1,8 & 0,34 & 4,9 & 0,67 & 7,3 \\
\hline & & n.s. & n.s. & $* * *$ & $* * *$ & n.s. & * & $* * *$ & n.s. & $* *$ & * & n.s. & n.s. & n.s. & $* *$ & n.s. \\
\hline \multicolumn{17}{|c|}{ INTERACCIÓN } \\
\hline \multicolumn{17}{|l|}{ Racimo } \\
\hline \multirow[t]{3}{*}{2} & 0 & $1,32^{\mathrm{B}}$ & $2,5^{\mathrm{b}}$ & $6,1^{\mathrm{c}}$ & $4,6^{\mathrm{C}}$ & 9,4 & 18,0 & 0,25 & 0,44 & 0,37 & 0,32 & 2,3 & 0,47 & 5,2 & 0,69 & 8,5 \\
\hline & 50 & $0,74^{\mathrm{a}}$ & $1,9^{\mathrm{a}}$ & $4,9^{b}$ & $3,5^{\mathrm{b}}$ & 8,0 & 24,0 & 0,22 & 0,32 & 0,22 & 0,16 & 1,6 & 0,28 & 7,3 & 0,39 & 9,5 \\
\hline & 200 & $0,85^{a}$ & $1,8^{\mathrm{a}}$ & $4,2^{b}$ & $3,2^{b}$ & 7,8 & 18,7 & 0.20 & 0,32 & 0,21 & 0,14 & 1,7 & 0,26 & 5,8 & 0,35 & 7,9 \\
\hline \multirow[t]{4}{*}{7} & 0 & $0,99^{a b}$ & $1,9^{\mathrm{a}}$ & $3,1^{a}$ & $2,3^{a}$ & 8,2 & 17,2 & 0,30 & 0,42 & 0,49 & 0,39 & 2,2 & 0,46 & 4,6 & 0,88 & 7,7 \\
\hline & 50 & $0,83^{a}$ & $1,9^{a}$ & $3,1^{a}$ & $2,3^{\mathrm{a}}$ & 8,0 & 20,5 & 0,27 & 0,45 & 0,30 & 0,23 & 1,8 & 0,35 & 6,7 & 0,52 & 9,2 \\
\hline & 200 & $0,77^{a}$ & $2,0^{a}$ & $2,8^{a}$ & $2,3^{a}$ & 8,0 & 12,2 & 0,29 & 0,38 & 0,32 & 0,27 & 1,2 & 0,25 & 4,3 & 0,59 & 5,9 \\
\hline & 0 & $* * *$ & $* *$ & * & * & n.s. & n.s. & n.s. & n.s. & n.s. & n.s. & n.s. & n.s. & n.s. & n.s. & n.s. \\
\hline
\end{tabular}


Tabla 8.4. Efecto de quitosano (Q) sobre las concentraciones ( $\mu \mathrm{g} \mathrm{g}^{-1} \mathrm{PF}$ ) de violaxantina (1), luteína (2), fitoeno (3), fitoflueno (4), all trans- $\beta$-caroteno (5), all trans-licopeno (6), $\zeta$-caroteno (7), $\gamma$-caroteno (8), 13 cis- $\beta$-caroteno (9), 9 cis- $\beta$-caroteno (10), 13 cis-licopeno (11), 9 cis-licopeno (12), 5 cis-licopeno (13), suma de cis- $\beta$-caroteno (14) y suma de cis-licopeno (15).

\begin{tabular}{|c|c|c|c|c|c|c|c|c|c|c|c|c|c|c|c|c|}
\hline & & 1 & 2 & 3 & 4 & 5 & 6 & 7 & 8 & 9 & 10 & 11 & 12 & 13 & 14 & 15 \\
\hline Dosis & 0 & 0,93 & $2,2^{b}$ & 5,2 & 4,2 & $9,5^{b}$ & 18,5 & $0,28^{b}$ & $0,46^{\mathrm{b}}$ & $0,39^{b}$ & $0,30^{b}$ & $1,7^{\mathrm{b}}$ & $0,40^{\mathrm{b}}$ & 5,5 & $0,69^{b}$ & 8,0 \\
\hline \multirow[t]{3}{*}{$\left(g^{-1}\right)$} & 0,1 & 0,99 & $2,1^{\mathrm{ab}}$ & 4,5 & 3,4 & $8,9^{a b}$ & 16,6 & $0,29^{b}$ & $0,42^{\mathrm{ab}}$ & $0,34^{\mathrm{b}}$ & $0,24^{\mathrm{ab}}$ & $1,4^{\mathrm{ab}}$ & $0,25^{\mathrm{ab}}$ & 5,8 & $0,61^{\mathrm{b}}$ & 7,7 \\
\hline & 1 & 0,84 & $1,8^{\mathrm{a}}$ & 3,5 & 2,8 & $7,8^{\mathrm{a}}$ & 15,5 & $0,21^{a}$ & $0,36^{\mathrm{a}}$ & $0,24^{\mathrm{a}}$ & $0,20^{\mathrm{a}}$ & $1,3^{\mathrm{a}}$ & $0,20^{\mathrm{a}}$ & 4,5 & $0,44^{a}$ & 6,2 \\
\hline & & n.s. & * & n.s. & n.s. & * & n.s. & ** & $* *$ & $* * *$ & $* * *$ & * & * & n.s. & $* * *$ & n.s. \\
\hline \multirow[t]{3}{*}{ Racimo } & 2 & 0,95 & 2,2 & 5,6 & 4,4 & 9,5 & 16,8 & 0,25 & 0,42 & 0,29 & 0,23 & 1,6 & 0,27 & 5,1 & 0,52 & 8,0 \\
\hline & 7 & 0,89 & 1,9 & 3,3 & 2,6 & 8,0 & 16,5 & 0,26 & 0,40 & 0,34 & 0,28 & 1,4 & 0,28 & 4,7 & 0,62 & 6,7 \\
\hline & & n.s. & $* *$ & $* * *$ & $* * *$ & $* *$ & n.s. & n.s. & n.s. & n.s. & * & n.s. & n.s. & n.s. & * & n.s. \\
\hline \multicolumn{17}{|c|}{ INTERACCIÓN } \\
\hline \multicolumn{17}{|c|}{ Racimo Dosis } \\
\hline \multirow[t]{3}{*}{2} & 0 & 1,07 & 2,5 & $7,5^{\mathrm{b}}$ & $6,0^{\mathrm{C}}$ & 11,0 & 20,0 & 0,30 & 0,49 & $0,39^{c}$ & 0,30 & 2,0 & 0,32 & $6,9^{b}$ & 0,68 & 9,5 \\
\hline & 0,1 & 0,99 & 2,2 & $6,0^{b}$ & $4,7^{\mathrm{bc}}$ & 9,9 & 16,8 & 0,29 & 0,45 & $0,33^{b c}$ & 0,24 & 1,5 & 0,28 & $4,4^{a}$ & 0,57 & 6,7 \\
\hline & 1 & 0,85 & 1,9 & $3,9^{a}$ & $3,1^{\mathrm{ab}}$ & 8,2 & 14,3 & 0,20 & 0,35 & $0,19^{a}$ & 0,17 & 1,3 & 0,22 & $4,5^{\mathrm{ab}}$ & 0,36 & 6,3 \\
\hline \multirow[t]{4}{*}{7} & 0 & 0,85 & 2,0 & $3,7^{a}$ & $3,0^{a}$ & 8,5 & 17,1 & 0,27 & 0,44 & $0,39^{c}$ & 0,31 & 1,5 & 0,44 & $4,6^{a b}$ & 0,69 & 7,0 \\
\hline & 0,1 & 0,84 & 1,9 & $3,1^{\mathrm{a}}$ & $2,4^{\mathrm{a}}$ & 8,0 & 16,6 & 0,29 & 0,39 & $0,35^{b c}$ & 0,30 & 1,3 & 0,23 & $5,1^{a b}$ & 0,65 & 6,8 \\
\hline & 1 & 0,93 & 1,8 & $3,0^{\mathrm{a}}$ & $2,4^{\mathrm{a}}$ & 7,5 & 16,7 & 0,23 & 0,37 & $0,29^{b}$ & 0,23 & 1,3 & 0,18 & $4,5^{\mathrm{ab}}$ & 0,52 & 6,2 \\
\hline & & n.s. & n.s. & $* *$ & * & n.s. & n.s. & n.s. & n.s. & * & n.s. & n.s. & n.s. & * & n.s. & n.s. \\
\hline
\end{tabular}


Tabla 8.5. Efecto de 2,4-epibrasinolido (BR) sobre las concentraciones ( $\mu \mathrm{g} \mathrm{g}^{-1} \mathrm{PF}$ ) de violaxantina (1), luteína (2), fitoeno (3), fitoflueno (4), all trans- $\beta$-caroteno (5), all trans-licopeno (6), $\zeta$-caroteno (7), $\gamma$-caroteno (8), 13 cis- $\beta$-caroteno (9), 9 cis- $\beta$-caroteno (10), 13 cislicopeno (11), 9 cis-licopeno (12), 5 cis-licopeno (13), suma de cis- $\beta$-caroteno (14) y suma de cis-licopeno (15).

\begin{tabular}{|c|c|c|c|c|c|c|c|c|c|c|c|c|c|c|c|c|}
\hline & & 1 & 2 & 3 & 4 & 5 & 6 & 7 & 8 & 9 & 10 & 11 & 12 & 13 & 14 & 15 \\
\hline Dosis & 0 & $1,16^{\mathrm{b}}$ & $2,2^{b}$ & 4,6 & 3,5 & 8,8 & 17,6 & 0,28 & 0,43 & $0,43^{b}$ & $0,36^{b}$ & 2,3 & $0,46^{b}$ & 4,9 & $0,78^{b}$ & 8,1 \\
\hline \multirow[t]{3}{*}{$(\mu \mathrm{M})$} & 10 & $0,95^{\mathrm{a}}$ & $2,0^{\mathrm{ab}}$ & 4,3 & 3,3 & 8,4 & 18,8 & 0,24 & 0,39 & $0,30^{\mathrm{a}}$ & $0,27^{\mathrm{a}}$ & 1,8 & $0,31^{a}$ & 5,2 & $0,57^{a}$ & 7,7 \\
\hline & 30 & $0,89^{a}$ & $1,8^{\mathrm{a}}$ & 4,9 & 3,7 & 7,9 & 17,0 & 0,24 & 0,37 & $0,29^{a}$ & $0,27^{\mathrm{a}}$ & 2,1 & $0,32^{a}$ & 4,7 & $0,56^{a}$ & 7,5 \\
\hline & & * & * & n.s. & n.s. & n.s. & n.s. & n.s. & n.s. & ** & * & n.s. & $* *$ & n.s. & $* *$ & n.s. \\
\hline \multirow[t]{3}{*}{ Racimo } & 2 & 0,99 & 2,1 & 6,2 & 4,7 & 8,8 & 18,9 & 0,22 & 0,39 & 0,29 & 0,27 & 2,1 & 0,37 & 5,5 & 0,56 & 8,3 \\
\hline & 7 & 1,01 & 2,0 & 3,0 & 2,2 & 8,0 & 16,7 & 0,29 & 0,40 & 0,39 & 0,33 & 2,0 & 0,36 & 4,4 & 0,71 & 7,2 \\
\hline & & n.s. & n.s. & $* * *$ & $* * *$ & n.s. & n.s & $* *$ & n.s. & * & * & n.s. & n.s. & $* *$ & * & * \\
\hline \multicolumn{17}{|c|}{ INTERACCIÓN } \\
\hline \multicolumn{17}{|c|}{ Racimo Dosis } \\
\hline \multirow[t]{3}{*}{2} & 0 & $1,32^{b}$ & $2,5^{\mathrm{b}}$ & 6,1 & 4,6 & 9,4 & 18,0 & 0,25 & 0,44 & 0,37 & 0,32 & 2,3 & 0,47 & 5,2 & 0,69 & 8,5 \\
\hline & 10 & $0,89^{a}$ & $2,0^{b}$ & 5,7 & 4,4 & 8,9 & 19,3 & 0,20 & 0,39 & 0,29 & 0,25 & 1,8 & 0,30 & 5,6 & 0,54 & 8,0 \\
\hline & 30 & $0,75^{\mathrm{a}}$ & $1,7^{\mathrm{a}}$ & 6,8 & 5,1 & 8,0 & 19,5 & 0,21 & 0,34 & 0,22 & 0,24 & 2,2 & 0,34 & 5,6 & 0,46 & 8,5 \\
\hline \multirow[t]{4}{*}{7} & 0 & $0,99^{a b}$ & $1,9^{\mathrm{a}}$ & 3,1 & 2,3 & 8,2 & 17,2 & 0,30 & 0,42 & 0,49 & 0,39 & 2,2 & 0,46 & 4,6 & 0,88 & 7,7 \\
\hline & 10 & $1,02^{\mathrm{ab}}$ & $2,0^{\mathrm{a}}$ & 2,8 & 2,1 & 8,0 & 18,4 & 0,28 & 0,39 & 0,32 & 0,29 & 1,8 & 0,32 & 4,8 & 0,61 & 7,3 \\
\hline & 30 & $1,03^{a b}$ & $2,0^{\mathrm{a}}$ & 3,0 & 2,3 & 7,8 & 14,5 & 0,27 & 0,40 & 0,35 & 0,30 & 2,0 & 0,30 & 3,8 & 0,66 & 6,5 \\
\hline & & $* *$ & $* *$ & n.s. & n.s. & n.s. & n.s. & n.s. & n.s. & n.s. & n.s. & n.s. & n.s. & n.s. & n.s. & n.s. \\
\hline
\end{tabular}




\subsubsection{Compuestos fenólicos}

Los compuestos fenólicos juegan un papel muy importante a nivel fisiológico, aumentando la tolerancia al estrés de las plantas y prolongando la vida útil postcosecha de frutas y hortalizas (Hodges y Forney, 2003). Dichas propiedades se basan en su capacidad para eliminar las especies reactivas de oxígeno implicadas en la senescencia de las hojas y en el sistema de defensa antioxidante de la planta. Además, numerosos estudios muestran la importancia de los compuestos fenólicos sobre la salud (Slimestad y Verheul, 2009) y su ingesta habitual a través de la dieta se ha relacionado con la disminución del riesgo de sufrir enfermedades cardiovasculares y diversos tipos de cáncer (Hertog y col., 1993).

Diferentes estudios muestran que la aplicación de bioestimulantes sobre la planta puede aumentar el contenido de los frutos en compuestos fenólicos. En un estudio realizado en pimiento dulce tratado con una mezcla de ácido jasmónico y chitosan, se observó un incremento del contenido en compuestos fenólicos totales, especialmente cuando dicha aplicación se realizó en un estado avanzado de maduración, debido principalmente al aumento de flavonoides y de taninos (García-Mier y col., 2015). Pérez-Balibrea y col. (2011), describieron un aumento en la concentración de flavonoides y derivados del ácido ferúlico en brócoli tratado con metil jasmonato y ácido salićlico, aunque no se observó dicho incremento con quitosano. De acuerdo con Schreiner y Huyskens-Keil (2006), metil jasmonato y ácido salicílico promueven la biosíntesis de antocianos, por inducción de la enzima chalcona sintasa en plantas ornamentales. Además, la aplicación de metil jasmonato en postcosecha, incrementó la concentración de antocianos y la capacidad antioxidante en manzana, patata y diversos frutos tropicales (Rudell y col., 2002; Reyes y Cisneros-Zevallo, 2003; Kondo y col., 2005). En una revisión realizada por Tomas-Barberán y Espín (2001), se muestra que metil jasmonato induce, en diversos cultivos hortícolas y arbóreos, la formación de flavonoides como consecuencia de un incremento de la actividad fenilalanina amonio liasa (PAL). 
En nuestro estudio, mientras que la aplicación de bioestimulantes (MJ, SA, $Q$ y $B R$ ) a la dosis más elevada (dosis 2), no afectó significativamente o incluso disminuyó la concentración de flavanonas totales (calculadas como la suma de naringenina y naringenina-O-hexósido), flavonoles (suma de rutina-O-hexósido, rutina-O-pentósido, kaempferol-3-O-rutinósido y quercetina), ácidos hidroxicinámicos (suma de ácidos clorogénico, p-cumárico, ferúlico, cafeico, ferúlico-O-hexósido y cafeíco-O-hexósido), floretina- $C$-diglucósido y ácido homovanílico-O-hexósido, el uso de dosis más bajas tuvo un efecto positivo en la concentración de ciertos compuestos fenólicos, dependiendo del bioestimulante estudiado (Figuras 8.12 - 8.16). Así, la aplicación de AS y Q (dosis 1), aumentó la concentración de flavanonas, flavonoles y floretina- $C$-diglucósido en frutos del segundo racimo; la aplicación de MJ (dosis 1) aumentó la concentración de floretina- $\boldsymbol{C}$-diglucósido en frutos del racimo 2 , pero disminuyó la de flavanonas en ambos racimos; por último, la aplicación de BR (dosis 1) disminuyó la concentración de flavonoles y ácidos hidroxicinámicos, tanto en el racimo 2 como en el 7, y de floretina- $C$-diglucósido en el racimo 7. El aumento observado en la concentración de flavanonas y flavonoles, en el caso de AS y $Q$, se debió principalmente a un aumento en la concentración de naringenin y de rutina, respectivamente. De forma similar, Tu y col. (2016) observaron un efecto estimulador de metil jasmonato sobre la concentración de flavonoles en cártamo, aumentando la concentración de kaempferol-3-O- $\beta$-rutinosido y rutina. Los resultados negativos obtenidos para las dosis más elevadas, pueden en parte justificarse, al igual que en el caso de otros metabolitos estudiados, a un efecto de dilución provocado por el aumento de producción alcanzado en dichos tratamientos. Sin embargo, también cabe esperar que a diferencia de los resultados alcanzados a dosis más bajas, la aplicación de elicitores a concentraciones elevadas pueda actuar como un factor de estrés que, en combinación con las condiciones de alta temperatura, especialmente en frutos del racimo 7, pueda tener un efecto negativo sobre la acumulación de compuestos fenólicos, tal y como se describió en un estudio sobre tomate sometido a una combinación de estrés salino y alta temperatura (Mestre, 2014). Este fenómeno de respuesta caracterizado por una estimulación por dosis baja y una inhibición para dosis altas (hormesis), ha sido estudiado por otros autores con el fin de 
aumentar la calidad de los vegetales mediante la aplicación de diferentes estreses abióticos, incluyendo la aplicación de elicitores (Duarte, 2005; Nadeau y col., 2012).

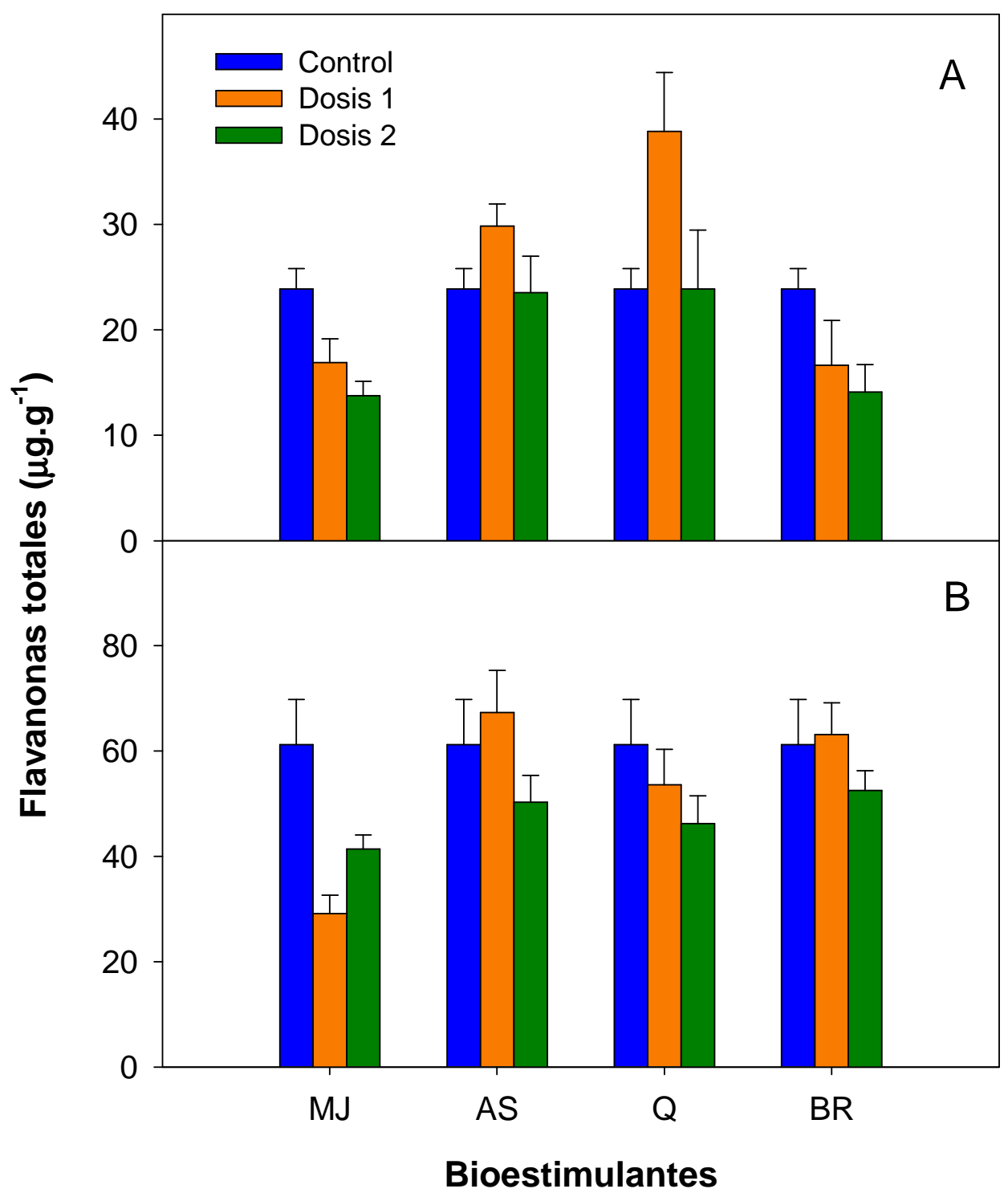

Figura 8.12. Contenido de flavanonas totales $\left(\mu \mathrm{g} \mathrm{g}^{-1}\right)$ en frutos procedentes de los racimos $2(A)$ y $7(B)$, en plantas tratadas con metil jasmonato $(M J)$, ácido salicílico (AS), quitosano (Q) y 2,4-epibrasinolido (BR). Las dosis (control, dosis 1 y dosis 2) corresponden a: MJ (0, 100 y $1000 \mu \mathrm{M})$, AS (0, 50 y $200 \mu \mathrm{M}), \mathrm{Q}(0,0,1$ y $\left.1 \mathrm{~g} \mathrm{~L}^{-1}\right)$ y $B R(0,10$ y $30 \mu \mathrm{M})$. Los valores son medias $\pm \mathrm{SE}(\mathrm{n}=10)$. 


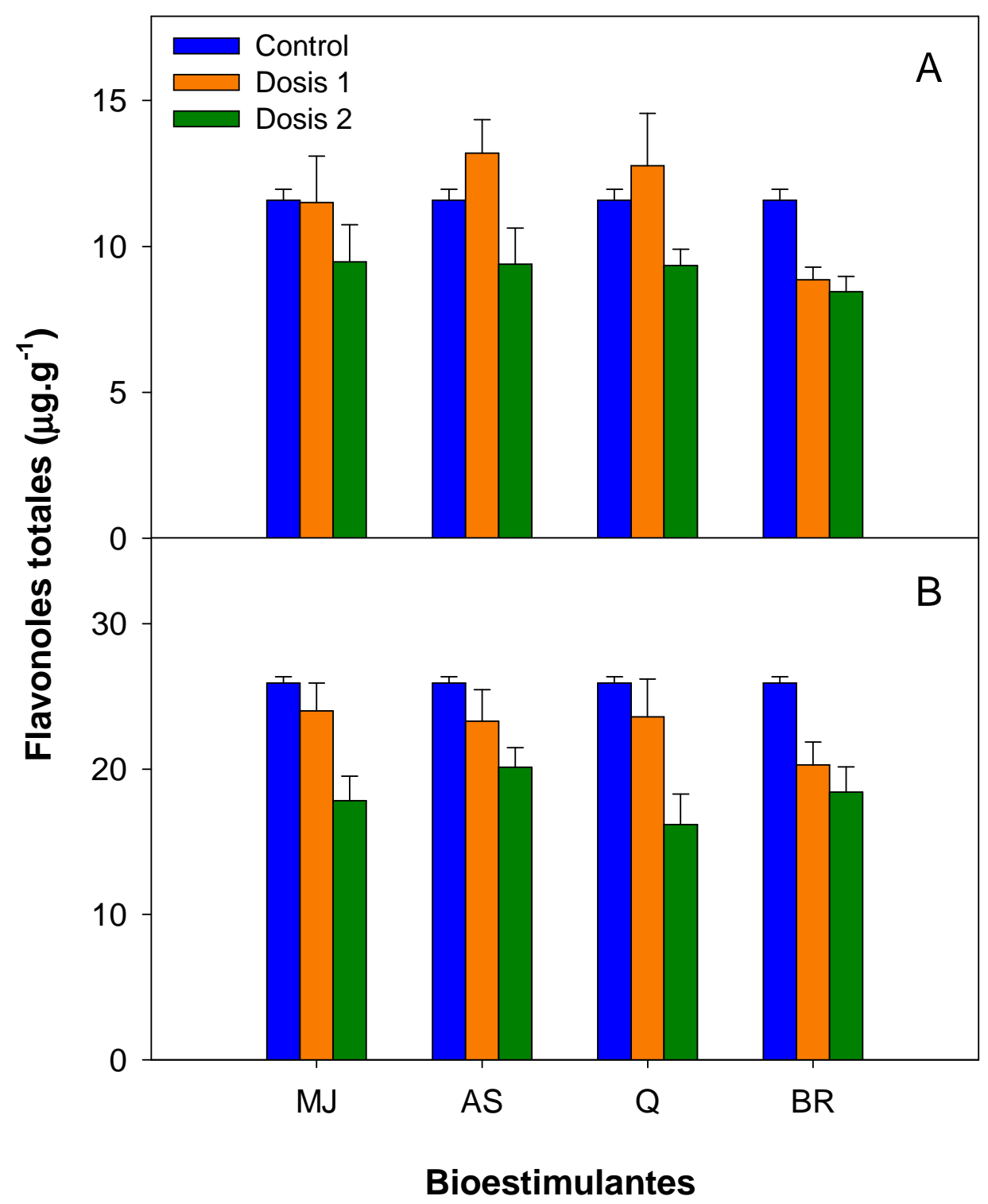

Figura 8.13. Contenido de flavonoles totales $\left(\mu \mathrm{g} \mathrm{g}^{-1}\right)$ en frutos procedentes de los racimos 2 (A) y 7 (B), en plantas tratadas con metil jasmonato (MJ), ácido salicílico (AS), quitosano (Q) y 2,4-epibrasinolido (BR). Las dosis (control, dosis 1 y dosis 2) corresponden a: MJ (0, 100 y $1000 \mu \mathrm{M})$, AS (0, 50 y $200 \mu \mathrm{M}), \mathrm{Q}(0,0,1$ y $\left.1 \mathrm{~g} \mathrm{~L}^{-1}\right)$ y $\mathrm{BR}(0,10$ y $30 \mu \mathrm{M})$. Los valores son medias $\pm \mathrm{SE}(\mathrm{n}=6)$. 


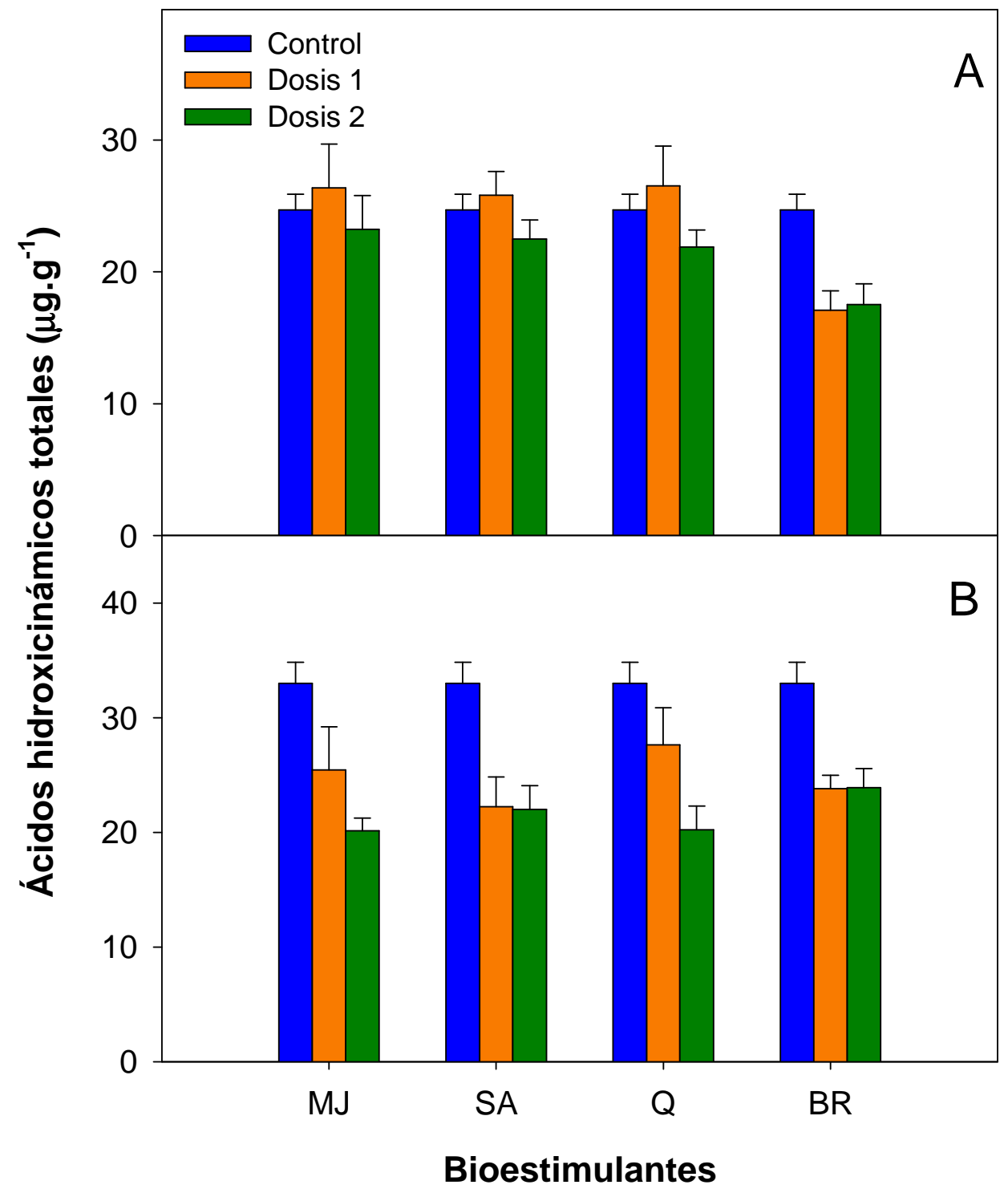

Figura 8.14. Concentración de ácidos hidroxicinámicos totales $\left(\mu \mathrm{g} \mathrm{g}^{-1}\right)$ en frutos procedentes de los racimos 2 (A) y 7 (B), en plantas tratadas con metil jasmonato (MJ), ácido salić́lico (AS), quitosano (Q) y 2,4-epibrasinolido (BR). Las dosis (control, dosis 1 y dosis 2) corresponden a: MJ (0, 100 y $1000 \mu \mathrm{M})$, AS (0, 50 y $200 \mu \mathrm{M}), \mathrm{Q}\left(0,0,1\right.$ y $\left.1 \mathrm{~g} \mathrm{~L}^{-1}\right)$ y $\mathrm{BR}(0,10$ y $30 \mu \mathrm{M})$. Los valores son medias $\pm \mathrm{SE}$ $(n=6)$. 


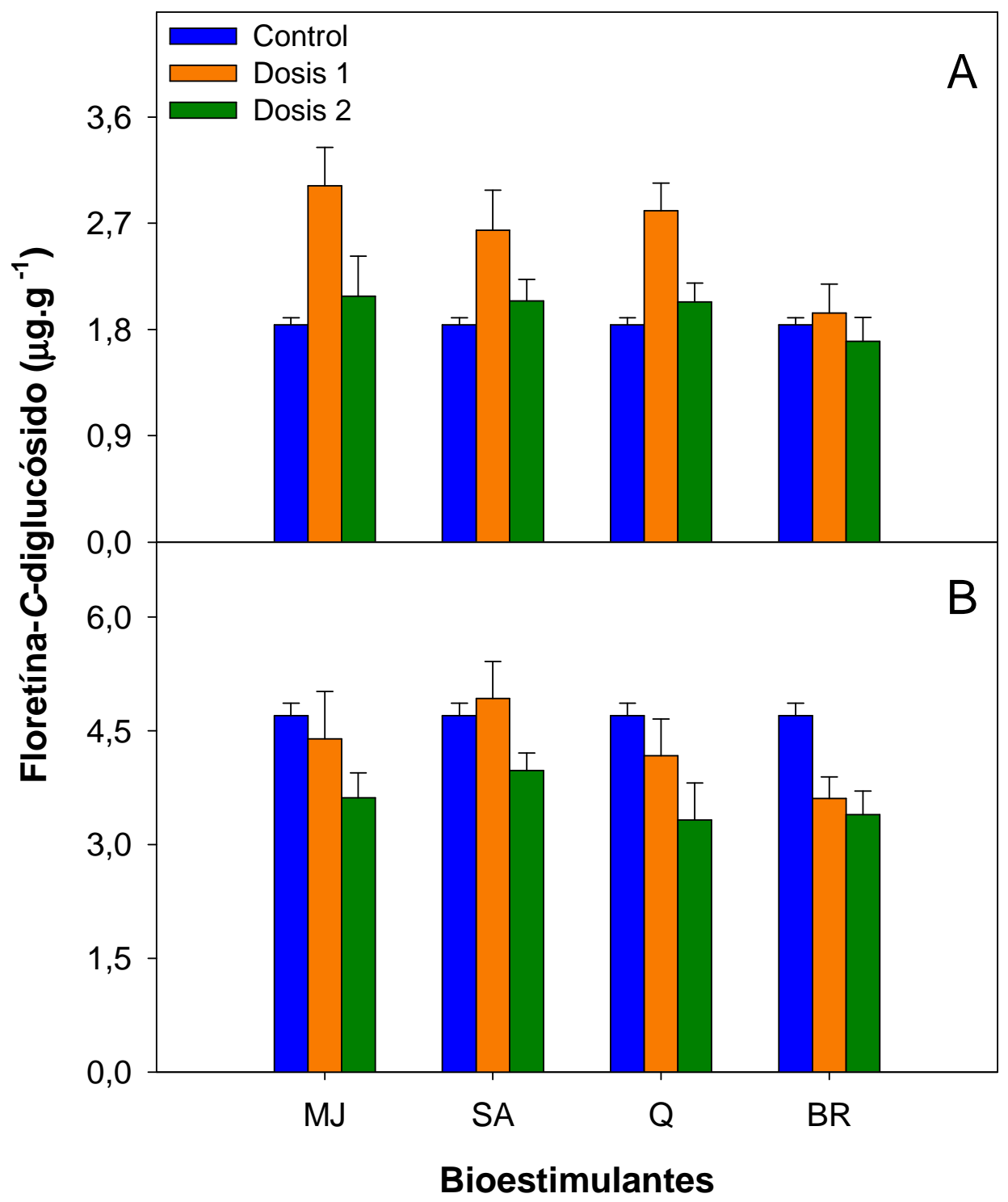

Figura 8.15. Concentración de floretina-C-diglucósido $\left(\mu g g^{-1}\right)$ en frutos procedentes de los racimos 2 (A) y 7 (B), en plantas tratadas con metil jasmonato (MJ), ácido salićlico (AS), quitosano (Q) y 2,4-epibrasinolido (BR). Las dosis (control, dosis 1 y dosis 2) corresponden a: MJ (0, 100 y $1000 \mu \mathrm{M})$, AS $(0,50$ y $200 \mu \mathrm{M}), \mathrm{Q}\left(0,0,1\right.$ y $\left.1 \mathrm{~g} \mathrm{~L}^{-1}\right)$ y $\mathrm{BR}(0,10$ y $30 \mu \mathrm{M})$. Los valores son medias $\pm \mathrm{SE}$ $(n=6)$. 


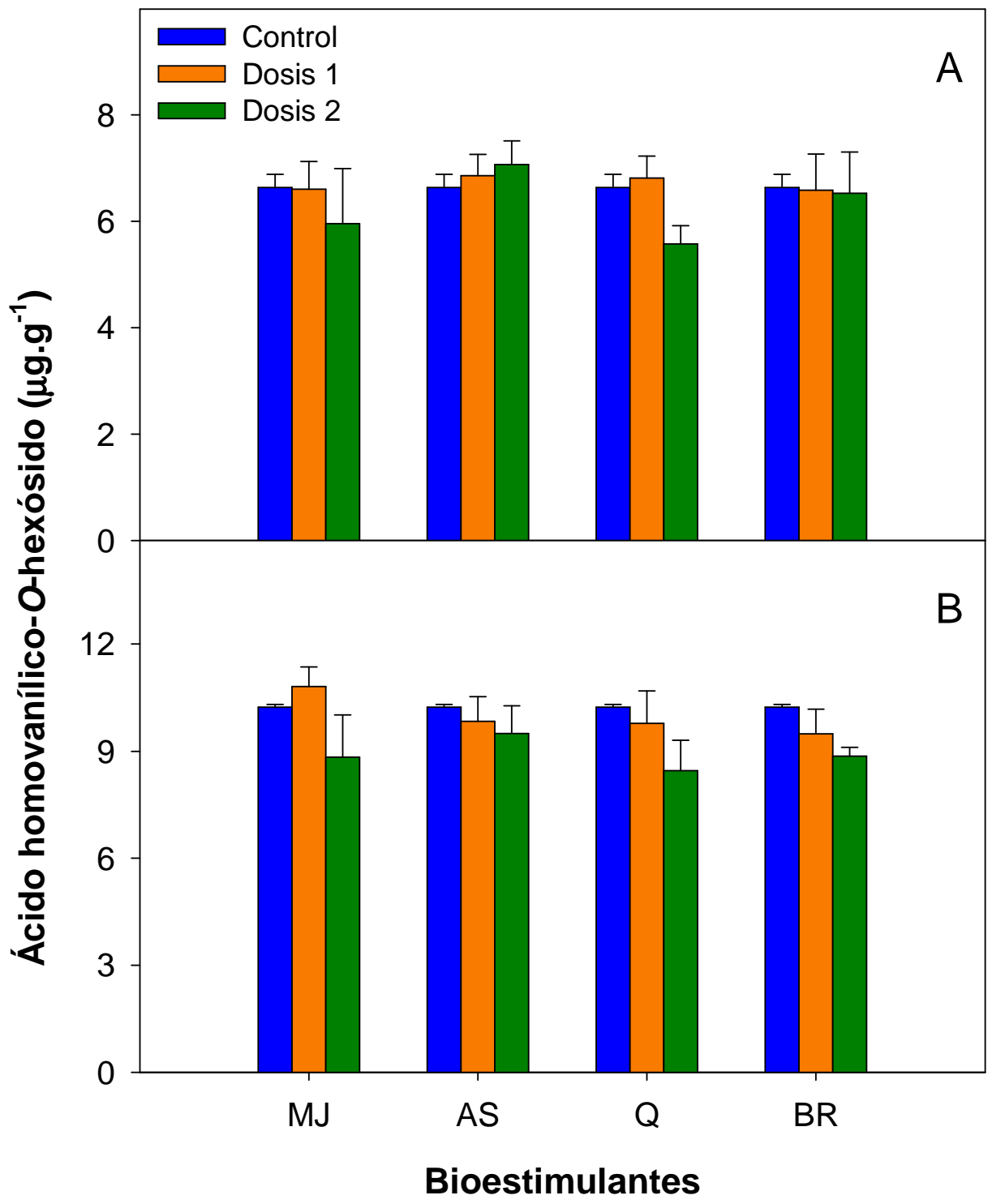

Figura 8.16. Concentración de ácido homovanílico-O-hexósido $\left(\mu \mathrm{g} \mathrm{g}^{-1}\right)$ en frutos procedentes de los racimos 2 (A) y 7 (B), en plantas tratadas con metil jasmonato (MJ), ácido salicílico (AS), quitosano (Q) y 2,4-epibrasinolido (BR). Las dosis (control, dosis 1 y dosis 2) corresponden a: MJ (0, 100 y $1000 \mu \mathrm{M})$, AS (0, 50 y

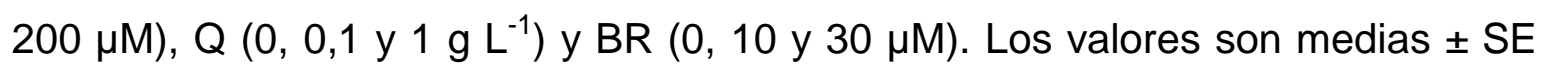
$(n=6)$.. 


\subsection{CONCLUSIONES}

En general, todos los bioestimulantes estudiados mejoraron la producción de tomate cultivado bajo condiciones de alta temperatura, aunque su efecto dependió de la naturaleza de cada compuesto y de la forma y dosis de aplicación. Respecto a la forma de aplicación, la pulverización directa sobre los frutos obtuvo mejores resultados respecto a la aplicación generalizada sobre la parte aérea. A las dosis más altas, todos los elicitores aumentaron la producción, aumentando el número de frutos y, en el caso de los tratamientos $Q$ y $B R$, también el peso medio. El mayor rendimiento se alcanzó con el tratamiento con $\mathrm{Q} 1 \mathrm{~g} \mathrm{~L}^{-1}$. A las dosis más bajas, los mejores resultados de rendimiento se obtuvieron con AS y BR, ya que aumentaron la producción incrementando el número de frutos sin detrimento (AS) o incluso aumentando (BR) el peso medio de los mismos, y sin mostrar diferencias significativas respecto a la producción alcanzada con las dosis más elevadas.

El efecto de los bioestimulantes sobre la concentración de metabolitos en fruto dependió del racimo analizado. Mientras que el efecto positivo de los bioestimulantes sobre la concentración de vitamina $C$ y carotenoides, fue más evidente en los frutos procedentes del racimo 7 (expuestos a temperaturas más elevadas que los del racimo 2), el aumento de la concentración de compuestos fenólicos como respuesta a ciertos tratamientos, fue más evidente en frutos del racimo 2. Respecto al contenido en azúcares, MJ y BR aplicados a la mayor dosis, fueron los dos únicos tratamientos que aumentaron la concentración de glucosa, MJ en frutos procedentes de los racimos 2 y 7 y $\mathrm{BR}$ en los correspondientes al racimo 7. Sin embargo, la aplicación de cualquiera de los bioestimulantes estudiados, a las dosis más elevadas, provocó, en la mayoría de los casos, una disminución de la concentración de metabolitos secundarios relacionados con las propiedades beneficiosas para la salud (excepto de vitamina $\mathrm{C}$ en frutos del racimo 7 tratados con MJ y AS). A las dosis menores, los dos tratamientos que aumentaron la producción respecto al control (AS y BR), afectaron de forma diferente al contenido en compuestos bioactivos del fruto. Mientras que en el tratamiento BR el aumento de la producción estuvo acompañado de una disminución de la concentración de vitamina $\mathrm{C}$ y de la de los 
diferentes grupos de compuestos fenólicos, el tratamiento AS aumentó la concentración de vitamina $C$ (racimo 7 ), flavanonas, flavonoles y floretina- $C$ diglucósido (racimo 2) y licopeno (racimo 2 y 7 ).

En resumen, al contrario de otras prácticas agronómicas encaminadas al aumento de la producción, en las que a menudo la calidad se ve afectada negativamente, el uso de bioestimulantes se mostró como una alternativa capaz de mejorar el rendimiento bajo condiciones de alta temperatura, aumentando además, en el caso de AS $50 \mu \mathrm{M}$, el contenido de tomate en compuestos bioactivos con reconocidos efectos beneficiosos sobre la salud, como son vitamina $\mathrm{C}$, licopeno y compuestos fenólicos. Para aumentar el rendimiento, sin considerar aspectos relacionados con la calidad funcional del fruto, la aplicación $Q$ $1 \mathrm{~g} \mathrm{~L}^{-1}$, seguido de las de BR 10 y $30 \mu \mathrm{M}$, fueron los tratamientos con los que se obtuvieron los mejores resultados, aumentando en todos los casos el número y el peso de los frutos y además, en el caso de BR $30 \mu \mathrm{M}$, el contenido en azúcares. La aplicación MJ, además de ser un tratamiento cuya aplicación presenta importantes inconvenientes debido a su volatilidad, solo aumentó la producción cuando se aplicó a la dosis más elevada y aunque este tratamiento aumentó la concentración de glucosa y vitamina $\mathrm{C}$, tuvo un efecto negativo sobre la concentración de muchos metabolitos de interés. Por último, la aplicación de $\mathrm{Q}$ $0,1 \mathrm{~g} \mathrm{~L}^{-1}$, no mejoró la producción pero si el contenido del fruto en ciertos grupos de compuestos fenólicos. 


\section{Capítulo 9}

\section{CONCLUSIONES}

En este capítulo se recogen las conclusiones mas relevantes que conforman esta tesis doctoral, cuyo objetivo ha sido evaluar la influencia de la alta temperatura sobre el rendimiento y la calidad de tomate, en particular sobre la acumulación de metabolitos relacionados con la calidad organoléptica y nutricional del fruto, y establecer diferentes estrategias agronómicas para minimizar los efectos negativos del estrés térmico.

\section{Respuesta de la variedad enana de tomate Micro-Tom al estrés salino y nutricional}

- Los resultados indican que las mutaciones de la variedad Micro-Tom, causantes del fenotipo enano, no alteran el perfil de metabolitos primarios y secundarios relacionados con la calidad nutricional y funcional de tomate. Sin embargo, su uso como planta modelo para el estudio del efecto del estrés salino y nutricional podría estar limitado por la menor respuesta de esta variedad respecto a la de variedades comerciales a dichos estreses abióticos.

Variación del contenido de compuestos bioactivos en tomate como respuesta al aumento de la temperatura

- El aumento de temperatura afectó negativamente al tamaño y al peso del fruto, proporcionalmente al tiempo de exposición al estrés, excepto en los frutos sometidos a altas temperaturas desde floración, los cuales mostraron tamaño y pesos similares a los frutos del tratamiento control debido a una 
mayor incidencia de aborto floral y al aumento de peso de los frutos restantes.

- El estrés por alta temperatura, impuesto durante un corto período de tiempo, disminuyó la concentración de licopeno y vitamina $\mathrm{C}$ en fruto. El efecto negativo del estrés sobre dichos metabolitos disminuyó a medida que aumentó el tiempo de exposición a la alta temperatura, alcanzando valores similares a los obtenidos en los frutos control, o incluso superiores, en el caso de frutos bajo estrés térmico desde la floración.

- La disminución de la concentración de licopeno, como consecuencia del aumento de la temperatura, estuvo correlacionada con una disminución de la concentración de sus precursores fitoeno y fitoflueno y un aumento de su degradación hacia la síntesis de luteína, en detrimento de la acumulación de $y$-caroteno y violaxantina.

- El aumento de temperatura no afectó a la concentración de $\beta$-caroteno, independientemente del tiempo de exposición al estrés, lo que pudo ser explicado por la canalización metabólica entre las diferentes ramas de la ruta de biosíntesis de los isoprenoides.

\section{Influencia de la nutrición nitrogenada y su interacción con el sombreo, en el rendimiento y la calidad de tomate}

- La aplicación de malla de sombreo afectó negativamente a la producción de tomate cultivado con $14 \mathrm{mM} \mathrm{N}$. La disminución de la dosis de N permitió compensar el efecto negativo del sombreo sobre el rendimiento.

- El sombreo no afectó a la concentración de azúcares en fruto, pero disminuyó la de compuestos fenólicos y vitamina C. Por el contrario, la disminución de la dosis de $\mathrm{N}$ aumentó la concentración de dichos metabolitos con y sin sombreo. 
- El sombreo disminuyó la concentración de $\beta$-caroteno solo en el caso de plantas cultivadas con la concentración más alta de $\mathrm{N}$.

- La concentración de licopeno, al contrario de lo observado en el resto de metabolitos de interés, aumentó con el sombreo. Bajo dichas condiciones, la disminución de la dosis de $\mathrm{N}$ no afectó a su concentración.

- La disminución de la dosis de $\mathrm{N}$ de 14 a $7 \mathrm{mM}$ no afectó a la producción, independientemente del momento fenológico en el que se aplicó (trasplante o floración del primer racimo). La disminución hasta $3 \mathrm{mM} \mathrm{N}$ desde trasplante, provocó una pérdida de rendimiento, sin embargo, desde floración, la pérdida de peso fue compensada con un aumento del número de frutos.

- El efecto de la disminución de la dosis de $\mathrm{N}$ sobre la calidad dependió en gran medida del momento fenológico en el que se aplicó. Desde trasplante, la disminución de $\mathrm{N}$ provocó una disminución del contenido del fruto en azúcares y carotenoides. Por el contrario, desde floración, la disminución del $\mathrm{N}$ resultó en un aumento de azúcares, licopeno y fitoeno, y no afectó al contenido de $\beta$-caroteno y otros carotenoides, excepto luteína.

- La concentración de vitamina $\mathrm{C}$ en fruto, aumentó como consecuencia de la disminución de la dosis de $\mathrm{N}$ desde trasplante y desde floración.

\section{Influencia de la temperatura y la salinidad sobre el contenido de tomate en compuestos bioactivos}

- El aumento de la salinidad en el medio de cultivo provocó una disminución de la producción de tomate, como consecuencia de la disminución del peso de los frutos. Este problema se agravó con el aumento de temperatura ambiental, debido a una disminución del número de frutos. 
- En ausencia de estrés térmico, la salinidad aumentó el valor nutritivo de los frutos, al incrementar la concentración de licopeno, $\beta$-caroteno, vitamina $C$ $y$ vitamina $E$

- En ausencia de estrés térmico, la salinidad aumentó el valor nutritivo de los frutos, al incrementar la concentración de licopeno, $\beta$-caroteno, vitamina $C$ y vitamina E. La alta temperatura solo aumentó la concentración de vitamina C.

- No se observó una interacción entre estreses térmico y salino sobre el contenido de bioactivos, excepto para $\beta$-caroteno, de forma que solo en presencia de alta salinidad $(90 \mathrm{mM})$, el estrés térmico disminuyó su concentración.

\section{Respuesta de la planta de tomate a la aplicación de bioestimulantes en condiciones de alta temperatura}

- En general, la aplicación de bioestimulantes (metil jasmonato, ácido salicílico, quitosano y 2,4-epibrasinolido) aumentó el rendimiento de tomate cultivado bajo condiciones de alta temperatura, aumentando además, en el caso de ácido salićlico $50 \mu \mathrm{M}$, el contenido del fruto en compuestos bioactivos (vitamina $\mathrm{C}$, licopeno y compuestos fenólicos).

- La aplicación quitosano $1 \mathrm{~g} \mathrm{~L}^{-1}$ fue la mejor opción para aumentar el rendimiento, sin considerar aspectos relacionados con la calidad funcional del fruto, seguido de 2,4-epibrasinolido 10 y $30 \mu \mathrm{M}$, aumentando en todos los casos el número y el peso de los frutos y además, en el caso de 2,4epibrasinolido $30 \mu \mathrm{M}$, el contenido en azúcares.

- La aplicación metil jasmonato, además de ser un tratamiento cuya aplicación presenta importantes inconvenientes debido a su volatilidad, solo aumentó la producción cuando se aplicó a la dosis más elevada y aunque este tratamiento aumentó la concentración de glucosa y vitamina 
C, tuvo un efecto negativo sobre la concentración de la mayoría metabolitos de interés.

- La aplicación quitosano $0,1 \mathrm{~g} \mathrm{~L}^{-1}$, no mejoró la producción pero fue el más eficaz para aumentar el contenido del fruto en compuestos fenólicos. 


\section{Capítulo 10}

\section{BIBLIOGRAFÍA}

Abogadallah, G.M. (2010). Antioxidative defense under salt stress. Plant Signaling \& Behavior, 5(4), 369-374.

Adams, P. (1980). Nutrient uptake by cucumbers from recirculating solutions. Acta Horticulturae, 98, 119-126.

Adams, P. \& Ho, L.C. (1992). The susceptibility of modern tomato cultivars to blossom-end rot in relation to salinity. Journal of Horticultural Science, 67, 827-839.

Aguirre, R. \& May, J.M. (2008). Inflammation in the vascular bed: Importance of vitamin C. Pharmacology and Therapeutics, 119, 96-103.

Alasalvar, C., Grigorr, J.M. \& Zhang, D. (2001). Comparison of volatiles, phenolic compounds, sugars, antioxidant vitamins and sensory quality of different coloured carrot varieties. Journal of Agricultural and Food Chemistry, 49, 1410-1416.

Albacete, A., Martinez-Andujar, C., Ghanem, M.E., Acosta, M., Sanchez-Bravo, J., Asins, M.J., Cuartero, J., Lutts, S., Dodd, I.C. \& Pérez-Alfocea, F. (2009) Rootstock-mediated changes in xylem ionic and hormonal status are correlated with delayed leaf senescence, and increased leaf area and crop productivity in salinized tomato. Plant, Cell and Environment, 32(7), 928938.

Albersheim, P. \& Valent, B.S. (1978). Host-pathogen interactions in plants: plants when exposed to oligosaccharides of fungal origin defend themselves by accumulating antibiotics. Journal Cell Biology, 78, 627-643.

Amancio, S. \& Stulen, I. (2007). Nitrogen acquisition and assimilation in higher plants. Springer Science \& Business Media, 300.

Ambuludi, J.R. (2015). Efectos de elicitores en el comportamiento agronómico del híbrido tomate (Lycopersicon esculentum Mill.) Yuval 810 cultivado en 
waterboxx. Ed. La Libertad. UPSE, Matriz. Facultad de Ciencias Agrárias, $120 \mathrm{pp}$.

Ananthi, S., Veeraragavathatham, D. \& Srinivasan, K. (2004). Influence of sources and levels of potassium on quality attributes of chilli (Capsicum annuum L.), South Indian Horticultura, 52(1-6), 152-157.

Arbona, V. \& Gómez-Cadenas, A. (2008). Hormonal modulation of Citrus responses to flooding. Journal of Plant Growth Regulation, 27, 241-250.

Arbona, V., Hossain, Z., López-Climent, M.F., Pérez-Clemente, R.M. \& GómezCadenas, A. (2008). Antioxidant enzymatic activity is linked to water logging stress tolerance in citrus. Physiologia Plantarum, 132, 452-466.

Arias, R., Lee, T., Logendra, L. \& Janes, H. (2000). Correlation of lycopene measured by HPLC with the $L^{*}, a^{*}, b^{*}$ color readings of a hydroponic tomato and the relationship of maturity with color and lycopene content. Journal of Agricultural Food Chemistry, 48, 1697-1702.

Asri, F.O. \& Sonmez, S. (2010). Reflection of different applications of potassium and iron fertilization on tomato yield and fruit quality in soilless medium. Journal of Food Agriculture \& Environment, 8(3-4), 426-429.

Aung, L.H. (1976). Influence of certain plant factors on the growth and flowering of the lower axillary shoot of Lycopersicon esculentum Mill. Annals of Botany, 40, 723-729.

Ávalos, A. \& Pérez-Urria, E. (2009). Metabolismo secundario de plantas. Carril Reduca (Biología). Serie Fisiología Vegetal, 2(3), 119-145.

Azcón-Bieto, J. \& Talón, M. (2008). Fisiología de las plantas y el estrés. En: Fundamentos de Fisiología Vegetal. Ed: Interamericana-McGraw-Hill, Madrid, 577-597.

Barnes S. (2003). Phytoestrogens and osteoporosis: What is a safe dose? British Journal of Nutrition, 89, 101-108.

Bartley, G. \& Scolnik, P. (1995). Plant carotenoids: pigments for photoprotection, visual attraction, and human health. Plant Cell, 7, 1027-1038.

Wani, A.B., Chadar, H., Wani A.H., Singh, S. \& Upadhyay, N. (2016). Salicylic acid to decrease plant stress. Environmental Chemistry Letters. DOI 10.1007/s10311-016-0584-0 (En prensa). 
Becatti, E., Petroni, K., Giuntini D., Castagna, A., Calvenzani, V., Serra, G., Tonelli, A. \& Ranieri, A. (2009). Solar UV-B radiation influences carotenoid accumulation of tomato fruit through both ethylene-dependent and independent mechanisms. Journal of Agricultural and Food Chemistry, 57 (22), 10979-10989.

Bènard, C., Gautier, H., Bourgaud, F., Grasselly, D., Navez, B., Caris-Veyrat, C, Weiss, M. \& Gènard, M. (2009). Effects of low nitrogen supply on tomato (Solanum lycopersicum) fruit yield and quality with special emphasis on sugars, acids, ascorbate, carotenoids, and phenolic compounds. Journal of Agricultural and Food Chemistry, 57(10), 4112-4123.

Benhamou, N.P., Lafontaine, J. \& Nicole, M. (1994). Induction of systemic resistance to Fusarium crown and root rot in tomato plants by seed treatment with chitosan. Phytopathology, 84, 1432-1444.

Bernstein, L. \& Hayward, H.E. (1958). Physiology of salt tolerance. Annual Review of Plant Physiology and Plant Molecular Biology, 9, 25-46.

Beverly, R.B., Latimer, J.G. \& Smittile, D.A. (1993). Postharvest Handiling. En: A System Approach. Ed. Academic Press, New York, 73-98.

Billard V., Etienne P., Jannin L., Garnica M., Cruz F. \& Garcia-Mina J. M. (2014). Two biostimulants derived from algae or humic acid induce similar responses in the mineral content and gene expression of winter oilseed rape (Brassica napus L.). Journal of Plant Growth Regulation, 33, 305-316.

Bita, C.E., Zenoni, S., Vriezen, W.H., Mariani, C., Pezzotti, M. \& Gerats, T. (2011). Temperature stress differentially modulates transcription in meiotic anthers of heat-tolerant and heat-sensitive tomato plants. BMC Genomics, 12, 384408.

Bita, C. \& Gerats, T. (2013). Plant tolerance to high temperature in a changing environment: scientific fundamentals and production of heat stress tolerant crops. Fronties Plant Science, 4, 273-311.

Bohm, V. (2001). Use of column temperature to optimize carotenoids isomer separation by C-30 high performance liquid chromatography. Journal of Separation Science, 24(12), 955-959. 
Boileau, A., Merchen, N., Wasson, C., Atkinson, C. \& Erdman, J. (1999). Cislycopene is more bioavailable than trans-lycopene in vitro and also in vivo in the lymph cannulated ferret. FASEB Journal, 13(4), 210-210.

Boileau, T.W., Boileau, A.C. \& Erdman, J.W. (2002). Bioavailability of all-trans and cis-isomers of lycopene. Journal Experimental Biology and Medicine, 227(10), 914-919.

Borghesi, E., Gonzalez-Miret, M.L., Escudero-Gilete, M.L., Malorgio, F., Heredia, F.J. \& Melendez-Martinez, A.J. (2011). Effects of salinity stress on carotenoids, anthocyanins, and color of diverse tomato genotypes. Journal of Agricultural and Food Chemistry, 59(21), 11676-11682.

BORM, (2012). Boletín Oficial de la Región de Murcia Orden de 10 de mayo de 2012, de la Consejería de Agricultura y Agua por la que se regulan las normas técnicas de producción integrada en el cultivo de tomate, 2221722236.

Botella, M.A., del Amor, F.M., Amoros, A., Serrano, M., Martinez, V. \& Cerda, A. (2000). Polyamine, ethylene and other physico-chemical parameters in tomato (Lycopersicon esculentum) fruits as affected by salinity. Physiologia Plantarum, 109(4), 428-434.

Bourbouloux, A., Raymond, P. \& Delrot. S. (1998). Effects of salicylic acid on sugar and amino acid uptake. Journal of Experimental Botany, 49, 239-247.

Bramley, P.M. (2002). Regulation of carotenoid formation during tomato fruit ripening and development. Journal of Experimental Botany, 53(377), 21072113.

Briggs, W., T.S. Tseng, H.T. Cho, T. Swartz, S., Sullivan, R., Bogomolni, E., Kaiserli, \& Christie, J. (2007). Phototropins and their LOV domains: versatile plant blue-light receptors. Journal of Integrative Plant Biology, 49, 4-10.

Britton, G., Liaaen-Jensen, S. \&. Pfander, H. (1995). Carotenoids: Spectroscopy. Birkhäuser Verlag Basel, 1B, 13-62.

Burns, E.R., Carter, J., Pile, R.S. \& Roetheli, J.C. (1979). Crop production in humid greenhouses heated with direct contact heat exchangers and power plan waste heat. Proc. Natl. Greenhouses Veg. and Energy Conf. Cleveland, Ohio, 49-64. 
Burns, J., Yokota, T., Ashihara, H., Lean, M.E.J. \& Crozier, A. (2002). Plant foods and herbal sources of resveratrol. Journal of Agricultural and Food Chemistry, 50, 3337-3340.

Busch, J.M., Savage, G.P. \& Searle, B.P. (2008). Sensory evaluation and physicochemical measurements of tomatoes commonly consumed in New Zealand. International Journal of Consumer Studies, 32(5), 535-544.

Buta, J.G. \& Spaulding, D.W. (1997). Endogenous levels of phenolics in tomato fruit during growth and maturation. Journal of Plant Growth Regulation, 16(1), 43-46.

Callejon Ferrer, A.J. (2003). Efecto del sombreado mediante pantallas aluminizadas, sobre el microclima, fisiología, producción y calidad en fruto de tomate bajo invernadero. En: Técnicas de Producción en cultivos protegidos, tomo 2. Ed. Caja Rural Intermediterránea, Cajamar, Almería, 281-318.

Calvert, A. (1973). Morphology, development and environmental responses En: The U.K. tomato manual. Grower Books. Ed: H.G. Kingham, London, 1934.

Camarena-Gutiérrez, \& de la Torre-Almaráz, R. (2007). Resistencia sistémica adquirida en plantas: estado actual. Revista Chapingo. Serie Ciencias Forestales y del Ambiente, 13(2), 157-162.

Camejo, D., Rodriguez, P., Morales, A., Dell'Amico, J.M., Torrecillas, A. \& Alarcon, J.J. (2005). High temperature effects on photosynthetic activity of two tomato cultivars with different heat susceptibility. Journal of Plant Physiology, 162, 281-289.

Cameron, K.C., Di, H.J. \& Moir, J.L. (2013). Nitrogen losses from the soil/plant system: a review. Annals of Applied Biology, 162(2), 145-173.

Canene-Adams, K., Campbell, J.K., Zaripheh, S., Jeffery, E.H. \& Erdman, J.W. (2005). The tomato as a functional food. The Journal of Nutrition, 135, 1226-1230.

Cantos, E., Espin, J.C. \& Tomás-Barberán, F.A. (2002). Varietal differences among the polyphenol profiles of seven table grape cultivars studied by LCDAD-MS-MS. Journal of Agricultural and Food Chemistry 50, 5691-5696. 
Cantos, E., Espin, J.C., Fernandez, M.J., Oliva, J. \& Tomas-Barberan, F.A. (2003). Postharvest UV-C-irradiated grapes as a potential source for producing stilbene-enriched red wines. Journal of Agricultural and Food Chemistry, 51(5), 1208-1214.

Caris-Veyrat, C., Amiot, M.J., Tyssandier, V., Grasselly, D., Buret, M., Mikolajczak, M., Guilland, J.C., Bouteloup-Demange, C. \& Borel, P. (2004). Influence of organic versus conventional agricultural practice on the antioxidant microconstituent content of tomatoes and derived purees; Consequences on antioxidant plasma status in humans. Journal of Agricultural and Food Chemistry, 52, 6503-6509.

Carvalho, R.F., Campos, M.L., Pino, L.E., Crestana, S.L., Zsoegoen, A., Lima, J. E., Benedito, V.A. \& Peres, L.E.P. (2011). Convergence of developmental mutants into a single tomato model system: 'Micro-Tom' as an effective toolkit for plant development research. Plant Methods, 7(1), 18-38.

Chamarro, J. (1995). Anatomía y fisiología de la planta. El cultivo del tomate. Ed: Ediciones Mundi-Prensa, Madrid, 43-91.

Chang, J.H., Shin, J.H. \& Chung, I.S. (1998). Improved menthol production from chitosan-elicited suspension culture of Mentha piperita. Biotechnology Letters, 20, 1097-1099.

Chang, J.H., Shin, J.H. \& Chung, I.S. (1998). Improved menthol production from chitosan-elicited suspension culture of Mentha piperita. Biotechnology Letters, 20, 1097-1099.

Chasse, G.A., Mak, M.L., Deretey, E., Farkas, I., Torday, L.L., Papp, J.G., Sarma, D.S.R., Agarwal, A., Chakravarthi, S., Agarwal, S. \& Rao, A.V. (2001). An ab initio computational study on selected lycopene isomers. Journal of Molecular Structure-Theochem, 571, 27-37.

Chaves-Barrantes, N.F. \& Gutiérrez-Soto, M.V. (2017). Respuestas al estrés por calor en los cultivos. 1. Aspectos moleculares, bioquímicos y fisiológicos Agronomía Mesoamericana, 28(1), 237-253.

Chen, J.P., Tai, C.Y. \& Chen, B.H. (2004). Improved liquid chromatographic method for determination of carotenoids in Taiwanese mango (Mangifera indica L.). Journal of Chromatography A, 1054(1-2), 261-268. 
Cheong, J.J., \& Choi, Y.D. (2003). Methyl jasmonate as a vital substance in plants. Trends in Genetics, 19, 409-413.

Clifford, M.N. (1999). Review: Chlorogenic acids and other cinnamates: nature, occurrence and other dietary burden. Journal of the Science of Food and Agriculture, 79, 362-372.

Clifford, M.N. (2000). Chlorogenic acids and other cinnamates nature, occurence, dietary burden, absorption and metabolism. Journal of Science and Food Agriculture, 80, 1033-1043.

Clifford, M.N., Johnston, K.L., Knight, S. \& Kuhnert, N. (2003). A hierarchical scheme for LCMS identification of chlorogenic acids. Journal of Agricultural and Food Chemistry 51, 2900-2911.

Cockshull, K.E. (1988). The integration of plant physiology with physical changes in the greenhouse climate Acta Horticulturae, 229(82), 113-123.

Colmenero-Flores, J. \&. Rosales, M. (2014). Interaction between salt and heat stress: when two wrongs make a right. Plant, Cell and Environment, 37, 1042-1045.

Creelman, R.A. \& Mullet, J.E. (1997). Oligosaccharins, brassinolides, and jasmonates: Non-traditional regulators of plant growth, development, and gene expression. Plant Cell, 9, 1211-1223.

Crisosto, C.H. \& Mitchell, F.G. (2007). Factores precosecha que afectan la calidad de frutas y hortalizas. Tecnología Poscosecha de Productos Hortofrutícolas. $3^{\underline{a}}$ edición. Ed. Kader, A. University of California, Division of Agriculture and Natural Resources, Oakland, California, USA, 55-62.

Croteau, R., Kutchan, TM. \& Lewis, N.G. (2000) Natural products (secondary metabolites). En: Biochemistry and Molecular Biology of Plants Eds: B. Buchanan, W. Gruissem, R. Jones. American Society of Plant Physiologists, Rockville, MD, 1250-1268.

Crozier, A., Jensen, E., Lean, M.E.J. \& McDonald, M.S. (1997) Quantitative analysis of flavonoids by reversed-phase high performance liquid chromatography. Journal Chromatography A, 761, 315-321.

Crozier, A., Clifford, M. \& Ashijara, H. (2006). Plant secondary metabolites occurrence, structure and role in the human diet. Ed. Blackwell, 1-372. 
Cuartero, J. \& Fernández-Muñoz R. (1999). Tomato and salinity. Scientia Horticulture, 78, 83-125.

Davey, M.W., Van Montagu, M., Sanmatin, M., Kanellis, A., Smirnoff, N., Benzie, I.J.J., Strain, J.J., Favell, D. \& Fletcher, J. (2000). Plant L-ascorbic acid: chemistry, function, metabolism, bioavailability and effects of processing. Journal Science Food Agricultural, 80, 825-860.

De Koning, A.N.M. (1996). Quantifying the responses to temperature of different plant processes involved in growth and development of glasshouse tomato. Workshop on Mathematical and Control Applications in Agriculture and Horticulture, (406), 99-104.

De Pascale, S., Vincenzo, A., Fogliano, V. \& Ritieni, A. (2001). Irrigation with saline water improves carotenoids content and antioxidant activity of tomato. Journal of Horticultural Science and Biotechnology, 76(4), 447-453.

De Rosso, V.V. \& Mercadante, A.Z. (2007). Identification and quantification of carotenoids, by HPLC-PDA-MS/MS, from amazonian fruits. Journal of Agricultural and Food Chemistry, 55, 5062-5072

Dégenéve, A. (2004). Antioxidants in fruits and vegetables. MSc Thesis, University of Glasgow, 252 pp.

Deutsch, J.C. (2000). Dehydroascorbic acid. Journal of Chromatography A, 881, 299-307.

Devlieghere, F., Vermeulen, A. \& Debere, J. (2004). Chitosan: antimicrobial activity, interacytions with food components and applicability as a coating on fruit and vegetables. Food Microbiology, 21, 703-704.

Di Pietro, N., Di Tomo, P. \& Pandolf, A. (2016). Carotenoids in cardiovascular disease prevention. JSM Atheroscler, 1(1), 1002-1015.

Dixon, R.A. \& Steele, C.L. (1999). Flavonoids and isoflavonoids.a goldmine for metabolic engineering. Trends in Plant Science, 4, 394-400.

Doares, S.H., Narvaez-Vasquez, J., Conconi, A. \& Ryan, C.A. (1995). Salicylic acid inhibits synthesis of proteinase inhibitors in tomato leaves induced by systemin and jasmonic acid. Plant Physiolpgy, 108, 1741-1746.

Dong, X. (1998). SA, JA. Ethylene and disease resistance in plants. Current Opinion in Plant Biology, 1, 316-329. 
Du Jardin, P. (2015). Plant biostimulants: Definition, concept, main categories and regulation. Scientia Horticulturae, 196, 3-14.

Duarte, A. (2015). Abiotic stress hormesis: hormetic stresses to maintain quality and enhance glucosinolates and phenolic compounds in broccoli (Brassica oleracea var. italica) during storage. Tesis. Canadá.

Dumas, Y., Dadomo, M., Di Lucca, G. \& Grolier, P. (2003). Effects of environmental factors and agricultural techniques on antioxidant content of tomatoes. Journal of the Science of Food and Agriculture, 83(5), 369-382.

Dzhavakhiya, V.G. \& Shcherbakova, L.A. (2016). Control of plant pathogens by biogenic elicitors and possible mechanisms of action. Fronties Plant Science, 24, 7, 340. doi: 10.3389/fpls.2016.00340.

Ehret, D.L., Usher, K., Helmer, T., Block, G., Steinke, D., Frey, B., Kuang, T. \& Diarra, M. (2013). Tomato fruit antioxidants in relation to salinity and greenhouse climate. Journal of Agricultural and Food Chemistry, 61(5), 1138-1145.

El Ahmadi, A.B. \& Stevens, M.A. (1979). Reproduction responses of heat-tolerant tomatoes to high temperatures. The Journal of the American Society for Horticultural Science, 104, 686-691.

El Ghaouth, A., Arul, J., Grenier, J., Benhamou, N., Asselin A. \& Bélanger, R. (1994). Effect of chitosan on cucumber plants: Suppression of Pythium aphanidermatum and induction of defense reactions. Phytopathology, 84, 313-320.

Elia, A. \& Conversa, G. (2012). Agronomic and physiological responses of a tomato crop to nitrogen input. European Journal of Agronomy, 40, 64-74.

Erge, H.S. \& Karadeniz, F. (2011). Bioactive compounds and antioxidant activity of tomato cultivars. International Journal of Food Properties, 14(5), 968-977.

Espín, J.C. \& Tomás-Barberán, F.A. (2006). Polifenoles y Salud: Propiedades biológicas de uva y de la granada. Investigación y Ciencia, 34-36.

Eyal, E. \& Levy, A.A. (2002) Tomato mutants as tools for functional genomics. Current Opinion in Plant Biology, 5, 112-117.

Fabre, N., Rustan, I., de Hoffmann, E. \& Quetin-Leclercq, J. (2001). Determination of flavone, flavonol, and flavanone aglycones by negative ion liquid 
chromatography electrospray ion trap mass spectrometry. Journal of the American Society for Mass Spectrometry, 12(6), 707-715.

Fan, X.T., Mattheis, J.P., \& Fellman, J.K. (1998). Responses of apples to postharvest jasmonate treatments. Journal of the American Society for Horticultural Science, 123(3), 421-425.

FAO (2013). Statistics division of the food and agriculture organization of the unitednations.http:/faostat.fao.org/.

Farmer, E.E., Almeras, E. \& Krishnamurthy, V. (2003). Jasmonates and related oxylipins in plant responses to pathogenesis and herbivory. Current Opinion in Plant Biology, 6, 372-378.

Fenoll, J., Martinez, A., Hellin, P. \& Flores, P. (2011). Simultaneous determination of ascorbic and dehydroascorbic acids in vegetables and fruits by liquid chromatography with tandem-mass spectrometry. Food Chemistry 127, 340-344.

FEPEX, 2012. http://www.fepex.es/noticias/.

Fernandez-Garcia, N., Martinez, V., Cerda, A. \& Carvajal, M. (2004). Fruit quality of grafted tomato plants grown under saline conditions. Journal of Horticultural Science \& Biotechnology, 79(6), 995-1001.

Feys, B.J. \& Parker, J.E. (2000) Interplay of signalling pathways in plant disease resistance. Trends in Genetics: TIG, 16(10), 449-455.

Flores, P., Navarro, J.M., Carvajal, M., Cerda, A. \& Martinez, V. (2003). Tomato yield and quality as affected by nitrogen source and salinity. Agronomie, 23(3), 249-256.

Flores, P., Navarro, J.M., Garrido, C., Rubio, J.S., \& Martinez, V. (2004). Influence of $\mathrm{Ca}^{2+}, \mathrm{K}^{+}$and $\mathrm{NO}^{3-}$ fertilisation on nutritional quality of pepper. Journal of the Science of Food and Agriculture, 84(6), 569-574.

Flores, P., Castellar, I. \& Navarro, J. (2005). Nitrate leaching in pepper cultivation with organic manure and supplementary additions of mineral fertilizer. Communications in Soil Science and Plant Analysis, 36 (19-20), 2889-2898.

Flores, P., Hellín, P. \& Fenoll, J. (2012). Determination of organic acids in fruits and vegetables by liquid chromatography with tandem-mass spectrometry. Food Chemistry, 132, 1049-1054. 
Flores, P., Hernandez, V., Hellin, P., Fenoll, J., Cava, J., Mestre, T. \& Martinez, V. (2015). Metabolite profile of the tomato dwarf cultivar Micro-Tom and comparative response to saline and nutritional stresses with regard to a commercial cultivar. Journal of the Science of Food and Agriculture, 96(5), 1562-1571.

Foolad, M.R. (2004). Recent advances in genetics of salt tolerance in tomato. Plant Cell Tissue and Organ Culture, 76, 101-119.

Foyer, C.H. \& Noctor, G. (2005). Redox homeostasis and antioxidant signaling: A metabolic interface between stress perception and physiological responses. Plant Cell, 17, 1866-1875.

Fraser, P.D. \& Bramley, P.M. (2004). The biosynthesis and nutritional uses of carotenoids. Progress in Lipid Research, 43(3), 228-265.

Frontela, C, Canali, R. \& Virgili, F. (2009). Use of dietary phenols to modulate inflammatory bowel response. Gastroenterology Hepatology. 33(4), 307-12.

Fujioka, S. \& Sakurai, A. (1997). Brassinosteroids. Natural Product Reports, 19(1), 1-10.

Furusawa, N. (2001). Rapid high performance liquid chromatographic identification-quantification of total vitamin $\mathrm{C}$ in fruit drinks. Food Control, 12, 27-29.

Gallie, D.R. (2013). Review: Increasing vitamin c content in plant foods to improve their nutritional value successes and challenges. Nutrients, 5, 3424-3446.

Garcia-Mier, L., Jimenez-Garcia, S., Guevara-Gonzalez, R., Feregrino-Pérez, A., Contreras-Medina, L. \& Torres-Pacheco, I. (2015). Elicitor mixtures significantly increase bioactive compounds, antioxidant activity, and quality parameters in sweet bell pepper. Journal of Chemistry, 2015, 1-8.

Gautier, H., Diakou-Verdin, V., Benard, C., Reich, M., Buret, M., Bourgaud, F., Poessel, J.L., Caris-Veyrat, C. \& Gènard, M. (2008). How does tomato quality (sugar, acid, and nutritional quality) vary with ripening stage, temperature, and irradiance? Journal of Agricultural and Food Chemistry, 56(4), 1241-1250.

Gautier, H., Massot, C., Stevens, R., Serino, S. \& Gènard, M. (2009). Regulation of tomato fruit ascorbate content is more highly dependent on fruit irradiance than leaf irradiance. Annals of Botany, 103(3), 495-504. 
Gènard, M., Lescourret, F., Gomez, L. \& Habib, R. (2003). Changes in fruit sugar concentrations in response to assimilate supply, metabolism and dilution: a modeling approach applied to peach fruit (Prunus persica). Tree Physiology, 23(6), 373-385.

Gent, M.P.N. (2008). Density and duration of shade affect water and nutrient use in greenhouse tomato. Journal of the American Society for Horticultural Science, 133(4), 619-627.

Ghaderi, N., Normohammadi, S. \& Javadi, T. (2015). Morpho-physiological responses of strawberry (Fragaria $x$ ananassa) to exogenous salicylic acid application under drought stress. Journal of Agricultural Science and Technology, 17(1), 167-178.

Gill, S.S. \&Tuteja N. (2010). Reactive oxygen species and antioxidant machinery in abiotic stress tolerance in crop plants. Plant Physiology Biochemistry, 48, 909-930.

Gomez, P., Ferrer, M.A., Fernandez-Trujillo, J.P., Calderon, A., Artes, F., EgeaCortines, M. \& Weiss, J. (2009). Structural changes, chemical composition and antioxidant activity of cherry tomato fruits (cv. Micro-Tom) stored under optimal and chilling conditions. Journal of the Science of Food and Agriculture, 89(9), 1543-1551.

González-Chávez, M. (2005). Recuperación de suelos contaminados con metales pesados utilizando plantas y microorganismos rizosféricos. Terra Latinoamericana, 23(1), 29-37.

González-Real, M.M. \& Baille, A. (1998). Calefacción en invernaderos En: Tecnología de invernaderos II. Ed: Dirección general de Investigación Agraria de la Junta de Andalucía y FIAPA, 338-398.

Goykovic, C.V. \& Saavedra R. (2007). Algunos efectos de la salinidad en el cultivo del tomate y prácticas agronómicas de su manejo. Ed: IDESIA (Chile), 25(3),47-58.

Gratao, P.L., Monteiro, C.C., Antunes, A.M., Peres, L.E.P. \& Azevedo, R.A. (2008). Acquired tolerance of tomato (Lycopersicon esculentum cV. MicroTom) plants to cadmium-induced stress. Annals of Applied Biology, 153(3), 321-333. 
Gruda, N. (2005). Impact of environmental factors on product quality of greenhouse vegetables for fresh consumption. Critical Reviews in Plant Sciences, 24(3), 227-247.

Guidi, L., Lorefice, G., Pardossi, A., Malorgio, F., Tognoni, F. \& Soldatini, G.F. (1998). Growth and photosynthesis of Lycopersicon esculentum (L.) plants as affected by nitrogen deficiency. Biology plant, 40, 235-244.

Han, X., Shen, T. \& Dietary L.H. (2007). Polyphenols and y their biological significance. International Journal of Molecular Sciences, 8, 950-988.

Harms, K., Ramirez, I.I. \& Peña-Cortes, H. (1998). Inhibition of wound-induced accumulation of allene oxide synthase transcripts in flax leaves by aspirin and salicylic acid. Plant Physiology, 118, 1057-1065.

Harper, L.A., Pollas, J.E. \& Bruce, R.R. (1979). Greehouse microclimate for tomatoes in the southeast. Horticultural Science, 104, 659-663.

Hedhly, A., Hormaza, J.I. \& Herrero, M. (2009). Global warming and sexual plant reproduction. Trends in Plant Science, 14(1), 30-36.

Helander, I.M., Nurmiaho, E.L., Ahvenaine, R., Rhoades, R. \& Roller S. (2001). Chitosan disrupts the barrier properties of the outer membrane of Gramnegative bacteria. International Journal of Food Microbiology, 71, 235-244.

Hennig, J., Malamy, J., Grynkiewicz, G., Indulski, J.D.F. \& Klessig. (1993). Interconversion of the salicylic acid signal and its glucoside in tobacco. Plant Journal, 4(4), 593-600.

Heredia J.B. \& Cisneros-Zevallos L. (2009). The effects of exogenous ethylene and methyl jasmonate on the accumulation of phenolic antioxidants in selected whole and wounded fresh produce. Food Chemistry, 115, 15001508.

Hernández, V., Hellín, P., Fenoll, J. \& Flores, P. (2015). Increased temperature produces changes in the bioactive composition of tomato, depending on its developmental stage. Journal of Agricultural and Food Chemistry, 63, 23782382.

Hernández, E. \& García-Martínez, I. (2016). Brasinoesteroides en la agricultura. I. Revista Mexicana de Ciencias Agrícolas, 7, 441-450. 
Hertog, M.G.L., Feskens, E.J. M., Hollman, P.C.H., Katan, M.B. \& Kromhout, D. (1993). Dietary antioxidant flavonoids and risk of coronary heart-disease. Lancet, 342(8878), 1007-1011.

Hewett, E.W. (2006) An overview of preharvest factors influencing postharvest quality of horticultural products. International Journal of Postharvest Technology and Innovation, 1, 4-15.

Hodges, D.M., \& Forney, C.F. (2003). Postharvest ascorbate metabolism in two cultivars of spinach differing in their senescence rates. Journal of the American Society for Horticultural Science, 128(6), 930-935.

Hong, Y.J., Barrett, D.M. \& Mitchell, A.E. (2004). Liquid chromatography/mass spectrometry investigation of the impact of thermal processing and storage on peach procyanidins. Journal of Agricultural and Food Chemistry, 52, 2366-2371.

Hu, Y. \& Schmidhalter, U. (1997). Interactive effects of salinity and macronutrient level on wheat. 2. Composition. Journal of Plant Nutrition, 20, 1169-1182.

Huertas, L. (2008). El control ambiental en invernaderos: humedad relativa. Revista Horticultura Tecnología de Producción Industria Hortícola, 52-54.

Hurd, R.G. \& Sheard, G.F. (1981). Fuel saving in greenhouses. En: The biological aspect. Grower Books, Ed: H.G. Kingham, London, 52-55.

Hyson, D. (2002). The health benefits of fruits and vegetables. A scientific overview for health professionals. Produce for Better Health Foundation, Wilmington DE, 20 pp.

Intergovernmental Panel on Climate Change. (2011). Third Assessment ReportClimatic Change, Synthesis Report, 63pp.

Iriti, M., Rossoni, M., Borgo, M., Ferrara, L. \& Faoro, F. (2005). Induction of resistance to gray mold with benzothiadiazole modifies amino acid profile and increases proanthocyanidins in grape: Primary versus secondary metabolism. Journal of Agricultural and Food Chemistry, 53(23), 91339139.

Jarquin-Enriquez, L., Mercado-Silva, E.M., Maldonado, J.L. \& Lopez-Baltazar, J. (2013). Lycopene content and color index of tomatoes are affected by the greenhouse cover. Scientia Horticulturae, 155, 43-48. 
Javaria, S., Khan, M.Q. \& Bakhsh, I. (2012). Effect of potassium on chemical and sensory attributes of tomato fruit. Journal of Animal and Plant Sciences, 22(4), 1081-1085.

Jin, P., Zheng, Y.H., Tang, S.S., Rui, H.J., \& Wang, C.Y. (2009) Enhancing disease resistance in peach fruit with methyl jasmonate. Journal of the Science of Food and Agriculture, 89, 802-808.

Johansson, F., Paul, L. \& Finlay, R. (2004). Microbial interactions in the mycorrhizosphere and their significance for sustainable agriculture. FEMS Microbiology Ecology, 48, 1-13.

Kähkönen, M., Hopia, A. \& Heinonen, M. (2001). Berry phenolics and their antioxidant activity. Journal of Agricultural and Food Chemistry, 49, 40764082.

Kanazawa, K. \& Sakakibara, H. (2000). High content of dopamine, a strong antioxidant, in Cavendish banana. Journal of Agricultural and Food Chemistry, 48(3), 844-848.

Karipcin, M.Z., Dinc, S., Kara, M., Kahraman, S., Alp, I. \& Cicekci, H. (2016). High temperature-tolerant tomato lines: bioactive compounds. Journal Fur Verbraucherschutz Und Lebensmittelsicherheit-Journal of Consumer Protection and Food Safety, 11(2), 117-125.

Karuppusamy, S. (2009). A review on trends in production of secondary metabolites from higher plants by in vitro tissue, organ and cell cultures. Journal of Medicinal Plants Research, 3, 1222-1239.

Katiyar, D, Hemantaranjan, A. \& Singh, B. (2015). Chitosan as a promising natural compound to enhance potential physiological responses in plant: a review. Indian Journal of Plant Physiology, 20(1), 1-9.

Kavitha, P., Shivashankara, K.S., Rao, V.K., Sadashiva, A.T., Ravishankar, K.V. \& Sathish, G.J. (2013). Genotypic variability for antioxidant and quality parameters among tomato cultivars, hybrids, cherry tomatoes and wild species. Journal Science Food Agricultural, 34(5), 677-691.

Kazemi, M. (2014). Effect of foliar application with salicylic acid and methyl jasmonate on growth, flowering, yieldand fruit quality of tomato. Bull. Enviromental Pharmacology Life Science, 3(2), 154-158. 
Keen, N.T., Partridge, J.E. \& Zaki, A.I. (1972). Pathogen produced elicitor of a chemical defense mechanisms in soybeans monogenically resistant to Phytophthora megasperma var. sojae. Phytopathology, 62, 768.

Khachik, F., Carvalho, L., Bernstein, P.S., Muir, G.J., Zhao, D.Y. \& Katz, N.B. (2002). Chemistry, distribution, and metabolism of tomato carotenoids and their impact on human health. Experimental Biology and Medicine, 227(10), 845-851.

Khan, T.A., Peh, K.K. \& Ch"ng, H.S. (2000). Mechanical, biadhesive, strength and biological evaluations of chitosan film for wound dressing. Journal of Phamacy and Pharmaceutical Science, 3(3), 303-301.

Khan, M.N., Siddiqui, M.H., Mohammad, F., Naeem, M. \& Khan, M.M.A. (2010). Calcium chloride and gibberellic acid protect linseed (Linum usitatissimum L.) from $\mathrm{NaCl}$ stress by inducing antioxidative defence system and osmoprotectant accumulation. Acta Physiologiae Plantarum, 32(1), 121132.

Kimura, M. \& Rodriguez-Amaya, D.B. (2003). Carotenoid composition of hydroponic Leary vegetables. Journal of Agricultural and Food Chemistry, 51, 2603-2607.

Kinet, J.M. (1977). Effect of light conditions on the development of the inflorescence in tomato. Scientia Horticultural, 6, 15-26.

Kiokias, S. \& Gordon, M.H. (2004). Antioxidant properties of carotenoids in vitro and in vivo. Food Reviews International, 20(2), 99-121.

Kondo, S., Kittikorn, M. \& Kanlayanarat, S. (2005). Preharvest antioxidant activities of tropical fruit and the effect of low temperature storage on antioxidants and jasmonates. Postharvest Biology and Technology, 36(3), 309-318.

Krause, M. \& Galensa, R.Z. (1992). Bestimmung von Naringenin und NaringeninChalkon in Tomatenschalen mit RP-HPLC nach Festphasenextraktion Lebensm Unters Forch, 194(1), 29-32.

Krauss, S., Schnitzler, W.H., Grassmann, J. \& Woitke, M. (2006). The influence of different electrical conductivity values in a simplified recirculating soilless system on inner and outer fruit quality characteristics of tomato. Journal of Agricultural and Food Chemistry, 54(2), 441-448. 
Kuznetsov, V.V. \& Shevyakova, N.I. (1997). Stress responses of tobacco cells to high temperature and salinity. Proline accumulation and phosphorylation of polypeptides. Physiologia Plantarum, 100(2), 320-326.

Lacker, T., Strohschein, S. \& Albert, K. (1999). Separation and identification of various carotenoids by C-30 reversed-phase high-performance liquid chromatography coupled to UV and atmospheric pressure chemical ionization mass spectrometric detection. Journal of Chromatography A, 854(1-2), 37-44.

Le Mire, G., Nguyen, M.L., Fassotte, B., du Jardin, P., Verheggen, F., Pierre Delaplace, P. \& Jijakli, M.H. (2016). A review: Implementing plant biostimulants and biocontrol strategies in the agroecological management of cultivated ecosystems. Biotechnology, Agronomy, Society and Environment, 20(S1), 299-313.

Lee, S.K. \& Kader, A.A. (2000). Preharvest and postharvest factors influencing vitamin C content of horticultural crops. Postharvest Biology and Technology, 20(3), 207-220.

Lester, G.E. (2006). Environmental regulation of human health nutrients (ascorbic acid, beta-carotene and folic acid) in fruits and vegetables. Hortscience, 41(1), 59-64.

Li, J.Y., Oulee, T.M., Raba, R., Amundson, R.G. \& Last, R.L. (1993). Arabidopsis flavonoid mutants are hypersensitive to UV-b irradiation. Plant Cell, 5(2), 171-179.

Liang, Y.S., Choi, Y.H., Kim, H.K., Linthorst, H.J.M. \& Verpoorte, R. (2006a). Metabolomic analysis of methyl jasmonate treated Brassica rapa leaves by 2-dimensional NMR spectroscopy. Phytochemistry, 67, 2503-2511.

Liang, Y.S., Kim, H.K., Lefeber, A.W.M., Erkelens, C., Choi, Y.H. \& Verpoorte, R. (2006b). Identification of phenylpropanoids in methyl jasmonate treated Brassica rapa leaves using two-dimensional nuclear magnetic resonance spectroscopy. Journal Chromatography A, 1112, 148-155.

Lin, C.H. \& Chen, B.H. (2003). Determination of carotenoids in tomato juice by liquid chromatography. Journal of Chromatography A, 1012(1), 103-109. 
Liu, K., Zhang, T. Q., Tan, C.S. \& Astatkie, T. (2011). Responses of fruit yield and quality of processing tomato to drip-irrigation and fertilizers phosphorus and potassium. Agronomy Journal, 103(5), 1339-1345.

López, F. (2001): El riesgo de desertificación. En: Agricultura y Desertificación, Ed: F. Martín de Santa Olalla, Mundi-Prensa. Madrid, 15-38.

Lovdal, T., Olsen, K.M., Slimestad, R., Verheul, M. \& Lillo, C. (2010). Synergetic effects of nitrogen depletion, temperature, and light on the content of phenolic compounds and gene expression in leaves of tomato. Phytochemistry, 71(5-6), 605-613.

Luthria, D.L., Mukhopadhyay, S. \& Krizek, D. (2006). Content of total phenolics and phenolic acids in tomato (Lycopersicon esculentum Mill.) fruits as influenced by cultivar and solar UV radiation. Journal of Food Composition and Analysis 19, 771-777.

Luthria, D., Singh, A.P., Wilson, T., Vorsa, N. \& Banuelos, G.S. (2010). Influence of conventional and organic agricultural practices on the phenolic content in eggplant pulp: plant-to-plant variation. Food Chemistry, 121, 406-411.

Maeder, P., Fliessbach, A., Dubois, D., Gunst, L., Fried, D. \& Niggli, U. (2002). Soil fertility and biodiversity in organic farming, Science, 296 (5573), 16941697.

Majumdar, S.P, Meena, R.L. \& Baghel G.D.S, (2000). Effect of levels of compaction and potassium on yield and quality of tomato and chilli crops grown on highly permeable soils, Journal Indian Society Soil Science, 48(2), 215-220.

Manach, C., Scalbert, A., Morand, C., Rémésy, C. \& Jiménez, L. (2004) Polyphenols: food sources and bioavailability. American Journal Clinicla Nutrition; 79, 727-747.

Margna, U. (1977). Control at level of substrate supply alternative in regulation of phenylpropanoid accumulation in plant-cells. Phytochemistry, 16(4), 419426.

Marti, E., Gisbert, C., Bishop, G.J., Dixon, M.S. \& Garcia-Martinez, J. L. (2006). Genetic and physiological characterization of tomato cv. Micro-Tom. Journal of Experimental Botany, 57(9), 2037-2047. 
Martínez-Valverde, I., Periago, M.J., Provan, G. \& Chesson, A. (2002). Phenolic compounds, lycopene and antioxidant activity in commercial cultivars of tomato. Journal of the Science Food and Agricultural, 82, 323-330.

Matsuzoe, N., Zushi, K. \& Johjima, T. (1998). Effect of soil water deficit on coloring and carotene formation in fruit of red, pink and yellow type cherry tomatoes. Journal Japanese Society Horticultural Science, 67, 600-606.

Mcguire, R.G. 1992. Reporting of objective color measurements. HortScience, 27, 1254-1255.

Mein, J.R., Lina, F. \& Wang, X.D. (2008). Biologycal activity of Lycopene metabolites: implications for cancer prevention. Nutrition Reviews, 66(12), 667-683.

Meissner, R., Jacobson, Y., Melamed, S., Levyatuv, S., Shalev, G., Ashri, A., Elkind, Y. \& Levy, A. (1997). A new model system for tomato genetics. Plant Journal, 12(6), 1465-1472.

Mejia-Teniente, L., Torres-Pacheco, I., Gonzalez-Chavira, M.M., OcampoVelazquez, R.V., Herrera-Ruiz, G., Chapa-Oliver, A.M. \& GuevaraGonzalez, R.G. (2010). Use of elicitors as an approach for sustainable agriculture. African Journal of Biotechnology, 9(54), 9155-9162.

Mestre, T. (2014). Respuestas de las plantas de tomate a la combinación de salinidad y altas temperaturas. Tesis Doctoral. Facultad de Biología. Universidad de Murcia.

Mikkelsen, M., Petersen, L., Glawischnig, M., Bøgh Jensen, Erik, A. \& Ann, B. (2003). Modulation of cyp79 genes and glucosinolate profiles in arabidopsis by defense signaling pathways. Plant Physiology; 131(1), 298-308.

Mimouni, H., Wasti, S., Manaa, A., Gharbi, E., Chalh, A., Vandoorne, B., Lutts, S. \& Ben Ahmed, H. (2016). Does salicylic acid (SA) improve tolerance to salt stress in plants? A study of SA effects on tomato plant growth, water dynamics, photosynthesis, and biochemical parameters. MICS, 20(3),180190.

Miranda-Ham, M.L. \& Castro-Concha, L. (2009) El estrés oxidativo en plantas. En: Temas Modernos de Nutrición Vegetal. Ed: Sociedad Mexicana de la Ciencia del Suelo, A.C. 214 pp. ISBN: 978-607-95106-2-6. 
Mittler, R. (2006). Abiotic stress, the field environment and stress combination. Trends in Plant Science, 11(1), 15-19.

Morales, D., Rodriguez, P., Dell'Amico, J., Nicolas, E., Torrecillas, A. \& SanchezBlanco, M. J. (2003). High-temperature preconditioning and thermal shock imposition affects water relations, gas exchange and root hydraulic conductivity in tomato. Biologia Plantarum, 47(2), 203-208.

Moreno, F.D. Blanch, G.P. \& Del Castillo, R.L. (2010). Methyl jamonate- induced bioformation of miricetin, quercetin and kaempferol in red raspberries. Journal of Agricultural and Food Chemistry, 58, 11639-11644

Munns, R. \& Tester, M. (2008). Mechanisms of salinity tolerance. Annual Review of Plant Biology, 59, 651-681.

Nadeau, F., Gaudreau, A., Angers, P. \& Arul, J. (2012). Changes in the level of glucosinolates in broccoli florets (Brassica oleracea var. italica) during storage following postharvest treatment with UV-C. IV International Conference Postharvest Unlimited 2011, 945, 145-148

Nguyen, M.L. \& Schwartz, S.J. (1998). Lycopene stability during food processing. Proceedings of the Society for Experimental Biology and Medicine, 218(2), 101-105.

Nicoleta, A. Boca, A. Flavia R, Nielsen, L. Pop, R Vesa S, Dana, A., Tataru, A. \& Vener, D. (2016) The effects of sea buckthorn and tomatine extracts on skin lesions. DermatoVenerol. (Buc.), 61, 89-96.

Niki, T., Mitsuhara, I., Seo, S., Ohtsubo, N. \& Ohashi, Y. (1998). Antagonistic effect of salicylic acid and jasmonic acid on the expression of pathogenesisrelated (PR) protein genes in wounded mature tobacco leaves. Plant Cell Physiology, 39, 500-507.

Obiadalla-Ali, H., Fernie, A.R., Kossmann, J. \& Lloyd, J.R. (2004). Developmental analysis of carbohydrate metabolism in tomato (Lycopersicon esculentum cv. Micro-Tom) fruits. Physiologia Plantarum, 120(2), 196-204.

Ochoa-Velasco, C.E., Valadez-Blanco, R., Salas-Coronado, R., Sustaita-Rivera, F., Hernández-Carlos, B., García-Ortega, S. \& Santos-Sánchez, N.F. (2016). Effect of nitrogen fertilization and Bacillus licheniformis biofertilizer addition on the antioxidants compounds and antioxidant activity of 
greenhouse cultivated tomato fruits (Solanum lycopersicum L. var. Sheva). Scientia Horticulturae, 201, 338-345.

O'Donnell, P.J., Calvert, C., Atzorn, R., Wasternack, C., Leyser, H.M.O. \& Bowles, D.J. (1996). Ethylene as a signal mediating the wound response of tomato plants. Science, 274, 1914-1917.

Oliveira, A.B., Moura, C.F.H., Gomes-Filho, E., Marco, C.A., Urban, L. \& Miranda, M.R.A. (2013). The impact of organic farming on quality of tomatoes is associated to increased oxidative stress during fruit development. PLoS ONE, 8(2), e56354. doi:10.1371/journal.pone.0056354.

Olle, M. \& Bender, I. (2009). Causes and control of calcium deficiency disorders in vegetables: A review. Journal of Horticultural Science \& Biotechnology, 84(6), 577-584.

Ono, K., Terashima, I. \& Watanabe, A. (1996). Interaction between nitrogen deficit of a plant and nitrogen content in the old leaves. Plant and Cell Physiology, 37(8), 1083-1089.

Paganga, G., Miller, N.G. \& Rice-Evans, C.A. (1999). The phenolic content of fruits and vegetables and their antioxidant activities, What does a serving constitute? FEBS Letter, 401, 78-82.

Parisi, M., Giordano, I., Pentangelo, A. \& Villari, G. (2006). Effects of different levels of nitrogen fertilization on yield and fruit quality in processing tomato. Proceedings of the International Symposium Towards Ecologically Sound Fertilisation Strategies for Field Vegetable Production, 700, 129-132.

Pastor, A. \& Higuera, I. (2004). Fuentes y Procesos. En: Quitina y Quitosano: obtención, caracterización y aplicaciones. Ed: Fondo Editorial del Pontifica Universidad Católica del Perú, 1, 312 pp.

Peet, M.M., Willits, D.H. \& Gardner, R. (1997). Response of ovule development and post-pollen production processes in male-sterile tomatoes to chronic, sub-acute high temperature stress. Journal of Experimental Botany, 48, 101-111.

Percival, D. \& MacKenzie, J.L. (2007). Use of plant growth regulators to increase polyphenolic compounds in the wild blueberry. Canadian Journal of Plant Science, 87(2), 333-336. 
Pereira, C.A., Maycotte, C.C., Elena, B., Mauro, F., Calle, A. \& Velarde, M. (2011). Sistema de producción vegetal II. Primera edición. Ed: Espacio Gráfico Comunicaciones S.A, 1-148.

Pérez, A.G., Sanz, C., Richardson, D.G. \& Olias, J.M. (1993). Methyl jasmonate vapor promotes beta-carotene synthesis and chlorophyll degradation in golden delicious apple peel. Journal of Plant Growth Regulation, 12(3), 163167.

Pérez-Balibrea, S., Moreno, D.A. \& García-Viguera, C. (2011). Improving the phytochemical composition of broccoli sprouts by elicitation. Food Chemistry, 129(1), 35-44.

Pérez-Parra, J., Montero, J.I., Baeza, E. \& Antón, A. (2001). Ventilación y refrigeración de invernaderos. En: Incorporación de tecnología al invernadero mediterráneo. Ed: Caja Rural de Almería y Málaga (CAJAMAR), 49-58.

Petersen, K.K., Willumsen, J. \& Kaack, K. (1998). Composition and taste of tomatoes as affected by increased salinity and different salinity sources. Journal of Horticultural Science \& Biotechnology, 73(2), 205-215.

Poiroux-Gonord, F., Bidel, L.P.R., Fanciullino, A.L., Gautier, H., Lauri-Lopez, F. \& Urban, L. (2010). Health benefits of vitamins and secondary metabolites of fruits and vegetables and prospects to increase their concentrations by agronomic approaches. Journal of Agricultural and Food Chemistry, 58(23), 12065-12082.

Poór, P., Gémes, K., Horváth, F., Szepesi, A., Simon M.L. \& Tari, I. (2011). Salicylic acid treatment via the rooting medium interferes with stomatal response, $\mathrm{CO}_{2}$ fixation rate and carbohydrate metabolism in tomato, and decreases harmful effects of subsequent salt stress. Plant Biololgy, 13, 105-114.

Poovaiah, B.W., Glenn, G.M. \& Reddy, A.S.N. (1988). Calcium and fruit softening: Physiology and biochemistry. Horticultural Reviews, 10, 107-152.

Popova, L., Ananieva, E., Haristova, V., Christov, K., Georgiera, K., Alexieva, E., Stoinova, Z. (2003). Salicylic acid and methyl jasmonate-induced protection on photosynthesis to paraquat oxidative stress. Bulgary. Journal Plant Physiology, 133-152. 
Porter, L.J. (1988). Flavans and proanthocyanidins. En: The Flavonoids: advances in research since 1980, Ed: Chapman and Hall, 21-62.

Raiola, A., Tenore, G.C., Barone, A., Frusciante, L. \& Rigano, M.M. (2015). Vitamin $E$ content and composition in tomato fruits: beneficial roles and biofortification. International Journal of Molecular Sciences, 16, 29250-29264.

Ramakrishna, A. \& Aswathanarayana, G. (2011). Influence of abiotic stress signals on secondary metabolites in plants. Plant Signaling Behavior, 6(11), 1720-1731.

Ramaprasad, V., Sasikala, C. \& Ramana, C. (2013). Neurosporene is the major carotenoid accumulated by Rhodobacter viridis JA737. Biotechnology Letters, 35(7), 1093-1097.

Raskin, I. (1992). Role of salicylic acid in plants. Review of Plant Physiology and Plant Molecular Biology, 43, 439-463.

Rawson, H.E., Begg, J.E. \& Woodward, R.G. (1977). The effect of atmospheric humidity on photosynthesis, transpiration and Water use efficiency leaves of several plant species. Planta, 134, 5-10.

Reboucas, T.N.H., Porto, J.S., Jesus, J.S. \& Moraes, M.O.B. (2015). Effects of different nitrogen sources and levels on tomato fruit quality. En: XXIX International Horticultural Congress on Horticulture: Sustaining Lives, Livelihoods and Landscapes (IHC2014), 1106, 79-83.

Rexroth, S., Poetsch, A., Roegner, M., Hamann, A., Werner, A., Osiewacz, H. D., Schaefer, E. R., Seelert, H. \& Dencher, N.A. (2012). Reactive oxygen species target specific tryptophan site in the mitochondrial ATP synthase. Biochimica et Biophysica Acta-Bioenergetics, 1817(2), 381-387.

Reyes, L.F. \& Cisneros-Zevallos, L. (2003). Wounding stress increases the phenolic content and antioxidant capacity of purple-flesh potatoes (Solanum tuberosum L.). Journal of Agricultural and Food Chemistry, 51(18), 52965300.

Ristic, Z., Bukovnik, U., Prasad, P.V.V. \& West, M. (2008). A model for prediction of heat stability of photosynthetic membranes. Crop Science, 48(4), 15131522.

Rivero, R.M., Mestre, T.C., Mittler, R., Rubio, F., Garcia-Sanchez, F. \& Martinez, V. (2014). The combined effect of salinity and heat reveals a specific 
physiological, biochemical and molecular response in tomato plants. Plant Cell and Environment, 37(5), 1059-1073.

Riveros, A.S. (2001). Moléculas activadoras de la inducción de resistencia, incorporadas en programas de agricultura sostenible. Manejo Integrado de Plagas (Costa Rica), 61, 4-11.

Rizhsky, L., Liang, H.J., Shuman, J., Shulaev, V., Davletova, S. \& Mittler, R. (2004). When Defense pathways collide. The response of Arabidopsis to a combination of drought and heat stress. Plant Physiology, 134(4), 16831696.

Robbins, R.J. (2003). Phenolic acids in foods: an overview of analytical methodology. Journal of Agriculture and Food Chemistry, 51, 2866-2887.

Rodriguez-Amaya, D.B. (1999). Carotenoides y preparación de alimentos: La retención de los carotenoides provitamina A en alimentos preparados, procesados y almacenados". Primera Impresión en Español. Universidade Estadual de Campinas, SP, Brasil. 99p.

Rodriguez-Amaya, D.B. \& Kimura, M. (2004). Harvest plus handbook for carotenoid analysis. International Food Policy Research Institute (IFPRI) and CIAT, Washington, DC and Cali, 58 pp.

Rohwer, C.L. \& Erwin, J.E. (2008). Horticultural applications of jasmonates: A review. Journal of Horticultural Science and Biotechnology, 83, 283-304.

Rojo, E., Solano, R. \& Sanchez-Serrano, J.J. (2003). Interactions between signaling compounds involved in plant defense. Journal of Plant Growth Regulation, 22, 82-98.

Romojaro, F., Martínez, M.C. \& Pretel, M.T. (2006). Factores precosecha determinantes de la calidad y conservación en postcosecha de productos agrarios. En: Innovaciones Fisiológicas y Tecnológicas de la Maduración y Post-Recolección de Frutas y Hortalizas. Eds: Valero D., Serrano M (ISHS), 91-96.

Romojaro, F., Martínez Madrid, M.C. \& Pretel, M.T. (2007).Factores precosecha determinantes de la calidad y conservación en poscosecha de productos agrarios Phytoma España: La revista profesional de sanidad vegetal, 189, 43-50. 
Rosales, M.A., Ruiz, J M., Hernandez, J., Soriano, T., Castilla, N. \& Romero, L. (2006). Antioxidant content and ascorbate metabolism in cherry tomato exocarp in relation to temperature and solar radiation. Journal of the Science of Food and Agriculture, 86(10), 1545-1551.

Rosello, S., Adalid, A., Cebolla-Cornejo, J. \& Nuez, F. (2011). Evaluation of the genotype, environment and their interaction on carotenoid and ascorbic acid accumulation in tomato germplasm. Journal of the Science of Food and Agriculture, 91(6), 1014-1021.

Rothman, S. \& Tonelli, B. (2010). El cultivo del tomate. Facultad de Ciencias Agropecuaria Universidad Nacional Entre Ríos (Argentina),1-31.

Rudell, D.R., Mattheis, J.P., Fan, X. \& Fellman, J.K. (2002). Methyl jasmonate enhances anthocyanin accumulation and modifies production of phenolics and pigments in 'Fuji' apples. Journal of the American Society for Horticultural Science, 127(3), 435-441.

Rueda, I.J. (2013).Estudio de la influencia de factores pre- y poscosecha en la calidad y vida útil del tomate tipo Raf. Tesis. Escuela Politécnica Superior y Facultad de Ciencias Experimentales. Universidad de Almería.

Ruiz, Y. (2014). Elicitores: una herramienta para Incrementar el color y el aroma de uvas y vinos. Tesis. Facultad de Veterinaria. Universidad de Murcia.

Rylski, I. (1979). Effect of temperatures and growth regulators on fruit malformation in tomato. Science Horticultural (Amsterdam), 10, 27-35.

Saito, T., Fukuda, N., Matsukura, C. \& Nishimura, S. (2009). Effects of salinity on distribution of photosynthates and carbohydrate metabolism in tomato grown using nutrient film technique. Journal of the Japanese Society for Horticultural Science, 78(1), 90-96.

Salgado, R., Cortés, M. \& del Río, R. (2008). Uso de brasinoesteroides y sus análogos en la agricultura. Biológicas, 10, 18-27,

Sams, C.E. (1999). Preharvest factors affecting postharvest texture. Postharvest Biolology Technology. 15, 249-254.

Sanchez-Rodrıguez, E., Leyva, R., Constan-Aguilar, C., Romero, L. \& Ruiz, J.M. (2012). Grafting under water stress in tomato cherry: improving the fruit yield and quality. Annals of Applied Biology Volume, 161, 3, 302-312. 
Saniewski, M., Czapski, J. \& Nowacki, J. (1987a). Relationship between stimulatory effect of methyl jasmonate on ethylene production and 1aminocyclopropane-1-carboxylic acid content in tomatoes. Biologia Plantarum, 29(1), 17-21.

Saniewski, M., Czapski, J., Nowacki, J. \& Lange, E. (1987b). The effect of methyl jasmonate on ethylene and 1-aminocyclopropane-1-carboxylic acid production in apple fruits. Biologia Plantarum, 29(3), 199-203.

Sasse, J.M. (1991). Brassinolide-induced elongation. Chemistry, bioactivity and Aplications. Washington American Chemistry Society.

Sathiyabama, M. \& Balasubramanian, R. (1998). Chitosan induces resistance components in Arachis hypogaea against leaf rust caused by Puccinia arachidis Speg. Crop Protection, 17, 307-313.

Sato, S., Peet, M.M. \& Thomas, J. F. (2002). Determining critical pre- and postanthesis periods and physiological processes in Lycopersicon esculentum Mill. exposed to moderately elevated temperatures. Journal of Experimental Botany, 53(371), 1187-1195.

Saure, M.C. (2001). Blosson end rot of tomato (Lycopersicum scolentum mill.) a calcicum or a estress related disorder? Scientia Horticulturae, 20,193-208.

Sayyari, M., Babalar, M., Kalantari, S., Martínez-Romero, D., Guillén, F., Serrano, M. \& Valero, D. (2011). Vapour treatments with methyl salicylate or methyl jasmonate alleviated chilling injury and enhanced antioxidant potential during postharvest storage of pomegranates. Food Chemistry, 124, 964970

Schaller, F., Schaller, A. \& Stintzi, A (2005) Biosynthesis and metabolism of jasmonates. The Journal of Plant Growth Regulation, 23, 179-199.

Schierle, J., Bretzel, W., Buhler, I., Faccin, N., Hess, D., Steiner, K. \& Schuep, W. (1997). Content and isomeric ratio of lycopene in food and human blood plasma. Food Chemistry, 59(3), 459-465.

Scholberg, J., McNeal, B.L., Boote, K.J., Jones, J.W., Locascio, S.J. \& Olson, S.M. (2000). Nitrogen stress effects on growth and nitrogen accumulation by field-grown tomato. Agronomy Journal, 92(1), 159-167. 
Schreiner, M. \& Huyskens-Keil, S. (2006). Phytochemicals in fruit and vegetables: Health promotion and postharvest elicitors. Critical Reviews in Plant Sciences, 25(3), 267-278.

Scott, M.F. \& Harbaugh, B.K. (1989). Micro-tom: a miniature dwarf tomato, Agricultural Experiment Station, Institute of Food and Agricultural Sciences. University of Florida, S-370.

Serio, F., Leo, L., Parente, A. \& Santamaria, P. (2007). Potassium nutrition increases the lycopene content of tomato fruit. Journal of Horticultural Science \& Biotechnology, 82(6), 941-945.

Sgherri, C., Kadlecova, Z., Pardossi, A., Navari-Izzo, F. \& Izzo, R. (2008). Irrigation with diluted Seawater improves the nutritional value of cherry tomatoes. Journal of Agricultural and Food Chemistry, 56(9), 3391-3397.

Sgherri, C., Navarilzzo, F., Pardossi, A., Soressi, G.P. \& Izzo, R. (2007). The influence of diluted seawater and ripening stage on the content of antioxidants in fruits of different tomato genotypes. Journal of Agricultural and Food Chemistry, 55(6), 2452-2458.

Shang, J., Xi, D.H., Xu, F., Wang, S.D., Cao, S., Xu, M.Y., Zhao, P.P., Wang, J.H., Jia, S.D. \& Zhang, Z.W. (2011). A broad-spectrum, efficient and nontransgenic approach to control plant viruses by application of salicylic acid and jasmonic acid. Planta, 233, 299-308.

Shewfelt, R.L. (1990). Sources of variation in the nutrient content of agricultural commodities from the farm to the consumer. Food Quality, 13, 37-54.

Simmone, A.H., Simonne, A.H., Fuzere, J.M., Simonne, E., Hochmuth, R.C. \& Marshall, M.R. (2007). Effects of nitrogen rates on chemical composition of yellow grape tomato grown in a subtropical climate. Journal of Plant Nutrition Kiel, 30(6), 927-935.

Slimestad, R. \& Verheul, M. (2009). Review of flavonoids and other phenolics from fruits of different tomato (Lycopersicon esculentum Mill.) cultivars. Journal of the Science of Food and Agriculture, 89(8), 1255-1270.

Slimestad, R. \& Verheul, M.J. (2005). Seasonal variations in the level of plant constituents in greenhouse production of cherry tomatoes. Journal of Agriculture and Food Chemistry, 53, 3114-3119. 
Smirnoff, N., Conklin, P.L. \& Loewus, F.A. (2001). Biosynthesis of ascorbic acid in plants: a renaissance. Annual Review of Plant Physiology and Plant Molecular Biology, 52, 437- 467.

Stevens, M. A. \& Rudich, J. (1978). Genetic potential for overcoming physiological limitations on adaptability, yield, and quality in the tomato. Hortscience, 13(6), 673-678.

Stewart, A.J., Bozonnet, S., Mullen, W., Jenkins, G.I., Lean, M.E.J. \& Crozier, A. (2000). Occurrence of flavonols in tomatoes and tomato-based products. Journal of Agricultural and Food Chemistry, 48, 2663-2669.

Stewart, A.J., Chapman, W., Jenkins, G. I., Graham, I., Martin, T. \& Crozier, A. (2001). The effect of nitrogen and phosphorus deficiency on flavonol accumulation in plant tissues. Plant Cell and Environment, 24(11), 11891197.

Story, E., Kopec, R., Schwartz, S. \& Harris, K. (2010). An update on the health effects of tomato lycopene. The Annual Review of Food Science and Technology, 1,189-210.

Stout, M.J., Brovont, R.A. \& Duffey, S.S. (1998). Effect of nitrogen availability on expression of constitutive and inducible chemical defenses in tomato, Lycopersicum esculentum. Journal of Chemical Ecology, 24(6), 945-963.

Sudha, G. \& Ravishankar, G.A. (2003). Elicitation of anthocyanin production in callus cultures of Daucus carota and involvemente of calcium channel modulators. Current Science, 84(6), 775-779.

Suhita, D., Raghavendra, A.S., Kwak, J.M. \& Vavasseur, A. (2004). Cytoplasmic alkalization precedes reactive oxygen species production during methyl jasmonate- and abscisic acid-induced stomatal closure. Plant Physiology, 134(4), 1536-1545.

Szalai, G., Kellos, T., Galiba, G., Kocsy, G. (2009). Glutathione as an antioxidant and regulatory molecule in plants under abiotic stress conditions. Journal of Plant Growth Regulation 28, 66-80.

Takatsuji, H., Jiang, C.J. \& Sugano, S. (2010). Salicylic acid signaling pathway in rice and the potential applications of its regulators. Jarq-Japan Agricultural Research Quarterly, 44(3), 217-223. 
Taylor, P.E., Spuck, K., Smith, P.M., Sasse, J.M., Yokota, T., Griffiths, P.G. \& Cameron, D.W (1993). Detection of brassinosteroids in pollen of Lolium perenne by immunocytochemistry. Planta (Heidelberg), 189, 91-100.

Taylor, M.D. \& Locascio, S.J. (2004). Blossom end rot: A calcium deficiency. Journal of Plant Nutrition, 27(1), 123-139.

Tomas-Barberan, F. \& Espin, J.C. (2001). Phenolic compounds and related enzymes as determinants of quality in fruits and vegetables. Journal of the Science of Food and Agriculture, 81(9), 853-876.

Tu, Y., Liu, F., Guo, D., Fan, L., Zhu, Z., Xue, Y., Gao, Y. \& Guo, M. (2016). Molecular characterization of flavanone 3-hydroxylase gene and flavonoid accumulation in two chemotyped safflower lines in response to methyl jasmonate stimulation. BMC Plant Biology, 16.

Turner, J.G., Ellis, C. \& Devoto, A. (2002). The jasmonate signal pathway. Plant Cell, 14, S153-S164.

Tzortzakis, N.G \& Economakis, C.D. (2007). Maintaining postharvest quality of the tomato fruit by employing methyl jasmonate and ethanol vapor treatment. Journal of Food Quality, 30, 567- 580.

Vallverdú-Queralt, A., Arranz, S., Casals-Ribes, I. \& Lamuela-Raventós, R.M., (2012). Stability of the phenolic and carotenoid profile of gazpachos during storage. Journal of Agricultural and Food Chemistry, 60, 1981-1988.

Van de Voorent (1986). Precision agricultura: Convective and ventilation transfers in greenhouses. Biosystems Engineering, 83.1.

Van Koot, Y. \& Van Ravestijn, W. (1963) .The germination of tomato pollen on the stigma (as an aid to the study of fruit setting problems). En: Proceedings of the 16th International Horticultural Congress, 1, 452-461.

Vicinaiz, M.M. (2004). Cuantificación de los niveles de ácido salicílico en cultivos celulares de tomate (Lycopersicon esculentum Mill.) sometidos a estrés oxidativo. Tesis. Facultad de Química. Universidad Autónoma de Yucatán. Mérida, México.

Wahid, A., Gelani, S., Ashraf, M. \& Foolad, M.R. (2007). Heat tolerance in plants: An overview. Environmental and Experimental Botany, 61, 199-223.

Walker, A.J. \& Ho, L.C. (1977). Carbon translocation in the tomato: Carbon import and fruit growth. Annals of Botany, 41, 813-823. 
Wang, Y.T., Huang, S.W., Liu, R.L. and Jin, J.Y. (2007) Effects of nitrogen application on flavor compounds of cherry tomato fruits. Journal of Plant Nutrition and Soil Science, 170, 461-468.

Wang, L., Allmann, S., Wu, J. \& Baldwin, I.T. (2008a) Comparisons of lipoxygenase 3- and jasmonate-resistant 4/6-silenced plants reveal that jasmonic acid and jasmonic acid-amino acid conjugates play different roles in herbivore resistance of Nicotiana attenuata. Plant Physiology, 146, 904915.

Wang, Z.H., Li, S.X. \& Malhi, S. (2008b). Effects of fertilization and other agronomic measures on nutritional quality of crops. Journal of the Science of Food and Agriculture, 88(1), 7-23.

Warner, J., Zhang, T.Q. \& Hao, X. (2004). Effects of nitrogen fertilization on fruit yield and quality of processing tomatoes. Canadian Journal of Plant Science, 84(3), 865-871.

Wasternack, C., Stenzel, I., Hause, B., Hause, G., Kutter, C., Maucher, H., Neumerkel, J., Feussner, I. \& Miersch, O. (2006). The wound response in tomato-role of jasmonic acid. Journal of Plant Physiololy, 163, 297-306.

Waterhouse, A.L. (2002). Wine phenolic. Annals of the New York Academic of Sciences, 957, 21.36. Went, F.W. (1957). The experimental control of plant. Growth Chronica, Botanica Company, Waltham, Mass.

Went, F.W. (1957). The experimental control of plant growth. Chronica Botanical, 17, 343-349.

Wingler, A., Purdy, S., MacLean, J.A. \& Pourtau, N. (2006). The role of sugars in integrating environmental signals during the regulation of leaf senescence. Journal of Experimental Botany, (57), 391-399.

Winspear, K.W., Postlethwait, J.D. \& Cotton, R.F. (1970). The restriction of cladosporium and Botrytis cinerea attacking glasshouse tomatoes by automatic humidity control. Biology, 65, 75-83.

Wise, R.R., Olson, A.J., Schrader, S.M. \& Sharkey, T.D. (2004). Electron transport is the functional limitation of photosynthesis in field-grown pima cotton plants a thigh temperature. Plant, Cell and Environment, 27, 717-724. 
Woitsch, S. \& Romer, S (2003). Expression of xanthophyll biosynthetic genes during light-dependent chloroplast differentiation. Plant Physiology, 132, 1508-1517.

Wu, M. \& Kubota, C. (2008). Effects of high electrical conductivity of nutrient solution and its application timing on lycopene, chlorophyll and sugar concentrations of hydroponic tomatoes during ripening. Scientia Horticulturae, 116(2), 122-129.

Yang, Y.N., Qi, M. \& Mei, C.S. (2004). Endogenous salicylic acid protects rice plants from oxidative damage caused by aging as well as biotic and abiotic stress. Plant Journal, 40(6), 909-919.

Yang, C.M; Wang, M.C; Lu, Y.F; Chang, I.F; Chuou, C. (2004). Humic substances affect the activity of chlorophyllase. Journal of Chemical Ecology. (30)5, 1057-1065.

Yang, S.Y., Chen, Y.L., Feng, L.Y., Yang, E., Su, X.G. \& Jiang, Y.M. (2011). Effect of methyl jasmonate on pericarp browning of portharvest lychees. Journal of Food Processing and Preservation, 35, 417-422.

Yildirim, E. \& Dursun, A. (2009). Effect of foliar salicylic acid applications on plant growth and yield of tomato under greenhouse conditions. International Symposium on Strategies towards Sustainability of Protected Cultivation in Mild Winter Climate, 807, 395-400.

Yin, Y.G., Tominaga, T., lijima, Y., Aoki, K., Shibata, D., Ashihara, H., Nishimura, S., Ezura, H. \& Matsukura, C. (2010). Metabolic alterations in organic acids and gamma-aminobutyric acid in developing tomato (Solanum lycopersicum L.) fruits. Plant and Cell Physiology, 51(8), 1300-1314.

Yokoi, S., Quintero, F.J., Cubero, B., Ruiz, M.T., Bressan, R.A., Hasegawa, P.M., \& Pardo, J.M. (2002). Differential expression and function of Arabidopsis thaliana $\mathrm{NHX} \mathrm{Na} / \mathrm{H}^{+}$antiporters in the salt stress response. Plant Journal, 30(5), 529-539.

Yoon, J.Y., Hamayun, M., Lee, S.K. \& Lee, I.J. (2009). Methyl jasmonate alleviated salinity stress in soybean. Journal of Crop Science and Biotechnology, 12, 63-68. 
Yuan, G.F., Luo, Y., Sun, X.M. \& Tang, D.Y. (2004). Evaluation of a crop water stress index for detecting water stress in winter wheat in the North China Plain. Agricultural Water Management, 64(1), 29-40.

Zhou, Y.H., Zhang, Y.Y., Zhao, X., Yu, H.J., Shi, K. \& Yu, J.Q. (2009). Impact of light variation on development of photoprotection, antioxidants, and nutritional value in Lactuca sativa L. Journal of Agricultural and Food Chemistry, 57(12), 5494-5500.

Zhu, T., Tan, W.R., Deng, X.G., Zheng, T., Zhang, D.W. \& Lin, H.H. (2015). Effects of brassinosteroids on quality attributes and ethylene synthesis in postharvest tomato fruit. Postharvest Biology and Technology, 100, 196204.

Zotarelli, L., Scholberg, J.M., Dukes, M.D., Munoz-Carpena, R. \& Icerman, J. (2009). Tomato yield, biomass accumulation, root distribution and irrigation water use efficiency on a sandy soil, as affected by nitrogen rate and irrigation scheduling. Agricultural Water Management, 96(1), 23-34. 